\title{
Older adults, informal support, and the process of driving cessation
}

\begin{abstract}
Amy Murray
Submitted to Swansea University in fulfilment of the requirements for the Degree of Doctor of Philosophy
\end{abstract}

July, 2019 


\section{DECLARATION}

This work has not previously been accepted in substance for any degree and is not being concurrently submitted in candidature for any degree.

Signed

(candidate)

Date

STATEMENT 1

This thesis is the result of my own investigations, except where otherwise stated. Where correction services have been used, the extent and nature of the correction is clearly marked in a footnote(s).

Other sources are acknowledged by footnotes giving explicit references. A bibliography is appended.

Signed (candidate)

Date 


\section{STATEMENT 2}

I hereby give consent for my thesis, if accepted, to be available for photocopying and for inter-library loan, and for the title and summary to be made available to outside organisations.

Signed (candidate)

Date

NB: Candidates on whose behalf a bar on access has been approved by the University (see Note 7), should use the following version of Statement 2:

I hereby give consent for my thesis, if accepted, to be available for photocopying and for inter-library loans after expiry of a bar on access approved by the Swansea University.

Signed (candidate)

Date 
For my beloved late grandparents: Margaret, Jean, Alwyn Eீ Charlie... 


\section{Acknowledgments}

Ever since beginning my doctoral research, I have been pondering over the acknowledgement section of my thesis, for a number of reasons. I initially revelled in the excitement of what it would feel like to be in the final throws of completing a $\mathrm{PhD}$, perceiving this stage to consist of feelings of pride, achievement, and reflection. I wondered who would become central actors across the process, helping me to reach that all important finishing line. Fast forward to over four years on and here I am; it's 4 am in the morning the day before the submission date and I am finally writing the much thought about acknowledgment section. Building upon my initial thoughts and perceptions surrounding this task, I can honestly say that I do feel a sense of pride. However, this feeling is fraught with a complex mix of other emotions, which those who have undertaken a PhD would know only too well. I feel like this is such an important section to complete, as had it not been for a number of influential and supportive individuals, I would absolutely not be where I am right now. I would therefore like to pay a sincere thank you to those mentioned below.

Firstly, I would like to thank each and every participant who gave their invaluable time and experiences, without which, this doctorate would not have been possible.

I give thanks to the Centre for Innovative Ageing and the College of Human and Health Science, Swansea University, for providing the funding support to complete my $\mathrm{PhD}$ and previous MSc in Ageing Studies. Without this support, it would have impossible to pursue and continue with my passion for ageing research.

Next, I would like to thank my wonderful PhD supervisory team, Dr Charles Musselwhite, and Dr Sarah Hillcoat-Nalletamby. Charles has been the most supportive primary supervisor I could have wished for and has kept me going throughout this journey. Through his kind, calming, wise, and sometimes much needed humorous influence, Charles has undoubtedly helped to keep me grounded when I have felt out of my depth. Sarah, as my secondary supervisor, has provided support at several stages of my $\mathrm{PhD}$, particularly helping me through the latter part of the journey. Sarah was one of my initial inspirers when I began my time at Swansea 
University, within her role of Social Policy lecturer on the undergraduate programme, which I was studying. Sarah has believed in me tremendously over the years, having always motivated me to continue in my studies, through her insightful support and guidance. Thank you both for always having faith in me and helping me along this pathway to date.

I also give sincere thanks to a number of academic staff within the Centre for Innovative Ageing, Swansea University, for their invaluable help and guidance throughout the duration of my PhD study. This includes Dr Deborah Morgan, Dr Ruth Hopkins, and Dr Alexandra Sardani, amongst many, many others. Thank you to all who have provided your support, guidance and encouragement, alongside exciting opportunities through my doctoral journey.

I have been lucky enough to share this experience with other PhD students, inside and outside of my own department. Firstly, Dr Joanna Wolton - the first fellow PhD student I met, and somebody who understands me very well. Thank you for your calming nature and invaluable support, which has undoubtedly helped me in many instances, throughout the duration of study. Carole Butler - for your humour, wise words, and continued heartfelt support and Caitlin Reid - for your thoughtfulness and continued support. Thank you to the many other $\mathrm{PhD}$ students I have encountered throughout the course of study - I have met the most wonderful, inspiring, motivated group of people. I know I have made lifelong friends within each of you and it has been a real honour to share this journey with you all. I honestly believe you would only understand the challenges if you have experienced the undertaking of a PhD first-hand.

And last, but certainly not least, my incredible family - my unconditional, lifetime supporters. Thank you from the bottom of my heart for being with me every step of the way throughout my career, and in life, particularly over the last four years. I can honestly say this has been the most challenging experience I have ever embarked upon, and I know I could not have seen it through without your love, support, patience and encouragement. This includes my much-loved Mam and Dad - Ann and Paul. My sister Hannah, late grandparents, and aunties and uncles. You have all 
comforted and reassured me when I have doubted myself, and have been the springboard to get back up and continue chasing my dream. Also, a special mention to my Siamese cats, Hugo and Hetty, for keeping me company on numerous occasions where I have worked around the clock!

I would like to give a special thank you to my partner Gareth - for being my absolute rock throughout this journey, and for providing endless support (including listening to numerous conference presentations and lecture plans, instead of watching your box sets!), to help me reach this final hurdle.

And to my wonderful group of friends, for understanding and supporting me throughout my entire time at university - particularly over these last few years and especially during the latter parts whilst I have been completely non-existent during our get-togethers!

There are also many other special people who have formed an important part of my journey in some way - I will be forever grateful to you all. 


\begin{abstract}
The following thesis is based upon an exploration into the process of driving cessation in later life, with a specific focus upon informal support. Although informal support has been highlighted as a highly important factor across the process of driving cessation (Johnson, 2008; Hanson E Hilldebrand, 2011; Ichikawa et al, 2016; Schryer et al, 2017), there is limited research which has explored this in depth. There is even less literature available which has incorporated the views of informal support network members, to understand their lived experiences of the driving cessation process. Studies which have addressed this gap, have tended to focus upon the views of adult children only (Rosenbloom, 2010; O'Connell et al, 2013). Using a phenomenological line of qualitative inquiry, individual semi-structured interviews with current and retired older drivers $(n=15)$, and their family, friends, and wider community members $(n=15)$ were completed. This was to provide a holistic approach to understand the driving cessation process, for the receivers and providers of informal support. Following a detailed thematic analysis, findings revealed both the process of driving cessation and informal support, to be profoundly complex, multifaceted phenomena's, holding multiple meanings for participants. This included a range of practical and psychosocial outcomes, which were both positive and negative. Often, findings were inter-linked, demonstrating the complexity of experiences amongst this far from homogeneous sample. The implications of the study have important messages for a number of individuals and groups, including older adults, their informal networks, policy and practice, and third sector organisations.
\end{abstract}




\section{Contents}

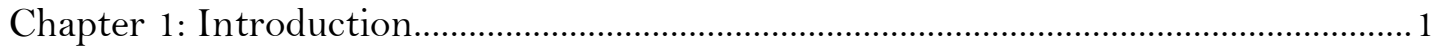

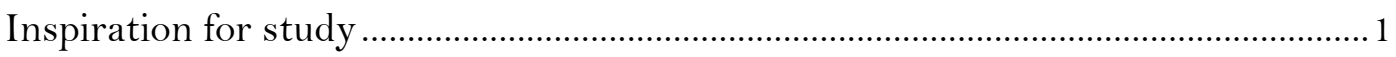

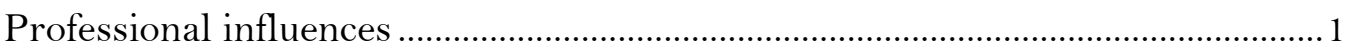

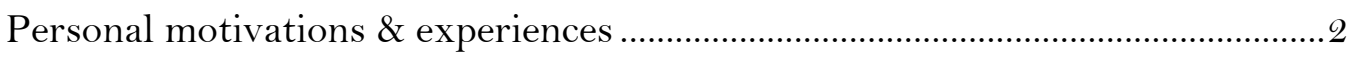

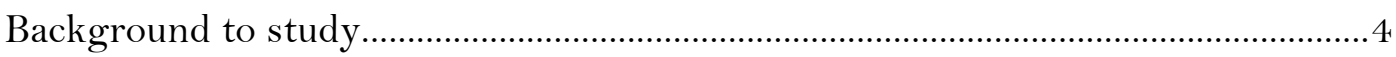

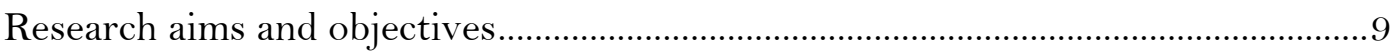

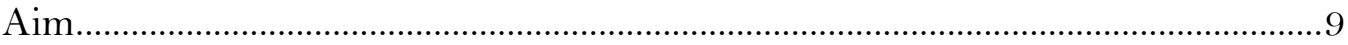

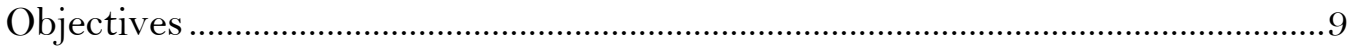

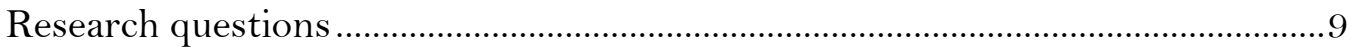

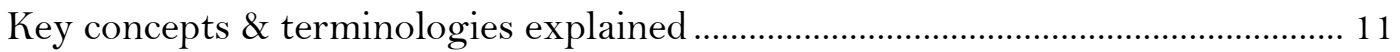

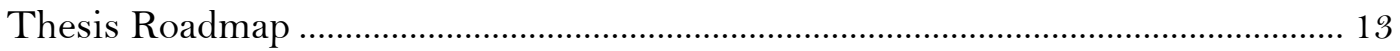

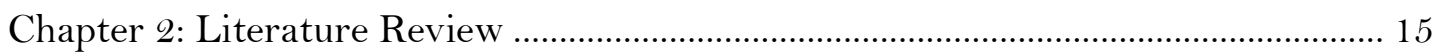

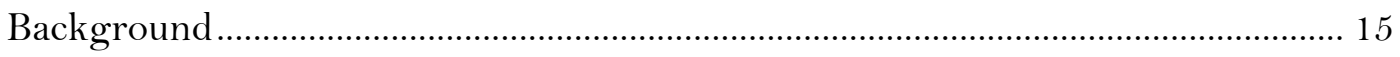

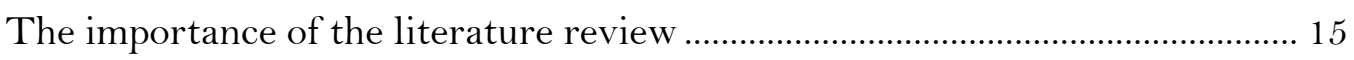

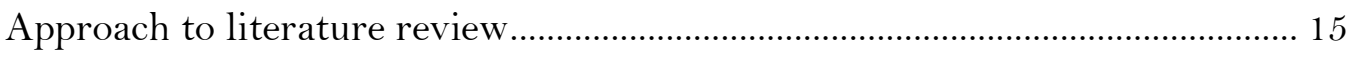

Process undertaken to complete literature review ................................................ 16

The meaning of driving in later life ……................................................................. 19

The meaning of driving cessation for older people …………………….................... 28

Triggers for driving cessation and the role of planning ....................................... 28

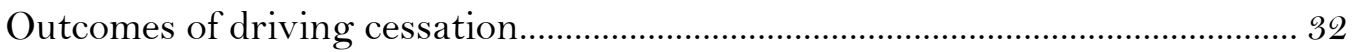

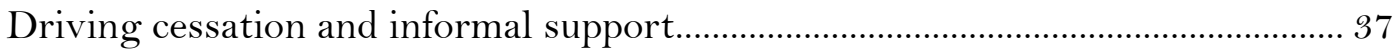

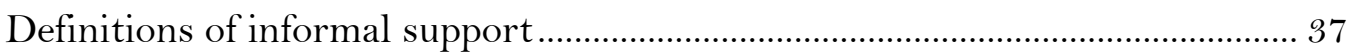

Perspectives of informal support network members ............................................. 42

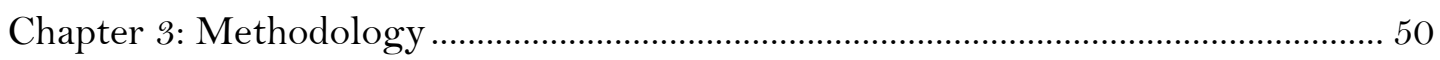

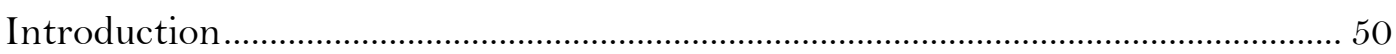

Research Approach \& Design.............................................................................. 50

Traditional Methods in Transport Studies …………………………………......... 51

An interdisciplinary approach to the research study ……………………….......... 53

Philosophical underpinnings \& research paradigm ................................................ 54 


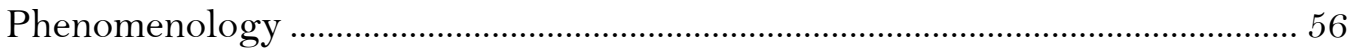

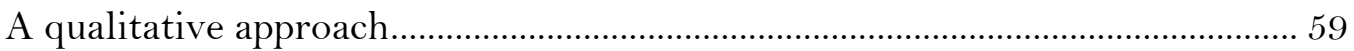

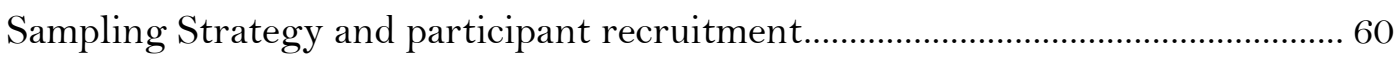

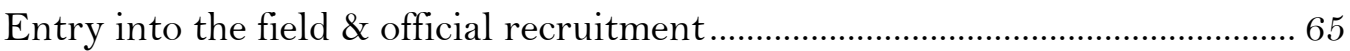

Visual representation of sample set by individual group ..................................... 74

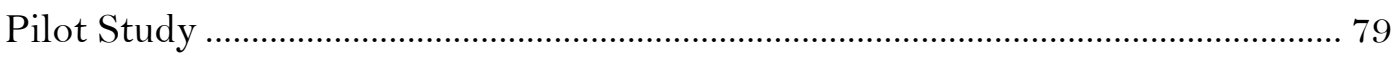

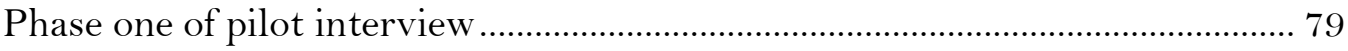

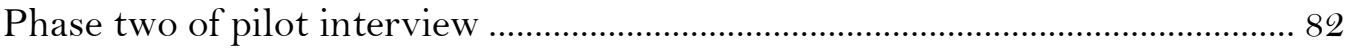

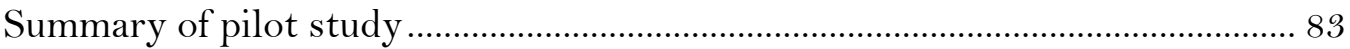

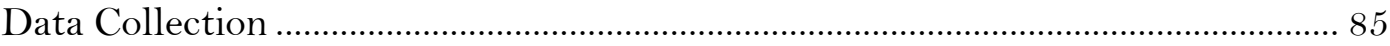

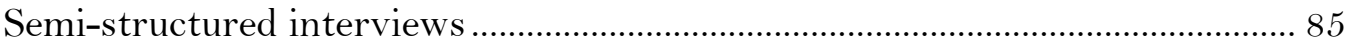

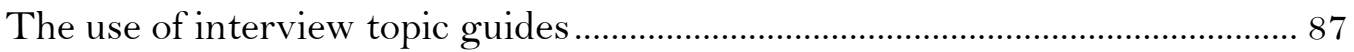

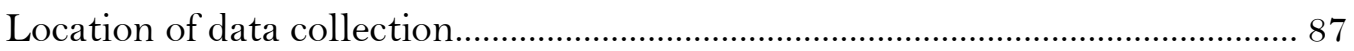

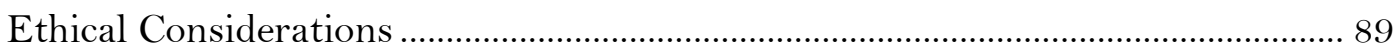

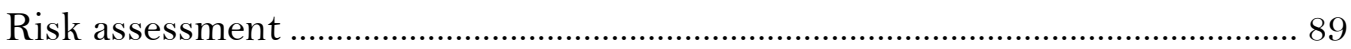

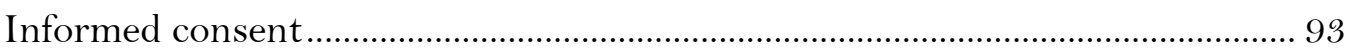

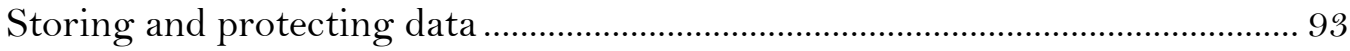

Signposting support ............................................................................................. 94

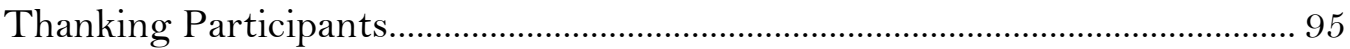

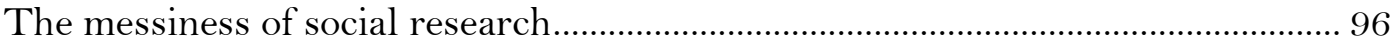

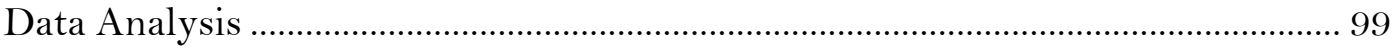

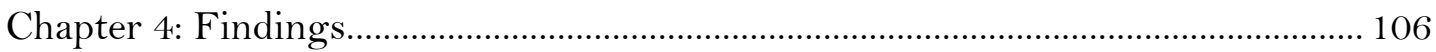

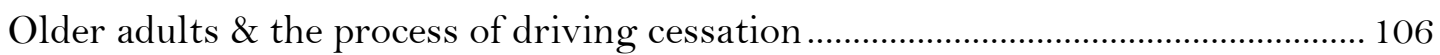

The meaning of driving for older people ................................................................ 106

The meaning of driving cessation for older people …................................................ 119

Older people's perceptions and experiences of informal support throughout the

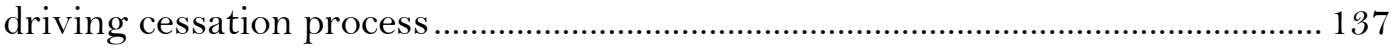

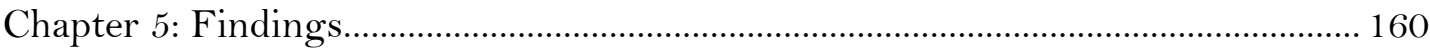

Informal support network members \& the process of driving cessation................... 160

The decision-making context of providing informal support: Perspectives of network members. 
Outcomes of the driving cessation process for informal support network members

Chapter 6: Discussion 181

The meaning of driving in later life 183

The meaning of driving cessation for older adults 194

Older adults experiences of informal support throughout the process of driving cessation 200

Informal support network members and the process of driving cessation 208

Chapter 7: Conclusion 217

Key messages from study 217

Limitations and directions for future research 218

Key contributions to knowledge 220

Bibliography 224

Appendices 262

Appendix 1: Ethical Application 262

Appendix 2: Briefing letter - Study invitation. 272

Appendix 3: Written consent form for all participants 274

Appendix 4: Example of interview transcribed verbatim 276

Appendix 5: Participant information sheet 277

Appendix 6: Participant information sheet - Informal support network members 279

Appendix 7: Interview prompt - Current older drivers......................................228

Appendix 8: Interviews prompt - Retired older drivers.......................................... 282

Appendix 9: Interviews prompt: Informal Social Network Members ....................284

Appendix 10: Online support for current and retired older drivers ........................286

Appendix 11: Information Sheet: Current \& retired older drivers .......................... 287

Appendix 12: Information sheet for Informal support network members........... 290

Appendix 13: Coloured coding in word document - alternative transport example

Appendix 14: Collated codes - alternative transport example 292

Appendix 15: Coding process undertaken by hand 293 


\begin{tabular}{|c|c|}
\hline Appendix Number & Appendix Title \\
\hline Appendix 1 & Ethical application \\
\hline Appendix 2 & Briefing letter - Study invitation \\
\hline Appendix 3 & $\begin{array}{l}\text { Written consent form for all } \\
\text { participants }\end{array}$ \\
\hline Appendix 4 & $\begin{array}{l}\text { Example of interview transcribed } \\
\text { verbatim }\end{array}$ \\
\hline Appendix 5 & $\begin{array}{l}\text { Participant information sheet - current } \\
\text { and retired older drivers }\end{array}$ \\
\hline Appendix 6 & $\begin{array}{l}\text { Participant information sheet - } \\
\text { informal support network members }\end{array}$ \\
\hline Appendix 7 & $\begin{array}{l}\text { Interview prompt - current older } \\
\text { drivers }\end{array}$ \\
\hline Appendix 8 & $\begin{array}{l}\text { Interview prompt - retired older } \\
\text { drivers }\end{array}$ \\
\hline Appendix 9 & $\begin{array}{l}\text { Interview prompt - informal support } \\
\text { network members }\end{array}$ \\
\hline Appendix 10 & $\begin{array}{l}\text { Online support for current and retired } \\
\text { older drivers }\end{array}$ \\
\hline Appendix 11 & $\begin{array}{l}\text { Information sheet - current and retired } \\
\text { older drivers }\end{array}$ \\
\hline Appendix 12 & $\begin{array}{l}\text { Information sheet - informal support } \\
\text { network members }\end{array}$ \\
\hline Appendix 13 & $\begin{array}{l}\text { Coloured coded word document - } \\
\text { alternative transport example }\end{array}$ \\
\hline Appendix 14 & $\begin{array}{l}\text { Collated codes - alternative transport } \\
\text { example }\end{array}$ \\
\hline Appendix 15 & Coding process undertaken by hand \\
\hline
\end{tabular}


Figure List

\begin{tabular}{|c|c|c|}
\hline Figure number & Figure title & Page number \\
\hline 1 & $\begin{array}{l}\text { Hierarchal model of mobility needs } \\
\text { (Musselwhite \& Haddad, 2010) }\end{array}$ & 21 \\
\hline 2 & $\begin{array}{l}\text { Inclusion \& exclusion criteria - current older } \\
\text { drivers }\end{array}$ & $67 / 68$ \\
\hline 3 & $\begin{array}{l}\text { Inclusion \& exclusion criteria - retired older } \\
\text { drivers }\end{array}$ & 68 \\
\hline 4 & $\begin{array}{l}\text { Inclusion \& exclusion criteria - informal support } \\
\text { network members }\end{array}$ & 72 \\
\hline 5 & Sampling profiles - current older drivers & 76 \\
\hline 6 & Sampling profiles - retired older drivers & 77 \\
\hline 7 & $\begin{array}{l}\text { Sampling profiles - informal support network } \\
\text { members of current older drivers }\end{array}$ & 78 \\
\hline 8 & $\begin{array}{l}\text { Sampling profiles - informal support network } \\
\text { members of retired older drivers }\end{array}$ & 79 \\
\hline 9 & Visual map of entire data set & 80 \\
\hline 10 & $\begin{array}{l}\text { Braun \& Clarke's (2006) six-step thematic } \\
\text { analysis process model }\end{array}$ & 97 \\
\hline 11 & $\begin{array}{l}\text { Seven-step thematic analysis process model - } \\
\text { adapted from Braun \& Clarkes (2006) model }\end{array}$ & 98 \\
\hline 12 & $\begin{array}{l}\text { The meaning of driving in later life - } \\
\text { Independence model }\end{array}$ & 185 \\
\hline
\end{tabular}




\section{Chapter 1: Introduction}

\section{Inspiration for study}

"Let's Start at the Very Beginning, a Very Good Place to Start"

Since becoming a doctoral student, I have been asked by a number of people why I have chosen to study driving cessation and informal support in later life. In response to this question, I often draw upon my inspirations or motivators for choosing this particular topic. My aim is to provide an open and honest account, to offer an essence about my personal and professional background, and how this has influenced the field of study. Specific examples of how these factors influenced the research methodology are discussed within Chapter 3 - Methodology, where the link between my position as a researcher, and the influence this has had on the research process is discussed.

\section{Professional influences}

Firstly, professional influences across academia, employment, and voluntary work are essential to mention. When deciding upon what course to study at university following my A Levels, I was in the same situation as many other young people finding myself totally bewildered and confused about my options and interests. A helpful starting point for myself was the part-time employment which I was involved in at the time, with the Department for Work and Pensions. My role here involved processing State Pension applications and in the latter part of my employment focusing upon bereavement. Speaking to older adults reaching the transition from work to retirement, as well as those who had experienced the loss of a loved one, provided first-hand knowledge and insights into what this meant for individuals. I recognised how diverse this section of the population were, in terms of their personal accounts and experiences.

I used these professional interests to help guide my choice of undergraduate degree, subsequently applying to study a BSc in Social Policy \& Criminology. Throughout the 3 years of the degree, it was obvious that my interests were more closely aligned with the Social Policy aspects of the programme, rather than Criminology. I relished 
each opportunity to write assignments which echoed my personal preferences, largely involving policies and welfare for older people. After completing my BSc, there were no questions over what my career interests were, leading to my immediate application for the MSc in Ageing Studies, where I was awarded a scholarship to continue studying.

Whilst working for the DWP and studying at university, I also volunteered for the Royal Voluntary Service \& Stroke Association, gaining further hands on experience of working with older people, who were living in differing contexts and situations. The combination of these professional experiences undoubtedly led to the application of my PhD.

\section{Personal motivations $E^{2}$ experiences}

Aside from my important professional impetus which was brought to the current study, personal interests and family life further helped to guide and develop the direction for my career choices. This largely stems from a very close, ongoing relationship with both sets of grandparents (Nannies \& Bampi’s) growing up, which continued until September 2018, when I lost my grandmother, Margaret.

Countless experiences of receiving care and support from both sets of grandparents taught me invaluable lessons, particularly about how close the bond is between grandparent and grandchild. This ranged from wide reaching instrumental support, including school runs, making school lunches, the provision of pocket money, and general childcare. Additionally, an unconditional level of emotional support was always present, where I could turn to each of my grandparents in the good times and bad, as their knowledge and wisdom were something which I will be forever grateful for. However, what I experienced in the latter part of my relationship with each of my grandparents, was a complete role reversal. Strangely, I vividly remember as a young girl telling both of my grandmothers 'I'll look after you when you get old, Nan', which is exactly how things materialised.

Situating this information within the context of my $\mathrm{PhD}$ research on driving cessation in later life, it is important to note that none of my grandparents drove, or 
owned a car after I was born. Nevertheless, the type and nature of informal support provided to my grandparents was still highly related to their mobility, and wider support needs. This included the provision of a range of tasks, from accompanying my grandfather to the post office once a week, where he would often forget his PIN and information, to going to the corner shop for my grandmother to pick up her bread and daily paper. The most recent example of role reversal related to my grandmother Margaret, through undertaking a number of different roles for her. This ranged from visiting her as often as possible, ensuring she had company, to making her food and changing her bedding. It also largely involved the provision of transport to medical appointments, along with taking her on days out, to make sure she was not isolated at home.

With my own lived experience of being the provider of informal support to my grandparents, I have always had an interest in how others may undertake similar roles, and what this actually means for family members, and older people themselves.

The combination of both my professional and personal insights have largely shaped my interest in ageing research. Therefore, the choice to pursue my $\mathrm{PhD}$ on the topic of driving cessation and informal support is not something which I had no previous connection to, or background knowledge of. Instead, it is the outcome of a range of experiences which I have encountered up until this point. 


\section{Background to study}

On a global level, lower mortality rates have resulted in people living longer than ever before. In the UK, there has been a stark increase in the number of older adults within the population, a trend which is set to further expand in future years. In 2007, 16 percent of the UK's population were aged 65 and over, reaching 18 per cent by 2017. This figure is projected to grow to 21 per cent by 2027 (ONS, 2018). In Westernised countries such as the UK, this has contributed towards higher proportions of people driving in later life, compared to previous cohorts. For example, 64 per cent of people aged 70 and over held a full UK driving licence in 2017, compared to only 39 per cent in 1997. This pattern is also consistent amongst 60-69 year olds, with driving licence holders in this age bracket increasing from 64, to 81 percent between 1997 and 2017 (Dft, 2018). More specifically, drawing upon the Welsh context, The National Survey for Wales (2017) found that eight out of ten people in the $50+$ population have access to a car $(81.3 \%)$, with this figure slightly reducing, but remaining relatively high amongst the $65+$ and $75+$ age groups $(77.2 \%$ and $67.7 \%$ respectively) (Welsh Government, 2018). There are multiple reasons for the increased number of older drivers in the UK, including individual factors, and wider influences. However, driving cessation is something which many older adults have to deal with in later life. Both explanations for increasing numbers of older drivers, along with factors shaping driving cessation, with subsequent outcomes are explained in detail below in the current chapter, and literature review.

In general, a more active generation of older adults has resulted in broader horizons, and an increased level of mobility and travel needs. A large body of research has found a positive link between mobility and health status in later life, with those who are able to independently meet their mobility needs reporting increased levels of wellbeing, and overall quality of life (Musselwhite, 201 1; Weber et al, 2010; Musselwhite E̊ Haddad, 2010; Groessl et al, 2007; Gardezi et al, 2006; Siren \& Hakamies-Blomqvist, 2005; Ellaway et al, 2003). Research has found the car to be a salient feature in the lives of many older people, contributing towards the foundations in which entire lifestyles are built upon (Musselwhite, 2011). The element of inconvenience which is associated with wider transport modes, such as bus and train travel, walking, and 
cycling, places further emphasis upon the importance of driving in later life (Adler $\mathbb{E}^{\circ}$ Rottunda, 2006; Pike et al, 2002). The car offers continuity, freedom, and independence, and is perceived as a lifeline by many, acting as the mechanism which ensures a life outside of one's own four walls (Curl et al, 2013). Ralston et al (2001) notes that the ability to drive in later life ensures older people remain active, engaged, and connected to society. These concepts of activity, connectivity, and engagement, have been recognised as crucial factors on a global policy level, through the World Health Organisation's Active Ageing policy framework (2002) and the European Commission (2010), advocating the most successful way to age is by continuing to contribute and participate in society (Foster \& Walker, 2015).

Wider factors also need to be considered when explaining the increasing number of older drivers in the UK. This includes legal requirements for driving licence renewal. In comparison to other countries, it has been suggested the UK has a fairly lenient driving licence renewal procedure, with older drivers renewing their licence at age 70 , and every three years from then on, based upon a self-declaration of personal health status and driving ability (Butcher, 2017). However, in other European countries, far more stringent approaches are in place. For example, driving licence renewal begins at age 45 in Spain, and is based upon a comprehensive physical and psychological assessment (Siren \& Haustein, 2015; Mitchell, 2008). The current legislation in the UK is often subject to political and media debate, with a recent high profile case bringing significant attention to this topic. In 2019, the Duke of Edinburgh was involved in a serious road traffic collision, leading to a call for more stringent rules and laws around the safety of older drivers ("Older Drivers: Is age a factor behind the wheel?," 2019). However, Estes (2001) criticises such debates for solely focusing upon the biomedical discourse of ageing, which suggests ageing is a process of inevitable incremental decline in people's physical, visual and cognitive capacities (Estes, 2001). Such arguments highlight the complexity surrounding the ethics of driving licence renewal procedures. 
Despite some of the negative connotations surrounding driving in later life, a growing numbers of older drivers in the UK is a profound achievement, in terms of improved longevity and healthier lifestyles. Nevertheless, this does not immunise older adults from health declines which often accompany the ageing process. Amongst these health issues are deteriorating vision and hearing, decreased muscle strength and range of motion, and cognitive decline, all of which hinder the ability of older drivers to remain behind the wheel (Bonder \&o Dal Bello-Haas, 2009). Wider factors have also been identified as trigger points for driving cessation amongst older adults. This includes psychological challenges such as negative stereotypes and pressure from other road users, which have been highlighted as barriers for some older people continuing to drive (Joanisse et al, 2012; Selwyn, 2014).

An extensive body of research has explored the impact of giving up driving in later life, with some scholars concluding that driving cessation constitutes a major later life event, which has similar consequences for older adults as the bereavement of a spouse, or retirement from the workplace (Ziegler E Schwanen, 2011).

Whilst some studies have highlighted positive outcomes of driving cessation, such as financial gain, and feelings of less stress and responsibility (Liddle et al, 2016), the majority of findings suggest that giving up the keys has many detrimental impacts upon the lives of older adults, resulting in reduced levels of wellbeing and overall quality of life. "The loss of driving privileges in later life may be synonymous of a person's last breath of personal liberty" (Ralston et al, 2001: 61). Depression, loneliness, isolation and feelings of being 'cut off' are commonplace amongst retired older drivers, through a significant reduction in out-of-home activities (Fonda et al, 2001; Whitehead et al, 2006). These negative implications associated with driving cessation result in an increased need for support, with the primary source of this support being provided informally by family and friends, often through the provision of lifts (Alsnih $\mathcal{E}^{2}$ Hensher, 2003; Burkhardt et al, 1998; Liddle, 2003 \&̊ Musselwhite, 2012; Azad et al, 2002).

However, research on driving cessation in later life has provided little attention to the support provided by informal networks, such as help from family, friends and 
neighbours. To date, informal support has been something which has only been identified as a factor which forms part of the wider research focus on driving cessation (Windsor $\mathcal{F}^{2}$ Anstey, 2006). Additionally, previous literature which has provided more attention to informal support has focused upon this in relation to a singular stage of the driving cessation process, rather than exploring this as a factor which occurs across the entire process (Mezuk \& Rebok, 2008; Johnson, 1998). Nevertheless, amongst research which has drawn upon informal support, this has been highlighted as a critical element for older people in relation to giving up driving. One study by Johnson (2008) found that amongst older women who gave up driving voluntarily in rural areas, those who were without an informal support network shortly returned to driving, through fear of not being able to survive and meet their personal needs. Additionally, a more recent study by Musselwhite \& Shergold (2013) found that family and friends often provide support to older adults at all stages of the driving cessation process. For example, through the provision of occasional transport when some older adults are still driving, to help making the decision to give up driving, to the provision of support post-cessation, which often significantly increases. However, there is a lack of in-depth knowledge relating to the nature and outcomes of this type of support.

Furthermore, there is an even more significant gap in knowledge relating to the perspectives or experiences of the providers of informal support, in relation to driving cessation. Limited research including the perspectives of family and friends has reported significant consequences of driving retirement for these individuals. For example, Freund \& Szinovacz (2002) found that caregivers of retired older drivers reported missing or reducing work, with some giving up their employment altogether to provide support for their loved ones. However, the body of research which has incorporated the views of informal support providers at specific stages of the driving cessation process, has been largely limited to the views of adult children (Rosenbloom, 2010; Connell et al, 2012), with few others including the perspectives of wider family members, such as spouses', or siblings (Ralston et al, 2001 and Taylor $E^{\circ}$ Tripodes, 2001). Also, similarly to the gap associated with, or including research focusing upon older people, literature which has been identified which incorporates 
the views of informal support networks, has also focused upon one stage of the driving cessation process only. For example, Frost-Steward (2015) explored the viewpoints of multiple family members regarding the conversations and actions taken to convince an older driver to end his or her driving career, from the point of first becoming aware of difficulties surrounding the older adult driving. However, the research did not include the perceptions and experiences of family members in relation to life after driving cessation, limiting knowledge and understanding relating to how post-driving is experienced by informal support networks.

In order to address the overall gaps identified, along with a consideration of current economic circumstances in the UK, relating to rising austerity cuts, resulting in informal support in later life becoming increasingly important in the context of an ageing population (Broese van Groenou $\&$ De Boer, 2016), it is the aim of the present thesis to provide a specific lens on this type of support, in relation to the phenomena of driving cessation. Additionally, an exploration into the meanings of driving and driving cessation have been provided. In order to address these aims, the views of current and retired older drivers, along with members of their informal support networks have been examined, using a phenomenological line of enquiry. 


\section{Research aims and objectives}

The research aims and questions which were devised for the present study were not homogenous in terms of where they were derived from. Firstly, the overall topic of 'investigating driving cessation in older adults' was pre-defined by Swansea University (2014), as part of an advertised PhD scholarship. After conducting a thorough, indepth search of the literature (see Chapter 2), to explore the research landscape on giving up driving in later life, this enabled the researcher to identify common areas of study focus, and also to recognise which areas required further attention. Subsequently, the studies aims, objectives and research questions were formulated.

Aim

The overall aim of the present study was to explore the process of driving cessation in later life, amongst current and retired older drivers, and members of their informal support networks.

\section{Objectives}

The specific research objectives are as follows:

- To explore driving cessation as a process, rather than a one off, static event

- $\quad$ To explore the meaning of driving in later life to older people

- To explore the meaning of driving cessation for older people and their informal support network

- To critically discuss the role of informal support throughout the driving cessation process

Research questions

In order to meet these objectives, a number of research questions have been implemented. These are as follows:

- What is the meaning of driving in later life?

- What is the meaning of driving cessation in later life?

- What are older people's experiences of informal support, throughout the process of driving cessation? 
- What are informal support network member's experiences of the driving cessation process? 


\section{Key concepts \& terminologies explained}

The following key concepts and terminologies outlined below, which feature within the present thesis, have been informed by the literature review, along with the researchers own interpretation of these concepts, in relation to the present study.

Older Adults: Participants aged 60 and over, in relation to literature reviewed

Current older drivers: Participants aged 60 and over, holding a valid UK driving licence, actively undertaking regular driving

Retired older drivers: Participants aged 60 and over who have given up driving within the previous 7 years, and no longer possess a valid UK driving licence

Informal support network members: Family members, (e.g. adult children, spouses, siblings, niece), friends, neighbours and wider members of the community (e.g. pub landlord)

Driving: Participants included in the study who are actively driving; hold a valid UK driving licence; use the car on a regular basis e.g. daily/few times per week

Driving reduction: Participants who have previous temporary periods of giving up driving; still hold a valid UK driving licence; self-regulating; thinking/thought about driving cessation

Driving cessation: Participants who have completely given up driving; no longer possess a valid UK driving licence; gave up driving within the last 7 years; in the 'life after driving' stage

Driving cessation process: Three stages involved in the event of giving up driving; including active driving, driving reduction, and complete driving cessation

Informal support: Help and support from kin, and non-kin members of current and retired drivers informal networks. This does not include the provision of formal support e.g. by a paid carer. This includes instrumental and emotional support, as 
identified by research participants e.g. over the phone advice/provision of company, to the provision of transport, \& running errands for older adult

Mobility needs: The transport and travel needs of older adults, as outlined in Musselwhite \& Haddad's model of hierarchal mobility needs (2010). This incorporates primary, secondary and tertiary mobility \& travel needs, including psychosocial and practical aspects

Consideration factors in relation to the provision of informal support: Aspects drawn upon by older adults, and informal support network members, relating to the provision of informal support. Consideration factors identified act as both motivators, and de-motivators of informal support provision.

Meanings: The expression of participant's thoughts, feelings \& experiences

Lived experience: Lived experiences refer to each participants current experiences relating to the stage of the driving cessation they are at. This includes those who have given up driving, and those who have not, along with the informal support network members of both groups of older adults

Perceptions: Participant views and opinions, how a phenomenon (e.g. driving cessation) is regarded, understood and interpreted by participants

Prospective views: The anticipated and perceived perceptions about a phenomena (e.g. driving cessation)

Outcomes: Outcomes of the driving cessation process, including both practical and psychosocial perceived and lived experiences

Coping strategies: Specific tactics employed or thought about in response to driving cessation, from the perspective of current and retired older drivers, and informal support network members. This included strategies such as 'managing' an older adults needs, for example 


\section{Thesis Roadmap}

The present thesis is comprised of seven chapters in total. In order to clarify the structure and organisation of the document, each chapter has been outlined and explained, in terms of the sections and sub-headings used, which make up each substantial chapter.

Firstly, section 1 is the introduction to the study. This set outs the background and context of the topic under investigation, and provides a statement of the research aim, objectives, and research questions. A list of key concepts and terminologies which are referred to throughout the thesis has also been included in the introductory chapter. Chapter 2 is the literature review, which is comprised of 4 substantive sections. This includes 2a) background $\Xi^{2}$ approach to literature review, before moving on to specific research which has been published on the topic of driving cessation and informal support. This includes 2b) the meaning of driving in later life, 2c) the meaning of driving cessation in later life, and 2d) informal support and the process of driving cessation. Section $2 \mathrm{~d}$ includes literature on older adults and informal support, and secondly, perspectives of informal support networks of older adults, in relation to driving cessation. Chapter 3 outlines the methodological underpinnings of the present thesis, and the specific methods which have been utilised. The purpose of the research is primarily stated, followed by the research approach and design. This includes an overview of previous, traditional methodological strategies adopted within the field of transport studies, along with an explanation of the ontological and epistemological principles which have been drawn upon, leading to the application of a wholly qualitative research approach. In relation to the specific methods which have been employed, the following sub-sections have been included: ethical considerations; pilot study; sampling strategy \& recruitment; data collection, \& data analysis.

Chapters $4 \& 5$ outline the findings of the study. Two chapters have been written for the findings, to reflect the two separate groups included in the research; (a) current and retired older drivers, and; (b) their informal support network members. 
Chapter 6 is the discussion section, where the studies research aim and questions have been revisited, in order to apply the findings to previous research and theory.

Finally, chapter 7 concludes the thesis. This section includes the strengths and limitations of the study, suggestions for policy \& practice, and recommendations for further research. The bibliography and appendices have been inserted following the conclusion chapter. 


\section{Chapter 2: Literature Review}

\section{Background}

The importance of the literature review

This chapter explores relevant academic literature and social theories which have been drawn upon to inform the focus of the present study, methods of data collection, and interpretation of the findings.

The literature review is an imperative part of the research process as it allows the researcher to identify and make sense of a range of information associated with a particular topic or research area. Broadly speaking, "the literature review provides the reader with a comprehensive overview and helps place that information into perspective" (Green et al, 2006: 102). This process also determines the breadth and depth of what current research entails, whilst highlighting the contex ts upon which specific subject areas have been investigated. Identifying and analysing published literature in a given field begins to illuminate a potential 'gap' or research 'niche', which often underpins the focus of the research project (Cronin et al, 2008). The literature review also enables the investigator to understand the selection of methods which have previously been employed within a given area of study, along with social theories which have been drawn upon. All in all, the review allows the researcher to critique the current knowledge base, identify a gap, and essentially "demonstrate that this research contributes something new to our understanding of the world" (Hart, 2018: 2).

\section{Approach to literature review}

The topic of driving cessation was pre-defined by Swansea University prior to embarking on the present doctoral study. Nevertheless, as explained in the introductory chapter, the researcher did have previous knowledge and experience relating to other later life transitions, namely retirement. Viewing driving cessation as a similar, major later life transition, the researcher explored current literature on driving cessation in later life, and designed a research study under this initial umbrella topic. 
For the purpose of the present thesis, a narrative approach was adopted to conduct the literature review. Green et al (2006) define narrative reviews as "A comprehensive, critical and objective analysis of the current knowledge on a topic" (p. 103). The authors acclaim the use of narrative literature reviews for their ability to combine a large body of information into a readable format. Also, this approach to reviewing the literature provides a broad perspective and knowledge base of what a current research picture entails, in relation to a particular phenomenon. In line with the present studies qualitative methodological approach, a narrative review assisted in the formulation of some of the studies research questions, which ensured the questions were grounded in a broad understanding of relevant studies, methodological approaches used, and overall research findings.

However, narrative literature reviews have been criticised by a number of scholars. This is mainly due to the primarily subjective nature of this approach, where researchers have been criticised for being too selective, potentially contributing towards a biased, non-valid representation of published literature, by only including studies which are deemed to be most relevant, to fit the aims and objectives of a study (Green et al, 2006). In these cases, critics favour systematic reviews, which offer a more stringent approach to reviewing a body of research. Although this method of undertaking the literature review was considered at the outset of the present study, a systematic review was discarded due to the 'top down' nature of this method (Bryman, 2016). For example, systematic reviews are often used where questions are pre-defined and there is a hypothesis which requires testing. This is also a method which is typically utilised within the natural or medical sciences. Due to the present study having no pre-determined research questions, this method was deemed unsuitable (Wright et al, 2007; Victor, 2008). Instead, a narrative review allowed the researcher to review existing literature on the topic of driving cessation, whilst determining the focus of the study.

\section{Process undertaken to complete literature review}

In order to begin the literature review, the first step involved a generic search of the term 'driving cessation', by using the non-specific search engine, Google Scholar. This broad concept was purposefully entered into the search engine to gain an initial 
insight into the topic as a whole, for the researcher to familiarise herself with the body of work which has previously been undertaken on the given subject matter. To ensure no obvious studies were excluded at this early stage, the search term was broken down and reconstructed to include other terms including 'giving up driving' and 'driving retirement'. At this stage, the researcher was interested in how widely studied the topic had been up until the present search. Key scholars were identified during these initial searches, revealed by how frequent authors names appeared by using the three alternate search terms several times.

Once the researcher had broadly read around the topic, which included the reviewing and summarising of each text, a more specific stage of the literature search was performed. This included using more refined research databases as well as more alternative search terms, guided by initial reading and understanding. Swansea Universities IFind database and library catalogue were used, followed by Social Science research databases. This included Scopus, Web of Science and ProQuest. More specifically, ageing, social policy and transport research databases were included, such as The Gerontologist, the Journal of Transport \& Health, Ageing \& Society, and the Journal of Sociology. This recognises that driving cessation in later life spans across the study of Social Gerontology, Transport, Social Policy, and Sociology. Search terms at this stage included 'the impact of driving cessation', 'driving cessation and mobility needs' and the 'process of giving up driving'. Boolean operators were also employed at this stage. This refers to conjunction words, such as AND, OR, NOT. For example, driving cessation AND older adults, driving cessation OR driving retirement, and older people NOT younger people giving up driving. This is useful when combining search terms. Truncation was also used, by use of the asterisk alongside search terms. This was to capture plurals, through the use of one term. For example inserting 'old*' ensured that papers with the word 'old', 'older', 'oldest' were identified. The above practices ensured that search terms were broad enough to capture relevant research, without excluding articles due to poor literature search practices.

Once the research gap and interest became more pronounced after reviewing a number of papers, it became evident that more of a focus was required on the element 
of informal support and driving cessation. Additional search terms were therefore used in order to pursue this potential gap, such as informal support and driving cessation' and 'giving up driving and family members'. This included the use of wider journals, including the Journal of Family Relations, for example. This provided more clarity and knowledge around informal support and driving cessation, where it also became evident from an extensive search of the literature that minimal research had been conducted on informal support and giving up driving in later life, particularly within the UK context.

In line with the narrative approach to the literature search and the iterative nature of the overall study, the researcher ensured that literature searches, including nonacademic sources, were continually performed throughout the duration of the study. This recognises that a primary research study is a 'live' piece of work, requiring the most current and topical information on a subject. "The literature on any given topic is an evolving resource" (Hart, 2018: 2). A continuing literature search also ensured the risk of reproducing already published material was eliminated as much as possible. To the knowledge of the researcher, it became evident towards the end of the research process that no other research had been conducted on the driving cessation process and informal support in later life, including both drivers, ex-drivers and their support networks.

The literature review has been categorised into three primary sections, reflecting the overall aims of the thesis. These sections emerged through undertaking the literature review, rather than being identified prior to the literature review. This includes; the meaning of driving in later life, the meaning of driving cessation in later life, and informal support throughout the driving cessation process. The informal support section has been categorised into two sub sections, including; older adults and informal support throughout the driving cessation process, and; the perspectives and experiences of driving cessation by informal support network members. 


\section{The meaning of driving in later life}

The following section draws upon available literature which has been published on driving in later life. Firstly, generic concepts were identified, which have been drawn upon within published research on older drivers. This includes 'meanings', 'needs', and 'outcomes' of driving. For the purpose of the present literature review, all three terms have been structured around a hierarchal model of mobility needs, produced by Musselwhite \& Haddad in 2010 (Seefigure 1). This is because the model is the only available visual representation available, which attempts to explain the meaning of driving to older people. Key aspects of the model have been explained in depth below, with wider relevant literature surrounding the meaning of driving being applied to the three distinct categories, outlined by Musselwhite \& Haddad (2010). In addition to previous research findings, theoretical aspects and explanations of driving have also been incorporated, where applicable.

Drawing upon the increasing number of older drivers in the UK, along with the recognition that driving cessation is a process, rather than a singular, isolated event (Musselwhite $E^{2}$ Shergold, 2013; Dickerson et al, 2019), the meaning of driving needs to be understood. It would, for example, be difficult to understand the meaning of driving cessation to older people, without firstly considering how people experience driving in later life, and what this means to them.

Research which has focused upon driving in later life is wide reaching, in terms of the areas and contexts upon which this phenomena has been explored. Beginning with a broad approach to the topic, Musselwhite \& Haddad (2010) undertook qualitative research with 57 current and retired drivers aged 65 and over in the UK, to explore the role of mobility and accessibility in older peoples self-reported quality of life. Based upon interviews, personal diaries, and focus groups, findings were related to a hierarchy, based upon self-defined mobility needs. This included primary, 'utilitarian' needs, secondary 'affective', needs, and tertiary 'aesthetic', needs. Primary mobility needs were articulated as the most important by participants, with secondary, followed tertiary needs, becoming less important. Findings revealed the car as the 
preferred, most important mode of transport amongst participants, which met all three levels of mobility needs.

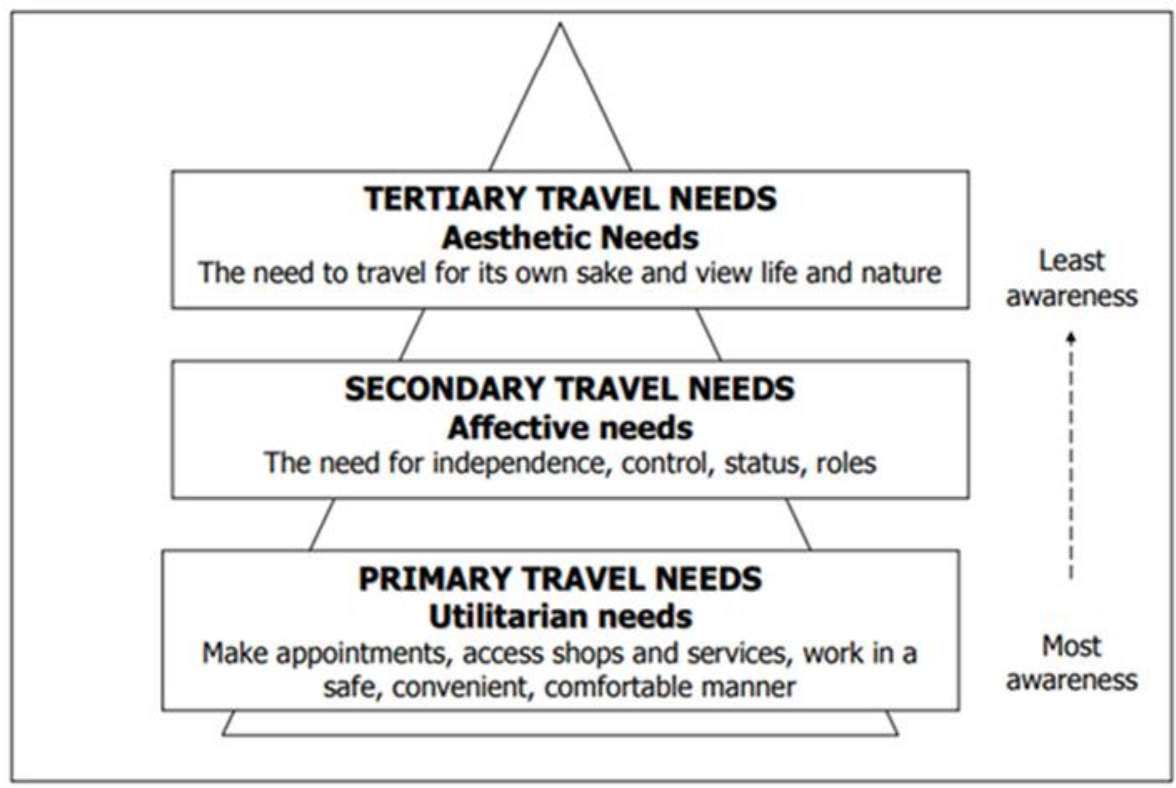

Figure 1: Hierarchal model of mobility needs (Musselwhite $\mathcal{E}^{2}$ Haddad (2010)

\section{Primary level of mobility needs relating to driving}

Firstly, on a primary level, Musselwhite \& Haddad (2010) found that the most important aspect of driving for older people, was to meet their utilitarian mobility needs. This included the most practical, basic need to get from A to B, to access shops and services, as comfortably and conveniently as possible. This has therefore been placed at the bottom of the hierarchal model, demonstrating that participants had the most awareness about this practical level of needs, which are met through driving. Other research focusing upon older drivers has found similar outcomes, with convenience being highlighted as a key reason to continue behind the wheel in later life, along with accessing basic services and amenities (Liddle et al, 2007; Gillhooly et al, 2004). The latter study by Gilhooly et al (2004) examined public and private transport needs in relation to quality of life in old age. Research was undertaken in two areas of Scotland, and London. Data collected through surveys revealed that convenience was one of the most important aspects of driving for older people, with 
participants describing this as having the option to travel out of choice, when required, due to having a car parked nearby. Additionally, the ability to undertake work opportunities was cited as an equally important meaning of driving. Both of these aspects were found to have a positive influence on older participants' quality of life (Gilhooly et al, 2004). However, findings from this study need to be interpreted with caution. Firstly, there is no explanation of the ages of older adults in the sample, excluding potentially important distinctions between age groups. For example, in a previous study by Loughran et al (2007), it was found that drivers aged 65 and over were 16 per cent likelier than those 25-64 years old to cause a road incident. Car crashes in later life can lead to complete driving retirement, through many older drivers suffering a huge knock to their confidence, and subsequent perceived driving ability. Findings by Loughran et al (2007) highlight that age results in profound differences in driving experiences, with older age groups having an increased risk of road traffic collisions. This therefore supports the criticism of Gillhooly et al's (2004) study, in terms of recognising the importance of incorporating the views of different categories of older age groups into research. Secondly, Gilhooly et al (2004) also stated that not all data collected was reported upon, due to the large amount of information which was generated. This resulted in only a small proportion of the findings from the study being published within the final report. As the authors state, this resulted in the exclusion of information which revealed interesting differences between the study areas, including Paisley, inner and outer London, and rural Renfrewshire' (Gilhooly et al, 2004: 11). Sometimes the most interesting findings are outliers from the main findings and hence may be missed in the reporting of this study. Both criticisms highlighted reduce the overall validity of this piece of research.

Referring back to the practical meaning of driving in later life, Liddle et al (2012) conducted a cross sectional survey of 234 older people, to explore the impact of driving status on time use, role participation and life satisfaction. Findings revealed that driving was primarily referred to by participants for its ability to undertake practical activities, with participants reporting no emotional meaning of driving. It was also revealed that driving became less important in later life for some study respondents, due to diminishing personal roles, such as the need to transport their 
own children, which typically occurred at earlier stages in the life course. This particular finding draws upon the concept of 'role loss', which is a central principle of the social gerontological theory of disengagement. The 1961 theory developed by Cumming and Henry suggests that role loss in later life is inevitable, through events such as retirement, bereavement, and the 'emptying of the familial nest' (Utz et al, 2002: 523). It is accepted, from this perspective, that the most natural, normative pathway to successful ageing is through older adults withdrawing from society, whilst society mutually withdraws form the older adult. Such transactions are deemed necessary, as older adults prepare for their inevitable demise. However, this perspective on successful ageing has been heavily criticised. Hooyman \& Kiyak (1997) suggest that rather than role loss being natural in later life, older adults actually substitute former roles with other alternatives. This perspective relates to the activity theory of ageing, developed by Robert J. Havighurst in 1961, which is often referred to in sharp contrast to disengagement theory. This theory suggests that successful ageing is actually achieved through older people staying active in their later years, through the uptake of new activities and maintenance of social relationships. Gerontologists have suggested that disengagement theory is an outdated explanation for ageing, as it is largely stereotypical. This is because it views older people as passive, unresponsive individuals, who are content to disengage from all personal roles and responsibilities (Hochschild, 1975; Boudiny, 2013), ignoring the fact that many older people have agency in later life, whereby they make their own informed decisions and life choices (Boudiny, 2013). In support of these criticisms, and relating back to role loss, a study by O'Neil et al (2012) conducted on the experiences of being a grandparent in later life, found that this role often involves the uptake of new instrumental practices, such as becoming transport provider for grandchildren. This supports the proponents of activity, rather than disengagement theory. A further 2007 American-based study by the National Highway Traffic Safety Administration (NHTSA) further supports this finding, reporting that 42 per cent of lifts provided to young children within their survey were provided by the child's grandparents (Henretig et al, 2011). Both findings suggest that although previous roles may have come to an end for older drivers, such as being an employee, or being the primary transport provider for the family, these 
roles are, in fact, substituted with the take up of news roles, such as that of being a grandparent.

In relation to driving in later life being linked to roles, such as that of transport provider, this was something which was perceived as highly important in a Swedish study by Siren \& Hakamies-Blomqvist (2005). The research investigated the personal meanings attached to cars and driving, amongst 10 women, aged 69-87. Upon describing experiences of driving, participants referred to the car as a mere tool which allowed them to play out their life roles. Specifically, this largely related to 'caring' responsibilities. For example, women talked about embodying traditional female caring and nursing roles, which the car allows them to fulfil. Musselwhite \& Haddad (2010) reported similar results, also finding the car to be closely related to the role of being a mother, grandmother or carer, for female participants. However, for men in the study, more symbolic aspects of driving were referred to. This included status, masculinity and power. This was articulated through the account of a male participant: "I worked hard all my life. My cars show how well I did. My father didn't have a car, so I suppose I was proud and still am of having a decent car" (Musselwhite and Haddad, 2007: 3). This raises an importance issue, relating to gender-specific based meanings of driving in later life. Investigating the psychosocial benefits associated with public and private motor vehicle transportation through a postal based survey in Scotland, Ellaway (2003) also found notable gender differences amongst respondents. Only male participants drew upon driving as an important factor relating to their selfesteem, although this was not the case for females. The element of self-esteem was also associated with type of car among men, but not women. This finding relates to the concept of 'impression management', outlined by Musselwhite (2011). This refers to a process, whereby individuals attempt to influence the perceptions of others, about themselves through the displaying of certain behaviours, and including items purchased, such as clothes, furniture, homes, cars etc. (p. 8). Although findings from Ellaway et al (2003) highlighted important findings in relation to gender differences, these results need to be carefully considered. This is because of the primary method of data collection involving a postal survey. For example, Mathers et al (2009) state that postal surveys entail the practice of isolated data collection. Therefore, there is 
no opportunity for the researcher to probe, or explore initial responses which are recorded, usually through tick box exercises. Face-to-face data collection techniques would therefore ensure that important issues, such as the gender element outlined, could be explored in greater details, providing a more thorough understanding of a phenomenon.

Although gender differences are apparent within previous literature on driving in later life, a more recent report undertaken by Bevan et al (2017) reported findings which suggesting a blurring of these gender boundaries. The research, which critically explored mobility and wellbeing for people aged 55+ in three locations in the north of England, revealed the car as being a highly important means for older people to meet their needs. One of the most important reasons stated also related to fulfilling care practices, although this was something which was found to also be reflective of male participants in the study. For example, the adult child of a retired older driver talked about providing regular care for his older father, which involves him providing transport several times a week, in order for him to attend appointments, as well as attending social clubs.

Relating back to driving in later life being interpreted in terms of older adults' practical needs, a wide range of studies have drawn upon negative perceptions of public transport, as something which places even further emphasis on the importance of the car. Through reviewing evidence on the mobility needs and travel patterns of older adults, Alsnih and Hensher (2003) found the car to be the most popular mode of transport, with previous studies noting a growing reluctance of older adults to shift their modal behaviours later in the life course. Additionally, a more recent scoping review of published literature (Luiu et al, 2018) which analysed transport barriers affecting use of alternative modes of transport to the car in later life, adds further weight to these findings. Relating to UK, US, and Australian contexts, one of the main reasons for older people not using alternative transport was because of a lack of valid alternative transport modes which are available. Other negative aspects were also reported. This included long waiting times and overcrowded conditions associated with bus use, the risk of falling through walking, and high fares and 
negative driver behaviour, associated with the use of taxis. Musselwhite \& Shergold (2013) further expand upon these findings, finding the car to be the most simple and straightforward mode of transport for older adults to meet their practical needs, as it involves the least amount of physical and cognitive effort, in comparison to walking or cycling. Aside from directly removing the physical elements required when walking and cycling, which directly draw upon the cardiovascular and respiratory systems, the car also eliminates other forms of physical exertion, which may become more problematic in later life, such as the task of carrying heavy shopping bags from supermarkets to the home (Musselwhite E̋ Shergold, 2013). This latter finding relates to an increasingly growing area of transport research, relating to the hypermobile society, where high levels of mobility are undertaken to stay connected to friends, family, services and shops. Private mobility centred around the car is central to this hyper-connectivity, affording more choice over the location of work and home. This also results in shops and services being placed on the outskirts of towns and cities, placing further emphasis upon driving, in order to provide accessibility.

\section{Secondary level of mobility needs}

Relating to the second level of mobility needs postulated by Musselwhite \& Haddad (2010), this describes the more psychosocial aspects of driving, drawn upon more implicitly by participants. This included driving for independence, choice, freedom, control, autonomy, and self-identity. There is a plethora of research highlighting similar findings, in relation to the positive psychosocial reasons for, and outcomes of driving in later life. A key finding which has been widely reported in relation to the psychosocial aspects of driving in later life, is the element of freedom, which in turn, relates to independence (Coughlin, 2001; Ralston et al, 2001). "Well, really a car is independence to me. And independence is important to me because independence is power" (Finlayson $\&$ Kaufert, 2002: 82). Gardezi et al (2006) undertook a review of qualitative literature on older drivers. Amongst 25 studies that used focus groups or interviews to learn about the experiences and concerns of older drivers, one of the main themes identified was the importance of driving. One of the most common themes identified was that driving equates to a sense of freedom and independence for older adults, 
whereas losing the ability to drive was depicted as being in a state of dependency (Coughlin, 2001; Ralston et al, 2001; Eisenhandler, 1990). This emphasis on independence is closely aligned with principles underpinning wide reaching policy documents, such as the World Health Organisations Active Ageing Framework (2002).

Remaining socially engaged and active is also something which is drawn upon by the Active Ageing Framework. Other findings amongst current literature on the meaning of driving in later life relate to this aspect. For example, research has found the car to be highly important for older adults, as this ensures they are able to access their informal support network. This includes their family and friends. Reichstadt et al (2010) found involvement and engagement in social interactions were a major contributor towards how to age successfully. This finding also links in with specific literature on driving in later life, as maintenance of social contacts and engagement is often cited as a primary reason for remaining behind the wheel for older adults. Participants in the study emphasised the critical need to maintain or develop social relationships and seek community and social support.

Aside from the positive practical and psychosocial aspects of driving which have been outlined and illustrated around Musselwhite \& Haddad's (2010) model, a number of negative outcomes of driving in later life have been identified. For example, the financial cost of owning and maintaining a car has been found as a negative factor for some (Burkhardt et al, 2002). Glasgow and Blakely (2000) and Rothe (1990) also found that older drivers perceive there to be a social 'stigma' attached to them by younger drivers where they are viewed negatively because they are an older driver. Other studies have also drawn upon older drivers being very aware of ageist attitudes from other road users, which are attached to them through a process of labelling and stereotyping (Musselwhite $\mho^{2}$ Haddad, 2018).

\section{Tertiary level of mobility needs}

Relating to the third level of mobility needs, Musselwhite \& Haddad (2010) found the meaning of driving to older people was related to a third, aesthetic level of needs. 
However, this level of needs were the least talked about, in terms of participant awareness. Driving was seen as important for older people to access nature and open spaces. This has been termed 'biophilia' by Kellert \& Wilson (1993). Hence, mobility affords escapism and relaxation which are important for good mental and physical health (Driver et al, 1991; Weissinger Eீ Iso-Ahola, 1984). Mobility was seen as enjoyable through the literal kinaesthetic experience of mobility, of movement and motion (Musselwhite and Haddad, 2018). In addition, driving in particular can help continued learning, through using cognitive skills (Musselwhite and Haddad, 2010). This level is also linked to simply seeing the world as in an important third space, observing places, times and space, and other people (Musselwhite, 2017).

To summarise, research which has been reviewed exploring the meaning of driving to older adults, has revealed wide ranging experiences, which are influenced by a number of factors. Musselwhite \& Haddad's (2010) hierarchal model of mobility needs has been useful in terms of categorising older people's needs of driving, which has been supported by wider research findings. 


\section{The meaning of driving cessation for older people}

There has been a plethora of research undertaken focusing upon driving cessation in later life. This, it could be argued, presents how wide reaching this topic is, parallel to an ageing population. A number of key areas have been identified through a thorough search of the literature, including; triggers for driving cessation and the role of planning; outcomes and meanings of driving cessation, and; understanding life after driving. The following sub-sections have been presented below.

\section{Triggers for driving cessation and the role of planning}

Much of the research on driving retirement in later life has focused upon the triggers, or reasons for giving up the car. These triggers have been found to have important implications, in terms of how this transition is experienced amongst older adults.

Drawing upon specific reasons for driving retirement, much of the literature has identified health as a major determinant. "Driving cessation is certainly influenced by health status, and reasons given for stopping driving are often medical" (Bauer et al, 2013: 310). Amongst these health triggers, sensory impairments, particularly relating to eyesight, have been cited as common reasons why the driving task becomes problematic in later life. In a study assessing the impact of health issues on driving ability amongst older adults, Macleod et al (2014) found visual problems to be the most common factor for driving cessation, with cognitive impairments, such as dementia, coming close second. In an earlier study, Adler \& Rottunda (2006) also found vision problems to be main trigger points amongst a third of participants, namely cataracts and double vision, relating to why giving up driving occurred. Other participants drew upon a feeling of fatigue behind the wheel, with one respondent admitting he had fallen asleep whilst driving. In addition, the study identified blackouts as a problem amongst the group, as well as poor reflexes. Similarly, another study comparing older drivers with older ex-drivers to look at the reasons to continue with, or stop driving, found that a person's age was not solely a reason to give up driving. It was more to do with health status, including functional impairments as an individual becomes older "Instead of having an age problem, we thus have an age-related illness problem" (Hakamies-Blomqvist and Wahlsrom, 1998: 305). This point was reflected in a later study, finding that age was a poor predictor of safe 
driving "Chronological age, per se, seems to be, in the case of mature drivers, only a weak predictor of safe driving performance at best" (Siren \& Haustein, 2014).

Dellinger et al (2001) conducted a study on the reasons for older people giving up driving amongst community dwelling Californian older adults. It was found that reasons to stop driving were mainly health related, or age related. Interestingly, results revealed that medications, crashes in the last 5 years, and gender were not related to cessation. Overall, the study found that the relationship between medical conditions and driving is complex. While medical conditions were the most common reason given for driving cessation, those who stopped had fewer medical conditions than current drivers. This suggests a broader measure of general health or functional ability may play an important role in decisions to stop driving. Dellinger et al (2001) note that other studies which have focused upon reasons for driving cessation have found that older people give different reasons to what they found in their study. This suggests that the decision to stop driving is a complex one, and is likely to be influenced by several factors. For example, Marottoli et al (2000) looked at possible predictors of driving cessation and found that increasing age, unemployment, low income, neurological disease, cataracts, decreased physical activity and functional disability were all associated with cessation. On a study in how social factors affect driving cessation, Chipman et al (1998) also found that gender and marital status were more influential in this decision, compared to the presence of chronic diseases.

Drawing upon 'increasing age' as a specific trigger for driving cessation, outlined by Marottoli et al (2000), a recent study has expanded upon this factor. Barrett \& Gumber (2019) found that older (or less youthful) identities amongst older adults was positively related to increased self-regulation and overall driver cessation. This suggests that older people's interpretation of themselves, in terms of their identity and how they view themselves has important implications in relation to the decision to continue driving in later life. This links with other research which has found that older people who experience negative pressure from other road users, including physical and psychological pressure, tend to view themselves as less capable drivers (Musselwhite and Haddad, 2010). This links with the theory of the self-fulfilling 
prophecy, where individuals being to act in accordance with the labels which are applied to them.

Also identified within the literature on reasons for driving cessation, was a gender difference. This highlighted that females are more likely to retire from driving at younger ages, compared to males, and in better health (Dellinger et al,2001; Eberhard,1998; Gallo et al, 1999). One suggestion for this is because women are more akin to utilising members in their informal support networks for help, compared to their male counterparts (Addis and Mahalik, 2003; Courtenay, 2000). However, not many studies actually found older adults to give up driving voluntarily (see Musselwhite and Shergold, 2013 for review), though these tend to be much more likely to be female (Meng, 2013; Rosenbloom \& Herbel, 2009; Siren et al, 2004). Many studies have also identified an attitude of 'never giving up'. This relates to older adults, studied within different contexts, reporting they would hold on to their driving licences for as long as possible. This is largely related to older male drivers (Musselwhite and Shergold, 2013).

Furthermore, due to the ageing of the population, cognitive diseases such as dementia and Alzheimer's are becoming more and more prevalent. This has resulted in many people facing no other option than to surrender their driving licences (Taylor and Tripodes, 2001). There has recently been a specific focus upon dementia and driving cessation, with findings holding important messages for the present study, despite the present sample set excluding those with cognitive impairments. Breen et al (2007) note that it is fairly safe for an older driver to continue for up to three years following early diagnosis of a cognitive impairment, although it is crucial that doctors inform the Drivers and Vehicle Licensing Agency of any changes in a person's mental health which could impact upon their driving ability.

Relating to the 'giving up' part of driving cessation, an important concept arising from previous research is the 'locus of control'. Studies have found that when the decision to give up driving is made by an older adult themselves, and not influenced by third parties, such as members of their informal networks, medical professionals, or other authoritative organisations, older adults have more positive outcomes 
(Liddle et al, 2008). When the locus of control is shifted, such as the decision to give up driving being taken out of the hands of older adults, this has been found to have far more negative outcomes (Liddle et al, 2008). This has been evidenced by Windsor et al (2007), who found that for those participants who gave up driving not through their own choice, this resulted in increased depression levels. Musselwhite \& Shergold (2013) have also drawn attention to this issue, stating that a crucial element within the process of driving cessation is where the locus of control lays. For participants within this study, benefits were reported for those who were in control of the decision to give up driving, as this allowed older drivers to plan for the changes brought upon by driving retirement. Findings outlined relating to the importance of maintaining control in the decision to give up driving, link with the topic of planning to give up driving. The authors also found that people who engaged in pre-planning reported a relatively higher quality of life beyond the car, whilst for those who were more reactive and engaged in little or no pre-planning, reported a poorer quality of life. However, as Curl et al (2013) note, despite driving cessation being normative as people age, few actually plan for this transition. The study recommends that what is required for older drivers is prompting and support, prior to driving cessation. Undertaking practices such as using alternative transport whilst still being able to drive would make the transition easier, ensuring the adjustment process is less difficult once driving is ceased. 


\section{Outcomes of driving cessation}

A number of psychosocial impacts have been drawn upon as a result of driving cessation in later life. Bonnel (1999) states that often, many older adults have been driving for up to sixty years, with the loss of this skill resulting in a "severe psychological blow" (p.5). Undertaking one of the earliest studies examining the effects of driving cessation in later life, Marottoli et al (1997) used data from in-person interviews, conducted in 1982, 1985, and 1988, as part of the New Haven Established Populations for Epidemiologic Studies of the Elderly Project. Depressive symptoms were also assessed using the Center for Epidemiologic Studies Depression (CES-D) scale. The researchers found that for individuals who stopped driving over the 6 year interval, driving cessation was among the strongest predictors of increased depressive symptoms, even when adjusting for health-related and sociodemographic factors. Fonda et al (2001) also reported similar findings, in 2001, using data from the Asset and Health Dynamics Among the Oldest Old (AHEAD) study, along with an abbreviated version of the Center for Epidemiologic Studies-Depression scale. The authors examined whether driving cessation was linked to depressive symptoms amongst older adults. Results found that older participants were at greater risk of experiencing worsened depressive symptoms if they had stopped driving, compared to those who had given up driving before the study began, or who had never driven. Specifically, participants who had given up driving between Waves 1 and 2 of data collection experienced a 34 per cent increase in depressive symptoms. The study also revealed that for respondents who stopped driving, having a spouse available to drive them did not mitigate the risk of worsening symptoms. Almost identical findings were reported in another study using the same CES-D depression scale, to compare depression levels between active older drivers and retired drivers. Ragland et al (2005) found that depression levels were higher amongst participants who were former drivers, compared to older adults who were still actively driving. This was the case at baseline, as well as for those who stopped driving during the three year interval, as part of the longitudinal analysis. The authors point out that levels of depression remained higher for ex-drivers, even when controlling for changes in health status and cognitive functioning. The study also identified a gender difference 
in relation to depression levels, with retired male drivers experiencing higher levels compared to female drivers.

Most recently, Chihuri et al (2016) undertook a meta-analysis on quantitative studies focusing upon driving cessation and health outcomes in later life. Based upon pooled data which met specific inclusion criteria, the risk of depressive symptoms almost doubled for older people who had given up driving. Ex-drivers were more than twice as likely to score above the screening cut off for depressive symptoms, with a score of 41 per cent, compared to only 19 per cent of current drivers experiencing depressive symptoms. This finding was consistent across the five studies included. Although Chihuri et al's findings are crucially important in terms of recognising the distinct link between giving up driving and depression, there are a number of limitations which need to be addressed. Firstly, the geographical context of the largest body of the research is restricted. For example, amongst the 16 studies which met the inclusion criteria by Chihuri et al (2016), 12 were undertaken in America, 2 in Australia, and only 1 each in the Middle East and Europe. No research using a quantitative approach to explore driving cessation and depression was identified from the United Kingdom. Therefore, these findings may not be applicable to the UK context.

A wider criticism of findings presented up until this point relating to depression and driving cessation needs to be drawn upon, for not including in depth explanations from the perspective of older adults. A deeper exploration into this link would help to develop knowledge and understanding about why depression is an outcome of driving cessation. However, an Australian study also using the CES-D scale to examine driving cessation and levels of depression by Windsor et al (2007) tapped into this unexplored area. The study focused upon the reasons behind increased levels of depression amongst former drivers. For example, the higher depressive-symptom scores of ceased drivers relative to those who remained driving at both waves of data collection was partly explained by a decrease in the sense of control among ceased drivers. Nevertheless, the study does not explore this is any further detail.

Studies undertaken primarily over the last 10 years have begun to address this gap, with more qualitative approaches being utilised to explore the impacts of driving 
cessation amongst older adults. Corresponding with the significant theme of depression, Liddle et al (2008) found that retired older drivers experienced low mood and feelings of unhappiness once they had given up their keys. This was elaborated upon and linked to feelings of sadness and loss in the amount of freedom that was once available through the ability to drive. One participant stated "It's just like the shutters coming down over your life, your freedom's gone ... the horizons that you loved ... they're gone forever" (Liddle et al, 2008: 384). Also drawing upon the experience of loss as a result of giving up driving, Whitehead et al (2006) found that loss was a multifaceted concept amongst older participants in their study who had ceased driving. Reflecting upon life without driving, interviewees talked about a loss of independence, as levels freedom and spontaneity had been compromised once they were no longer able to drive. "You lose your independence. I can't go anywhere - I go by public transport, but I can't go where I want to go when I want to go... My independence is gone as far as I'm concerned" (Whitehead et al, 2006). However, these findings need to be interpreted with caution due to their sample characteristics. For example, retired drivers were only included in the study if they had their driving licence cancelled due to failing to meet guidelines determining fitness to drive, or as a result of failing an occupational therapy driver assessment. Therefore, there were no participants included who had given up driving based upon their own individual decision. As previous research demonstrates, removing the locus of control from an older adult when making the decision to give up driving can lead to detrimental outcomes to levels of health and wellbeing (Musselwhite $E^{2}$ Shergold, 2013). Those who remain in control of the decision are able to make plans for their mobility needs post-car. "Events that convey to older drivers that they lack control over their lives could deleteriously affect their self-concept" (M.M. Baltes and Skinner, 1983).

Additionally, it is important to note that Whitehead et al's (2006) study was under representative in terms of males and females, with four male participants taking part, and only one female. It has also been identified within the literature that men often have worse psychosocial outcomes once they give up driving, compared to females. For example, Sullivan (2013) found that men had worse outcomes than women in their study on epilepsy and driving cessation in Ireland. Therefore, Whitehead's 
findings need to be interpreted with caution due to the element of potential bias present in the sample set. Adler \& Rottunda (2006) support Whitehead's findings, as a loss of independence was identified amongst retired drivers in their study. A participant described this when talked about her enjoyment in cooking, and finding it depressing asking a neighbour to get items for her while out shopping. Previously, the participant was able to "dash out and get what I needed". A loss of spontaneity was also a key issue as participants found there was the inability to be able to jump in the car and drive on the spur of the moment. This meant that participants had to preplan all of their trips and they didn't always know where they needed to go or where they may want to go a few days in advance.

Remaining with the feeling of loss as a result of driving cessation, Liddle et al (2008) found that participants included in their study reported a loss of social interaction and engagement with friends following driving cessation. "I lost my fair weather friends ... because I couldn't take them anywhere" (Liddle et al, 2008: 384). A further study by Mezuk \&Rebok (2008) supports this finding, reporting that over a 13 year period, driving cessation was associated with a reduced network of friends, and this decrease was not mediated by the ability to use public transport. However, wider explanations for the decrease in network of friends need to be considered. For example, the friends of participants may have passed away due to natural attrition at later stages of the life course. Additional findings from a further two studies may underpin some of the reasons for this reduction in social interaction and engagement with friends following driving cessation. It was found that former drivers were more likely to spend less time undertaking social activities and more time in solitary leisure, or to completely abandon previous social activities once they had given up driving, resulting in less opportunity for social contact with their network of friends (Liddle et al, 2011; AlHassani $E^{\circ}$ Alotaibi, 2014). Most recently, Musselwhite (2017) highlights that following driving cessation, car travel for its own sake, for less purpose-based trips goes largely unaccounted amongst older people. Musselwhite notes that when older people give up driving, their primary needs are still often met, such as medical appointments and shopping. However, what often goes unmet following driving cessation are the wider needs of older people, such as driving the car for the sake of 
it. It is a well-known factor that being able to get out and about is commonly cited by older people needs as being important to their physical and mental well-being, as it allows for social interaction and variety as well as some physical exercise (Holland, et al., 2005; Bowers, et al., 2009; Williamson, 2010). Evidence suggests that most people benefit from some kind of contact with nature: fresh air; a sight of the sea, woodlands or flowers; or being able to see the birds out of their window (Bhatti, 2006). This draws upon the importance of older peoples built environments and local communities, which could potentially become more central in their lives when no longer able to drive.

On a more practical level, another study talked about loss in the sense of losing personal identity after giving up driving in later life. A sense of finality was felt when participants sent their driving licence back to the licencing authority. Interviewee's talked about how the licence was a familiar staple which had been enclosed in their wallet for at least fifty years, and the loss of this tangible form of personal identification evoked deep feelings of sadness, and even led some participants to talk about other losses they had experienced in their lives (Adler $\&^{2}$ Rottunda, 2006).

\section{'Getting around things'}

One of the key alternatives which has been outlined in the literature is the use of information technology, which some have suggested can act as a replacement for literal or physical mobility, which often gets sacrificed once driving cessation occurs. Musselwhite (2018) stated that virtual mobility, referring to the use of technology and the internet, could be viewed as a poor substitute for physical mobility. However, it was stated that there is a lack of knowledge or research available which explains why this is.

A further strategy employed by older adults is the usage of informal support from their family and friends. Research relating to this alternative has been drawn upon within the next section of the literature review. 


\section{Driving cessation and informal support}

The following section begins by drawing upon published research on informal support, in relation to older adults, including definitions. This is then followed by specific literature identified which has included a focus, or reported upon findings relating to informal support and the process of driving cessation. Finally, this section reports on findings from a few limited studies, which have incorporated the view of informal support network members, relating to driving cessation in later life.

\section{Definitions of informal support}

In order to understand the association between driving cessation and informal support in later life, it is essential to firstly draw upon the concept of informal support, in relation to the wider study of social gerontology.

Previous scholars have provided various definitions of informal support, in relation to ageing. Thoits (2011) refers to this as "positive exchanges with network members that help people stay healthy, or cope with adverse events" (p. 146). Triantafillou (2010) expands upon the definition of network members, in the context of informal support, referring to this as 'unpaid care provided to older and dependent persons by a person with whom they have a social relationship, such as a spouse, parent, child, other relative, neighbour, friend or other non-kin (Triantafillou et al. 2010: 271; cited in Broese van Groenou $\mathcal{E}^{\circ}$ De Boer, 2016). It has been widely reported within published research that informal support is something which mainly occurs between family members. This is reflected by concepts such as filial piety and responsibility, intergenerational exchanges, and cultural, as well as family values. "In traditional societies, old people have always enjoyed a privileged position based on respect, consideration, status and authority. But this is starting to be upset under the nature of modern trends and that privileged position is now being questioned" (UNO, 1982, cited in Aboderin, 2004).

Aside from identifying 'who' informal support relates to, it is also important to talk about the type or nature of this support. A plethora of research has been published on the types of informal support which occur in later life, although this has typically been applied to ageing as a generic topic, or as something which is associated with a 
specific health problem, with a focus upon activities of daily living. Dykstra (2015) suggests informal support in later life can be categorised into three main areas. This includes instrumental aid, the expression of emotional caring or concern, and the provision of advice and guidance. Specifically, this may involve help with household chores or other practical errands, transport to doctors or social visits, social companionship, emotional guidance or help with arranging professional care (Broese van Groenou Eं De Boer, 2016).

Although informal support is an important factor throughout the driving cessation process, as previously outlined, Aboderin (2004) draws upon the changing nature of informal support in westernised countries. Many scholars have written about the abandonment of older adults, in terms of the diminishing face of familial care and support. This draws upon the theory of modernisation (Cowgill \& Holmes, 1971), which suggests the decline in informal support for older people is the result of the breakdown of the traditional extended family - with the emergence of the isolated nuclear family. This theory suggests that older peoples roles and status' are therefore undermined, and older people become trapped in a 'role-less' role, with adult children and relatives no longer ready to pay them as much attention, or indeed, offer support. Aboderin (2004) suggests that ultimately, declines in informal support in later life is the consequence of an increasing unwillingness of younger family members providing support for their older kin. "Migration, urbanisation, the shift from extended to smaller, mobile families.. and other socio-economic changes can marginalise older persons.. taking away their purposeful economic and social roles and weakening their traditional sources of support” (UN, 2002: 9). Referring back to modernisation theory, Cowgill \& Holmes (1972: 307) note "In all societies there is evidence of mutual obligations and responsibilities between aged parents and their adult children, but these obligations appear to be less clear and less binding in modern societies.. there is considerable resistance to it, and state insurance and assistance programmes have been instituted as partial substitutes for such filial responsibility". Aboderin (2004) notes the decreased willingness of family members providing support for ageing parents could be due to the erosion of familism (where filial obligation and responsibility are deemed an integral part) whereby increasing secularisation and the growing influence of 'modern' values which are 
underpinned by values of individualism. Silverstein et al (2012) note that early sociologists, such as Wirth (1938) and Ogburn (1933) identified the changing nature of familial support, in terms of declining fertility rates and postponed marriages at the time, as factors which were "weakening bonds of kinship", and being replaced by impersonal and superficial relationships, being named as responsible for "unravelling the social fabric of family life" (Silverstein et al, 2012: 1247).

With this gap between needs and available support for older people and with the evidence pointing to an ever widening of the area of need, it is not surprising that gerontologists are looking to family, friends, and neighbours to sustain the aged as a priority in the delivery of services (Buckholz, 1978). These trends and factors drawn upon have remained the same within the present context of an ageing population, and it could be argued that the focus on informal support is something which has become even more important.

\section{Older adults and informal support throughout process of driving cessation}

An element which is considered as highly important in the process of driving cessation is the relationship between family and friends. There is a common perception that families have always cared for their frail elderly members, and helping them once they have stopped driving is apparently part of this caring role. As family members become old and frail, their children, grandchildren, or other members of the family are often expected to co-operate with one another to meet their transport needs. This expectation is often held by older adults themselves, family members, and, it could be argued, by society as a whole (Silverstein et al, 2006).

Musselwhite and Haddad (2010) and Steg (2005) found that pre-existing relationships with family and friends are important in determining outcomes for older people following driving cessation. Findings suggest that if the older person had a good, close relationship with family and could ask for lifts without feeling like a burden, they were more likely to ask family members for lifts which did not involve practical needs, but included discretionary journeys, such as driving to visit nature, which have been found to have a positive impacts on wellbeing. However, some 
participants involved would not even ask for lifts to meet their essential needs, including visiting the hospital, or GP appointments. The unwillingness to ask friends for lifts was also marked, unless some kind of reciprocal relationship was involved. Other studies have found similar patterns in terms of older people feeling like a burden on family members to meet their transportation needs once they have given up driving. Adler and Rottunda (2006) found a shared feeling amongst participants of not wanting to be a burden on family members after giving up the car. A participant in the study described how she would wait to be asked by a family member if she needed anything, or required a lift somewhere. Additionally, the respondent talked about how she would always buy lunch for her family member, as a way of paying back for the lift received.

Nevertheless, other studies have found more positive outcomes for older people asking for, or accepting lifts from family members. Musselwhite and Shergold (2013) found that after giving up driving, some study participants noted a sense of closeness with their family as an outcome of accepting lifts as an alternative means of transport, whereas this is an aspect which could possibly have been missed whilst being an owner of a car. However, for study participants who did not have family and friends living close by, there were far more detrimental effects identified and a poorer overall quality of life was reported as an outcome of giving up driving.

Duner \& Nordstrom (2007) undertook qualitative in depth interviews with older Swedish people, to explore experiences of informal support in later life, when formal support is also provided. Some key concepts which arose from the study were 'symmetry and direction'. This related to mutual exchanges of support within the relationship between themselves and their family members. For example, some older adults talked about watering plants for neighbours who helped them, or financially compensating friends and family members who provided help. Previous flows of support from older people to their informal support networks were also drawn upon. This relates to reciprocity, described by the authors as an 'outstanding account', or a 'credit note', which could be used when the older person needed help themselves in their later years. 
Most recently, Dickerson et al (2019) undertook a study reviewing published research on safe mobility among older adults transitioning from driving to nondriving. Within the review, two key areas were focused upon. Firstly, the process of transitioning to non-driving, and secondly, the maintenance of mobility after driving has ceased. The article concludes by highlighting a number of research gaps which became apparent from this most recent review within the field of driving cessation in later life. One of the potential questions which the authors draw upon, which needs addressing is; what resources or services are needed for family members/caregivers to help with driver cessation? This recognises the importance of the present research, in terms of focusing upon those individuals who surround an older adult during the process of driving cessation. It also highlights the concept of 'caregivers', potentially recognising that not all older people have family members around them.

Overall, drawing upon the research gaps outlined by Dickerson et al (2019), other than the above examples, there is little research which has focused solely on informal support as an aspect of driving cessation. Instead, informal support is largely something which is simply referred to as being part of the driving cessation landscape. Therefore, the knowledge base upon this topic is limited, requiring further exploration. 


\section{Perspectives of informal support network members}

Research which has been undertaken with the family and friends of older adults in relation to driving cessation has primarily focused upon two key areas. Firstly, the personal experiences of family and friends in relation to their older relative or friend giving up driving have been documented, in relation to what this transitions means from their individual points of view. For example, Liang et al (2014) conducted a scoping review across six research databases between 1985 to 2013 , leading to the inclusion of twenty-seven articles. The purpose of the study was to understand the experiences, viewpoints and needs of family members with regards to an individual undergoing driving disruption across various population groups. This included articles on dementia or cognitive impairment (16 articles), older adults ( 8 articles) and brain injury ( 3 articles). Results found that the most common topic raised was related to decisions and consequences for the individual. Other concerns were related to family members' occupational role changes, emotional and communication issues and support needs of family members and their recommendations for services. This highlights the importance of family members, in relation to the process of driving cessation. Although it is recognised these articles were not specific to 'older' adults, as they included those experiencing a change to active driving due to cognitive changes and brain injury, the results have been echoed amongst other studies which have explored the viewpoints of family members. Additionally, recommendations and conclusions from the article state that research in the area of the impact of driving disruption on family members is limited, which was highlighted by the fact that the majority of articles included in the review did not set out to explore family members' experiences and needs, and this highlights an area that requires critical attention.

Although not related to driving cessation, a study by Lorca \& Ponce (2015) in Chile focused upon why adult children provide support to their ageing parents. Some of the major factors which were highlighted as important in terms of motivating, or enabling support was geographical proximity, having a parent aged over 80, and frequency of contact. Sons or daughters who lived in the same home as their parents, as well as those who were in daily contact with their parents who lived in their own 
homes, were four times more likely to provide support, compared to those adult children who had less contact. However, health was not stated as a motivator amongst participants. A theoretical standpoint which is central to understanding caregiving between two or more parties, is social exchange theory. This theory was developed in 1958 by George Homans. The theory states that individuals make rational choices, and act accordingly, based upon a cost-benefit analysis of a particular circumstance, relating to social relationships (Homans, 1958). Reciprocity stands at the core of this explanation. For example, when a person 'puts in' to the relationship, they will receive something back. Relating this theory to the provision of support for older adults, this would relate to aspects such as an individual providing instrumental or emotional support to another person, whereby this provision of support would be rewarded. Typically, the application of social exchange theory has been applied to familial caregiving contexts (Raschick \& Ingersoll-Dayton; 2010; Silverstein, 2002). Despite findings which have focused upon the viewpoints of informal support network members highlighting aspects which are consistent with social exchange theory, such as the concept of reciprocity, a continual search of the literature revealed that this theory has not been relating to the process of driving cessation, in any context.

Rosenbloom (2010) undertook several focus groups with the adult children of older drivers in the UK and the US. The aim of the research was to explore how the adult children of older drivers thought their parents would meet their mobility needs, if and when driving cessation occurred. The study also investigated what adult children thought the impact on their own lives would be if their older relatives reduced or ceased driving. Findings were complex and varied. Firstly, to explore outcomes of driving cessation, the adult children of older parents who were currently driving were asked what their parents would do if they could no longer drive. Respondents drew upon the importance of driving for their older parents, in relation to their independence and freedom. One participant stated 'the car 'keeps her going' so to speak. It gives her a chance to get out. Freedom...that's her reaction" (pg. 636). Participants also drew upon alternative means of transport when thinking about the implications of their parents giving up driving. The bus as an alternative to driving one's own car 
was perceived as a viable alternative amongst some adult children. This was related to a number of enabling factors, including the older adults' personality type, positive health status, and the continual improvement in public transport. "I think, because he's a very outgoing person...he'll probably catch a bus", and "If they're healthy enough then they can get out to use public transport" (Rosenbloom, 2010: 636). Other participants held opposing views in relation to public transport being a viable alternative to driving in the event of driving cessation. There were a number of reasons behind these differing views, including the recognition that older parents were unfamiliar with how to operate public transport systems as a result of being car dependent for so many years. Negative perceptions and personal experiences of using the bus were also talked about as reasons for why the bus would not be a suitable alternative to driving for their older parents. "If we don't like the buses, then why would our parents?" (Rosenbloom, 2010: 636). For other participants whose older parents had already given up driving, a loss of confidence relating to the use of public transport was reported as a disabling factor: "There is a bus stop right there but he liked to drive.. he's just lost his confidence [in using the bus] over the years" (pg. 636).

In relation to what driving cessation would mean for adult children themselves, participants in Rosenbloom et al's (2010) study spoke about this prospect invoking feelings of dread. This was elaborated upon, with some respondents explaining that they feared intrusion upon their own time and other commitments. Some thought this form of intrusion could result in a loss to their own independence, due to increasing their responsibilities for the older relatives' transport and other support needs. 'I'm glad my mom's still driving cause' I don't have to do the running. When she was ill I was doing a lot of running. So I'm grateful that she's pretty decent behind the wheel" (Rosenbloom, 2010: 638). The feeling of having responsibility for older parents has been more widely identified in the research base on giving up driving in later life. However, Johnson (1998) found that the family and friends of retired older drivers interpreted the feeling of responsibility over the older adult in a more positive way. For example, one friend of an older retired driver stated that the provision of informal support was her responsibility, which was shaped by her cultural and societal norms. The participant also drew upon the advantage of driving herself, in order to meet the 
retired drivers needs (Johnson, 1998). An adult child in Connell et al's (2012) study talked about the underpinning principles behind this feeling of responsibility they had taken on since their older parent gave up driving. For this participant, providing support was a way of repaying their older parent back for the support and guidance which they provided throughout childhood: "I would be happy to drive my parents. I had to accept my responsibility that I was raised by this person. Now it's my turn to turn around and do something back" (Connell et al, 2012: 984). This links with social exchange theory, recognising the importance of reciprocity.

A more recent study by Sanford et al (2018) with the caregivers and healthcare providers of older adults who have dementia, explored their perspectives about driving cessation, relating to the older adults cognitive impairment. Many of the caregivers, who were primarily family members, talked about the impact which they perceived driving cessation to have upon the older adult. One participant drew upon the element of sadness which giving up driving has caused for her older mother. The participant stated "Well, in my mom's case, like I said, it was like losing a spouse. It was really traumatic. And, because of her pride, she would never even ask a neighbour ... you know for a ride or anything like that. And literally she would just sit in her house and go nowhere. So, it was devastating. Devastating” Sanford et al (2018: 7). However, other participants within the study perceived the older adult to have a fairly low-key response to driving cessation, which did not involve much emotion.

Drawing upon a direct outcome of driving cessation, Schryer et al (2017) explored the association between giving up driving and levels of wellbeing, amongst older adults and their social partners. This included spouses, wider family members, and friends. Findings revealed that over a two-year period, life satisfaction reduced for the social partners of retired older drivers once driving cessation had occurred, although this was not the case for older adults themselves. Findings revealed that life satisfaction was greater amongst the family members and friends when the retired driver used public transport more frequently after giving up the car. This may suggest the family member or friend therefore had less of a role to play in terms of providing the older adult with private transportation. However, the results reported by Schryer et al (2017) need to be interpreted with caution. This is because the study 
only focused upon older adults retiring from driving who had experienced vision loss. It could be suggested that those with vision loss have specialist mobility and support needs, although this was not measured in the present study. For example, Khan et al (2016) state that those who experience vision loss face a number of challenges. This includes communication barriers, and major challenges to their social and economic prosperity, which could additionally result in increased levels of stress and depression for those around them who provide informal support. This in turn, could reduce the overall level of life satisfaction experienced (Khan et al, 2016).

Drawing upon the findings by Schryer et al (2017) in relation to the reduction in life satisfaction amongst the social partners of older ex-drivers, other studies which have included the perspectives of family and friends have highlighted specific reasons why driving cessation has negative implications for these individuals. For example, Chacko et al (2015) undertook a qualitative study with older adults who had given up driving due to dementia, along with their family members. It was found that most family members were negatively affected by the older adults' driving cessation. Significant emotional impacts were detected amongst the support network members. This included feeling resentful (sometimes described as a form of punishment by the provider of support), frustrated, and feeling that their own lives had been intruded upon. This was due to increased time at home with the older adult, resulting in heightened feelings of stress.

Findings from other studies focusing upon the experiences of the family and friends of older drivers have also revealed some of the reasons why these individuals provide support in the event of driving cessation. For some adult children in Rosenbloom's (2010) study, this was related to withstanding cultural values. "It's a cultural thing, but because my brother is the nearest person, it would be natural for him to do the little jobs.. to rally around.. it's already natural" (Rosenbloom, 2010: 638).

Other findings have highlighted familial related factors for the provision of informal support. A participant in Connell et al's (2012) study draws upon these family values: 'they're the parent, and we respect that.. I have to give up my freedom because I'm going to have to take mom or dad wherever.. it's a drain.. but it is a responsibility on us and we need 
to take care of our parents" (Connell et al, 2012: 984). Lorca \& Ponce refer to the term 'filial obligation', described as an expectation of duty from an adult child to their ageing parents, to provide support in times of need. Silverstein et al (2012) also draw upon 'moral capital', which is "the stock of internalised social norms that obligate children to care for and support their older parents" (pg. 1246). The origins of filial obligation between adult children and their ageing parents have been reported by a number of scholars. Cicirelli (1993) suggests the concept arises from the early socialisation process which occurs at the beginning of the life course, where norms of expected behaviour are passed on by the family unit, echoing what is socially responsible behaviour. These learned norms are drawn upon later in the life course, in response to the needs of older parents. In this case, adult children may grow to perceive support to their ageing parents as their duty, responsibility, or obligation.

However, not all informal support network members hold the same views in terms of support provision for older adults as a result of driving cessation. An adult child in Rosenbloom's (2010) study held a pragmatic view when talking about the extent to which they could or would provide lifts for their older parent "well, not all families do take it on. And logistically it's not always possible" (Rosenbloom, 2010: 637). A similar view was help by another participant, who stated that when older parents stop driving, this shouldn't solely be down to adult children to meet their mobility needs, as there are other transport services available if older people are willing to use them. "If elderly people do stop driving it doesn't mean they're dependent on their children purely for the driving. There are other ways and means of doing that (Rosenbloom, 2010: 637).

Relating back to the psychosocial impacts of driving cessation upon the informal support network members of older drivers, the element of guilt has also been highlighted within the current literature base. For example, the following participant talked about experiencing a sense of guilt as a result of the older adult reacting negatively if the participant was unable to meet her needs in a prompt manner. "I have to ... fit her in ... on my lunch hour ... pick her up some Kentucky Fried Chicken and bring it right away or ... take her to the grocery store. It's not an option for me to say, I cannot come today... and then she makes you feel bad" (Connell et al, 2012: 984). 
Aside from the psychosocial and emotional impacts identified, other scholars have found driving cessation to have practical impacts and outcomes upon older people's informal support network members. Taylor \& Tripodes (2001) undertook a study on the effects of driving licence removal on older adults with dementia, and their informal carers, comprising of mainly family members. One of the major findings with the care providers was that formal work was often missed by 33 per cent of caregivers, with 13 per cent of the sample exiting the labour market entirely. Participants stated that reasons for this change in their labour market activity was due to the need to provide transport and support for the retired drivers. Talking more in depth about their experiences, some caregivers stated the effect of providing support as a type of strain. Nevertheless, caution needs to be taken when interpreting these findings, as older adults with dementia may have a substantially different type and level of support needs, which in turn may have a different effect on their informal support network members. Research which has been undertaken with family members of those who have given up driving for other reasons other than the onset of dementia, have also found that an older parent giving up driving has practical outcomes for those in their informal support network. Rosenbloom (2010) found that the lives of some adult children had changed, in terms of how they approach their own routines "I've got to think more about kinds of things like what, where and when he wants" (Rosenbloom, 2010: 639). Similar findings were highlighted amongst participants in Ralston et al's (2010) study, including escalating personal responsibilities, rising stress levels and more hurried schedules. However, there is no further contextual or descriptive information for these findings in this particular paper, limiting the scope to develop a more in depth understanding.

However, adult children in Rosenbloom et al's (2010) study touch upon some of the reasons why there is an increase in stress levels amongst support providers in the event of driving cessation. For example, some older adults place heavy demands and expectations upon those around them, in order to meet their mobility and transport needs. A UK based focus group was asked "Do your parents think they have the right to ask you to drive them?" there were similar responses amongst some participants. The following example's highlight the intense, persistent nature of older adults 
expectations. "Yeah.. they just pick up the phone.. it's now, now. 'Tou sleeping? Come on, get up!'”, and "I've actually tried to say no, but he calls day or night". In this case, it was revealed that it was the older adult who thought it was their adult children's duty and responsibility to look after them and meet their needs following driving cessation. Other research has found conflicting outcomes. For example, some family members and friends of older drivers talked about an awareness of the older adult feeling like a burden in terms of the informal support they required. "I don't think driving is a real big issue to him, but I think he wants to not be a burden on anyone . . it's got to be hard " (Connell et al, 2012: 984).

In terms of coping strategies amongst informal support network members in the event of driving cessation, Ralston et al (2001) anticipated that there would be cooccupation amongst family members and older adults once they had given up driving. This refers to the support provider combining their own needs with the mobility needs of older adults, in order to satisfy both sets of needs. However, it was revealed that when transport was provided by family members, this either focused upon the needs of the older adult alone, such as taking them grocery shopping or to medical appointments, or on the needs of the family member. Participants stated this was because they wanted to entirely devote their efforts and attention on the older adult's needs during out-of-home trips.

To summarise, literature which has focused upon the views and experiences of informal support network members of older adults, in relation to the driving cessation process, has revealed a number of important findings. This largely relates to reasons for providing support, along with outcomes. However, the body of literature which is available has largely focused upon the views of family members only, particularly adult children (Rosenbloom, 2010; Connell et al, 2012; Sanford et al, 2018). Where research in this area has included the experiences of non-kin network members, this has been limited to exploring only one stage of the driving cessation process. For example, by focusing upon driving cessation only (Johnson, 1998), instead of including the driving stage, which recognises that giving up driving is a process (Musselwhite E' Shergold, 2013). 


\section{Chapter 3: Methodology}

\section{Introduction}

The purpose of this chapter is to provide a comprehensive account of the methodological approaches employed within the present study, in order to address the overall aim of the research. Specifically, this was to 'explore the process of driving cessation in later life, with a specific focus upon informal support".

Firstly, the chapter begins with an overview of the research approach and design adopted. This includes a description of traditional methodological approaches applied within the field of transport studies, before leading on to the philosophical underpinnings of the study. The ontological and epistemological standpoints of the researcher have been drawn upon, which have influenced the research paradigm. Namely, this includes a justification of why a phenomenological line of inquiry has been used, as a specific type of qualitative methodology. Secondly, this is followed by an explanation of the snowball sampling approach which has been applied, as well as specific recruitment strategies adopted. Thirdly, the chapter includes a discussion of the data collection methods, referring to the use of semi-structured interviews. An explanation as to why a pilot study was undertaken prior to official data collection is also outlined in this section. Ethical considerations have been inserted as a fourth sub-section of the chapter, drawing upon issues such as participant confidentiality and anonymity. Finally, the steps undertaken to conduct a thematic analysis of the data are also included.

To address the issue of 'quality' in qualitative research, the aspects of rigour, transparency and reflexivity have been referred to throughout the chapter, recognising that these issues are relevant to the entire research process.

\section{Research Approach \& Design}

The importance of employing a sound research design at the outset of any study to ensure efficient and successful functioning has been well documented (Maxwell, 2013; Congdon and Dunham, 1999). Carter and Little (2007) draw upon three fundamental facets of research which ought to be addressed in order to provide the framework for 
planning, implementing and evaluating the quality of research. These include epistemology, methodology and method. "Quality research is much more than simply selecting methods and following recipes. By thoughtfully considering the epistemological assumptions about knowledge production, and what kinds of evidence might be used to warrant claims, novice researchers will be able to more effectively design and conduct studies of quality" (Roulston, 2010: 225).

\section{Traditional Methods in Transport Studies}

Although the present thesis spans across a number of academic disciplines, including transport studies, social gerontology, human geography, sociology, and social policy, a key message to arise from drawing upon literature from each subject area, relates to the history of research methods in transport studies, specifically. May (2001) notes this area has predominantly been based on a positivist epistemological assumption that reality can be directly apprehended through observation. Civil engineering was the original discipline which transport research has been built upon, resulting in transport and travel studies being conducted through the use of quantitative methods, with concepts of applied physics and mathematics dominating within the field (Musselwhite, 2011). Ksiazkewicz (2012) suggests the heavy reliance upon quantitative methods within transport research relates to the fact that transport planning is a process of problem solving which includes analyses, evaluations and implementations of optimal solutions. Factors which are usually considered in the transport planning process include an assessment of journey potential and demographical and urban planning forecasts. This has led to the perception of mobility as a form of mass movement, which ought to be analysed at a macro level. Therefore, the very nature of quantitative research is in accordance with these aims and objectives of transport planning, through the high levels of statistical validity such methods provide, which accurately reflect the population (Vanderstroep $\mathbb{E}^{\circ}$ Johnson, 2010). Furthermore, quantitative research is easily replicable as surveys and questionnaires tend to be of a standard format, which could be repeated with any sample of the population (Monette et al, 2005). Ksiazkewicz (2012) notes that transport planners are reliant upon factors such as replicability, validity and generalizability which provide accurate information, forming the basis of their knowledge and 
understanding of a given issue. Also referring to the traditional use of quantitative methods within transport studies, Lyons et al (2007) draws upon the longstanding idea that people only travel based on time and money. Transport planners assume that users of a transport system want to minimize their expenses whilst reaching their destination in the timeliest manner, resulting in the optimization of transport systems with services being designed to respond to this ideal. "The public transport system is organised around the needs of the able, working population, with the majority of services running into central locations at peak times" (Cvitkovich \& Wister, 2001). Although time and money may be of most relevance to working age travellers, this assumption makes it difficult for other travellers, such as older adults, to identify with other uses of travel. For example, Green et al (2013) found in their study on the role of the free bus pass with older people in London, that travelling by bus provided important opportunities for older people in terms of social interaction with other passengers. This draws upon the important link between transport and social engagement and opportunities in later life, which have been highlighted as crucial factors when it comes to successful ageing. Both concepts have been given significant research attention in recent years, particularly when considering fundamental drives to combat loneliness, one of the 'wicked problems' associated with an ageing society (Lucas, 2013; Gardiner et al, 2013; ven den Berg et al, 2016).

Through these traditional assumptions and longstanding history of quantitative methods in transport research, much of the literature within the area has overlooked people being at the centre of enquiry. Therefore, it has been argued that "what is needed is a change in philosophy alongside an introduction of the human element into transport studies" (Musselwhite, 2011:1). Musselwhite (2011) has suggested the intricacies of human behaviour cannot alone by understood purely in a mathematical manner. Therefore, a more person-centred approach is required alongside a shift from the macro to the micro. Although quantitative data gathering techniques are beneficial when studying mass numbers, this strategy is not suitable when studying people. Additional factors which are considered in transport research are spatial management, environmental protection and social equality (to name a few), all of which require an understanding of the attitudes and behaviours of transport users 
(Ksiakzewicz, 2012). Therefore, the standardised nature of quantitative methods may not capture the entire details of a research problem, and in turn may generate inaccurate forecasts that could produce negative social and economic consequences, and further marginalises and excludes certain groups of people at the expense of others. Furthermore, Grosvenor (2000) argues that results generated through large data collection techniques can result in a superficial understanding of participants' thoughts and feelings. When specifically focusing upon questionnaires as a form of quantitative data collection, Grosvenor notes these are an isolated activity: whereas interviews and focus groups are more of an interactive process, where any misunderstanding of concepts or questions can be clarified. Lucas (2013) supports the use of qualitative research methods in transport studies, and notes that this approach is being recognised as increasingly valuable for understanding the underlying motivations behind people's travel behaviours and for teasing out their more hidden attitudes and perceptions. Although much transport research is still conducted within the quantitative paradigm, there has been a significant shift in approach, resulting in a growing number of transport studies adopting qualitative methodologies (Mars et al, 2016; Lucas, 2013; Carr, 2008), with an emphasis on the need to study the social context within which transport systems are embedded.

Taking the above information into account, a qualitative research approach has been undertaken to conduct the present study. Further justifications for utilising this type of approach have been expanded upon in the subsequent sections of this chapter.

\section{An interdisciplinary approach to the research study}

Referring back to the above point, relating to the present study spanning multiple academic disciplines, aside from just transport studies, it is important to outline the value this brings to the research.

Firstly, the literature review has identified that driving cessation is a multidimensional topic, which has been explored through various academic disciplines. Much of the published research within the field of driving cessation and/or informal support has tended to approach the research from one position only. For example, some scholars have come from a social work perspective, where recommendations 
have been made for how social workers who are in contact with older drivers can help to support those experiencing the transition (Bauer et al, 2003). Other studies have focused purely upon a transport and mobility perspective, where much of the research has been undertaken on crash and accident prevention amongst older adults (Braitman et al, 2007), whilst others have purely recommended suggestions for policy makers working within the field of transport (Adler \& Rottunda, 2006).

Drawing upon this issue, the multidisciplinary approach adopted towards the current research helps to ensure findings and subsequent recommendations are transferable to a range of individuals or groups. This recognises that the topic of driving cessation and the element of informal support are complex, which would benefit from a holistic approach.

This includes, for example, potential implications for those working in older peoples services, such as social workers or third sector organisations; leisure and tourism organisations; the general labour market; policy makers; and general members of the public. On the other hand, if I had approached the research from only one academic discipline, such as social policy, this would have been largely focused upon suggesting policy recommendations. Adding further weight to this issue, Stock \& Burton (2011) highlight the benefits of research approaches incorporating differing academic viewpoints, suggesting that this ensures study implications are more robust, compared to approaching a topic from one viewpoint.

\section{Philosophical underpinnings Eீ research paradigm}

Bloomberg \& Volpe (2016) talk about a 'worldview', in terms of a research standpoint held by the researcher. This relates to a basic set of beliefs and assumptions that guide action, in terms of specific research methods. Within this 'worldview', ontological and epistemological philosophical underpinnings of research are referred to. Ontology relates to differing beliefs about the existence of facts and objects, while epistemology regards whether we can know them or not, and if so, whether this can be achieved objectively or subjectively (Bryman, 2015). Relating to the ontology epistemology of research, Carter and Little (2007) note that these are elements which are often overlooked in published literature, due to the perceived complex nature 
surrounding philosophical presumptions within various fields. However, the authors argue that addressing the ontological and epistemological position of any research study is crucial and apparent in all forms of research for a number of reasons. For example, it is the basis for explaining the rightness or wrongness of types of knowledge, whilst seeking to justify that knowledge. Carter and Little (2007) suggest that it is from an epistemological standpoint that the researcher forms conceptualisations of the participant in data collection and analysis. To illustrate, if the researcher is undertaking a study based on participant observation, the participants are likely to be thought of as passive individuals in the research process, where their behaviours and actions are studied to generate findings.

On the other hand, if the researcher is undertaking a study utilising interviews or a focus group, the participants are likely to be viewed as active contributors from the outset, as the researcher relies upon their interactive responses and valued experiences to generate data. Therefore, the researcher has drawn upon the ontological and epistemological values within their area, in terms of what they perceive to count as a reliable and justified methodology, shaping the choice of method used for the study. Epistemology gives meaning to research findings and is essentially the "justification of knowledge" (Carter and Little, 2007: 1317).

The present research study adopted interpretivism as an ontological position. This means that reality is socially, culturally, and historically constructed, and there is no set 'objective' reality or truth (Lincoln $\&$ Guba, 2000). Scholars have also stated that interpretivism is related to constructionism, whereby for the purpose of the present study, both concepts have been regarded as approaches which possess similar meanings (Creswell, 2013; Andrews, 2013). The central assumption of interpretivism is that reality is socially constructed, where individuals develop subjective meanings of their own personal experiences, giving way to multiple meanings regarding a particular phenomenon. As Crotty (1998) states: "Meaning is not discovered; it is constructed though the interaction between consciousness and the world" (p. 44). This differs greatly from positivism, or objectivism as an ontological position, which asserts that social phenomena and their meanings have an existence independent of social actors 
(Bryman, 2016: 29). Positivists believe that there is a single objective reality to any research phenomenon or situation, regardless of the researchers perspective or belief, which can be measured numerically to provide definite answers to a particular question (Edirisingha, 2012). On the other hand, from an interpretivist standpoint, the researcher is considered as an active part of the research process, where the researchers background, including their own cultural, social and historical experiences, form part of the meaning making process. It is therefore the researcher's role to understand the multiple realities from the perspective of participants (Bloomberg $\S^{2}$ Volpe, 2016). The role of myself, as a researcher, is discussed further in the subsequent sections of this chapter.

\section{Phenomenology}

After acknowledging interpretivism as the ontological standpoint of the current study, the epistemological approach also requires an explanation. Phenomenology has been adopted as the epistemological position for the present research, which is literally defined as "the study of "phenomena", appearances of things, or things as they appear in our experience, or the ways we experience things" (Stanford Encyclopedia of Philosophy, 2013: undated). Phenomenologists are concerned with understanding lived experience from consciousness in the world, which is subjective and constructed by an individual (Cal E Tehmarn, 2016: 4). This approach involves studying a small number of subjects, to develop patterns and relationships of meaning. The emphasis is on feelings, emotions and subjective responses of participants, relating to a specific phenomenon (Bloomberg \& Volpe, 2016).

However, as previously outlined, given the background of transport studies being in economics and engineering, it is unusual to take this epistemological standpoint within the field of transport research. Nevertheless, phenomenology has begun to take precedence in recent years, with scholars employing this approach towards the study of transport and travel behaviour (Todres $\S^{2}$ Galvin, 2008; Parkhurst et al., 2014). This also includes a previous $\mathrm{PhD}$ thesis, which employed phenomenology to study driving retirement amongst older adults (Pellerito, 2008). This reflects the need to 
understand peoples lived experiences, in order to understand how to effectively place people at the centre of transport systems (Musselwhite, 2011).

It is important to consider the origins of phenomenology as a philosophical position, in order to understand how utilising this approach relates to the overall methodological design. Phenomenology originated in the early $20^{\text {th }}$ century, by the 'father' of phenomenology, Edmund Husserl (Lopez \& Willis, 2004). Husserlian phenomenology is concerned with the description, foundation, and constitution of knowledge in consciousness. Thus, phenomenology is conceived as a "science of consciousness" (Hein $\mathcal{E}^{2}$ Austin, 2001: 4), involving the systematic study of experience or human meaning, in order to understand a particular phenomenon. Husserlian phenomenology is often also referred to as 'descriptive phenomenology', where it is the role of the study investigator to understand and describe individual lived experiences, as presented during data collection (Lopez E Willis, 2004). In order to achieve this understanding, Husserlian phenomenology believes that all prior personal knowledge needs to be stripped before embarking upon a research journey. This means that the researcher must actively shed his or her consciousness of all prior expert knowledge, as well as personal biases (Wojnar \& Swanson, 2007). From this viewpoint, this would require the researcher to refrain from undertaking a literature review, or employing set research questions, prior to data collection. The term 'bracketing' is often used, in order to describe this 'shredding of prior knowledge' (Lopez $\mathcal{E}^{2}$ Willis: 2004: 727), whereby if studying phenomena through a Husserlian lens, the researcher must bracket off all preconceptions, to focus only upon the lived experiences of participants. This process is also referred to as 'phenomenological reduction' (Beyer, 2016).

However, phenomenology has since adapted from the traditional, descriptive approach proposed by Husserl. This has been achieved through multiple successors of Husserl continuing to study this philosophical epistemological approach to 'knowing' (Reybold, 2002). One of these successors was Martin Heidegger, a pupil of Husserl. Heidegger moved the study of phenomenology on, from a descriptive, to an interpretative philosophical approach. Building upon traditional phenomenology, 
Heidegger rejected the concept of phenomenological reduction, or bracketing (Scotland, 2012). Rather, he argued that fully comprehending lived experience was, in essence, an interpretative process and that bracketing out preconceptions was neither possible, nor desirable (Lopez \& Willis, 2004). Heidegger instead, adopted the position of being in the world, where contextual interpretation and meaning were sought and valued (Gearing, 2004).

A common facet of Heideggarian phenomenology is the study of 'hermeneutics', described as a process and method for bringing out and making manifest what is normally hidden in human experience and human relations (Spielgelberg, 1976). Applying hermeneutics to phenomenology, this goes beyond the description of lived experience, to look for meanings embedded within the mind of an individual. These meanings are not always apparent to the participants, but can be extracted from the narratives produced by them. The focus of a hermeneutic inquiry is on what humans experience, rather than what they consciously know (Lopez $\mathcal{E}^{\circ}$ Willis, 2004). According to Gadamer (1960), a hermeneutic circle occurs whereby a text is understood by reference of the context in which it was generated. . Heidegger also places the active role of the researcher within this hermeneutic circle (Bowler, 2016). As oppose to Husserl's approach of phenomenological reductionism, where the researcher brackets off all preconceptions, Heidegger views the researcher as an active part of the research process, a type of participant themselves, alongside study participants (Daher et al, 2017). Hermeneutics focuses upon the 'wholeness of research', which involves the role of the researcher, rather than specific parts of the process; such as only describing experiences from the viewpoints of interviewees, ignoring the position of the researcher.

Furthermore, drawing upon the facets of interpretative phenomenology, Heidegger (1962) emphasized that it is impossible to rid the mind of the background of understandings that has led the researcher to consider a topic worthy of research in the first place. For example, a researcher's knowledge of the research literature is what leads him or her to the realization that research is needed in an area that is understudied. This has been evidenced in the present study by identifying the 
significant lack of research which has focused upon informal support, as a specific element of the driving cessation process. Lopez \& Willis (2004) note that it is the researcher's knowledge base that leads to specific ideas about how the inquiry needs to proceed, in order to produce useful knowledge. Therefore, personal knowledge, according to hermeneutic scholars, is both useful and necessary to phenomenological research (Geanellos, 2000). The technique of bracketing, as described by descriptive phenomenologists, is inconsistent and questionable within a hermeneutic approach (LeVasseur, 2003). Instead, the hermeneutic tradition requires preconceptions to be made explicit, explaining how they are being used in the inquiry. In this case, this has been evidenced by the researcher highlighting prior knowledge of later life transitions (see Chapter 1-personal inspiration for the study), as well as undertaking the literature review prior to data collection. Overall, Heidegger stated that interpretative phenomenology is achieved, when the researcher arrives at meanings of a phenomena, which are a blend of the meanings articulated by both participant and researcher, within the focus of the study (Salovaara, 2011).

\section{A qualitative approach}

Guided by the ontological and epistemological principles of interpretivism and phenomenology, the present thesis has adopted a wholly qualitative methodology. This is based upon the ability of this approach to "delve deep beneath the surface of superficial responses to obtain true meanings" (Bowling, 2002: 378). The interpretivist nature of qualitative research aims to understand unexplained phenomena through the words and experiences of each participant, where the quality of what is stated during the data collection stage is of most relevance. The aims and objectives of the study are not to quantify large numbers of data sets to highlight the number of older drivers in a given area, for example. Rather, the researcher is interested in gaining rich, in-depth insights into current and retired older driver's views and perceptions, along with members of their informal support networks, on the prospect of, or lived experiences of driving cessation. The key focus of enquiry is to explore and understand the process of giving up driving, by understanding subjective meanings and outcomes, as well as how participants understand this complex phenomena, by depicting the experience in their own words. Additionally, Grosvenor (2000) 
suggests that through the use of qualitative methods, the researcher can penetrate rationalised or superficial responses to questions which could be of particular relevance.

Referring back to the issue of quality within qualitative research, Cassel and Symon (2011) notes that what counts as 'good quality' research is a contested issue within the qualitative paradigm because of the difference in research and analysis strategies, which are generally more fluid and flexible, compared to quantitative research. Many scholars have suggested to ensure qualitative research is undertaken to the highest standards, an essential skill to employ is rigour, as this will enhance the credibility, transferability, dependability and confirmability of a study (Guba $\mathcal{E}^{2}$ Lincoln, 1994). Researchers are advised to adopt skills of transparency and reflexivity, referring to the process of reflection where the researcher consistently bares in mind the aims and objectives of the study and is aware of any potential personal bias (Anderson, 2008). Therefore, a constant self-assessment should be undertaken on behalf of the researcher to ensure these issues are addressed at all times (Cassel and Symon, 2011).

\section{Sampling Strategy and participant recruitment}

"Given the real world context in which most qualitative research is carried out, identifying and negotiating access to research sites and subjects are critical parts of the process" (Devers E Frankel, 2000: 263). In order to obtain the required sample of current and retired older drivers and their informal support network members, a purposive sampling approach was adopted for the present study. From the outset of the research design, alternative sampling approaches were considered, such as the use of probability sampling to ensure participants were selected from a representative sample. For example, the researcher contemplated approaching the local Driving, Vehicle \& Licencing Agency (DVLA) to access a sampling frame of public information of current and retired older drivers, within the context of South Wales. Through the use of a simple or stratified random sampling technique, each person on the list would have had an equal chance of being selected. Nevertheless, as part of the Civil Service, the DVLA would adhere to the Data Protection (1998), now General Data Protection Regulation Act (2018), in order to protect customer information. This would 
therefore entail a stringent and timely ethics procedure, carrying a strong possibility of the organisation declining access to sensitive customer information for the purposes of the research. Similarly, the researcher considered approaching GP surgeries for a list of older adults with certain medical issues, influencing their driving ability. However, using NHS patient information would have required two ethical applications (Medical Research Council, 2003), which would have been time consuming, carrying the possibility of this information being denied.

After careful consideration, a purposive sampling approach was considered most appropriate. Purposive sampling is strongly drawn upon by qualitative researchers, for its ability to select participants who fit a particular inclusion criteria (Bryman, 2016). In contrast to the use of random sampling techniques, which are largely used in the quantitative research paradigm, the aim of purposive sampling is to select information-rich cases, where the focus is upon each participant's capacity to describe a particular phenomenon from their own perspective, due to possessing knowledge or experience about that phenomena (Bryman, 2016). The goal of the present study was to explore the lived experiences of the driving cessation process, from the viewpoint of older adults and their informal support network members. Purposive sampling was deemed most appropriate, as it is only these individuals who possess the knowledge which is required to answer the studies

Once the researcher had decided to employ a purposive sampling approach, a number of recruitment strategies were considered. Firstly, poster advertisements in public places were considered, including supermarkets, medical services, and community centres where older people may attend groups. Each location was thought to be the most likely places older adults would attend on a regular basis, in order to meet their basic, and some social needs (Musselwhite $\mathcal{E}^{2}$ Haddad, 2010). Nevertheless, this form of recruitment was discarded after identifying a number of potential barriers, informed by reviewing published literature on the topic of driving cessation. For example, many older adults who have given up driving often experience detrimental psychosocial impacts to their health and wellbeing, including depression and loneliness, both of which can result in decreased out of home activities (Adler $\mathcal{E}^{\circ}$ 
Rottunda, 2006; Marottoli et al, 2000). A loss of mobility following driving cessation would therefore exclude potential participants who are no longer able to access these services on a regular basis, preventing them from viewing the research advertisements. The onset of depression and isolation following driving cessation would also potentially reduce the likelihood of individuals taking the pro-active step of engaging in a research project, as this would involve 'stepping out of their comfort zone'. Studies have shown a link between depression in later life and resulting in disengagement and a loss of interest in social activities, therefore decreasing the likelihood of actively participating (Fiske et al, 2009). Alternatively, the researcher contemplated the use of social media as another potential channel to recruit participants. This would have taken the form of posting a brief description of the study online, along with the researchers contact details to invite prospective participants to get in contact. Popular social media accounts such as Facebook and Twitter would have been utilised for their ability to 'share' information, hoping this would gain the attention of possible recruits. However, previous studies have found that older adults hold extremely negative perceptions of the internet, and in particular, social media accounts (Xie et al, 2013). Key issues surround viewing the internet as a dangerous place, with pivotal concerns over privacy, through the risk of intruders viewing personal information (Lehtinen et al, 2009). Using this more contemporary recruitment technique would carry the possibility of completely overlooking participants who may engage in more traditional methods of communication, such as word of mouth strategies. This was found in a study by Melenhorst et al (2006) where older participants noted they were most comfortable communicating with people over the telephone, or face to face.

Finally, the researcher decided the most suitable recruitment strategy for the present study was snowballing and word of mouth tactics. Snowball sampling has been defined as a technique which begins by sampling a small group of people relevant to the research questions, "and these sampled participants propose other participants who have had the experience or characteristics relevant to the research. These participants will then suggest others, and so on" (Bryman, 2016 : 414). Noy (2008) notes that snowball sampling is frequently presented as a strategy to be employed when probability sampling is 
not feasible. As already outlined, probability sampling was not applicable for the present study, because of the ethical implications surrounding access to lists, containing members of the public's personal information. Additionally, the researcher was not aware of any community-based programmes that would have been accessible locally for people giving up driving, which could have been another potential site to randomly select participants.

Atkinson \& Flint (2001) suggest one of the key advantages of a snowball sample is its ability to provide a 'way in' to recruit participants. In the context of the present research, this concept is twofold. Firstly, the researcher is able to find potential participants who would have been unidentifiable without the referral provided by the participant under study, as some individuals are 'concealed', or difficult to reach in the population under study (Atkinson $\mathcal{E}^{2}$ Flint, 2001). In this case, the researcher aimed to seek out current and retired older drivers who lived in both rural and urban contexts, in order to provide maximum variation by including a diverse number of participants who fitted the inclusion criteria. Research demonstrates that the residential context in which older adults live is a major factor to consider when attempting to obtain study participants. Upon giving up driving, many older people often report significant difficulties in remaining socially connected. This is particularly problematic in rural contexts, due to a lack of suitable and accessible transport (Ward et al, 2013; Johnson, 2008). Ziegler \& Schwannen (2010) note "the rurality of the area has an impact on the mobility of older people, in that many facilities and services are distant and difficult to access" (p. 765). Secondly, snowball sampling is a "way in' in terms of participants trusting the researcher. Through use of a mutual contact, interviewees are more likely to demonstrate an interest, through the knowledge they have gained about the study from the mutual contact. "Trust may be developed as referrals are made by acquaintances or peers rather than other more formal methods of identification" (Atkinson E Flint, 2001: para 7).

Snowball sampling is also recognised as a useful strategy to employ when researching a sensitive topic (Etikan, 2016). Previous scholars have used this recruitment method within the field of driving cessation in later life (Bryanton et al, 2010; Hanson $\mathcal{E}^{2}$ 
Hildebrand, 2011), reflecting the sensitivity surrounding this later life transition. Jolanda \& Pachana (2012) expand upon reasons for this sensitivity, explaining that giving up driving in later life is perceived as a highly stressful event, as it implies irreversible identity change, and essentially places individuals into a "stigmatised category of 'old'" (p. 104). Hill et al (2013) also highlights that the loss of a driving licence is strongly correlated with loss of mobility, and this is directly related to a reduction in an individual's independence. Findings from both studies help to explain why this would be a difficult topic to divulge personal information on.

Nevertheless, snowball sampling as a method for participant recruitment has been heavily criticised amongst academics, largely for the element of bias which is associated with this technique. Firstly, "the nature of similarity within social networks may mean that 'isolates' are ignored" (Atkinson E' Flint, 2001: 1). This refers to the assumption that within social networks, friends or acquaintances share common life experiences. This carries with it an essence of built in bias, purely because participants are normally interrelated through association (Etikan, 2016). Because elements are dependent on the subjective choices of the respondents first accessed, and not randomly selected, most snowball samples are biased (Griffiths et al, 1993). Secondly, snowball samples will miss 'isolates' who are not connected to any network that the researcher has tapped into (Atkinson $\mathcal{E}^{2}$ Flint, 2001). Addressing this issue, as opposed to undertaking a 'linear snowball sample', which refers to a participant referring one participant, and that next participant referring one more participant, this study was based upon 'exponential non-discriminate', and 'exponential discriminative' snowball sampling (Etikan, 2016). Firstly, exponential nondiscriminate snowballing refers to the subject under study providing the researcher with multiple referrals to follow up. Whereas exponential discriminative snowball sampling, refers to the process where some participants may only suggest one participant referral, or none at all (Etikan, 2016).

Remaining mindful of the risk of bias associated with snowball sampling, the researcher asked each interviewee to provide as many potential referrals as possible. However, it is important to highlight that some participants did only provide one 
referral for the researcher to follow up. And moreover, some participants did not know of any suitable individuals who met the studies inclusion criteria, with no referrals being made at all. This 'exponential discriminative' type of snowball sampling describes where the chain of referrals is discriminating (Etikan, 2016). The researcher tried to identify and obtain as many referral links as possible, as the "more links in each chain will generate substantial data about a particular sample" (Atkinson $\mathbb{E}^{\circ}$ Flint, 2001: para 14). As well as generating information required to answer the studies research questions, accessing varied referrals would also ensure that the researcher was gaining as diverse a sample as possible, leading to a number of chains being built in order to obtain the final sample set (Atkinson $E^{2}$ Flint, 2001).

\section{Entry into the field E official recruitment}

Recruitment began by the researcher informally mentioning the basic principles of the research to a number of individuals within her own personal network. This included family members, friends, neighbours, and work colleagues. Through adopting this word of mouth approach, one current female driver and one retired male driver became evident. Including individuals who were both pre and postdriving cessation was an imperative part of the research, in order to understand giving up driving as an entire process. This ensured the lived experiences of those who were pre, and post-driving cessation were included. The researcher did not know these initial participants personally, and ensured at all times that a professional research protocol was adhered to. The studies inclusion criteria came into effect at this stage, as participants who matched a certain profile were required (See figures 2 $\& 3)$.

\begin{tabular}{|l|l|}
\hline $\begin{array}{l}\text { Inclusion Criteria - Current older } \\
\text { drivers }\end{array}$ & Exclusion criteria \\
\hline Over 60 years old & Under 60 years old \\
\hline Holds a full valid UK driving licence & $\begin{array}{l}\text { Does not hold a full valid UK driving } \\
\text { licence }\end{array}$ \\
\hline
\end{tabular}




\begin{tabular}{|l|l|}
\hline Able to communicate in English & Unable to communicate in English \\
\hline $\begin{array}{l}\text { No serious physical or cognitive health } \\
\text { issues }\end{array}$ & $\begin{array}{l}\text { Serious health issues affecting } \\
\text { participation }\end{array}$ \\
\hline Living in South West Wales & Living outside of South West Wales \\
\hline $\begin{array}{l}\text { Consents to participate in study and share } \\
\text { information }\end{array}$ & $\begin{array}{l}\text { Does not consent to participate in } \\
\text { study or share information }\end{array}$ \\
\hline
\end{tabular}

Figure 2: Inclusion $\Xi^{2}$ exclusion criteria - Current older drivers

\begin{tabular}{|c|c|}
\hline $\begin{array}{l}\text { Inclusion criteria - Retired older } \\
\text { drivers }\end{array}$ & Exclusion Criteria \\
\hline Over 60 years old & Under 60 years old \\
\hline $\begin{array}{l}\text { No longer holds a valid UK driving } \\
\text { licence }\end{array}$ & Holds a valid UK driving licence \\
\hline Gave up driving within previous 7 years & $\begin{array}{l}\text { Gave up driving longer than } 7 \text { years } \\
\text { ago }\end{array}$ \\
\hline Able to communicate in English & Unable to communicate in English \\
\hline $\begin{array}{l}\text { No serious physical or cognitive health } \\
\text { issues }\end{array}$ & $\begin{array}{l}\text { Serious health issues affecting } \\
\text { participation }\end{array}$ \\
\hline Living in South West Wales & Living outside of South West Wales \\
\hline $\begin{array}{l}\text { Consents to participate in study and share } \\
\text { information }\end{array}$ & $\begin{array}{l}\text { Does not consent to participate in } \\
\text { study or share information }\end{array}$ \\
\hline
\end{tabular}

Figure 3: Inclusion $\Xi^{2}$ exclusion criteria - retired older drivers 
For example, both individuals had to be over the age of 60 , and living in the South West Wales area. The age of 60 was set as a minimum age as the study was concerned with exploring the process of giving up driving in 'later life'. Up until April 2010 when the Pensions Reform Act was introduced in the UK, 60 was set as the traditional State Pension age, where females were entitled to start claiming their pensions (Thurley $\mathcal{E}^{2}$ Keen, 2017). Additionally, in a European Social Survey (2012) capturing attitudes towards age, feedback revealed that people were classed as entering 'old age' at 59 years old (Abrams $\mathcal{E}^{2}$ Swift, 2012). Once it had been confirmed that both participants possessed these initial characteristics, more stringent inclusion criteria was applied, where the researcher was responsible for 'vetting' respondents for their suitability to take part in the study. For example, the researcher needed to determine if the retired driver had given up driving within the last 7 years. This parameter was put into place to ensure participants were able to recall their lived experiences relating to the driving cessation process, without too much time passing which may have influenced their adjustment to the transition. Also, in relation to current drivers, the researcher needed to establish if the referred individual was actively still driving, as opposed to just holding a driving licence. This was to make sure current experiences could be drawn upon by older drivers, in order for the study to explore the meaning of driving in the context of today's society. The same process was undertaken for all older participants, to ensure each individual met the requirements outlined in the inclusion criteria.

In terms of the practical research procedures which were undertaken to begin the study, once both initial potential candidates were identified, a briefing invitation letter was distributed to each participant via the mutual contact, providing more information about what the research entailed (appendix 1). The briefing letter included my contact details, via telephone, letter and email, ensuring all potential interviewees could get in touch in the most convenient way for them. Importantly to note, the original mutual contact also had permission to directly administer the contact details to each person. This was to ensure that potential participants could get in contact with the researcher straight away, if they felt they had received enough information before waiting for the research invitation. In this case, the first potential 
participant made contact over the phone, after having a conversation with the mutual contact. During the phone call, all necessary information in relation to the study was provided, and the caller decided to take part. This was followed by a suitable time and location being established for the interview to take place. In relation to the second initial participant, the mutual contact distributed the briefing letter to the older adult, which was also followed up by a phone call. An interview was also set up during this phone conversation. If each participant and subsequent individuals did not contact the researcher within one week of receiving the briefing invitation letter, the researcher contacted each person, providing this was originally agreed via the mutual contact. However, in the majority of cases, all potential participants were the first to contact the researcher once they had either had a conversation with the referee, or once they had read the study briefing letter.

In order to continue with the snowball sampling design of the research, the initial participants interviewed were asked if they could identify and refer any other individuals who may fit the studies inclusion criteria. This request was made by the researcher following completion of each interview. The first participant knew of one individual who was still driving who he agreed to have a conversation with about the research. The second participant knew of several older adults possessing the required attributes for participation. For example, all were living in South West Wales, and were either current, or retired drivers, over the age of 60 . A number of briefing letters were left with both participants to administer to those potential recruits identified, and to any other individuals who may become apparent from subsequent word of mouth conversations. Within a few days of both interviews being completed, a list of potential participants was drawn up, comprising of the suggested referrals made by the initial participants, and individuals who had directly got in contact following conversations with the mutual referrer. The next stage involved vetting these individuals, to determine their suitability to take part in the research. At this stage, out of a total of 8 referrals, only 5 interviews successfully took place. This was mainly due to these individuals not meeting the inclusion criteria. For example, one participant resided outside the South West Wales area, another was under the age of 60 , and the final person had given up driving almost 20 years ago. Overall, once data 
collection had been completed, only one older adult did not agree to take part in the research once they were approached by a current participant, and a further two individuals did not fit the inclusion criteria. This led to a total of six non-respondents.

Snowball and word of mouth sampling continued with current and retired older drivers, for a duration of 3 months. The completion of data collection was decided once 'data saturation' had been reached, alongside pragmatism, where time constraints needed to be taken into account. Bryman (2016: 412) describes data saturation as "sampling continuing until no new findings are generated, and theoretical saturation, which involves continuing to sample until conceptual categories are fully developed and relationships between them are accounted for". Guest et al (2006) take the definition of data saturation slightly further, and state "the number of interviews needed to get a reliable sense of thematic exhaustion and variability within their data set" (p. 65). A total of fifteen older adults were recruited overall, once data saturation had been achieved. This was apparent through older adult participants referring to consistent concepts or experiences. For example, 'convenience', independence' and 'burden', were things which all current and retired older drivers referred to.

In addition, the aim was to achieve maximum variation from the outset of the study. This was to ensure a variety of perspectives and lived experiences were captured, recognising that older people and their network members are not homogeneous groups. For example, current and retired drivers, males and females, rural and urban contexts, and a variety of ages were included amongst the sample set. In order to achieve this, a log was kept of participant characteristics, whilst data collection was ongoing. In accordance with how the sample was developing, in relation to specific profiles of each interviewee, each participant was purposefully selected in accordance with how the sampling was developing. More detailed participant characteristics were often unknown during initial contact and recruitment. For example, it was only once interviews took place that I became aware of older people's informal network type. However, on the whole, a varied sample was achieved, as documented below (see figures: 5, 6, 7, 8 \& 9). 


\begin{tabular}{|c|c|}
\hline $\begin{array}{l}\text { Inclusion criteria - Informal support } \\
\text { network members of current \& retired } \\
\text { older drivers }\end{array}$ & Exclusion criteria \\
\hline Has been referred via the older current driver & $\begin{array}{l}\text { Has not been referred via the older } \\
\text { current driver }\end{array}$ \\
\hline $\begin{array}{l}\text { Consents to participate in study and share } \\
\text { information }\end{array}$ & $\begin{array}{l}\text { Does not consent to participate in study } \\
\text { or share information }\end{array}$ \\
\hline Able to communicate in English & Not able to communicate in English \\
\hline No serious physical or cognitive health issues & $\begin{array}{l}\text { Serious physical or cognitive health } \\
\text { issues }\end{array}$ \\
\hline Over 18 years old & Under 18 years old \\
\hline $\begin{array}{l}\text { Lives in an area accessible/in reach of the } \\
\text { researcher }\end{array}$ & $\begin{array}{l}\text { Does not live in an areas accessible/in } \\
\text { reach of the researcher }\end{array}$ \\
\hline
\end{tabular}

Figure 4: Inclusion छ exclusion criteria - Informal support network members

In order to recruit the informal support network members of current and retired older drivers, the interview topic guide included a section on family, friends, community members, and neighbours. As part of this section, the discussion began with 'Could you tell me a bit about your family, friends and neighbours?' The open style of the question was designed to allow for a wide scope of answers, remaining mindful that not all older adults may have family, and may refer to neighbours or friends in a more prominent sense, if at all. A number of subsequent prompts were included in the interview topic guide, to maximise the quality of information on this particular theme. 
Following the discussion on informal support, each older adult was asked if they could identify and refer any of their informal support network members to participate in the research. This was to fit with the aim of exploring the process of driving cessation, from the viewpoints of informal network members, as well as older adults. Participants were asked to think about who they perceived as most suitable to take part, in terms of who currently supports them, or who could support them, as well as those who they thought would be willing to participate. Relating to the latter issue of willingness, older adults sometimes needed to have a conversation with their network members, before making any referrals during data collection.

In this sense, current and retired older drivers were the primary 'gatekeepers' to this second group of participants. There was no maximum limit in relation to how many network members were identified or referred. This was to ensure that in the case of non-response, there would still be a network member to interview for the second phase of the research. Additionally, the researcher was aware that some older adults many have more than one informal support network member who could take part in the study, based upon who they perceived as suitable.

After completing interviews with all current and retired older drivers, it became apparent that all older adults were able to talk about their family, friends and members of their local communities. However, not all older adults were able to refer an informal support network member. This was due to a number of reasons. For example, one gentleman, Grahame, who was still driving and had moved to the area within the last 5 years, did not feel he had anyone local who knew him well enough to be able to provide their viewpoints. In line with the iterative, emergent nature of qualitative research, it was at this point the researcher considered using wider data collection techniques, aside from face-to-face interviews. This included Skype, FaceTime, or telephone conversations. This approach was in recognition of this participants informal support network living beyond the geographical area, upon which the study took part in This also recognised that, as outlined in the literature review, informal support is not just something which is purely based upon the provision of transport (Musselwhite \& Shergold, 2013). Instead, there are deeper, 
psychosocial elements included, such as emotional support, advice, and guidance, which could be provided on a non-physical basis. However, in this case, the participant did not perceive his family members, including his adult children and siblings, to be suitable candidates for taking part in the research study. This was due to a relationship breakdown with adult children, and siblings having busy lives, resulting in a lack of time to invest in the study. Likewise, no informal network members were referred by another female driver, Daphne. This was despite living with her spouse, and having an adult daughter living nearby. This was because the participant classed herself as being completely independent, considering informal support to be something which is not drawn upon, or needed at this point in her life. I remained aware that this stage of the research was highly dependent upon each older adult's subjective thoughts and feelings about themselves, and their relationship with others. For example, not all older adults may be willing to refer their family members, friends or neighbours. Although not explicitly revealed, some older participants may have been uncomfortable agreeing to their informal network members taking part in a private discussion about their driving, or driving cessation. For example, previous research has found a reluctance of older drivers to include the views of their family members relating to their driving ability (Connell et al, 2012; D'Ambrosio, 2004).

Once potential informal network members had been established, based upon who the older adult perceived as being most suitable, and most likely to take part, the next stage involved obtaining each network members contact details. Some older interviewees provided the contact numbers and email addresses for their family, friends and neighbours directly on the day of the interview. Others preferred to have a separate conversation with their network members, to be followed up at a later date. In this case, it was agreed that all older participants could distribute my contact details to their network members. In addition, a few copies of the briefing letter inviting family, friends and neighbours to provide more information about the study, was left with all current and retired older drivers who were interviewed. 
In a number of cases, family members, friends and neighbours made contact by email to express their interest, or confirm participation. This form of communication was mainly employed by those who were in employment, perhaps reflecting their busy lives, whereby email is the most efficient way to communicate. Other's made contact via telephone. There were also a number of contact phone numbers which were obtained from older adults following completion of the first interviews, which were followed up within a week, if no network member had been in contact. The decision to leave this time period no longer than a week, was to minimise the risk of network members 'dropping out', or not following up on study information which was passed on from the older adult. Contact was only made after one week if the older adult had provided the information and had agreed for the researcher to contact the referred individuals. Respecting the confidential and private information of each participant was paramount to the investigator, throughout the recruitment process.

The final sample set, including the four individual groups of participants has been documented below (figure 5), through visually representing sample profiles. 
Visual representation of sample set by individual group

\begin{tabular}{|c|c|c|c|c|c|c|c|c|c|c|c|}
\hline 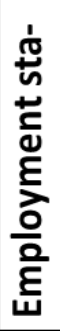 & $\stackrel{n}{D}$ & 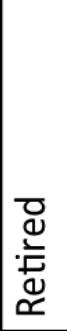 & 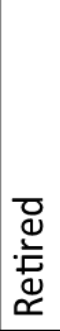 & 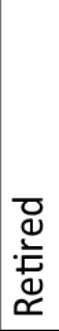 & 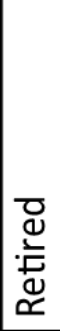 & 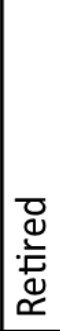 & 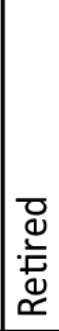 & & 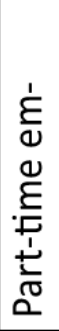 & 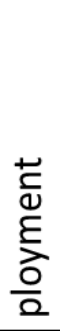 & 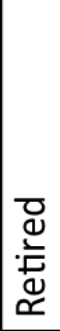 \\
\hline 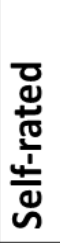 & 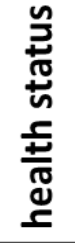 & $\begin{array}{l}\text { ర } \\
\text { ঠ } \\
\end{array}$ & 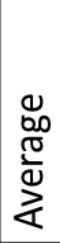 & $\begin{array}{l}\text { 음 } \\
\text { 잉 }\end{array}$ & 음 & $\begin{array}{l}\text { 음 } \\
\text { 암 }\end{array}$ & 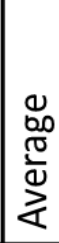 & & 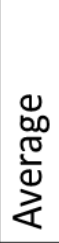 & & $\begin{array}{l}\text { 음 } \\
\text { 잉 }\end{array}$ \\
\hline 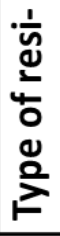 & 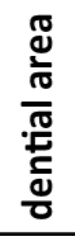 & 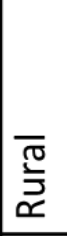 & 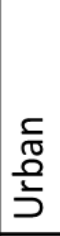 & 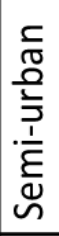 & 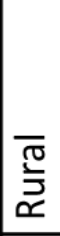 & 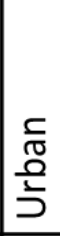 & 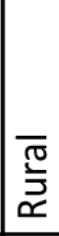 & & 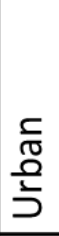 & & 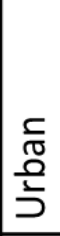 \\
\hline 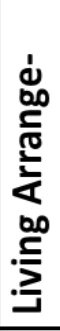 & 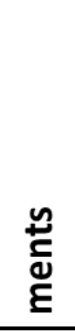 & 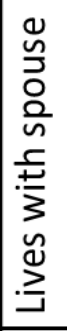 & 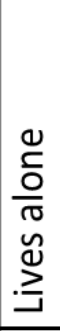 & 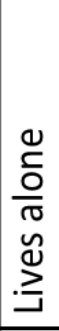 & 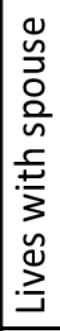 & 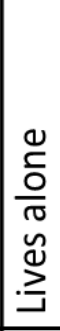 & 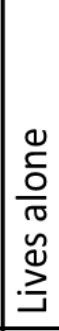 & & 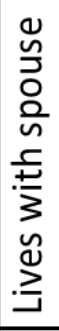 & & 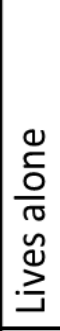 \\
\hline 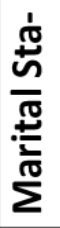 & $\stackrel{n}{D}$ & $\begin{array}{l}\frac{0}{\mathscr{d}} \\
\frac{2}{2} \\
\frac{\pi}{2}\end{array}$ & 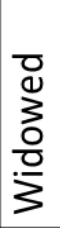 & $\begin{array}{l}0 \\
0 \\
0 \\
0 \\
0 \\
\frac{0}{3} \\
3\end{array}$ & 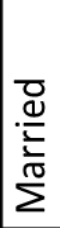 & $\begin{array}{l}0 \\
0 \\
3 \\
0 \\
0 \\
\frac{0}{3} \\
3\end{array}$ & 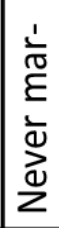 & 언 & 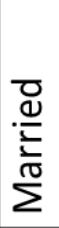 & & 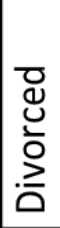 \\
\hline 品 & & $\curvearrowright$ & ১ & $\mathbb{N}$ & $\infty$ & 6 & $\infty$ & & ఠ & & 6 \\
\hline 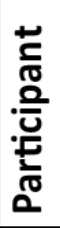 & & 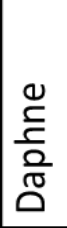 & 등 & 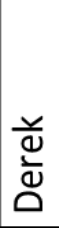 & $\begin{array}{l}\frac{0}{\pi} \\
\frac{0}{0} \\
\text { ○. }\end{array}$ & $\frac{\pi}{\frac{\pi}{0}}$ & 离 & & $\stackrel{\overline{\bar{o}}}{\stackrel{2}{\Sigma}}$ & & 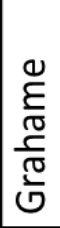 \\
\hline
\end{tabular}

Figure 1: Sampling profiles of current older drivers 


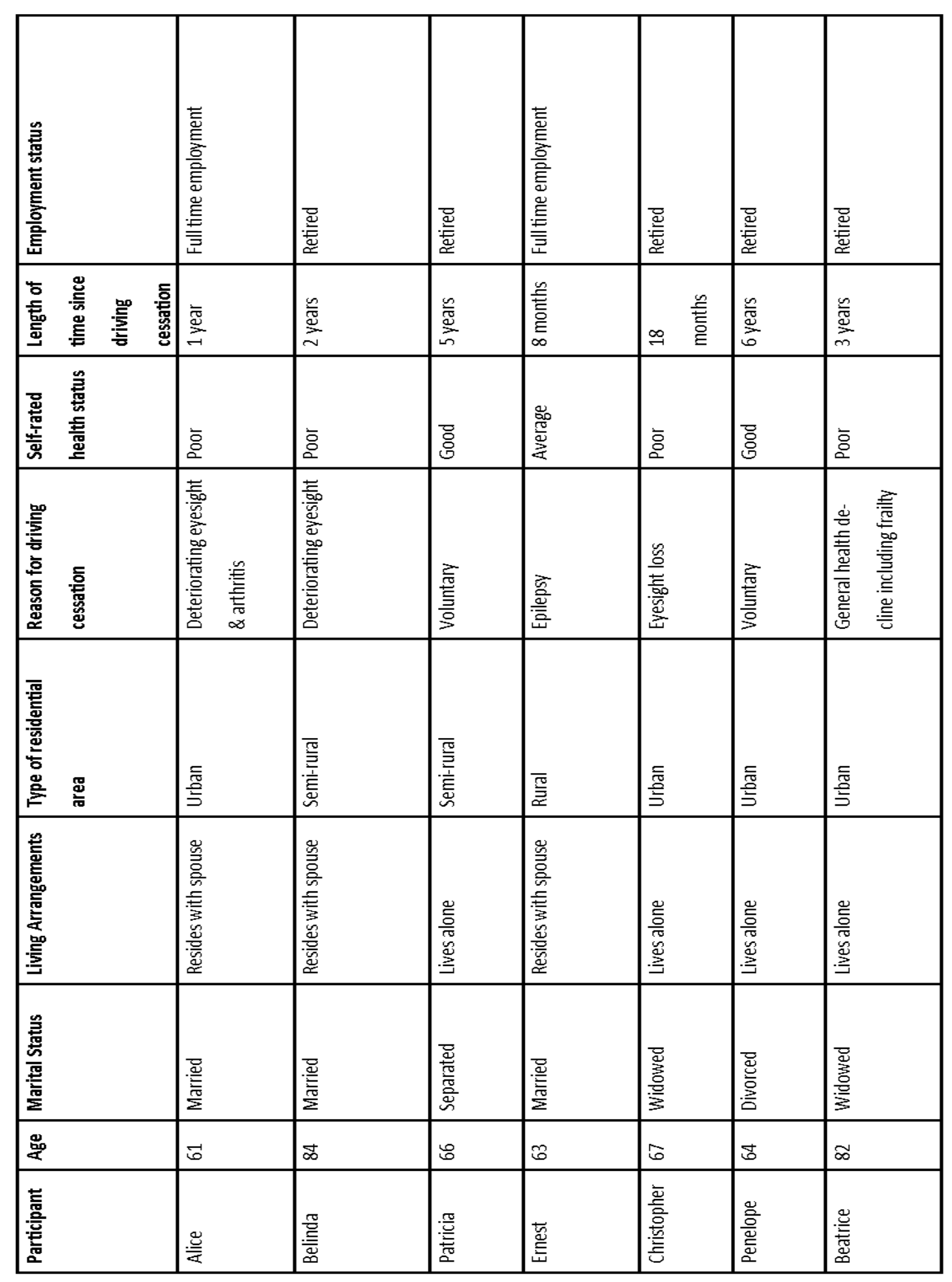

Figure 6: Sample profile of retired older drivers 


\begin{tabular}{|c|c|c|c|c|c|c|c|c|c|c|c|c|}
\hline 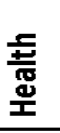 & 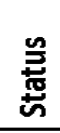 & $\begin{array}{l}8 \\
8 \\
\end{array}$ & $\begin{array}{l}8 \\
8 \\
\end{array}$ & $\begin{array}{l}8 \\
8 \\
8\end{array}$ & $\begin{array}{l}8 \\
8 \\
8\end{array}$ & $\begin{array}{l}8 \\
8 \\
8 \\
\end{array}$ & $\begin{array}{l}8 \\
8 \\
8 \\
\end{array}$ & $\begin{array}{l}8 \\
8 \\
\end{array}$ & $\begin{array}{l}8 \\
8 \\
\end{array}$ & $\begin{array}{l}8 \\
8 \\
\end{array}$ & & 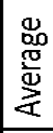 \\
\hline : & 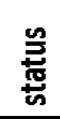 & : & - & 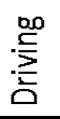 & 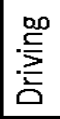 & 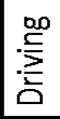 & 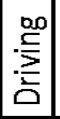 & : & : & & $\stackrel{\bar{D}}{\mathrm{I}}$ & $\stackrel{\bar{\Delta}}{\grave{\Delta}}$ \\
\hline 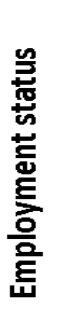 & & 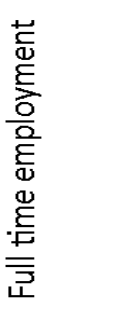 & 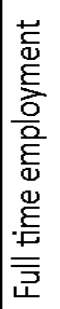 & 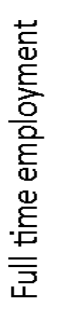 & 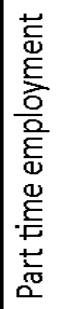 & 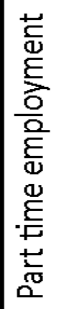 & 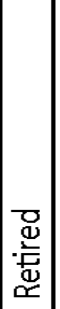 & 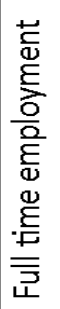 & 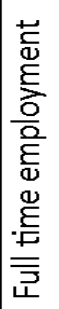 & 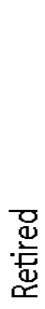 & & 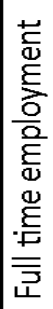 \\
\hline 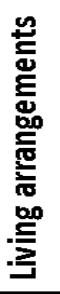 & & 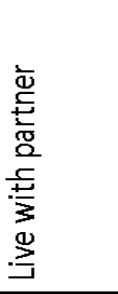 & 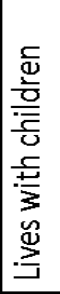 & 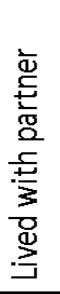 & 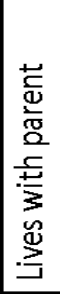 & 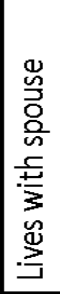 & 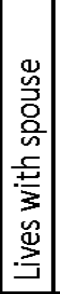 & 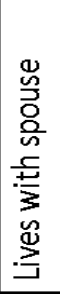 & 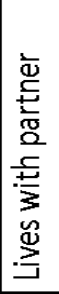 & 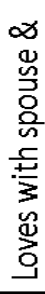 & $\begin{array}{l} \\
. \\
\frac{0}{\overline{ }} \\
\end{array}$ & 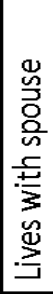 \\
\hline 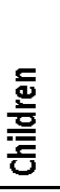 & & 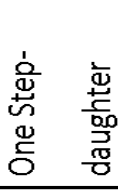 & 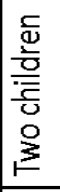 & 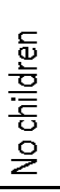 & 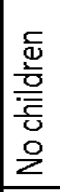 & 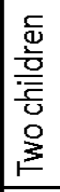 & 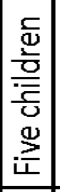 & 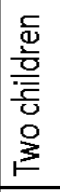 & 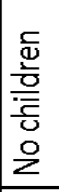 & 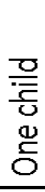 & & 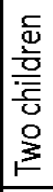 \\
\hline 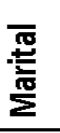 & 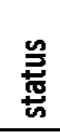 & 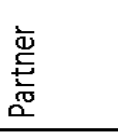 & $\begin{array}{l}\frac{0}{00} \\
i \frac{5}{5}\end{array}$ & 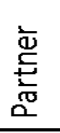 & 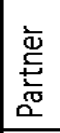 & 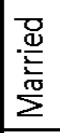 & 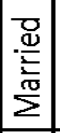 & 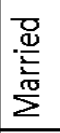 & 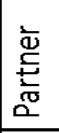 & 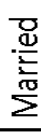 & & 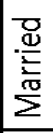 \\
\hline 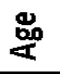 & & $\stackrel{\text { D }}{ }$ & 보 & $\lesssim$ & $\mathscr{\gamma}$ & $\overrightarrow{6}$ & ১ & $\widetilde{6}$ & $\hat{\mathrm{m}}$ & $\vec{\sigma}$ & & 욤 \\
\hline 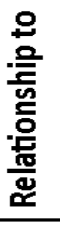 & 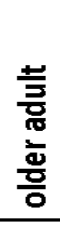 & 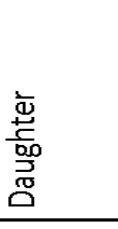 & 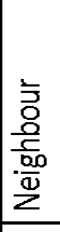 & 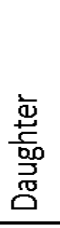 & 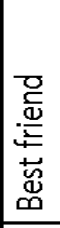 & 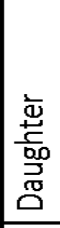 & \begin{tabular}{|c|}
0 \\
0 \\
0 \\
0 \\
03 \\
$\underline{3}$ \\
\end{tabular} & $\frac{4}{3}$ & ᄃ & 㯎 & & 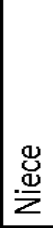 \\
\hline 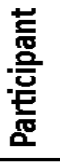 & & 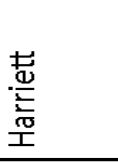 & 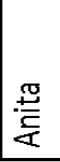 & 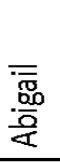 & 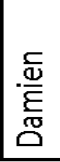 & 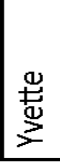 & 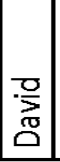 & 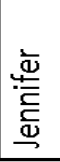 & 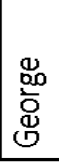 & & & 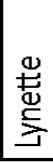 \\
\hline
\end{tabular}

Figure 7: Sample profile of informal support network members of retired drivers 


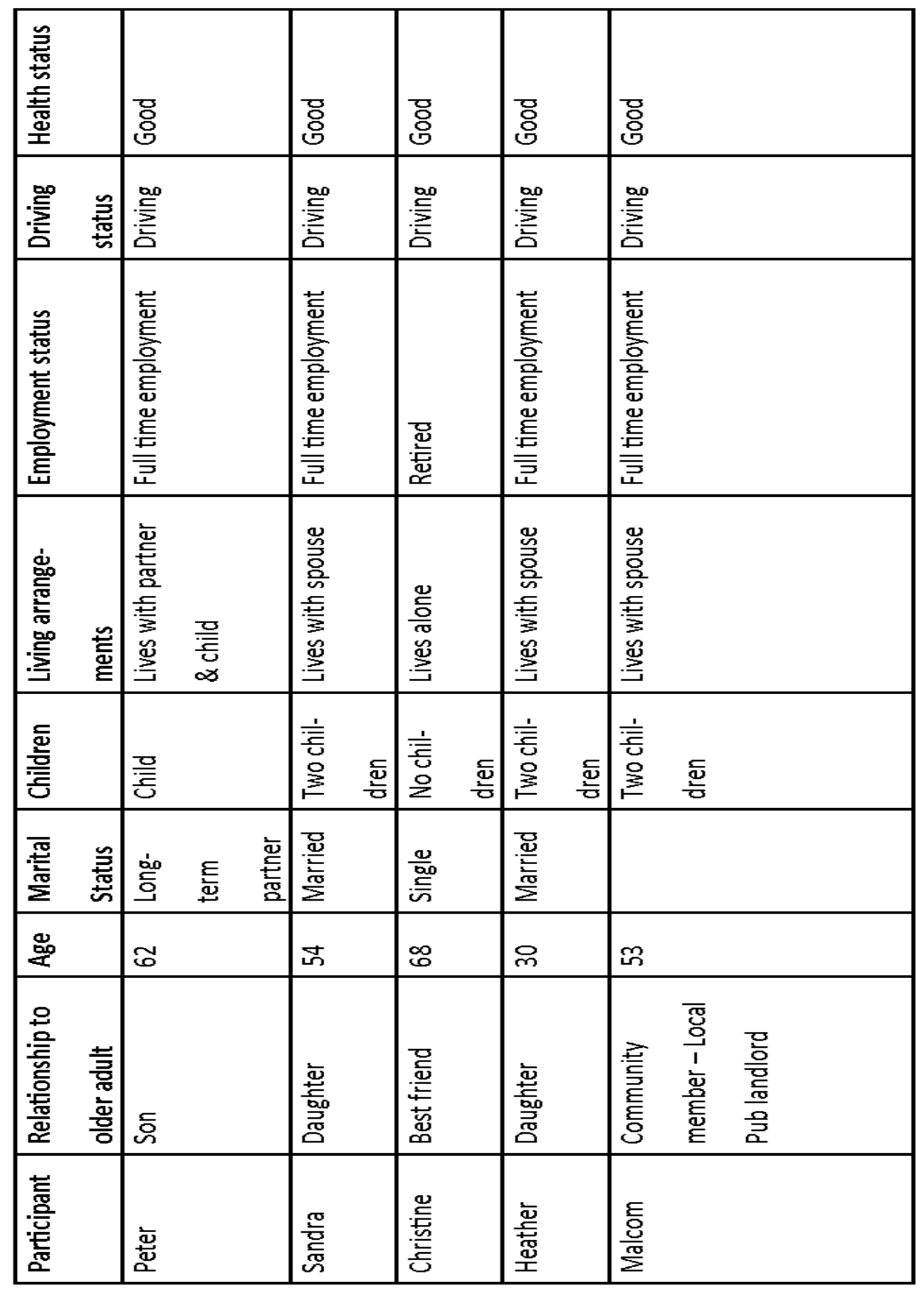

Figure 8: Sample profile of informal support network members of current drivers 


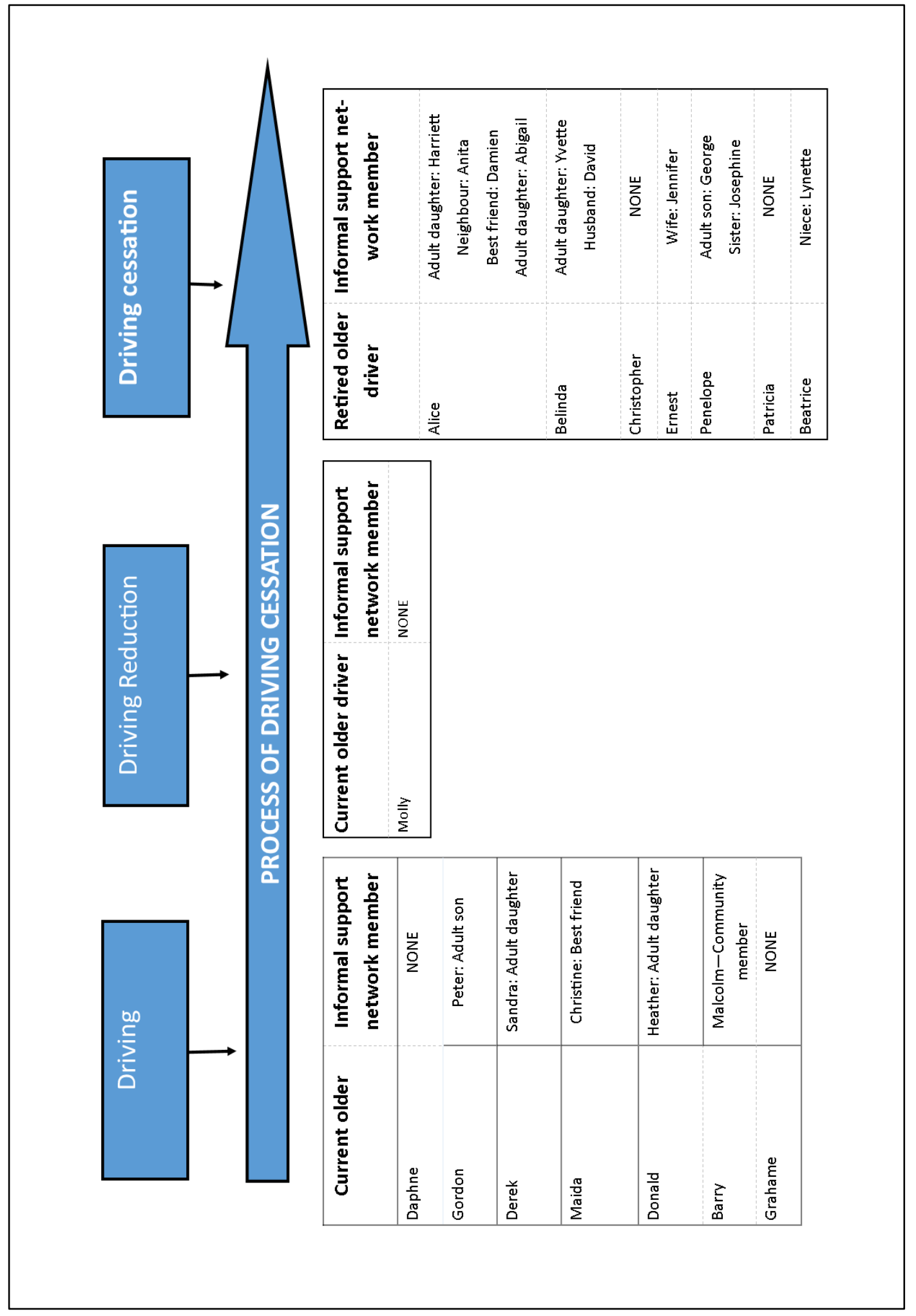

Figure 9 - Visual representation of entire sample set 


\section{Pilot Study}

A pilot study was undertaken prior to beginning official data collection. A pilot study has been defined as a small-scale implementation of a larger study, which typically lasts for shorter amounts of time and involves a smaller number of participants (Given, 2008). The advantage of undertaking pilot interviews in qualitative research has been well documented, for the role they play in ensuring "the research as a whole functions well" (Bryman, 2016: 260). Additionally, pilot studies provide researchers with the opportunity to make adjustments and revisions, identifying gaps and wastage in the data collection process, to essentially increase the overall successfulness of the main study (Kim, 2010). Pilot studies also directly address and strengthen issues of validity, ethics and credibility, all key concepts in qualitative research (Van Wijk \& Harrison, 2013).

There were two phases of the pilot interview undertaken for the purpose of the present study. Phase one involved recruiting an older driver, to discuss the topic of driving cessation from their personal perspective. Phase two was dependent upon phase one, and involved the recruitment of one member of the older adults' informal support network. This second phase drew upon the informal support network member's own perceptions and experiences in relation to the driving cessation process of the older adult.

\section{Phase one of pilot interview}

In order to begin phase one of the pilot interview, a current older driver fitting the studies inclusion criteria was recruited from the researcher's personal network. Bryman (2016) points out that pilot interviewees shouldn't include individuals who may be present in the official study. The researcher would not have included the pilot interviewee in the final study because of the pre-standing relationship which existed with the participant, potentially threatening the validity of the overall project, including the risk of researcher bias. Nevertheless, the pilot interviewee shared similar characteristics to the overall data set, so was comparable to the rest of the sample. Official research procedures were implemented from the outset of the pilot study. The researcher began by contacting the participant via telephone to explain 
the purpose of the research study, and to offer the opportunity to participate. In this first instance, the participant expressed an interest and verbally consented to take part in the research over the phone. This was followed up by agreeing a suitable time and location for the interview to take place. Before the pilot interview took place, an information sheet was sent to the participant in the post, providing more in depth knowledge about the study, including the purpose of the research and the role of ethics. Upon commencement of the pilot interview, written consent was obtained, and a participant information sheet was completed by the interviewee. In order to begin data collection, the initial interview topic guide was drawn upon. The planned technique of recruiting members of the older adults informal support network during the pilot study was trialled at this point. This was undertaken by drawing upon a section on family, friends and neighbours (see appendix 7), and asking the interviewee to identify potential participants based on this information. In this sense, the older adult acted as the gatekeeper to the second group of participants which were required for phase two of the study. This recruitment technique was a success, and the contact details for the son of the older driver were provided to myself, as the researcher. Additionally, I asked the pilot interviewee if there was anyone who he knew who may fit the studies inclusion criteria, to commence with the proposed snowball sampling technique. The participant knew of several older adults, who had both given up, and who were still driving. At this point, a number of research information sheets were left with the participant, for him to administer to potential participants. During completion of the pilot interview, the participant also directly phoned an older adult which he knew had recently given up driving. Following this conversation whilst I was still present, it was agreed that the potential recruits contact details would be passed on to myself, to make a follow up phone call. The snowballing strategy was a success, and this participant was the first official interviewee for the main study. This will be discussed in more depth in a subsequent section on sampling and the final data set. Phase one of the pilot interview lasted approximately 1 and a half hours, inclusive of recruitment procedures.

A number of outcomes arose following completion of phase one of the pilot interview with the older driver. Firstly, it became apparent that the order of some of the topic's 
being discussed were somewhat disjointed, disrupting the overall flow of the interview. For example, the original interview topic guide asked the participant to think about views on alternative transport, following a section on perceptions of the built environment and community. However, the pilot interviewee divulged the most information about alternative transport when talking about his perceptions of giving up driving. Therefore, before commencement of official data collection, the interview topic guide was restructured to ease the transition from one discussion point to another, and essentially improve the quality of the data collected. Additionally, when moving on to the topic area of exploring the meaning of driving, the pilot interviewee provided only a few short answers, and talked about driving in a wholly practical sense. Upon listening back to the interview recording, I decided to include an additional prompt at the start of this section, asking the participant to talk about their daily or weekly routine and lifestyle. This was an attempt to encourage the interviewee to delve more into the social and emotional meanings which being able to drive may represent. This was proven to be useful when undertaking official data collection, with this opening question providing the participant with something to think about, whilst providing the best chance of gathering the richest account of data possible. The pilot interviewee also queried a number of concepts which were posed, allowing the modification of questions, ensuring topic areas were put forward to participants in the most simplified manner. For example, the participant was unsure about the phrase driving cessation whilst completing the written consent form. I explained this was another term for giving up driving, which the participant understood. Whilst undertaking official data collection, the researcher clarified what driving cessation meant to all participants.

Phase one of the pilot interview was also extremely useful for demonstrating 'what works' in terms of data collection procedures. For example, it became apparent that recording the interview at the very start of the pilot study whilst the participant completed a personal information sheet was crucial, as the participant provided rich accounts of information in a number of areas, which would be further discussed during the interview. For example, uses of other transport modes, personal family information, and information on the history of driving were all drawn upon through 
the completion of basic information about the participant. Having this basic background information provided a solid foundation and talking point, to reiterate back to the interviewee to encourage discussion whilst working through the interview topic guide. For example, the researcher asked one retired older driver "So you said you have two daughters, now how often do you see them?"

\section{Phase two of pilot interview}

I undertook phase two of the pilot interview following completion of phase one. Phase two involved interviewing the son of the first pilot interviewee. This second phase of the pilot interview was also crucial to the overall success of the project, as it allowed myself to trial whether the initial interview topic guide for the informal support network members of older adults was relevant, in terms of exploring the process of driving cessation from their perspective. The information collected during phase two also provided an insight into how the larger official study may operate.

Similarly to the pilot study with the current older driver, I followed official research procedures with the second pilot interviewee. To begin the recruitment process, I phoned the potential participant, explaining why and where the contact details had been obtained from. Due to the second pilot interviewee being somewhat familiar with myself as the researcher, there was no reason to provide an official introduction at this point of contact. After explaining the purpose of the research and offering the opportunity to participate in the pilot study, the participant agreed to take part, and a suitable time and location for phase two of the pilot study was arranged. Before ending the call, I asked if the participant would like to be sent more information on the study in the meantime, although this was politely declined as the participant felt he had been provided with sufficient information during the initial phone call. Importantly to note, the interviewee suggested the interview take place in the home of the current older driver, although I asked whether there was an alternative location, in order to eliminate any potential bias during data collection, such as the son being influenced by the presence of his older parent. The participant understood these potential issues which could affect the validity of the study, and the interview was instead arranged to take place at his own home. Upon commencement of the pilot 
study, the interviewee also completed a written consent form and a participant information sheet. The interview topic guide for the informal support network members of current older drivers was drawn upon, and the interview lasted approximately 50 minutes.

Following completion of phase two of the pilot study, minimal amendments were needed to the interview topic guide. However, one section of the guide required more clarity. The guide included a section on views of driving cessation, if the older adult had to give up driving. The participant commented at this point that he wasn't able to answer this part, as the older adult was still driving. I explained that this question was based on prospective views, and was based around the possibility of his father giving up driving. Once this was explained in more detail, the participant opened up and talked about how he could foresee things changing. Following the interview, I decided to include in the opening of the section upon view on driving cessation, that the participant was required to draw upon prospective views, and to think about what could potentially happen if the older adult they were associated with was to give up driving. The 5 informal support network members of current older drivers who took part in official data collection all subsequently understood this, and provided valuable information.

In terms of providing reassurance that the data collection strategies utilised for the interviews with the family, friends and neighbours of current and retired older drivers were relevant, I identified a number of areas of good practice. For example, including a column on the self-reported health of the network member on the participant information sheet proved to be useful, allowing the drawing upon this basic information at several points during the interview; particularly when the interviewee was asked to talk about the current support they provide to the older adult, and what affect giving up driving would potentially have upon them both.

\section{Summary of pilot study}

Overall, completion of phase one and two of the pilot study revealed a number of positive outcomes, providing a highly valuable insight into how the official larger study would operate. Aside from the minimal additional prompts and slight re- 
structuring of topics on the interview prompt, the pilot interview demonstrated that the questions being asked were relevant and generated a wealth of information. Both interviews also provided the opportunity to trial the practical steps associated with undertaking individual face to face interviews. Additionally, the pilot study provided me with a greater sense of confidence when undertaking official data collection. This was due to gaining experience with both older adults, and their informal support network members, who were to comprise the overall data set. 


\section{Data Collection}

Semi-structured interviews

Data Collection is often the focal point of the entire research process, as this entails the researcher putting their ideas into practice, by actually getting out in the field to conduct primary research (Bryman, 2016). Individual, semi-structured interviews were used to collect data from 30 participants for the present study. Upon designing the project, alternative qualitative methods for data collection were considered, such as the use of focus groups to generate a large amount of data between participants in a group setting, who share similar characteristics or experiences (Milena et al, 2008). However, the aim of the current research was not to generate a high quantity of data on a specific topic, but to focus on the quality of the information being divulged, relating to the personal lived experiences of older adults and their informal support network members, regarding the process of driving cessation. Also, focus groups would have potentially threatened the ability for participants to provide open and honest accounts relating to a driving cessation, as a sensitive topic (Jolanda $\mathcal{\sigma}^{\circ}$ Pachana, 2010).

The decision to use semi-structured interviews was influenced by the study's phenomenological epistemological position. From this point of view, semi-structured interviews attempt to access participants' insider perspectives, whilst also being able to focus discussion on particular areas of exploration, in relation to a particular topic (Bevan, 2014). Bloomberg \& Volpe (2016) suggest a major benefit of collecting data through interviews is to capture a person's perspective of an event or experience, which has the "potential to elicit rich, thick descriptions" (p. 154). This is consistent with phenomenology, which is concerned with individual accounts of lived experience. The person interviewed is more a participant in meaning making than a conduit from which information is retrieved, which is how a participant may be perceived when conducting quantitative research methods, in accordance with the positivist school of thought (Di-Cicco Bloom E Crabtree, 2006).

The purpose of most qualitative interviewing is to derive interpretations, not facts or laws, from respondent talk, with the aim of understanding the meaning of 
respondents' experiences and life worlds (Warren, 2001). However, previous authors investigating social research methods have challenged the use of interviews as a tool for producing reliable data. For example, Silverman (2006b) questions the integrity of whether interviews actually capture the reality of participant's worlds. It has been suggested that what is being discussed during interviews is a partial representation of phenomena (Hammersley $\mathcal{E}^{\circ} \mathrm{Gomm}, 2008$ ). Suggested reasons for this relate to the 'Hawthorne Effect', where participants may act in accordance to what they perceive to be 'acceptable', or 'required' by the researcher (Payne \& Payne, 2004). Also, Mruck \& Mey (2007) have criticised interviews as a means of data collection, for potentially 'leading', or 'influencing' participants. The authors suggest that interview talk is influenced by the situated dynamics participants and researchers find themselves in. For example, the researcher recruits participants, arranges the interview and often directs the nature of questioning, through the use of interview topic guides. The data may then be interpreted on the basis that such conversations would have occurred naturally in everyday situations. From this point of view, this could lead to data which is biased, based upon the researcher having complete control over the process of data collection. On the other, hand, congruent with the principles of Heideggarian phenomenology, interviews are seen as credible approaches to capturing the lived experiences of interviewees, on a particular phenomenon. This involves the social exchanges between the interviewee and the interviewer. Additionally, the advantage of interviewing participants face to face ensures that people are comfortable sharing information on sensitive, personal topics, whereby the interviewer can pick up on signs of body language, or demeanour, and act accordingly (Bryman, 2008). Nevertheless, the criticisms of semi-structured interviews warrant a recognition and response, in order to demonstrate that qualitative interviews have credibility and worth. In order to respond to the potential of researcher bias or control, potentially resulting in the 'Hawthorne Effect', several reflexive practices were undertaken. Reflexivity refers to "giving as full and honest an account of the research process as possible, in particular explicating the position of the researcher in relation to the research" (Palagnas et al, 2017: 430). A continual self-assessment and evaluation of my position as a researcher, in order to question my own thoughts, feelings and perspectives about the research. Such strategies have been documented amongst previous qualitative 
researchers (Lambert, Jomeen, $\mathcal{E}^{2}$ McSherry, 2010). Field notes were also made during interviews, as well as once interviews were completed, for example, in the car after leaving the home of a participant. It was paramount to write down any thoughts and feelings which were apparent at the earliest opportunity following data collection, in order to record anything which was deemed particularly noteworthy, which may have helped in the data analysis phase. Making notes as a reflective practice is something which has been supported by previous scholars (Maharaj, 2016). Reading these notes, alongside transcribing, or reading interview transcripts allowed the 'marrying up' of any ideas which were presented during, or after data collection. This ensures that researcher interpretation is not completely bias or subjective (Birks et al, 2008).

The use of interview topic guides

Overall themes identified in the literature review helped guide the construction of the interview topic guides for current and retired older drivers, and informal support network members. These guides were also in line with the overall research aim, and research questions.

Topic guides for current and retired older adults (appendices $5 \Xi^{2} 6$ ) reflected the view that driving cessation is a process, which consists of three main phases (Musselwhite E Shergold, 2013; Adler $\&^{2}$ Rottunda, 2006; Dellinger et al, 2001). Therefore, topic areas referred to lived experiences of driving, giving up driving, and life after driving. Additionally, as highlighted by a thorough literature search, informal support was also drawn upon, to generate information on this specific, under researched element associated with the driving cessation process (Schryer et al, 2017). For informal support network members, main subject areas related to their views and perceptions about the older adult's process of driving cessation, including areas relating to their own lives (see appendix 7). Questions were open ended, and were by no means leading.

\section{Location of data collection}

Each interview took place in the preferred location of each participant. This included the option to visit the participant in their own home, or to meet at a public place of the participant's choice. For example, the university premises, local libraries, cafes 
and pubs. Interestingly, five out of the seven retired drivers opted for a home visit. This may have reflected the limited transport options which were available to these individuals following driving cessation, although this was something which was unknown before commencement of each interview. The remaining two retired drivers were met at coffee shops. From the eight current drivers, the location for data collection varied. Five current drivers opted to be interviewed at an alternative place to their own homes, including their local pubs where they were regular customers, and one nearby café. The remaining four current drivers were interviewed at their own homes.

Informal support network members chose to meet at a location which was most convenient for them, often reflecting their lifestyles and availability. These interviews took place in a coffee shop near each individuals' workplace, commonly once their working day had ended. For other family members, friends and neighbours, they chose to undertake the interview in their own homes. Out of the informal support network members; six chose to meet at a coffee shop, six in their own homes, two at their work premises, which was a public house in this case, and one at the home of the older adult - without the older adult being present.

Each interview differed in terms of how long they took to complete, although this ranged from between 50 minutes, to 2.5 hours. 


\section{Ethical Considerations}

Ethical guidelines and practices were adhered to throughout the entire research process. Prior to commencement of any research, this study received ethical approval from Swansea Universities ethics committee (See appendix 1). The ethical application involved stringent documenting of each stage of the research process, including potential risks or issues.

\section{Risk assessment}

A thorough risk assessment was carried out during the process of applying for ethical approval. This involved the identification of any actual or potential risks which may arise across the duration of the study, relating to both researcher and participants (see points 8 \& 9, appendix 1). Dickson-Swift et al (2008) draw upon the importance of undertaking risk assessments, stating that "Because it appears possible to minimize risks with knowledge, it is important that we build knowledge about risk in research so that we can put into place strategies to deal with the risks that arise" ( $p$. 133).

Firstly, for research participants, emotional harm was perceived as a potential risk, due to the sensitivity surrounding some of the research topics. For example, experiences of driving cessation, which as outlined in previous research, has been highlighted as a highly traumatic life event (Fonda et al, 2001; Curl et al, 2013). There may also be sensitivity surrounding older peoples informal support networks, as it could not be assumed that all participants would have a harmonious, supportive network, if they had on at all (Johnson, 2008; Rosenbloom, 2010). This potential risk was also highlighted within previous research, identified through the literature search. During data collection, this perceived risk was something which did in fact materialise, as some older participants reported major breakdowns in their informal support networks. One retired older driver, Christopher, talked about an estranged relationship with his daughter, since his wife passed away suddenly. This led to the participant not having a network member to rely upon, or indeed refer to take part in the present study. In order to ensure emotional harm was minimised as much as possible, the researcher allowed the participant to talk openly, without interrupting, 
and expressed empathy where appropriate. A comfort break was also suggested after the discussion regarding informal support. However, in this case, the participant did not feel the need to take a break, and actually stated that he felt a sense of relief through talking about the issue.

Another potential risk relating to participants related to fear of disclosure of personal information. This related to both older adults and their informal support network members possibly mistrusting the researcher with their personal information. For example, interviewees may think their honest accounts of personal driving abilities may be disclosed to official organisations, such as the Driving Vehicle and Licencing Agency. This could therefore impact upon how honest and truthful participants may have been in their responses. In order to address this potential issue, the researcher informed each interviewee that their personal accounts and lived experiences of the driving cessation process were for no other purpose than to use for the present research study. It was also reiterated that all personal information, such as names, and locations would all be protected through the use of pseudonyms. This would ensure anonymity and confidentiality. Additionally, to ensure participants were comfortable and trusted the researcher, several opportunities for contact were made prior to commencement of each interview. This also allowed for the building of rapport between interviewees, and the interviewer. As Bryman (2015) states, strengthening rapport is something which reduces feelings of mistrust, which is beneficial for both parties in the process of social research. In relation to rapport, it transpired that in many instances when interviewing older adults in particular, this was something which had built up to a comfortable level, which was evidenced by many participants inviting the researcher to stay to and have a cup of tea and an informal chat, once the interview had ended. Although this was dependent upon the availability of the researcher, as some interviews were scheduled for the same day, this offer was something which was accepted in most cases. Nevertheless, the researcher was aware that there were risks associated with spending additional, unscheduled time with participants. This included the potential of becoming too emotionally invested in interviewees, which could potentially affect the interpretation of findings, through the application of researcher bias (Owton \& Allen-Collinson, 
2013). However, a number of reflexive processes were adopted to ensure this risk was minimised as much as possible. These examples of reflexivity have been previously outlined ( $p$. 87-88). Also, the recording device which was used during data collection was turned off following completion of each interview, so there was no evidence of any conversations which took place afterwards. This latter point was important to ensure the researcher was not being dishonest in anyway, allowing the research process to be as transparent as possible. Overall, the researcher was delighted to spend additional time with research participants when possible, as this was perceived as a way of 'giving something back' to those who had kindly given their time to participate in the present research study. It also became apparent that it was those who were suffering from loneliness, isolation, and depression following driving cessation who were keen to spend some extra time with the researcher. In fact, some participants stated this was the first time they had a person visiting them at home for quite some time. This latter illustration and example also draws upon another important aspect of risk assessment, relating to the protection and safeguarding of the researcher.

Firstly, the location of data collection was something which posed a potential risk. This is because interviews took place at a location of participants' choice, including homes, and public places, such as coffee shops and public houses. The majority of interviews took place in people's homes, particularly relating to the older participants in the study. Although interviewing people in their own homes is something which is widely adopted and preferred by qualitative researchers, as it allows data collection to occur in the respondents natural setting (Elwood et al, 2000; Austin $E^{2}$ Sutton, 2014), this is also something which creates potential issues surrounding researcher health and safety. To ensure researcher protection at all times, the researchers primary supervisor, along with a close family member were informed prior to each interview of the approximate time and location of each visit. This acted as a safety net, whereby each person contacted the researcher beyond a certain time, if they had not received a text message confirming the interview had been completed and the location of each interview had been left. 
One particular situation which arose during the process of data collection incorporated elements of researcher safety, as well as presenting an actual example whereby a participant did not trust the researcher. To illustrate, during arrival at one older adults home, the researcher was confronted with a very apprehensive welcome. This occurred despite previously calling the participant before, and during the day of data collection, to confirm participation in the pre-arranged interview. Once the purpose of the visit had been explained, and the researcher had introduced herself, whilst presenting her Swansea University ID card, access to the participants home was granted. Nevertheless, another safety issue immediately followed, through the participant locking the door behind him. Combined with the initial confrontational demeanour of the older adult, this created feelings of being uncomfortable and somewhat threatened. In order to professionally respond to this situation, the researcher ensured the participant was reassured about the purpose of the visit, and given the option to withdraw from participation immediately, whereby all previous correspondence would be permanently deleted. The participant was also provided with informed consent, and information sheets, which held the contact details of the researchers department within the university, as well as for both $\mathrm{PhD}$ supervisors. This gave the older adult the option to call and double check the legitimacy of the researcher. Also, the researcher had thought about imitating a phone call, if the hostile atmosphere had not subsided. This would have given the opportunity to suggest an urgent call had come through, leading to the researcher making a swift exit. If the participant had questioned why the phone had not rung loudly, the researcher would have explained this was because it was placed on silent mode, which is protocol, not to interfere with the interview recording. Nevertheless, no such action was required as the hostile atmosphere soon subsided once each above step was undertaken, and the researcher began to build a rapport with the participant. The participant also apologised for initially being suspicions of the researcher, and explained that part of the reason for this was because he often had nuisance visits to his home, from sales people. In a later discussion during the interview, the older adult also explained how he has not lived in the area for very long, and he was to some extent suffering from harassment from young people in the local area who were knocking his door frequently, before fleeing. 


\section{Informed consent}

All respondents completed an informed consent form (see appendix 3) at the beginning of data collection, to ensure all participant was voluntary. Participants were also given several opportunities, before, during and after data collection, to express any concerns they may have had. This also included the right to withdraw from the study at any given time. In this case, all information up to and including the point of withdrawal would be destroyed. However, this was not necessary for any data collected in the present study.

\section{Storing and protecting data}

In order to protect participant information throughout the duration of the study, the researcher employed controlled regulations and practices to ensure all information was treated with the utmost security. For example, both laptop and a personal university-based computer were password protected, with only myself having access to both machines. Also, all paper work was securely locked away at all times over the course of the research project, in a locked cabinet based at the university - which only the researcher has a key to access. The office in which the researcher has been based over the course of the study is strictly for fellow PhD students, and is only accessible by presenting a university ID card. Also, in terms of storing project information, a memory stick was used throughout the duration of the study, to ensure there was a consistent back up of information, to eliminate the risk of misplacing crucial information. The memory stick and university ID card were always carried with the researcher on a lanyard, to ensure there was no risk of another individual accessing the information, or tampering with research material.

All data has been anonymised, to ensure all interviewees' information was treated with the strictest confidentiality. All names and locations were changed, to prevent each participant becoming identified. This has been achieved through the use of pseudonyms, whereby false names have been assigned to all respondents. Where actual locations have been referred to, the use of the asterisk has been employed to conceal this information. 


\section{Signposting support}

After completion of the each interview with current and retired older drivers, participants were provided with an information sheet (See appendix 10).This included information for a number of services and organisations, tailored for each group. This list was put together based upon findings from the literature review, as well as through a search of online sources. For older adults, this included contact details for alternative transport, including general transport information as well as for more specific services, based on where each participant lived. For example, local taxi services, community transport organisations operating within particular areas.

Additionally, information was provided for third sector organisations, associated with older peoples wellbeing. This included contact information for Citizens Advice, and Age UK. Specific points of contact relating to driving, and driving retirement in later life was also provided. For example, ROSPA and BRAKE. This was to provide the option of older people contacting services if they needed impartial advice on driving cessation, or the option of a befriending service, if they were lonely or socially isolated, for example.

I made sure to provide as many options for contact for each service as possible, recognising that older adult may not all have access to a computer, or be able to use one. This included each services' postal address, contact telephone number, website, and email address. However, some website, such as ROSPA did not have the option to call, potentially limiting communication options for some participants (see appendix $8)$.

I provided this basic, generic information which was left with each participant, and advised each participant to follow up any specific information themselves, if possible, recognising the importance of ethical considerations and procedures, and remaining mindful that it was important not to over step the mark, in terms of embodying the role of a social worker. It was simply the intention to provide some basic information, as a starting point for those who may require support. 
Information sheets were also provided to informal support network members in the study, which were also developed based upon findings from the literature search, along with independent research being carried out on what services are available for network members. Although there were no specific services identified, relating to support interventions for the family, friends and neighbours of current and retired older drivers, there was information available for wider carer services. This mostly related to generic wellbeing services such as Carers services, Social Services, and Citizens Advice (see appendix 10).

\section{Thanking Participants}

The present study was undertaken by an independent researcher, with no access to additional funds to offer remuneration to participants for taking part in the research. "Funding for these projects often come from institutional seed grants.. which provides minimal support for participant recruitment efforts" (Joseph, 2016: 2). The only incentive provided before recruitment took place was the awareness that each person's contribution would potentially inform research, policy and practice, based on the overall findings. However, in order to recognise the invaluable contribution of participants taking part in the research and sharing their personal information, I decided to give a small token gesture to each individual, in the form of a thank you card and a small box of chocolates. This was given at the end of the completed interviews. Additionally, each participant also received an official thank you letter in the post, following completion of the study. 


\section{The messiness of social research}

The following section draws upon reflections of the researcher, relating to the experience of conducting primary social research for the present study. To reiterate, this included undertaking 30 semi-structured interviews with current and retired older drivers, along with their informal support network members.

Documenting the realities surrounding what it is actually like to undertake social research is something which is barely drawn upon in academic writing, despite this being the most effective way to improve knowledge, and essentially improve the quality of qualitative research (Naveed et al, 2017).

To illustrate, the messiness of conducting social research refers to the aspects of the research process which could not be planned for in advance. Such issues creating learning curves in themselves. However, the examples provided below did involve the researcher employing some of her researcher training skills, whilst also drawing upon some ethical guidelines and procedures. Firstly, throughout the data collection process, there were a number of occasions when older participants requested if their partner, or family member could join them during the interview. This would have been an option if a dyad interview was required, although that was not the purpose of the current research. The aim was to delve into participants personal experiences, to understand their individual accounts of the driving cessation process. The researcher was aware that having another individual in the older adults support network present could have directly affected the quality of the overall interview. For example, the older person maybe intimidated to talk freely and openly about what their experiences of informal support really are, if there is a member of their network sitting with them. Also, there is the chance that the network member could interject throughout the interview process, whereby this could affect the quality or flow of the information being provided by the participant themselves. Both examples could affect the credibility and overall quality of the research (Easton et al, 2000). In order to address these situations as they presented themselves, the researcher requested that all participants were interviewed individually. The purpose of doing this was 
explained in depth to the participant, and network member where relevant, and in all cases, each individual understood and was happy for interviews to commence with only the participant who had agreed to take part in the research.

Although previous researchers (Ranney et al, 2015) talk about the importance of preparation in social research, relating to aspects such as ensuring the location of an interview is 'vetted' before data collection takes place, this was not possible in the present study. This was because there were no specific rooms which were hired to conduct interviews, which was a choice of each participant. Instead, participants opted to be interviewed in their homes, and in public places where they often frequented. As the authors point out, the location for the fieldwork can affect the overall quality of the interview and the data generated. Referring to the recommendation by Ranney et al (2015), in terms of vetting each location, this could only be achieved to a certain extent by the researcher, in some cases. For example, before commencing with interviews in coffee shops, a 'quite spot' was attempted to be identified if possible. if and when possible. This was to ensure that any sensitive topics were treated with caution and as much confidentiality as possible. However, in reality, many of the participants had arrived at each destination before the researcher, and had also selected where they would like to sit. In response to this, each participant was asked if they were comfortable with where they had positioned themselves, in light of some of the topics which would be discussed during the interview. In these cases, all participants accepted the offer, and understood the importance of confidentiality, relating to sensitive issues which maybe raised, although each person was comfortable with where they were. During one interview which took place in a local coffee shop of one of the participants, the participant actually chose to sit outside as she was a smoker. Due to the outside area being busy, the researcher did check if the participant would be more comfortable discussing her personal experiences indoors, within a quiet space. However, this offer was declined as the participant noted 'they all know me and my life story around here anyway!' (Patricia).

In reality, there were also a number of instances across the process of data collection whereby there were several interruptions which occurred. For example, the 
telephone ringing, people knocking the door, and family members dropping in on some older adults whilst interviews were taking place. Although Easton et al (2000) note that researchers should implement measures prior to data collection to avoid any disturbances, this was not something which was always possible during official data collection. For example, the researcher requested that the interview take place in the most suitable, quiet space possible for the participant. However, there was no way of controlling for these unplanned interruptions, and the fact remained that this was what each respondents life was like in reality. To deal with such interruptions, the researcher made a note of any disturbances when transcribing each interview.

Aside from interruptions which took place within peoples homes, other interruptions occurred whilst interviews were being conducted in public places. This included coffee shops and pubs. However, such interruptions also hold value, in the sense that many of these 'unplanned' or candid moments added to many of the participants overall profiles. For example, during once interview with a current male drive in his local rural pub, a local neighbour dropped by to let him know that he was visiting the widow of a gentleman in the village who had recently passed away. This evidenced the fact that rural communities often support one another in times of need. This has been referred to on page 206 of the discussion chapter. 


\section{Data Analysis}

In qualitative research, data analysis requires a degree of systematic searching and creativity. Bloomberg \& Volpe (2016) draw upon the importance of keeping an open mind during the analysis phase, remembering that qualitative research is all about discovery. According to the authors, this phase is about looking at, and reading the data, to uncover important insights regarding the phenomenon under investigation. This, in turn, is what becomes the research 'findings'.

Qualitative data analysis greatly differs from quantitative analysis, in the sense that analysis is a continual, complex process, which does not end once results have been formulated to test a pre-defined hypothesis. Instead, this process is continual and ongoing. "The analytical part of the researcher's brain should always be alert to the implications of their choices at each stage of the research process" (Bloomberg E Volpe, 2016 : 188). Although there are different types of qualitative data analysis, thematic analysis is the most frequently drawn upon strategy (Castleberry \& Nolan, 2018). Braun \& Clarke (2006) are often cited as key figures in the process of thematic analysis, through their development of a six-phase framework (see figure 10). Maguire \& Delahunt (2017) suggest that the popularity of this approach is undoubtedly linked to the applicability of the clear and usable framework for doing thematic analysis. Thematic analysis has been described as a process of identifying patterns or themes within qualitative data' (Maguire E Delahunt, 2017: 3352). An advantage of using thematic analysis is that it is a method, rather than a methodology. Therefore, this makes this a very flexible tool for analysing data, as it is not directly related to any epistemological or theoretical position (Braun Eீ Clarke 2006; Clarke Eं Braun, 2013). 


\begin{tabular}{|l|l|}
\hline Step 1 & Become familiar with the data \\
\hline Step 2 & Generate initial codes \\
\hline Step 3 & Search for themes \\
\hline Step 4 & Review themes \\
\hline Step 5 & Define themes \\
\hline Step 6 & Write-up \\
\hline
\end{tabular}

Figure 10: Braun E̊ Clarkes six-step data analysis process

Braun \& Clarke (2006) suggest that in qualitative research, analysis begins as early as the data collection phase of the research process. This includes the researcher making mental notes about an idea, or a concept, for example. Drawing upon my own experience of undertaking semi-structured interviews with 30 individual participants, I can confirm that this initial process of data analysis was apparent during each interview. As previously outlined, having personal and professional experience within the field of ageing research, along with knowledge built up from the literature review, this lead to the identification of concepts, or potential codes, based upon the participants' narrative. However, I ensured that a professional conduct was employed at all times, keeping these preconceptions to myself, not to influence the participant about their own experiences in any way. This was to ensure the validity of the investigation was not compromised.

Despite Braun \& Clarke (2006) outlining this initial stage of data analysis, the sixstep table (figure 10) does not include this 'pre-analysis' phase. Due to this initial stage of analysis occurring within each interview undertaken within the present study, this step has been incorporated into the original table, to accurately reflect the process which occurred (See figure 11). 


\begin{tabular}{|l|l|}
\hline Step 1 & $\begin{array}{l}\text { Identifying initial ideas and codes during data } \\
\text { collection }\end{array}$ \\
\hline Step 2 & Become familiar with the data \\
\hline Step 3 & Generate initial codes \\
\hline Step 4 & Search for themes \\
\hline Step 5 & Review themes \\
\hline Step 6 & Define themes \\
\hline Step 7 & Write-up \\
\hline
\end{tabular}

Figure 11 - 7-step process of thematic data analysis, adapted from Braun \& Clarke (2006)

The process of data analysis which followed the 'pre-analysis' stage, was congruent with the six-steps outlined by Braun \& Clarke.

Firstly, 'Step 1 - becoming familiar with the data', involved transcribing each interview, verbatim. This task was time-consuming, due to the length of each interview, as well as the level of precision required in transcription, to ensure every aspect of the interview was captured accurately (Oliver et al, 2005). This included documenting verbal and non-verbal expressions, such as laughter or hand movements, as well as pauses or interruptions. Previous authors have reported that capturing these aspects of an interview provides a holistic account of the participant-interviewer interaction, ensuring there is no level of description lost (Bailey, 2008; Tessier, 2012). An example of this was directly captured in the interview transcript from Patricia, a retired female driver (See appendix 2). I was aware of the important implications which such information may have upon the analysis and interpretation of findings. In this case, the participant paused the interview, which was undertaken in a coffee shop, to signal a known passer-by. Patricia later talked about the value she places upon regularly visiting that particular coffee shop, for providing opportunities for social engagement. This information later informed the development of the narrative around 'community cohesion' and driving cessation, as part of the discussion chapter. 
This time-consuming nature of interview transcription lends itself to the justification of using a small number of participants in qualitative research (Oliver et al, 2005). Additionally, Braun \& Clarke (2006) state that time spent during 'step 1' of data analysis is a way of familiarising yourself with the data, to develop an overall understanding.

Once transcription has been completed, Braun \& Clarke (2006) suggest the next stage of the analysis should involve the reading, and re-reading of transcripts. This adds an additional layer of familiarity with the data set (Green et al, 2007). In the case of the present study, each interview transcript was printed off, and read over as soon as possible. Once I had read over each transcript once, I then began 'actively' reading each data item. As guided by Braun \& Clarke, this phase involves searching for meanings, feelings, patterns, and so on.

Step 2 in the process is concerned with 'generating initial codes'. Braun \& Clarke (2006) suggest you draw upon any initial lists of ideas formed from the 'active' reading stage, as it is from here that codes are generated. Coding is defined as 'the process of analysing. qualitative text data by taking them apart to see what they yield before putting the data back together in a meaningful way" (Creswell, 2015: 156). Braun \& Clarke (2006) define two different types of coding which researchers need to consider. This includes an 'inductive', or bottom up approach, or a 'deductive', top down approach. An inductive approach describes codes which are explicitly derived from the transcript, which are not driven by any pre-determined knowledge or ideas. Deductive coding refers to a more 'theory-driven' approach, whereby codes maybe applied which are related to previous themes identified from undertaking the literature review. Coding for the present study involved the use of both inductive, and deductive coding. This reflected my epistemological standpoint of hermeneutic phenomenology, which places the researcher within the process of 'meaning-making'. This means that preconceptions and ideas were not bracketed off. Instead, they were incorporated into the coding stage of analysis.

Elliott (2018) states the use of a coding system is a way of 'tagging data' that are relevant to a particular point. For example, you may want to identify all the places in 
an interview where a participant has said something relevant to one research question. A coding system allows you to look at information which is only relevant to that one question, rather than looking at the entire data set, through chronological order. In order to create a coding system for the present study, different coloured highlighters were used in Microsoft Word. For example, all text relating to an older adults lifestyle was highlighted in yellow, whilst all text relating to alternative transport was highlighted in red.

Coding begins to group to data into meaningful groups (Elliott, 2018). This was achieved by coding each transcript, based upon the coding framework which was continually being developed throughout this stage of the analysis process. For example, if I had coded 'alternative transport', by highlighting this in red, I would apply the same process to the next transcript, and so on, until all transcripts had been coded. Once all data extracts had been coded, they were then collated together, based on 'common codes'. For example, all extracts of text which referred to alternative transport, within each transcript, were copied and pasted into a separate word document, underneath the collective title of 'alternative transport'. This ensured that all information on this particular topic had been collated together, in one place. To add a deeper level of rigour, a similar process was undertaken by hand, using different coloured post-it notes. For example, where a participant had talked about 'alternative transport', each quote relating to 'alternative transport' was written on a pink postit-not, and collated onto an A3 sheet of paper (appendix 13) and so on.

Step 3 in the six-step framework refers to 'searching for themes'. This stage occurs once every data set (transcript) has been coded, and collated together. Braun \& Clarke (2006) state that this phase re-focuses the analysis at the broader level of themes, rather than codes, and involves sorting potential codes into themes. At this stage, I used mind-maps to begin organising my list of codes into themes. It became apparent at this stage that the names of some codes, were in fact themes in themselves, some codes were sub-themes, and some codes were disregarded. This stage involved a lot of 'playing around', in order to form linkages between codes and themes. This stage 
of the analysis process ended with a list of what I has interpreted as initial main themes, and sub-themes.

Step 4 in the process of thematic analysis involved 'reviewing themes'. This involved the refinement of the list of themes developed from stage 3. This part of the process involved the collapsing of themes into one another. For example, the sub-themes of 'organising' and 'arranging' were combined, demonstrating that each theme held the same meaning. I chatted with my supervisor at this stage, which involved talking about particular examples which were in my mind, relating to the accounts provided by participants. This was helpful in helping me 'sound out' my ideas.

Next, it was my job to 'define and name themes' - represented by stage 5 of Braun \& Clarkes (2006) six-step data analysis process. This phase related to ensuring the 'name' which had been assigned to individual main and sub-themes, accurately captured the essence of what you I was trying to say. This part of the analysis process required precision and a clear focus. In order to achieve this, I again, chatted with my supervisor, as well are writing my own notes on a Word document, as well as on paper. Once this process was undertaken, I was confident that each theme name had been thoroughly defined.

This final stage in the process of thematic data analysis occurred once I had a final list of main and sub-themes. It is at this point the 'write-up' of themes occurred. Braun \& Clarke (2006) suggest that this stage needs to undertaken carefully, to ensure you are accurately 'telling the story' of the theme, whilst providing sufficient evidence. Writing up my themes/findings for this final phase involved describing the theme, in the most clear, non-repetitive way, whilst providing verbatim quotes from participants. This was to elicit originality, and to demonstrate the root of where the themes presented originated from.

Following the write up of my findings (see chapters $4 \mathcal{E}^{\circ} 5$ ), this led on to the 'discussion' (chapter 6) stage of the research process, where it was my job to describe these findings in relation to previous research, or theoretical explanations about the phenomena of driving cessation and informal support. 
In addition to following Braun \& Clarkes six-step process, a further layer of data analysis was undertaken within the present study. This involved the task of 'exchanging' transcripts with a fellow doctoral student. This process occurred once data collection had been completed, and all interview recordings had been transcribed verbatim. Also, a coding framework had been developed by this stage, in order for my fellow student to refer to, whilst providing her own interpretation of the transcript. This also incorporated the aspect of transparency, a key aspect of qualitative research, relating to the researcher being as open, honest, and accountable as possible. 


\section{Chapter 4: Findings}

\section{Older adults \& the process of driving cessation}

The following chapter draws upon findings from the 15 interviews undertaken with current and retired older drivers. The chapter has been categorised into three main sections, reflecting the three primary areas drawn upon during interviews. This included the meanings of driving, meanings of driving cessation, as well as perceptions and experiences of informal support throughout the process of driving cessation.

\section{The meaning of driving for older people}

All 15 older participants, including current and retired drivers, drew upon what driving meant to them from their personal points of view. Analysis revealed that the meaning of driving in later life can be categorised into outcomes. Outcomes have been presented according to whether participants viewed these as positive, or negative aspects of driving. Although the list of positive and negative themes outlined are recognisably 'practical', or 'psychosocial' in nature, these themes have not been filtered according to their nature, because many of these themes were interlinked. Additionally, some main themes had sub-themes, which have been presented beneath each main theme in the table below. Verbatim quotes have been used throughout, to elicit originality.

The following table outlines the main, and sub-themes identified from thematic analysis. 


\begin{tabular}{|c|c|}
\hline Category & Main themes \& sub-themes \\
\hline $\begin{array}{l}\text { Positive outcomes of driving in } \\
\text { later life }\end{array}$ & $\begin{array}{l}\text { Getting from A to B \& Accessibility } \\
\text { Meeting personal mobility needs } \\
\text { Comfort } \\
\text { Choice } \\
\text {. Responsibility } \\
-\quad \text { Enhancing the mobility of others } \\
-\quad \text { Roles, Self-identity \& Self-reliance } \\
\text { Convenience } \\
\text { Spontaneity \& freedom } \\
\text {. Enjoyment \& pleasure }\end{array}$ \\
\hline $\begin{array}{l}\text { Negative outcomes of driving in } \\
\text { later life }\end{array}$ & $\begin{array}{l}\text { Financial drain } \\
\text {. Car maintenance } \\
\text {. Stress } \\
\text {. Fear }\end{array}$ \\
\hline
\end{tabular}

\section{Positive outcomes of driving in later life}

\section{Getting from A to $B$ \& Accessibility}

All current and retired older drivers interviewed primarily talked driving being important in order to get them from A to B. In this sense, the car was perceived as the practical mechanism which allowed transportation from one place to another, such as the home, to a destination of choice: 
This was further illustrated by another participant, stating that it wasn't the destination that was important, but the actual means of getting there:

"For me, driving is one way of getting from one place to another at your own leisure, it doesn't matter where you're going.. just getting there is the main thing!" (Grahame)

For some participants, the car was a complete necessity in order to meet their mobility needs. This was linked to type of geographic area. For participants living in rural contexts, the lack of being in close proximity to services and amenities was perceived as problematic. In these cases, driving was perceived as a lifeline and a crucial skill to maintain:

"There are no shops, you've got to drive to get to any shops, there are no shops or anything. around here" (Barry)

This was further elaborated upon by others, who revealed that public transport in rural areas was inconvenient and unsuitable to meet their mobility needs. Issues such as infrequent bus services were stated as major factors for why alternative transport was not suitable. The following participant described public transport as being geared towards the working age population only, which ignores the needs of older adults who have alternative needs:

"Oh, it's [driving] essential! Especially living in this area, as there's only a bus here in the area to Carmarthen twice a day. It goes about half past nine, ten 'o' clock there and comes back ah, about five.. it's for working people, you know.. you can't fit your life around that

$$
\text { really" (Daphne) }
$$

Although all older adults who lived in rural areas drew upon driving as a crucial aspect in their lives, participants living in urban contexts also interpreted the ability to drive as a lifeline. In these cases, this was related to an element of independence afforded by driving, as well as ensuring they are connected to society: 
“Um, driving to me.. it's vital to me. Driving to me is my lifeline. Yes, my car's my lifeline. Without that, I'd be waiting here for people to come and visit me, and I would hardly get

$$
\text { out" (Gordon) }
$$

"Yes, driving does definitely allow that connection to the outside world, gosh I depend on it so much, you don't realise, but come to think about it, I really do" (Maida)

\section{Meeting personal mobility needs}

Aside from the obvious aspect of driving allowing direct transport from one place to another, participants talked about the importance of driving in terms of meeting their personal mobility needs. This ranged from basic everyday needs, such as attending medical appointments and supermarkets, to social and leisure based needs:

"I've got to say it is yes.. its [driving] everything, from going to do my shopping, to going to concerts in town, which are almost always in the night, not in the day, so then you need the car to be able to get to and from there as bus services wouldn't be running.. I'm totally reliant on the car.." (Barry)

\section{Comfort}

The practical aspect of driving providing comfort was also related to by participants. Some older adults talked purposefully about choosing cars that were specifically suited to their personal health and mobility needs:

"So, when I bought that one, going back to what you said.. I've got a false hip, so I decided I'd go for an automatic.. so I can stretch the old foot out! So I went for automatic. And um, like me.. she's old in age but young at heart haha!" (Gordon)

Being comfortable whilst driving seemed to be of increasing importance as the following participant got older: 
"I like to sit comfortably and it's even more important now that I'm getting older because of all my aches and pains! If you get a car that's too small or cramped and not very easy to drive then you get a bit fidgety and I like to be comfortable when I'm driving" (Grahame)

\section{Choice}

The element of choice was identified as a multi-faceted concept amongst participants, when talking about their personal accounts of driving in later life. Having choice meant a lot to people, as it also seemed to provide a level of autonomy. Firstly, choice was referred to in relation to food shopping. The ability to drive to the supermarket on a daily basis, to be able to choose what to purchase was something which was highly valued by the following participant:

"Well I go shopping every day into ***********. I like to have my food fresh, so I go down once a day and pick up whatever it is I feel like" (Derek)

Aside from driving allowing choice in relation to food practices, other respondents talked about choice in relation to their consumption patterns. One female driver talked about choosing different shops to visit each week, which was often determined by where the participant felt like going. In this case, this ensured shopping trips were kept interesting and not mundane. The participant stated these weekly trips provided her with an interest, and a feeling of anticipation to be able to search for deals or bargains in different shops:

"I can choose every week where I want to go, and I look forward to seeing whatever offers they have on, sometimes I come away with some odd stuff, but it's nice to have a nose!"

(Maida)

Driving also provided older adults with choice in terms of their social lives. The following quote was made by a female participant who talked about making choices in relation to eating out, which was largely influenced by spontaneity and present circumstances: 
"Well although my daughter runs the local pub and we often have Sunday lunch there, we sometimes decide to drive out and eat somewhere different on a Sunday" (Daphne)

Responsibility

- Enhancing the mobility of others

A number of participants talked about the ability to provide lifts to others as an important aspect of driving in later life. For some, people in their informal network were completely dependent upon them to meet their mobility and transport needs. The following female driver drew upon the importance of her holding onto her driving licence for as long as possible, due to being the primary transport provider for herself and her husband. This was the case following her husband suffering a stroke, and subsequently giving up driving:

"With myself, I'm completely independent, but I support my husband because he had to give up driving through his illness, so I do everything for him and myself" (Daphne)

For others, although there were no explicit references to others being dependent upon them for individual mobility needs, the ability to 'offer' support was a highly valued aspect of driving in later life:

"I often ask my neighbour if there is anything she needs while I'm out on my travels. I know she doesn't drive or have a husband.. and she's got young children.. we have got chatting over the wall! She's lovely, so if I see her I will often ask if there is anything she needs"

\section{(Gordon)}

The ability of providing help to others was also mentioned by another current driver. For this participant, frequent trips were often made to visit fellow church members during hospital stays. If the participant has an awareness of other members of her local community also wanting to make the trip, a lift is often offered:

“.. it's also the ability to help other people because you can offer other people lifts, you can take them somewhere if you know somebody else is in need of going somewhere, so being able to do that is important to me yes" (Maida) 


\section{Roles, Self-Identity, E゚ Self-Reliance}

Closely linked to the role of 'enhancing the mobility of others', current and retired older drivers drew upon other personal roles which they embodied. This included; worker, parent, grandparent, spouse, friend, neighbour, and a volunteer. One male driver drew upon the importance of driving, as this allowed him to independently drive to his daughter's pub where he sometimes 'helps out' behind the bar, also providing the participant with a sense of purpose:

“.. as a recent example, she rang me up on Saturday night to come up and cover a shift behind the bar, you know.. and we are only in the next village so I can do it for them, you have to drive like but it's not too far away" (Donald)

Another current female driver talked about the importance of driving, relating to the ability of this allowing her to fulfil her role of grandmother. This role involved picking her grandchildren up from school, and often taking them to leisure activities:

"I pick the kids up on a Monday and Thursday, I'm lucky because I work part time.. quite often as well I take them to kids parties, there's always one of those, and the little one goes to a gymnastic class on a Thursday!" (Molly)

Other participants also talked about driving being something which reflected their self-identity, and awarded them personal 'status'. One current male driver stated:

"I've got a Merc, I've always driven a Merc.. I wouldn't drive anything else! It's what I've worked hard for all my life. If people see my car parked somewhere, they know I'm not far

$$
\text { away!" (Barry) }
$$

Based on the perceptions and experiences of all current and retired drivers, the element of self-reliance which driving afforded was something which held important meanings. This was highly related to participants' independence. This was depicted in a number of ways, including the ability to rely upon oneself to travel independently, without needing the help of others to meet personal mobility needs. Many older adults related these feelings of independence to their overall subjective 
quality of life, which helps to explain the significance of driving in terms of the outcomes it has for older adults:

"Driving is important for a person's quality of life isn't it.. you haven't got to ask people then, you can just jump in and go! It's about independence" (Ernest)

However, not all participants perceived the element of self-reliance provided by driving as something which was of the same level of importance. For one current female driver, although driving was the preferred mode of transport to meet her mobility needs, ensuring self-reliance, it was stated that relying upon others for support was not something which she was totally against:

"Oh yes it is important to be independent, to do things yourself, um.. but I'm not completely averse to relying on other people if I need help' (Maida)

\section{Convenience}

A number of current and retired older drivers referred to the element of convenience related to driving in later life, with the concept being applied to a number of situations and contexts. Firstly, participants talked about driving being a convenience in terms of the lack of planning and organising which is required to undertake trips, which alternative transport modes often require. For example, using the bus requires preplanning to identify bus times or drop off points, and having a lift from family and friends requires prior communication and organising. Driving allows older adults to visit or leave a destination at their own discretion, without any prior organising:

".. well it means not having to work out the next time of the bus, or arrange with my son a time to be collected and that.. it's just convenient for me to jump in the car and go!"

\section{(Gordon)}

Convenience as a reason for driving in later life was also related to the ability to 'come and go', based on personal feelings and circumstances, which are often fluid. The following participant thought this was due to getting older and feeling more fatigued and lethargic: 
".. also, with the car I can leave and take off from places whenever I want too, so if I'm out and about somewhere and I get a bit tired or whatever, which I do now these days.. I can just come home on my own accord" (Grahame)

Wider environmental factors were also drawn upon in relation to convenience. A current female driver reflected on the importance of her car being parked directly outside her home, in terms of the level of ease which this provides to her in relation to avoiding bad weather conditions. The car was also used as a tool to transport heavy items to a local church volunteer group:

"I do a lot of volunteering work with the church, I normally walk but sometimes I take the car if it's raining, I don't like the rain I'm terrible! So it's nice to be able to do that yes.. and also sometimes, if I volunteer at the kids club or whatever I take crafts and bits like that.. so I can carry them easily in the car" (Maida)

\section{Spontaneity \& freedom}

The element of spontaneity was recognised as an important aspect of driving amongst participants. A retired female driver talked about the element of spontaneity being the most important part of driving to her:

"I think 'the' most important part in all of this is spontaneity. It's getting up and going when you want, when you feel like it, and I was able to do that when I was driving. Like now, I sometimes have things planned, then I don't feel like going” (Alice)

The importance of undertaking spur of the moment trips was also related to by another older female, who gave up driving two years previously. The participant talked about the ability to use the car as she desired, to visit places without having set plans in place. This was recognised as something which important for the participants wellbeing:

"Some days, if he [husband] was in here watching TV, I would just jump in the car and drive wherever I wanted to go, whether that be going down to Asda for a look, or into the 
town for a coffee.. and sometimes just driving and not getting out of the car, that was always good for me" (Belinda)

The aspect of freedom was also mentioned talked by current and retired older drivers. This was described as having endless geographic boundaries, with the ability to travel anywhere independently through driving. The same retired female driver talked about how just seeing her car parked outside her home provided a feeling of liberty, with no parameters or barriers to overcome:

"Just seeing the car outside, it meant I was free if that makes sense.. I knew I could just get in and go.. and go I would, I used to drive everywhere!" (Belinda)

\section{Enjoyment E̊ pleasure}

Current and retired older drivers talked about the element of pleasure associated with driving, with driving being described as an enjoyable task, and a hobby in itself for some:

"Well if I didn't like driving, I wouldn't do it, I'd just give up.. it's as simple as that"

\section{(Grahame)}

Another retired female participant echoed this, when reflecting upon some of the reasons for driving before cessation occurred. The participant drew upon a genuine passion for driving, which also provided her with great pleasure:

"I used to love it! 46 years on the road I was, I used to drive everywhere, I had no fear! Ohh,

I really did love it! I would never have given up if it was my choice!" (Belinda)

Driving being a complete hobby in itself was also provided in the account of the following retired male driver. In this case, the participant described a strong sense of attachment to driving through driving experiences earlier in the life course. Discussing this experience triggered fond memories.

"I loved driving, loved it! I would just drive for the fun of it, you know if I had the option, if I didn't have any work at all, then I would be into cars big time! I borrowed my father's van 
and hammered it around the country when I first passed, my first car then was a mini cooper, and boy did I have some fun in that car! They were bloody good times" (Ernest)

\section{Negative outcomes of driving in later life}

\section{Financial Drain}

For some participants, more negative aspects of driving were reported. For example, two retired female participants who gave up driving voluntarily talked about the expense of driving, which became even more difficult to manage as they got older. One of the participants stated this was due to other changes in her life, including changes to her employment contract and a reduction in working hours:

"In the end I gave the car to my son, I was finding it more and more expensive to run, especially with going part time in work, it was just a drain for me.. and I didn't really need to drive in the end" (Penelope)

Although not referred to in such a negative sense, another current male driver also recognised the expense of driving, when talking about the cost of parking becoming increasingly expensive:

"If I go into town now and park my car in the multi-story, you're talking three of four pound if I'm there a few hours, and that adds up.. but the thing is, that's the only car park near the shops I go to!" (Gordon)

Furthermore, another male driver talked about driving being something which he was finding increasingly expensive, with this actually reducing the amount of overall driving which is undertaken:

"It costs a fortune, half the time my car is sitting there outside and I can't afford the petrol to get where I want to go, then its paying to park.. I do find it really hard because money is tight for me" (Grahame)

Car maintenance 
Some participants also talked about car maintenance as a problematic factor. This was especially apparent for older females within the study population. The following retired female driver talked about how manual tasks associated with driving used to make her feel uncomfortable and embarrassed, due to a lack of knowledge surrounding the practical aspects of car maintenance:

"It was hard for me when something went wrong with the car because I had to sort things out myself.. and one time, I had to go into a garage on my own because I had a flat tyre that needed changing.. so my neighbour pointed out to me! I felt a complete idiot because I'd never done it before.. they were nice enough and sorted it for me, but I felt completely out of place being there!" (Penelope)

Another current female driver presented a similar account, when drawing upon her lack of experience and familiarity surrounding the maintenance of her vehicle. In this case, any work which needed to be undertaken on her car was assigned to her husband:

"I can't be doing with all the mechanics to do with the car, I've never dealt with any of that.. I just hand it all over to my husband, I'm clueless!" (Molly)

Interestingly, male participants interviewed did not refer to car maintenance, or the manual aspect of driving.

\section{Stress \& Fear}

On a more psychosocial level, the element of stress was drawn upon by a number of participants when talking about the lived experiences of driving in later life. Stress emanated for a number of reasons, including an increased lack of confidence in personal driving abilities, due to unfamiliarity with road systems and increasingly busier roads:

“.. when I got older, my confidence in driving got worse you know with more and more traffic on the road and things.. and I wasn't confidant, if I knew where I was going I wasn't 
too bad, but anywhere strange and it was busy I would just hit panic stations and get all

$$
\text { flustered!" (Penelope) }
$$

Fear was an element talked about which was closely related to stress. The following female participant talked extensively about the apprehension of her car breaking down in an unknown place at night, leaving her feeling fearful about the vulnerable situation this would leave her in:

“.. you know if I'm just driving around ********* in the dark that's no problem at all, but anywhere I'm not quite sure of.. you know it just looks so different, and when I'm coming back from ******** on my own, it's the loneliness of the mountain road and I'm thinking 'oh my god, what if I break down!' you know, that's a big fear of mine! I wouldn't have noticed it a few years ago, but I'm very wary of that now" (Maida)

When experiencing stress as a negative implication of driving in later life, some participants began to self-regulate their driving. In some cases, this also contributed towards complete cessation:

"I thought to myself, I can do without this, I was so worked up all the time.. so I had a chat with my son, and that was it.. he had my car, and I gave up" (Patricia)

Another female driver talked about eliminating some of the driving tasks which were becoming more difficult as she was getting older, to reduce the feeling of stress and fear. This related to the participant having deteriorating eyesight:

".. then a few times, you know, in the heat of the winter, when it's really dark and raining and you get all the lights.. I got a bit frightened a couple of times, so I thought 'oh no I'm not doing it again this year'so I try to avoid driving in those conditions altogether now. I couldn't be feeling like that anymore!" (Molly) 


\section{The meaning of driving cessation for older people}

The following section is based upon the perceptions and experiences of current and retired older drivers, in relation to the meaning of driving cessation in later life. Current drivers provided their prospective views about the possibility of giving up driving in the future, and retired drivers drew upon their lived experiences of driving cessation. It was revealed during data collection that some current drivers had begun self-regulating their driving, whilst others had experienced temporary periods of driving cessation due to health complications. All current drivers were actively driving at the time of the interview, and all retired drivers confirmed they no longer held a valid UK driving licence, having given it up within the last 7 years.

Findings were clearly expressed in relation to positive and negative outcomes of driving cessation, including both practical \& psychosocial factors, which were often interlinked.

It is also essential to note that some of the findings in the below section are closely linked to informal support, which will be expanded upon in the following section $-4 c$. Older people's perceptions $\mathcal{E}^{2}$ experiences of informal support throughout the driving cessation process. 


\begin{tabular}{|c|c|}
\hline Category & Main and sub-themes \\
\hline $\begin{array}{l}\text { Negative outcomes of driving } \\
\text { in later life }\end{array}$ & 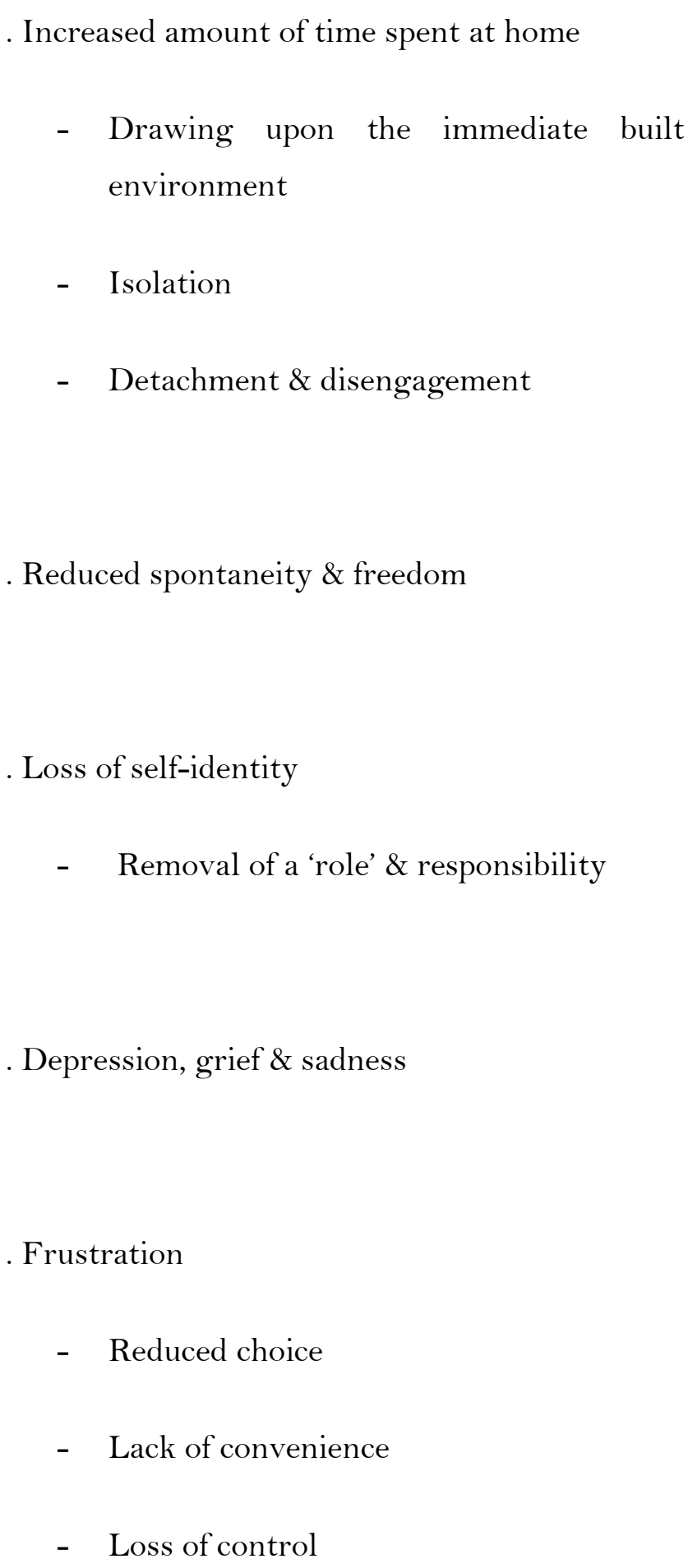 \\
\hline
\end{tabular}




\begin{tabular}{|l|l|}
\hline & - Increased planning and organising \\
\hline $\begin{array}{l}\text { Positive outcomes of driving in } \\
\text { later life }\end{array}$ & $\begin{array}{l}\text {. Financial gain } \\
\text {. Relief } \\
\text { The use of the internet }\end{array}$ \\
\hline
\end{tabular}

\section{Increased time spent in immediate surroundings}

Drawing upon their current lived experiences, a number of older drivers perceived driving cessation to mean an increased amount of their time being spent at home. Retired older drivers confirmed this perception, as giving up driving had resulted in spending more time at home.

\section{- $\quad$ Drawing upon the immediate built environment}

One of the main things drawn upon as an outcome of spending more time at home was the immediate built environment of participants. Namely, this related to the home and the garden.

A current male driver perceived this outcome in a negative sense, interpreting an increased amount of time within the home as a form of confinement, with there being no means of getting out. However, due to the rurality of where the participant lived, this was seen as an inevitable outcome of driving cessation:

"I'd have to be at home more, stuck here.. not out of choice you know, I wouldn't want to, but I'd have to.. I wouldn't have a choice, there's no way of me getting out really if I have to give up the car" (Barry)

A retired female driver confirmed this perception, through her experience of spending vast amounts of her time within her immediate surroundings since she had to give up 
driving. Although the participant talked about this being something she is comfortable with doing at times, there is still a deep urge felt to experience the outside world, in terms of moving beyond her immediate built environment:

"I am comfortable sitting around the home and being in the garden now, and I try and make the best use of it.. but that doesn't mean to say I feel like staying there all the time, I do still get a terrible urge to get out, I feel completely restricted at times, like a prisoner in my own home" (Alice)

On the other hand, for another male driver, the perceived increased amount of time being spent within his garden was viewed as a positive in the event of driving cessation:

"I think if I had to give up driving I would be in the garden even more than what I am now if that's even possible, and I'd be at home more like, the garden would be my saving grace!"

(Derek)

However, the option to spend time in the garden as an alternative to driving was no longer an option for another retired female driver. This was because she had relocated from her lifelong family home, to a smaller accommodation in recent years. This has resulted in the loss of a garden area:

"I would spend time in the garden if I was in the old house, ah you should have seen it.. I left my heart there! The house and garden were the most beautiful, but my family thought it best if I move here.. it's alright, don't get me wrong, but nothing like the old place. I really miss going in the garden, even more so now that I'm trapped here without my car' (Belinda)

\section{- Isolation}

Isolation was also linked with an increased amount of time being spent at home as an outcome of driving cessation. Although this finding was similar to 'drawing upon the immediate built environment' in many ways, participants often talked more directly about isolation as a consequence of driving cessation, warranting a sub-theme of its own. 
One female participant talked about feeling stuck within her own home since giving up driving, which was linked to her inability to walk or use public transport through her declining physical health status:

"Most of the time, unless I am at work I am completely stuck here within these 4 walls.. I'm not independent enough to go on the bus, or walk because of my eyesight and arthritis.. so yes, I do feel alone and trapped here quite a lot of the time" (Alice)

Another male participant drew upon feeling isolated since giving up driving, which was also combined with the issue of health and mobility restrictions, through completely losing his eyesight. In this case, the participant described how previous bad weather conditions had further exacerbated feelings of being trapped within his supported residential accommodation, due to no public or formal private transport running:

"Ifeel isolated myself here sometimes, when it snowed before I knew there was no chance a taxi would come for me, so I was trapped here like. If I was still able to drive I would have given it a go" (Christopher)

Although driving cessation was something which had not yet occurred for the following male driver, isolation was something which was closely associated with this transition. In this case, the participant drew upon his sociodemographic status as further exacerbating this issue: This was due to living alone, as well as living in a highly rural area:

"I would be completely cut off if I had to give up the car.. I haven't got neighbours for miles around, and I live on my own.. so I would definitely be isolated here if I couldn't get out, as I do now! (Barry)

- Disengagement $E^{2}$ detachment

Feelings of disengagement and detachment were expressed by a number of retired older drivers, when drawing upon their experiences of driving cessation. This was 
also related to spending an increased amount of time within the immediate environment, through a lack of independent mobility.

For example, a retired female driver talked about how the closure of a coffee shop where she was a regular weekly customer had shocked her, leaving her feeling detached and disengaged from a once familiar and well frequented place:

"It was my friend who told me that Holbrook's had closed down.. I honestly couldn't believe

it, I used to go there at least twice a week when I'd go into *********.. I knew the owners and all, it's really upset me because it shows I'm not part of anything anymore" (Belinda)

Another retired male driver also mentioned how he now relies upon other people to inform him of any news or changes which occur around him, since he is no longer actively engaged in the social world, following driving cessation:

"I don't get out anymore, so my grandson.. he phones me up and tells me all the news like" (Christopher)

For another retired female driver, experiencing a sense of detachment was not expressed in terms of feeling unfamiliar or withdrawn from places, it was more about feeling socially isolated and 'out of the loop' compared to the lifestyles of other people around her. Largely, those who were still had independent mobility:

"I feel like all my friends are all living a better quality of life than me at the moment, I feel like they are having more fun, and they are 'out there' if that makes any sense, they are part of life.. and I feel like they are actually out there and being a part of life moving around and socialising and just being involved in life you know" (Alice)

However, for another female who had given up driving voluntarily, an opposite account was presented in terms of how strongly attached to her local area she is. The participant ensures she visits her local village each and every day for a coffee. This keeps her in contact and up to date with any changes or news which occurs. Whilst interviewing this participant at her chosen coffee shop, there were two instances where passers-by stopped to chat to her: 
“..it's every day I get out, I come here for a coffee every day. I make a point of doing that every day, no matter what the weather, even if it's for half an hour I make sure I get out. I also call in the shops if there's anything I need or if I fancy a browse, I know all of the owners so it keeps me up to date" (Patricia)

Relating more specifically to disengagement, this was perceived to be something which would directly occur as a result of driving cessation by the following male driver. In this case, losing the ability to drive meant a loss of independence, which would result in him disengaging from life completely:

"I am dreading it [driving cessation] with a capital D, your independence is so important as you get older, it's what keeps you going.. once that's gone, you may as well throw in the towel! That's me done then" (Gordon)

\section{Reduced spontaneity \& freedom}

Retired drivers talked about losing the sense of spontaneity which was provided through their previous ability to drive. A retired female driver talked about how no longer being able to undertake spontaneous trips out of the home was what she missed the most since driving cessation occurred. In this case, the participant talked about how pre-planned trips are not always something which she wants to undertake when the time comes to leave the home:

"Now, everything is planned and sometimes, if I've planned to go out with my friend for a meal or a day out, I don't always feel like it when the time comes, and when I'm at home other days, that's when I feel like going out. I think the most important part in all of this is

$$
\text { spontaneity" (Alice) }
$$

Even a retired female driver who reported positive outcomes following driving cessation missed opportunities for spur of the moment trips, which were available through driving:

"It is a bit more difficult now using the bus to pop somewhere, like down to see my friend which I used to just do when I had the car. I always think now, is it worth the trip you know, there's no point in a wasted journey" (Penelope) 
The loss to personal freedom was also depicted in the following quote by a current male driver. In this case, thought driving cessation would reduce his horizons and general outlook on life:

'It would be like the curtains being drawn, with no view to freedom anymore.. the option to go out is no longer there.. that freedom you had is gone' (Barry)

\section{Removal of a 'role' E' responsibility}

The loss of previous roles which participants who had previously driven embodied was something which was drawn upon. For example, a retired male driver who had given up driving due to the sudden onset of epilepsy talked about losing his identity as a 'the driver' of his household. Since driving cessation has occurred, this role and status has been lost:

"I was always the 'driver', when the kids were small and over the last few years, for days out with myself $\Theta^{2}$ Josie, shopping, or whatever.. I always drove - so it feels like I have lost part of me now that I can no longer do that" (Ernest)

Other retired drivers also drew upon the loss of previous roles which were related to their self-identity. For example, the following female driver talked about losing the ability to drive her friends into the nearby town centre on a weekly basis, which formed a significant part of her social life:

'I used to pick Gaynor up, then go on to get Elsie.. and drive on into ******** then, every week I did that.. now, none of us go since I had to give up the car' (Belinda)

Also, a retired female driver talked about no longer playing as much of a caring role to her older mother since she is no longer driving:

'I was my mothers main transport provider taking her to all her appointments, or taking her out for the day bless her, now she's at home more, just like I am' (Alice) 


\section{Depression, grief $\mathfrak{E}^{2}$ sadness}

The majority of older adults who had given up driving displayed feelings of depression and unhappiness. This ranged from an instant depressed state of mind directly following the removal of the driving licence, to extended periods of sadness and low mood in the 'life after driving' phase.

For one older female participant who gave up driving due to declining eyesight and concerns from her closest family members, feelings of complete heartbreak were expressed:

"I broke my heart I remember, it's been terrible..just terrible" (Belinda)

The same participant talked about how depression and low mood has been something which had continued since giving up driving four years previously. A deep longing was still felt towards the respondent's previous ability to drive:

“.. it's as if something [ability to drive] huge has been taken away from me, and I still get up in the morning.. and I still do look outside, and the car isn't there, and I just feel awful.. it's a reminder that I'm no longer able to have the life I had when I could drive" (Belinda)

Another participant echoed this emotionally difficult time, directly stating that giving up driving and additional health problems have led to depression over the last 2 years. Physical expressions of emotion were also talked about as an outcome of these negative feelings:

"Depression is what's come on me through losing my independence since giving up driving and all the health problems. It was only last week I was on the phone to my friend, and I just burst into tears because I'm so low and down in the dumps" (Alice)

Retired male drivers also expressed feelings of depression when reflecting upon what giving up driving has meant to them. The following quote from an older male driver who was forced to give up due to an epileptic seizure reminds us that even once the transitional point of giving up driving has occurred, and each person tries to adjust 
to life without driving, when the transitional point is broached, it still evokes strong feelings of unhappiness and sadness:

"Ohh, I'm getting all depressed now again thinking about it.. now that we are talking about it, it's brought it all back" (Ernest)

Current older drivers also talked about depression and unhappiness being one of the outcomes they are fearful of, in the event of driving cessation. This was perceived to be the case for a multitude of reasons, including the loss of independence, spontaneity, and current social lives. The following female driver drew upon driving cessation affecting her ability to be independent, which would lead to negative psychosocial outcomes:

"If I couldn't drive, then I would be very sad I should imagine, I'd be dependent on others, I wouldn't go anywhere, many of my friends don't drive so I'd just be here"(Daphne)

\section{Frustration}

To an extent, it became evident that some form of frustration was felt and experienced by all participants who had given up driving. However, frustration was not something which was drawn upon by current older drivers, in their perceptions of driving cessation.

\section{- $\quad$ Reduced choice}

Frustration was expressed by some in relation to no longer having a choice. For the following female driver, no longer having the independent ability to visit the supermarket regularly means that she is dependent upon her niece to bring her fresh groceries, which does not always result in the participant getting what se wants:

'.the other day, she [niece]brought me the wrong batch of brown bread, it was the seeded one which I don't like.. I miss going to choose it myself, it's not the same.. I told her I don't like that one, it's just frustrating' (Beatrice) 
For other participants, feelings of frustration were related to using alternative methods of transport to meet their mobility needs. For example, the following retired male driver spoke about the rurality of his area being a barrier in terms of the provision of public transport. When the participant has used the bus to try and meet his needs independently, he spoke about feelings of frustration due to prolonged periods of waiting, due to minimal service provision:

"It's the waiting around for the bus which is so frustrating, it's every 4 hours in this area. I had to catch it to get to the opticians a few weeks back, and I had to get the bus at 9am, and my appointment wasn't until 11.. I was ages just waiting around" (Ernest)

Other participants also drew upon the use of public transport as an alternative to driving as a frustrating method of meeting their mobility needs, compared to what they were previously used to through driving:

"Sometimes it's just the inconvenience of the bus that puts me off if I only want to go and see my son you know.. walking to the bus stop, waiting at the stop, waiting for it to stop off at all the different places before you even get to where you're going, there's none of that when you have the car" (Patricia)

\section{- $\quad$ Loss of control}

For others, the element of frustration stemmed from a loss of control regarding the decision to give up driving; which some felt hindered their ability to successfully adapt to this transition. In these cases, elements of bitterness and disappointment were apparent. One retired male driver who suddenly lost his eyesight and therefore had to give up driving immediately, as well as completely adjusting his lifestyle by finding new ways to meet his needs, stated:

"The hard bit for me is that I can't do what I always did, it was just taken away from me, literally overnight, can you imagine how frustrating that was" (Christopher) 
For another retired female driver, not having the option to directly make the decision herself to give up driving was thought to have resulted in worse outcomes, in terms of how she has experienced the process of driving cessation:

"I definitely think because it was the hospital which told me I was not safe to drive anymore because of how god awful my eyesight is, I think I've come off far worse for it!" (Alice)

Similarly, another retired male driver expressed frustration over not being able to have any influence over the decision to give up driving. To add to these feelings, experiences with medical professionals regarding his health condition had also been problematic:

“.. the thing is it's so frustrating because first I'm told I can't drive because of my epilepsy, which I never expected, and then there was a mess up with the results going back to the doctor, and then the doctor didn't have them, and then he had to get in touch with the hospital, you know.. it was all just so annoying and endless" (Ernest)

\section{- $\quad$ Increased planning and organising}

Some participants talked about the need to plan and organize their lifestyles as something which caused them frustration. For the following retired female driver, the responsibility of having to organise a lift into work at the beginning of every week was something which was frustrating to her:

"On a Sunday night I always have to text one of the ladies living near me to see if it's alright for a lift to work, I get quite anxious over that as sometimes she isn't in work going in later.." (Alice)

A similar experience was presented by another retired female driver who spoke about the need to plan things in advance which were previously taken for granted through driving: 
"It do find it hard work trying to work out how I'm going to get somewhere these days.. if I've got a hospital appointment, it's working out, is there anyone to take me, if not, what time do I order the taxi for!" (Alice)

\section{Positive outcomes}

Although the vast body of findings relating to older peoples experiences of driving cessation were negative, some current and retired older drivers reported more positive outcomes.

Financial gain

Firstly, the same male participant who drew upon the cost of driving being problematic in later life, perceived driving cessation to be one way of releasing extra money for him:

"Well, it would release extra cash for me, because as I said, money is a bit tight. Driving is bloody expensive and becoming more expensive! You know, you've got to maintain a car, MOT's and all that, petrol doesn't come cheap. And neither does parking in pay and display places! So yes, it would release money for me which I could do with" (Grahame)

This positive financial aspect of giving up driving was also drawn upon by a retired female driver, who recalled driving being an expensive attribute in her life. The participant talked about how the use of her bus pass now allows her to travel for free, through which she has seen a significant change in her finances:

"It was really expensive, every time something went wrong with the car I'd think oh my god! I was only working part time, and whatever needed fixing was never cheap! Now I've got the bus pass, I don't have to spend anything to get to and from town, it's made a big difference to me, especially since I've retired" (Penelope)

However, for other retired drivers the cost of driving seemed an irrelevant factor, as the most important thing for these participants was the ability to drive. The following retired female driver talked about the financial costs of driving being classed separately to other monetary outgoings: 
"I never used to write down anything to do with the cost of the car along with things like bills for the house, the cost of driving was just covered, it must have come out of the same money in our account.. obviously.. but I never thought about that, it was just something I

$$
\text { paid" (Alice) }
$$

Another current male driver also remarked on the cost of driving being an irrelevant factor to him, because the positive aspects associated with driving outweigh the financial cost. In this case, driving was perceived as something which you cannot put a financial value to:

"Obviously driving isn't cheap, but I have never had a problem with paying for insurance, petrol or whatever else it is.. because, to me, driving is everything! And you can't buy that! I know I'll be lost without it.." (Barry)

\section{Relief}

The other positive outcome of giving up driving which was reported by current and retired older drivers was relief. Two females in particular expressed feelings of relief once they made the decision to voluntarily give up driving. For one participant, the dislike of driving, along with other instances such as her car being vandalised led to the process of giving up the car being a relief to her:

"I wasn't upset about it.. it was more of a relief to me because it was at the stage where I hated driving, and after the car was vandalised in town as well, that put me off too.. it was like a trigger of thinking I can do without this. I'd put it like this, it was more of a hindrance than a help to me in the end" (Penelope)

The other retired female driver expressed similar feelings of relief once she had decided to no longer drive. In this case, this was due to no longer having to afford the expense of driving, along with the removal of stress which was increasing towards the latter part of her driving career: 
“Overall, it's been a big relief to me.. I couldn't really afford the car because at that time I was on my own. Driving was also becoming more and more stressful, so I was glad to get rid of it.. I do still miss the independent sometimes though" (Patricia)

The use of the internet

The use of technology, and specifically online sources, was drawn upon as a positive strategy to compensate for driving, amongst some current and retired drivers. In a sense, some participants felt they could still independently meet their needs in a virtual way. Various uses of the internet were mentioned, although the most popular aspects talked about were social media, largely in respect of Facebook and Instagram, online shopping, and using the internet to look up information or to pursue personal interests:

"My daughters put me on to Instagram and Facebook.. I suppose it is good because I get to see all the things which are going on with people then.. that's the main way I find things out these days" (Alice)

However, another side to using the internet as an alternative to driving was drawn upon by the same participant, referring to a less positive experience:

".. although it's good in a way, I do find that it can pull me down no end looking on there.. I can see everyone else that's my age who's out and about, any everyone's having a lovely time, and it's just a reminder that I'm stuck in again, like a sad old woman" (Alice)

One current female driver talked about how she would increase her current use of social media, as a way of keeping engaged with her family who are not living nearby, in the event of driving cessation:

"I joined Facebook so I can find out more about what's going on with my brother and his family, they live in *******, so I often go on to have a look at what my niece has been up to. And I think I definitely would increase my interest and shall we say 'skills' with Facebook if I gave up driving, because I wouldn't see them as much in that case" (Maida) 
A number of retired older drivers also referred to the use of social media as something which was used as an alternative to driving. The following participant had learnt how to use sites such as Instagram and Pinterest, in order to try and pursue interests from her own home, since she is no longer physically able to meet all of her needs:

Another retired male driver also talked about using online banking and shopping for DIY items, which acts as an alternative to physically going to the shop to purchase goods since giving up driving. However, the participant recognised that his confidence using the internet has largely been based upon the fact he is still working, and uses a computer in his day to day job. Also, there are negative aspects as using the internet as a replacement to driving, particularly in relation to timing and deliveries:

"Well I do online banking, I was doing that before I lost my licence.. and it helps I work on a computer at work all day.. and I now buy quite a lot online for the DIX bits I can do at home, the trouble is the waiting for them to be delivered, whereas before I'd be in the shop buying what I needed and driving away with them" (Ernest)

Another current male driver also recognised the importance of using the internet, although this was something which the participant did not want to do out of choice. Instead, it was recognised that the use of the internet has become a necessity in society, as basic communication strategies like using the telephone or writing are no longer viable options. However, the participant also noted he is 'computer illiterate', and has experienced difficulties with other methods of technology, such as his mobile phone. In this case, the participant has been proactive and put himself forward for classes to learn how to use an iPad, although the first experience left the participant feeling embarrassed due to his complete lack of knowledge within this area.

"Ohh gosh, now I'm computer illiterate. Now, I had a mobile phone, and it's still there wrapped in tape show me. But I've started going to the library for computer beginner classes because that's the ways things are now.. www. This, and www. That.. there are no phone numbers to ring on the TV anymore! But anyway.. I went down this morning and started and I was the only one that didn't know how to turn it on.. I thought, they must all think I'm 
crackers! I think I'm making a fool of myself! And I thought of that old expression, you can't teach an old dog new tricks!" (Gordon)

Additionally, the participant also recognised the internet as only being a partial alternative to physical mobility, as actual social contact is of most importance:

"I don't think it's good to stop going out altogether and just use the internet anyway, I always say, a person's smile can brighten up your day. And I always chat to the girls on the check out in Morrison's, they know me there now!" (Gordon)

However, some participants were less positive or forthcoming about the use of technology as an alternative to driving. For example, a current male driver living in a rural area talked about having issues using his basic mobile phone, resulting in the thought of online sources being problematic. Another current male driver talked about being completely mistrusting of using the internet for any of his needs, due to the risk of cyber crime:

"I won't use the internet for anything, I don't like the thought of it because you hear of so many older people being scammed for this and that, I would rather do things the old traditional ways, like go into the bank, and go and buy my food" (Derek)

The above findings section relating to current and retired older driver's perceptions and experiences of giving up driving demonstrates how complex this process is. There have been a number of commonalities identified between participants, including those of different ages, genders, and socio economic statuses and contexts. There were also a number of specific findings identified. For example, those respondents who had given up driving voluntarily had improved subjective outcomes, compared to those who were told to stop driving by a third party. Also, it was revealed that the perceptions of current drivers in relation to what they think driving cessation will mean to them, were actually confirmed by those who had already given up driving. Nevertheless, there were specific themes which were pertinent to just one group of older adults. 
Overall, findings have demonstrated the highly complex and interlinked nature of the process of driving cessation, lending support to the fact that older people need to be supported on an individual level, as a one size fits all approach would not be an appropriate response through policy and practice. 


\section{Older people's perceptions and experiences of informal support throughout the driving cessation process}

After identifying the need to explore informal support throughout the driving cessation process as a solid research gap, a number of findings became apparent amongst current and retired older drivers. Similar to exploring the meaning of driving cessation, current older drivers drew upon their prospective views of informal support as an alternative to driving, whilst retired older drivers drew upon their lived experiences of informal support, once driving cessation had occurred. However, analysis revealed a more complex picture than originally anticipated. For example, informal support was something which occurred in the lives of many of the older participants, without the influence of driving cessation. Nevertheless, three distinct categories were identified overall. These categories have been outlined below.

\begin{tabular}{|l|l|}
\hline \multicolumn{1}{|c|}{ Category } & \multicolumn{1}{c|}{ Main \& sub-themes } \\
\hline $\begin{array}{l}\text { Reasons/Motivators for using } \\
\text { support }\end{array}$ & \begin{tabular}{l}
. Pre-existing support \\
. Limited personal mobility \\
. Public transport limitations \\
. Social interaction, engagement \& support \\
. Visiting mutual destinations/shared interests \\
. Reassurance \& feeling cared for \\
\hline $\begin{array}{l}\text { Reasons/De-motivators for not } \\
\text { using informal support }\end{array}$
\end{tabular} $\begin{array}{l}\text {. A 'limited' informal support network } \\
-\quad \begin{array}{l}\text { Migration of immediate family members } \\
\text { Ageing without children }\end{array}\end{array}$ \\
\hline
\end{tabular}




\begin{tabular}{|c|c|}
\hline & $\begin{array}{l}\text { - } \text { Relationship breakdown } \\
-\quad \text { The loss of friends in later life } \\
-\quad \text { Growing old alone } \\
\text {. Protection of independence \& self-reliance } \\
\text {. Informal support as only option }\end{array}$ \\
\hline Coping strategies & $\begin{array}{l}\text { Rationing support } \\
\text { Pragmatism } \\
\text {. Expressing gratefulness \& gratitude } \\
\text {. Reciprocation } \\
\text {. Trip chaining } \\
\text {. Suggesting \& recommending trips to network } \\
\text { member }\end{array}$ \\
\hline
\end{tabular}




\section{Reasons/Motivators for using support}

Pre-standing support

Older participants frequently noted they had been receiving support from their informal support network members before driving cessation had occurred. This type of support ranged from practical help with domestic duties in the older adults home, social contact over the phone, to the occasional provision of lifts, covering both practical and leisure based needs. It is important to note that no older adult suddenly began receiving informal support as a direct result of driving cessation. Each person reported a pre-standing relationship with their network members, which covered different types of support which was ongoing regardless of driving cessation:

"I've been going to Yvonne's for Sunday lunch for years, that hasn't changed" (Belinda)

Another current driver drew upon a wide range of support which is received from his adult children, regardless of the fact he is still an active driver. This included transport provision from his adult son who is the only driver amongst his children, as well as help at home and over the phone from his other three children:

"Bernie comes to clean for me on a Saturday, and Diane comes as well to change the beds or whatever else it is that they do.. and her and * ring me twice a day, every day! Peter comes here every Sunday after church with Jake, and we go to the ****** pub quiz on a Sunday night together too, he picks me up from the [name of local football team] when there's a home game too.. Chris then rings me once or twice a week from abroad to see how I am!”

\section{(Gordon)}

Other current drivers talked about the fact that although they were actively driving at the time of interview, previous recent health problems required them to lean on their informal support networks for help. The following male driver also drew upon an element of mutual support which is present between himself and his siblings: 
"When I was in hospital with my leg ulcers, my brother and sister came to get me and took me to stay down with them in ******** I couldn't do anything for myself I was in so much pain. I think they'd definitely help me if needed, as I would for them" (Grahame)

A similar account was provided by another current male driver living in a rural area. However, in this case, the participant reported his pub landlord as being his closest provider of informal support, who has previously helped him, and would continue to do so in the event of driving cessation:

"I couldn't drive for a good few months after I had open heart surgery, I was very very ill. But Malcom took me everywhere, all my hospital appointments, shopping, back and for the pub, you name it.. so because I've been through that, I know I can call on him again" (Barry)

\section{Limited personal mobility}

Limited personal mobility was drawn upon as a direct reason for utilising informal support as an alternative to driving, once participants had lost the ability to drive their own cars. Many of the retired drivers talked about physical health problems being the primary reason for giving up driving, also preventing the ability to walk or use public transport systems. The element of personal assistance and the accommodation of retired drivers physical mobility needs were recognised as important factors when receiving lifts from family, friends and neighbours:

"I can't use the bus or walk, I need door to door transport because I can't see anything at all now, my vision has completely gone, so I need door to door help. That's why I'm stuck in here most of the time, unless my mate takes me to the club once a week" (Christopher)

A retired female driver reiterated this point, and noted that feeling safe with her niece as her primary transport provider was something which was highly valued. This was even more significant for this participant, due to a continued decrease in health status, and previous experience of falling whilst out walking. In this case, the participant viewed informal lift provision with her family member as the only suitable mode of transport since she no longer has the ability to drive herself: 
"Lynette is the only person I normally go out in the car with now, I had one heck of a fright a few years back because I fell on the pavement when I was out posting a card, I ended up in hospital too... that really rocked me" (Beatrice)

A retired female driver who was still active in terms of her ability to walk and use public transport also recognised that whilst her current situation is desirable, and does not require much support from her family and friends, this situation is likely to change as the participant continues to age, resulting in the need for help relating to her physical mobility:

"Even though I am fine now, and I manage to do mostly everything myself without help, that doesn't mean to say that my situation won't change, I tell my son.. I say to him 'be grateful I'm not taking you up on your offers now'.. because if my health goes, which is something which is bound to happen because I'm 70 next year!.. I will need them to help me a lot more then" (Patricia)

\section{Public transport limitations}

Some participants drew upon restrictions relating to public transport as important triggers for using informal support following driving cessation. The implications of living in a rural area were drawn upon by two respondents, resulting in a very limited bus service. The infrequency of the bus service, combined with restricted operating times contributed to the bus being an unfeasible alternative to driving for both respondents. For one participant, this has contributed towards his complete reliance upon his spouse for all mobility needs. However, although recognising the paramount importance of this form of transportation, the participant talked about how this also results in feelings of frustration:

"To my wife, taking me to \{named DIY stores\} to get what I need is trivial, but to me, being able to do that is everything! She doesn't think going down the hairdressers and gassing for 2 hours is trivial!" (Ernest) 
Another current female driver also stated that without driving, herself \& her husband would be cut off from society, due to the significantly restricted bus service which operates within her local area:

"Well, we would be in complete dire straits really if I was stopped to drive. The bus service here is useless, it's for working age people, it runs once a day as far as I know!" (Daphne)

Another current female driver who actively uses her local bus once a week by utilising her free bus pass, mentioned that although her service suits her needs at present, this is not something which would serve as a complete alternative to driving in the event of driving cessation. In this case, this was down to the current bus service not providing direct routes to the hospitals within the local area, requiring the need to plan and organise bus times:

"I use the bus once a week now.. I go into town once a week. The only thing, if I had, say, a hospital appointment, there are no direct bus routes which run from the top of my road to either of the hospitals in ********, so it would mean a bus into town and a bus out, and looking into all that to make sure I didn't miss my appointment" (Maida)

Other retired drivers who lived in more urban contexts also talked about barriers relating to public transport, contributing towards their usage of informal networks in order to meet mobility needs. For one participant who gave up driving due to declining eye sight, the practical requirements of using a bus were drawn upon as problematic, also resulting in more negative psychological barriers:

"I can't see bus numbers if a bus is coming from a distance, or read bus information in the [named bus station]. It's the not seeing and the not knowing whether you are on the right bus, or if you are travelling on the correct route which frightens me, I feel really stupid"

$$
\text { (Alice) }
$$

\section{Social interaction, engagement and support}

An important aspect of informal support drawn upon by all retired drivers was the social interaction and engagement which normally came along with this type of 
support. For some participants, this acted as both a trigger for using informal support, as well as being recognised as a positive outcome. For example, the following participant stated that having lifts with her daughters provided an opportunity to fulfil her psychosocial need for social engagement, acting as a positive motivator for using informal support:

"I don't see them [daughters] both as much anymore because they've moved out, so at least I get to see them when they come to get me to go shopping or whatever it is we do!" (Alice)

However, the social interaction associated with transport provided by family members was experienced differently for another retired female driver. In this case, the participant occasionally had lifts from her husband to meet her mobility needs, sometimes travelling to places where the participant previously visited when able to drive, such as the town centre. However, this trip used to include other female relatives and friends, which the participant would pick up on the way into the town centre. The participants spouse trying to mirror or recreate this trip has not had the same outcomes for the retired driver, in terms of providing an opportunity for social interaction and engagement:

"I used to go into town twice a week with my cousin and my friend I'd pick up on the way.. we'd always have a coffee and have a look around, take our time.. now when he takes me he waits in the car for me because he hates shopping.. so I don't bother going anymore because

$$
\text { I've only got to rush back" (Belinda) }
$$

Reflecting the perhaps less positive outcomes of utilising informal support in relation to participant's psychosocial needs, the experiences of a retired male driver further illustrated this issue. A participant recognised the importance of accepting a lift and going out with a friend on a weekly basis in terms of maintaining a connection to the social world. However, although providing the opportunity for social contact, this outing is not something which actually provides the participant with much social interaction, although he continues to go to feel like he is still part of society: 
"Well an old mate of mine he comes to get me once a week on a Thursday and we go down the [named] social club for a pint, it's alright down there - but it's very clicky, I just go to get out of here to be honest, otherwise I wouldn't go anywhere or so anything" (Christopher)

For other retired drivers, informal support was talked about as something which was utilised for a less instrumental purpose, such as the provision of lifts, and more as a source for psychosocial support following the driving retirement transition. The following female participant talked about her best friend's ability to listen and support her on an emotional basis as being of crucial importance to her, which also acted as a trigger for utilising this type of support:

"I have leaned on him so much throughout it all, he listens and he understands me when I feel low, and isolated, and trapped.. which I often do these days. I know I can pick up the phone and ask him to call over or have a chat with him which means a lot to me" (Alice)

\section{Visiting mutual destinations/shared interests}

A finding amongst current and retired older drivers related to whether or not there were shared interests with their informal support network member, or whether there was a pre-arranged visit to a destination by the network member, in which case the current or retired older driver may go along. For example, a current female driver talked about being 'more inclined' to ask her best friend for a lift somewhere, if she knew her friend was visiting that place anyway:

"I may be more inclined to ask Christine if I could go along to say to Tesco, if I knew she had planned to go there anyway" (Maida)

The importance of travelling to a mutual or shared destination was also highlighted by a retired female driver, who travels to her workplace with work colleagues. In this case, the participant also mentioned how two close friends within the workplace visit a nearby supermarket during their lunch hour once a week, whereby the participant joins them to pick up any times which may be required. The participant also noted how she would still go along with both friends to the supermarket, even when there 
was no need to buy anything. This trip was seen as an opportunity for escapism, recognising the loss of this attribute following driving cessation:

"Nancy and Damien often go to Tesco on a Friday lunchtime, and I go with them if I know they're going to get nice bits in for the weekend. Even if I don't buy anything, I go along just to have a break out of the office!" (Alice)

\section{Reassurance E feeling cared for}

A number of current and retired older drivers talked about reassurance as an important factor which was provided by members of their informal support networks. For a retired female driver, the feeling of being cared for and looked after by her immediate family, including her spouse, was expressed:

"I know they would do anything for me, and I appreciate it no end" (Belinda)

Another retired female driver provided a similar account, recognising that although her present health and mobility status means she is self-reliant, with a high level of personal independence, the fact that her adult children are there as a safety net was mentioned, to help with her mobility needs:

"Even though I can manage on my own at the moment, I know he would be there if I ever needed him... if there is anything at all I do need, I can just ring him up" (Patricia)

A current male driver also mentioned an element of reassurance in relation to the support provided by his adult children. This was recognised as a trigger for utilising informal support in the event of driving cessation:

"I know my children are there for me, and they are wonderful to me.. so if I needed any help, of course they'd be there" (Graham) 


\section{Reasons/barriers and de-motivators for not using informal support}

A 'limited' informal support network

- $\quad$ Migration of immediate family members

A number of current and retired drivers talked about at least one of their adult children living a significant distant away from them, including countries abroad, and different parts of the UK. In each case, this was largely for educational or employment purposes. For some older participants, the sheer distance between themselves and their network members was highlighted as an obvious barrier in terms of accessing instrumental support:

"Well neither of my children can help me out in anyway, because my daughter lives in *****, and my son is in *************! They both went away for university, and found jobs where they were, and have settled.. you can't blame them, there are so little job opportunities here!"

(Ernest)

Although practical support was not possible for some, the maintenance of social contact with closest family members who lived away was viewed as a source of informal support in itself. This was highlighted by a current female driver, who stated that any advice or support relating to driving cessation would be provided by her brother, as part of their regular phone calls to one another:

"My brother and his family live in *******so I don't see them very often at all. Obviously he wouldn't be able to help me out regularly with my shopping or whatever if I gave up driving, but he would absolutely be there for me over the phone as he is now, and it would be him I would turn to for any help or guidance if it comes to giving up, I can talk to him about things" (Maida)

For another current female driver, alternative technologies were drawn upon as a way of keeping in contact with her adult son who lives abroad. Although the participant recognised this as a crucial factor in terms of social engagement with her son and his family, the participant stated that any support which may be required in 
relation to driving cessation would be provided by those family members and friends who are physically nearby:

"Simon lives out in *********, so we either Skype or FaceTime maybe once a week, to tell me all the goings on over there. I get to see the little one then as well" (Molly)

However, for another retired female driver who had a sister living over an hour's drive away, her experience revealed that instrumental support was still provided, despite the distance, albeit this was not on a regular basis, and was mainly during times of need:

"I hardly go up anymore because I no longer have my car, but they still visit me a ferw times a year.. and when I moved flat a year ago, they drove down and helped me move my things into a storage unit, and took me back with them to live there for a few weeks whilst the building work was being done" (Penelope)

- Ageing without children

Another crucial point raised by some older participants, in relation to barriers associated with the provision of informal support, was not having children of their own. Two of these participants drew upon this factor as significant in terms of there being a lack of support in later life from this type of source:

"I've never had children of my own, that's why I turn to Lynette [niece] so much, I don't have anybody else" (Beatrice)

However, the same participant also talked about her niece having so many other roles and responsibilities in her life, which acts as a barrier in terms of the support which is available for the participant, particularly since driving cessation has occurred:

"Lynette works full time, and does a lot for her husband because he's not well, and her daughter has just had a baby, so she is busy with them a lot of the time because her daughter still lives home" (Beatrice) 
A current male driver also talked about the connotations of not having his own family to turn to, and what this has previously meant in relation to support that was required when driving was given up temporarily due to serious health complications:

"I'm a man on his own, I've never been married, so I've never had children. I suppose it is important when you come to the grand old age that I am, to have family around.. but it just never happened for me.. that's why Mal in the ******** is so good to me" (Barry)

For one current female driver who also had no children of her own, an important point was drawn upon in relation to the age of the provider of informal support. In this case, the participant recognised that never having her own children meant that she would become more dependent on those closest to her, including her best friend. Nevertheless, the participant recognised that because her friend was the same age as her, this may be a barrier in terms of the provision or sustainability of support. The participant noted that it is important for older people to know 'younger people', as this would be a more reliable source of support in the event of driving cessation:

"As I've said, ********* would be the one I'd rely on for the most help, but saying that, ******** is getting older herself.. who knows, maybe she will have to give up driving before me! We've both got our [health] problems! I think it's important for older people.. like me.. to know younger people that can help them" (Maida)

\section{- Relationship breakdown}

Four current and retired male drivers talked about a breakdown in relationship with those who they deemed to be important in terms of comprising their informal support network. This largely included their adult children, although one participant who had never been married or had children of his own drew upon the loss of a relationship with his brother as something which caused him great upset and regret:

"I've got a brother, he doesn't live to far from me.. but his wife won't let me see him! He was my best best friend, we used to have a drink together regularly.. I really really miss him"

(Barry) 
Another retired male driver who had given up driving due to the sudden loss of his eyesight drew upon the fact that although informal support was desirable and would be the most appropriate alternative to driving, this sadly was not an option. The respondent talked about losing his spouse several years ago, along with a complete relationship breakdown with his daughter and granddaughter as barriers for using informal support:

"I'm on my own, I don't have nobody to turn to.. as I said, I lost my wife 5 years ago, and my daughter.. well, she's another story! And my granddaughter's the same" (Christopher)

Two current male drivers noted similar experiences in relation to a breakdown in the relationships they once had with their adult sons. This was highlighted as a barrier to using informal support to meet their mobility needs:

"My daughter, maybe she would help if I lived nearer.. but my son, not a chance! We used to be close, and over the years we have just gone further and further apart. I don't even hear

$$
\text { from him" (Grahame) }
$$

- $\quad$ The loss offriends in later life

In relation to participants drawing upon friends as a source of informal support in later life, this was not an option for some current and retired older drivers. For example, when asked about social relations with friends, many reported no longer having any friends due to many people their own age passing away:

"I don't really have any friends anymore, they've all passed away.. I was a miner see, and a lot of my mates contracted chest and lung diseases, so a lot of the boys I worked with have all gone now" (Derek)

Another retired female driver drew upon a similar account, and talked about how the large majority of her friends have passed away, further emphasising her reliance upon her family for informal support: 
"A lot of my friends, and my aunty, who was more like a sister to me.. have all gone now.. so I don't have the option for friends to help me, it's all family" (Belinda)

However, for the 'youngest old' females within the current sample of older people, these participants reported larger groups or numbers of friends, which were recognised as important in terms of being there to provide support to meet individual mobility needs. The following female driver talked about how she has a group of friends which she has known for many years, as well as a more recent group of friends, which she has met through frequenting the same local coffee shop on a daily basis. In this case, members of both groups currently provide the participant with social support, and could also be called upon for practical help if necessary:

"I've got a group of friends I've known most of my life that I'm still in regular contact with, they either come to mine and I cook, or I go to one of theirs and they cook, we do that quite a lot.. and I've got a new group of friends then that I've met through coming here [coffee shop] every day! We meet up once a week over in Nero's, to have a catch up and a good chat. As I said, I am managing as I am for now, but I know any one of those lot would help me in any way they could" (Patricia)

Although one retired male driver talked about a 'mate of his' visiting him on a weekly basis to take him to the nearest social club, the participant described this individual as more of an acquaintance, and somebody who he would not ask for any other type of, or additional levels of support from:

"My mate I told you about that comes for me once a week normally to go to the club, he's more of an acquaintance really. We used to work together, but we are not close of anything, we have a bit of a chat if we go to the club, but I wouldn't ring him up for anything apart from that like" (Christopher)

- Growing old 'alone'

An important factor highlighted by current and retired older drivers in terms of the provision of informal support, was their marital status, and living arrangements. Amongst the sample of older participants $(n=15)$, many were single and lived alone. 
This was the result of divorce $(n=3)$, widowhood $(n=5)$, and having never been married $(n=1)$.

Due to divorce and immediate family living away, a current male driver talked about how living alone has meant that informal support is not something which currently is, or would be easily accessible to him if driving cessation occurred. The participant also related living alone to not being thought about by others, both acting as barriers for the provision of informal support:

"Apart from my brother and sister that live away, I don't have nobody.. And because I'm a man on his own, I'm not at the centre of anything.. well, at the centre of other people's

$$
\text { thoughts then!" (Grahame) }
$$

A retired male driver also talked about how being widowed and not having close family members available to support him with his health and mobility needs, has resulted in him relocating from his family home to supported living accommodation:

"I lost my wife about 5 years ago.. so I don't live with nobody now. this is why I've had to move in here [support living] with my eyesight going.. I haven't got close people around me often enough to help me with everything I need" (Christopher)

\section{Protection of independence E self-reliance}

Two female participants shared similar experiences in terms of why informal support is not something which is drawn upon very often as an alternative to driving. In this case, both respondents talked about independence being something which was highly valued and protected, resulting in a self-reliant attitude which does not require help or support from others. However, the following comment from another participant does acknowledge that independently meeting her needs is something which is only possible because her current health and mobility status allows this: 
"At the moment, I don't need any help.. I'm physically OK.. I'm not saying that won't change as I get older, but I want to be as independent as I can, for as long as I possibly can!"

(Patricia)

This participant also talked about the advantage of living in very close proximity to shops, services and friends within her local area, which allows her to continue to be self-sufficient to meet her mobility needs:

"I meet my friends once a week for coffee, we go to [coffee shop name] over the road or sometimes they come to mine for a coffee depending on the weather.. it's lovely to meet up and catch up with them" (Patricia)

This approach to meeting personal needs was also shared by another participant, although this participant did state the occasional form of instrumental support is received from her son at particular times of the year, when there is a 'need'. For example, the participant talked about asking her son to provide her with a lift to get shopping at Christmas time only, when there are heavy items to carry, which the participant couldn't manage using her usual public transport mode:

"I do ask [son] to give me a lift home from town on a Christmas time when I try and do one big shop to get the majority of gifts out of the way, or if I'm buying a few bottles of wine.. the car is needed for that. I couldn't get everything home on the bus" (Penelope)

A current male driver living alone also emphasised a fierce sense of independence, which was related to the fact the participant lived alone, and has always been selfreliant:

“.. the way I see it right, is that I've always managed myself, because I've had to.. and I don't want that to change!" (Grahame)

Another current female driver living in a rural area also presented a strong sense of personal independence, and a real reluctance in relation to utilising informal support in the event of driving cessation. When asked about using the help of others if the ability to drive became restricted in the future, the following response was provided: 
"I am completely independent, I do everything for myself $\mathcal{E}^{\circ}$ my husband.. I don't need help from anyone! There's nothing wrong with me!" (Daphne)

Informal support as only option

Current and retired older drivers held fairly common perceptions surrounding what it means, or has meant, depending upon their informal support networks for help across the process of driving cessation. For the most part, participants interpreted this feeling as being a 'burden' on others, acting as a complete deterrent when utilising this type of support. For example, one respondent drew upon the social contact he has with his grandson on a weekly basis, where he calls to check on the participant and asks if there is anything which is needed. However, the participant talked about not asking his grandson for any type of instrumental, practical help because he is working hard to focus on his career, with the participant stating this is what his grandson's focus should be, rather than him becoming a burden to him:

"I don't like to ask, he offers to help, but I don't like to put upon him.. he's working hard trying to get a career and earn a living.. I'd always rather do things myself like" (Christopher)

This point was reiterated by a retired female driver, who recognised that lifts are needed and desirable at particular times, although this is something which the participant will not actively act upon or ask her son for, through not wanting to place any strain or pressure on her son:

"There are lots of times throughout the week where I may need a lift home from there [son's home ] after babysitting the children all day, particularly when it's getting late or its dark and raining, but I won't ask because I know it would put him out and cause stress there"

(Penelope)

The same participant also talked about how she often misses the opportunity for social events, through feeling an utter sense of reluctance to ask her family for lifts: However, the participant recognised that through not asking others for support when 
it is required, this results in a real lack of fulfilling opportunities when they present themselves:

"I don't go out in the evenings anymore, but they do have different events on at church, I can't get there in the evenings though, I don't want to be a hindrance to my family, when they are settling down to relax in the evenings. I think to myself then, if you don't ask people then, you are going to staying in and you're not included in anything then!" (Penelope)

Another retired female driver provided an almost identical account, referring to feelings of being a burden resulting in a reluctance to ask her closest network members for the provision of lifts, which includes social engagement and company:

"Put it like this, I feel like I'm stuck in a never ending circle of viciousness.. I don't want to ask them, [two adult daughters] because they are busy and have their own lives, then if I don't ask, I go into my little shell, and can feel that depressed feeling coming on" (Alice)

However, the same participant also recognised that because of her declining health and mobility status, which triggered driving cessation, informal support is the only suitable alternative for her, in order to meet her mobility needs. Nevertheless, relying upon this type of support was drawn upon, in terms of the impact which this has upon the providers of support:

"I feel like just a complete and utter massive, massive burden to them [two adult daughters]. But they are the closest to me, and the ones I turn to for the most help with everything now, because I have to accept the fact, I am dependent now! But it's just a nightmare all around, for all three of us.. they feel guilty because they know I don't get out anymore, and I feel guilty for asking them to take me places, it's really difficult” (Alice)

Although the majority of older participants drew upon the negative feeling of being a burden, often resulting in a sense of reluctance to ask for informal support, another current male provided an opposing account of what it would mean to become more dependent upon his family in the event of driving cessation: 
"I'm not afraid to ask any of them [three adult daughters] for help if I have to give up driving. The way I see it, is that I've always helped them over the years, and I continue to help them when I can.. like last Saturday, Heather was short staffed in the pub.. so I went up to help behind the bar for a few hours.. so it's their turn to look after me then when I need it"

(Donald)

A current female driver provided a similar response to Donald, and talked about being comfortable asking members of her local community and church for support, in the event of driving cessation:

"I'm not completely averse to relying upon other people. I don't think I would find that bit of giving up driving a problem. We have a close unit in the church, and I do feel like I would be looked after" (Maida)

\section{Coping Strategies associated with usage of informal support}

A number of retired drivers talked about employing coping strategies as a way of offsetting some of the negative aspects of using informal support as an alternative to driving.

\section{Rationing support}

A retired female driver talked about how she 'rationed' her sources of informal support, meaning that there was a maximum amount of support which the participant would request or use each member of her informal network for. This was talked about as a way of reducing the chances of exhausting individual channels of support, ensuring each support provider did not become overwhelmed:

"I try and ask both my daughters to take it in turns to take me food shopping, or into town, whatever.. I also try and pick things up when I'm with my friends if we are out and about, to save the girls taking me.. otherwise, that's when the stress starts!" (Alice)

Another participant also talked about how she feels the need to place limits on the amount of support which is received from her niece, as her only source of informal 
support. In this case, the participant tries to ensure she is as prepared as possible when seeing her niece, to get as many needs met at once:

"If I know she's [niece] coming here, I try and get as many things done that I need to. I ask her to pick me up what I need because I know that once she's gone back to *********, she wouldn't be happy if I rang again for things" (Belinda)

Rationing informal support was something which was not possible for all participants as a way of managing or sustaining this type of support. A participant talked about how he only draws upon his spouse for all transport and mobility needs, even though both sisters offer to provide support. Therefore, the option is not there to limit or share out informal support:

"They offered to take me and pick me up from my opticians appointment which was in [name of town], but I wouldn't want them to take me. Josie takes me everywhere I need to

$$
\text { go" (Ernest) }
$$

\section{Pragmatism}

Participants talked about how they tried to adopt a pragmatic approach to utilising informal support. For example, although one participant is mostly independent in terms of meeting her mobility needs, the occasional lift to places which are a bit more difficult to get to is required. For example, she attends church every week, although the reduced frequency of public transport on a Sunday, as well the church being located a fair distance from her home means that a lift is required. She talked about how she was offered a lift by a fellow church member, although this was only accepted because the lift provider lives nearby. The participant talked about not wanting others to go out of their way for her:

"Well I do need a lift to and from church on a Sunday, it's too far for me to walk now.. so when [church member] offered, I said yes because I know she lives nearby and I am on the same route she takes to get there, I don't feel so bad then" (Penelope) 
Accepting lifts from work colleagues who live nearby was something which was also echoed by another participant, who only has a lift to and from work by those who either live nearby, or who are passing her residential area on their commute to work:

"I get a lift with Sue or Joanne because Sue lives a few streets away, and Joanne passes my house on her way to work" (Alice)

\section{Expressing gratefulness $\Xi^{2}$ gratitude}

Some retired drivers talked about the importance of expressing their appreciation for the support provided by their informal network members. This was stated as a way of making sure the support provider feels appreciated and valued, as some participants recognised this type of help isn't something which all older adults have access to:

"She's good as gold to me she is, I always tell her that as well, I say Yvette 'I don't know what I'd do without you'.. I don't know what I'd do without any of my children. Some poor people haven't got that see, I'm lucky!" (Belinda)

\section{Reciprocation}

Reciprocation was drawn upon by retired drivers as something which is employed in relation to utilising informal support as an alternative to driving in later life. A retired female driver talked about reciprocation as something which is heavily employed as a coping mechanism for using informal support. The participant stated that reciprocal strategies are employed to all network members who are drawn upon, particularly for those who play an instrumental role in terms of meeting her mobility needs. In this case, an example was provided relating to car lifts which the participant gets with a work colleague who lives nearby, in order to successfully complete the commute to and from. The participant talked about ensuring she always 'offers petrol money', along with buying the lift provider gifts on annual occasions such as birthdays and Christmas. This was perceived as a way of paying back the help which is received by the participants work friends: 
"Neither of them will ever accept petrol money, so I make sure I always buy them nice things for Christmas and their birthdays. Also Joanne had her first grandchild a few months back, and I made sure I bought a little something for the baby. It's the only way I can think of to thank her" (Alice)

Aside from practical and tangible forms of reciprocation, the same participant stated she also plays a psychosocial role in terms of the help and support she provides back to those who support her, recognising that she is able to provide others with support, even though this is no longer instrumental, such as the provision of lifts. Examples of this included listening to, and advising friends over the phone, by offering support whenever this was required:

'I know I can't really 'do' anything for people anymore, but I try and 'do' in other ways. I always try and make sure I am here for people, like on Christmas morning, my best friend called to say he was upset because of a family row that had gone on, so I made sure I reassured him and tried to make him feel better" (Alice)

Another current male driver talked building in an element of reciprocation if driving cessation occurred. In this instance, the participant talked about offering a friend of his within the community a financial incentive if lift provision was required:

"I could call upon Harry if I needed to, he lives nearby and would give me a lift, I'd give him a couple of bob for his pocket" (Gordon)

However, when it came to reciprocation from family members, this was not something which was talked about amongst older participants. For example, when talking about visiting her son and his family, the following retired driver stated:

"When I go over my sons on a Sunday, I sometimes take beers for him and wine for his wife, and sweets or fruit for the kids.. but that's not because I feel like I have to, because they are having me over, it's because I want to" (Patricia)

Trip chaining 
Trip chaining was a strategy employed by the majority of retired drivers, when accepting lifts from family, friends and neighbours. This refers to visiting several places, or meeting several needs during one car trip. For example, a participant spoke about how he ensures his wife takes him to a number of DIY (Do It Yourself) stores and builder's merchants when he knows there is a trip planned:

"Well if we are going to [named DIY store] or something, I always make sure I go to any other places which maybe nearby that I have to go to, to save us going out and doing that

$$
\text { again" (Ernest) }
$$

Another participant who also employed trip chaining as a strategy to try and meet her mobility needs drew upon an important point, which recognises that although this idea is sensible in theory, it is not always possible due to informal network members often having a limited amount of time which they can spend providing transport:

"I try and pick up as much as I can when I go shopping with them. If I'm going to [shop name] I try and go to other shops nearby ... to get other things. They [daughters] are not always able to take me though because they are always rushing back for something" (Alice)

\section{Suggesting and recommending trips to network member}

A participant talked about how she sometimes uses financial or positive incentives of visiting a certain place based upon information which she has to encourage an outing to a particular place for her daughters, which the participant can go along to:

"If I've seen something online or say I've seen good buy on the weekly magazine from Lidl or something, I tell the girls about it and go along with them then" (Alice) 


\section{Chapter 5: Findings}

\section{Informal support network members \& the process of driving cessation}

The following section is based upon the perceptions and experiences of 15 informal support network members, of current and retired older drivers, in relation to how these individuals experience and perceive the process of driving cessation in later life. This included family members, marital partners, friends, neighbours, and wider members of the community. The study included 10 informal support network members of retired older drivers, and 5 informal support network members of current older drivers. A detailed thematic analysis revealed a number of outcomes for these network members, in relation to experiences of the driving cessation, as articulated by network members.

These outcomes included; consideration factors relating to the provision of informal support, and outcomes of the driving cessation process for network members, which included coping strategies. 


\section{The decision-making context of providing informal support: Perspectives of network members}

The first category identified was the decision-making context of providing informal support: perspectives of network members'. This related to a number of consideration factors which the family, friends, and wider community members of older adults referred to. Three main areas were identified relating to these consideration factors. This included the older adult's specific circumstances, the informal support network members specific circumstances, as well as relationship factors. Each consideration factor either acted as a motivator when providing support, or a de-motivator. However, in some cases, these factors acted as both motivators and de-motivators, demonstrating the nuanced nature and complex reality of this phenomena.

\begin{tabular}{|c|c|}
\hline Category & Main \& sub-themes \\
\hline Older adults specific circumstances & $\begin{array}{l}\text { Health \& mobility status } \\
\text {. Personality \& character } \\
\text {. Social capital } \\
\text {. The built environment }\end{array}$ \\
\hline $\begin{array}{l}\text { Informal support network members } \\
\text { specific circumstances }\end{array}$ & $\begin{array}{l}\text { Personal roles \& responsibilities } \\
\text { Proximity to older adult } \\
\text {. Awareness of older adults mobility } \\
\text { needs }\end{array}$ \\
\hline Relationship factors & $\begin{array}{l}\text {. Strength \& closeness of relationship } \\
\text {. Mutual support }\end{array}$ \\
\hline
\end{tabular}




\begin{tabular}{|l|l|}
\hline & $\begin{array}{l}\text { Pre-standing support } \\
\text {. Shared hobbies \& mutual interests }\end{array}$ \\
\hline
\end{tabular}

\section{Older adults specific factors \& attributes}

'Older adult's specific factors and attributes' relates to a number of elements raised by informal support network members, in relation to what factors are considered relating to the provision of informal support. This included factors which were directly related to the older adult and the older adults lives.

\section{Health and mobility status}

A number of informal support network members of older adults with health and mobility impairments talked about these issues often acting as a trigger for the provision of support. The daughter of a retired female driver directly drew upon the older adult's poor mobility through deteriorating eyesight and worsening arthritis as key reasons for providing support:

"She has trouble walking, she's got really bad arthritis in her knees which prevents her from walking far, so I take her to most places" (Abigail)

A similar account was provided by the niece of another retired female driver, who talked about her older aunty's worsening health issues affecting her physical mobility:

"She's not able to walk far because she's got so many things going wrong with her all the time, which have just got worse and worse, so I'm really the only one that can take her out"

$$
\text { (Lynette) }
$$

The son of a current male driver also drew upon his father's health issues as key triggers for providing support. In this case, the older adult suffered from a chronic lung condition which had recently lead to prolonged hospital stays, and periods of 
non-driving. The participant described how he provided all transport for the older adult after returning home, as well as meeting his wider needs:

"Dad suffers from idiopathic pulmonary fibrosis, he ended up in hospital for 3 weeks last year and he wasn't able to do anything for himself.. including driving! I took him where he needed for a good while after that" (Peter)

A neighbour of a retired driver also talked about the bus being an unsuitable option for the older adult to meet her needs since driving cessation occurred, hence the participant providing lifts when required:

"I would say lifts with other people is the most suitable option for Alice because her eyesight's really bad, getting the bus would be really daunting on her" (Anita)

Aside from physical health, other network members talked of the older adult's mental health as something which was considered in relation to the provision of informal support. This was drawn upon by the daughter of a retired female driver, who mentioned her mother's low mood is something which often encourages her to provide support:

"If my mother is feeling down, which she often is.. I can't switch off.. I am always texting her or ringing her to make sure she knows that I am only at the other end of the phone"

$$
\text { (Abigail) }
$$

\section{Personality Eं character}

A number of network members talked about the older adult's personality and character being something which was closely associated with the provision of informal support. For example, three network members of a retired female driver stated this as an important element when providing support, with the best friend of this older adult stating this as a direct motivator:

"I am more than happy and willing to help, because basically, she's just such good company, so um. you know, if somebody wasn't such good company then you wouldn't enjoy doing it as 
much for them, and they wouldn't have such a good support network, but ah .. she is a character and it's not a chore then, it's always fun and a good laugh" (Damien)

The positive character of the older adult acting as a motivator to provide support was also something which was drawn upon by the landlord of a current male driver, as he is the older adults main source of support. In this case, the participant plays a pivotal supportive role for the older adult, due to a worsening health problem which has also resulted in the older adult temporarily giving up driving over the last 12 months:

"He's hell of a boy is Baz.. he has me in stitches with the things he comes out with!"

$$
\text { (Malcolm) }
$$

However, for the niece of a retired female driver, her aunt's personal characteristics and subsequent negative outlook on life were something which acted as a deterrent, in terms of how the participant feels about helping her aunty since she has given up driving. In this case, these negative characteristics actually resulted in a reduction of support:

"She's become so negative and bitter since she gave up driving, like she's blaming the world. And she's always moaning she hasn't seen anyone even when I do my best to call in and do things for her, she never says thank you! So I've stopped doing so much for her now"

$$
\text { (Lynette) }
$$

\section{Social capital}

A number of network members drew upon the social capital of older adults as an important factor in the process of driving cessation. For some participants, the lack of a social network around the older person was stated as a direct motivator for the provision of informal support. For example, the landlord of a rural pub who provided numerous types of support to a current male driver, mentioned the fact that the older adult was a bachelor, and had nobody around him to be able to provide support. The need for support had become even more profound in recent years, due to the older adult experiencing serious health complications: 
"He lives on his own, he's never married or had children.. and his sister needs more help than he does.. I'm the nearest one to him" (Malcolm)

A similar account was provided by the niece of a retired female driver, who has always been the older adult's primary support provider, although this has been further exacerbated since driving cessation has occurred:

"She's lived on her own since my uncle passed away about 9 years ago, and they were never able to have children of their own, so I am the only close family member she has, she's my late fathers sister" (Lynette)

Other current and retired older drivers had richer social capital. For some network members, this was also considered when thinking about the provision of support. For example, the best friend of a current female driver talked about her friend being heavily involved within her local community, largely through her lifelong affiliation with the church. The participant stated this was an important factor if driving cessation occurred, as there would "always be someone to help her", living nearby (Christine). Nevertheless, this participant stated that despite the older adults rich social ties, she would still be willing to provide any type of support which her friend may require to meet her mobility needs.

However, for the son of a current male driver, although his older father had a rich informal network around him, comprised of other adult children, neighbours, and members of the community, this did not act as a de-motivator in terms of the provision of support. The participant explained how amongst his other brothers and sisters, he is the only one that is able to drive. This has led to becoming the primary provider of instrumental support, such as the provision of lifts to meet a variety of needs. In this case, the participant explained how his two sisters also provided support to his older father, although this was mainly support associated with domestic tasks, as well as social support:

"We are blessed by the fact that I have got 2 very good sisters as well who are always in contact and come up every week to do things around the house for Dad! But I am the only 
one that drives, so I take him everywhere when needs be.. as well as dropping things off to him.. compost most of the time for the garden!" (Peter).

For other participants, the informal support networks of older adults were not something which were stated as being a trigger, or de-motivator in terms of the provision of informal support. Instead, the social capital of the older person was something which was just appreciated and recognised as being an important factor in the process of driving cessation. For the daughter of a retired female driver, knowing there are people around her mother seemed to provide an element of comfort and reassurance:

“..she has a really good group of friends which take her out, plus myself and my sister.. we try and take her out as much as possible, ah.. but she has got a wide group of friends that provide support, like taking her places so she doesn't feel isolated, and I'm really grateful for that" (Harriett)

\section{The built environment}

The older adult's immediate built environment was something which was drawn upon by network members as a factor relevant in the process of driving cessation. This related to the type of area the current or retired driver lived in, from rural to urban contexts, to the provision of shops, services, and public transport. The son of a retired female driver talked about the advantage of his mother living in close proximity to shops, services, and public transport links. In this case, the participant described his mothers immediate built environment as adequate to meeting her mobility needs, also resulting in a minimal need to provide instrumental support:

"Mum lives a few minutes walk from the village, where she can pick up most things she needs, but she goes into town a few times a week which is easy as well because the bus stop is literally on her door step.. I give her lifts now and again if she asks me, but that's rare because she can get the bus" (George)

However, other network members talked about the immediate built environment being a barrier in terms of the older adult meeting their mobility needs. For example, 
the daughter of a current male driver talked about the rural context which her father lives in being problematic in the event of driving cessation, due to the lack of local shops and services being within walking distance, and the poor frequency of buses services:

"It would be really hard if he gave up driving because there's nothing in the area, apart from a pub and a doctors surgery.. and the buses are so few and far between, we would have to work something out between myself and my sisters because they'd never get by otherwise"

(Sandra)

Although the best friend of a retired female driver mentioned that his friend lived within close proximity to a corner shop, the limited stock and overprices items which are usually available in these types of shops was drawn upon as a barrier for the older adult to get purchase goods. This combined with the older adults deteriorating eyesight and walking difficulties were stated as reasons for providing lifts:

“Alice does live near a corner shop, but she couldn't do her shopping there, everything costs so much and there's hardly any selection there, so she definitely needs lifts to get to bigger shops to do her shopping" (Damien)

\section{Informal support network members specific factors \& attributes}

Informal support network members specific factors and attributes related to individual, personal factors which were solely related to the network member and their lives.

\section{Personal roles E̊ responsibilities}

A number of informal support network members drew upon their own roles and responsibilities when talking about the provision of informal support to the older person, relating to the process of driving cessation. This included familial roles, involving care and support to others, such as being a parent, grandparent, spouse, and adult child, to full-time and part-time employment based roles. 
Some participants talked about experiencing difficulty balancing multiple roles and responsibilities, in relation to the needs of the older adult following driving cessation. For example, the daughter of a retired female driver drew upon finding it stressful trying to balance the needs of her mother since driving cessation occurred, along with caring for a step daughter and working full time. In this case, the participant also talked about having the main responsibilities for running her household, despite having a partner:

“.. my partner has a little girl, and she lives with us.. I do most of the things around the house, the cleaning, cooking, you name it! I work full time as well.. I know Mum can't help it, but she needs a lot of support now and it's really hard" (Harriett)

For other network members, it became apparent that they were providing support to others within their personal networks, as well as to the older adult. For example, the neighbour of a retired female driver talked about how she has always helped others. This included looking after two children alone, providing support to her own ageing parents, as well as being a professional carer as her main employment. Having these other caring experiences seemed to act as a motivator for this participant:

"I have brought my two children up single handedly, I look after my mother and father, they are in their 80's now, and that's without the people at work I care for, but that's my job.. I have always cared for someone really, it's just what I do" (Anita)

Other informal support network members drew upon the fact that currently having less roles, compares to previous stages of their life course has meant they now have more time to invest in providing support for the older adult. For example, when asked about providing potential support to a current female driver in the event of driving cessation, a best friend stated:

"It wouldn't be a problem at all. I don't work anymore, retired years ago.. so it's not as if I wouldn't have the time to do it for Maida" (Christine)

Awareness of older adult's mobility needs 
A number of network members drew upon their personal views relating to what needs they thought were important for the older adult. Overall, network members thought older adults had a range of needs, from practical needs, to more social and leisure based needs.

The holistic nature of the older adults mobility needs was captured in the account of the best friend of a retired female driver:

"Well really, it's important for Alice to get to a lot of different places. Of course she needs to get to the GP, and hospital, you know, that's essential.. but its equally important for her to go out, socially you know. I support I try and play the role of both" (Damien)

The son of a current male driver also placed a heavy emphasis on ensuring his father undertakes a variety of out of home trips. This also covered essential and more social based needs:

"I think the key for Dad is to keep his mind active.. you know, he would just vegetate otherwise. And he's always been so active. I take him where he needs to go, but part of our routine is that we go to the pub quiz every Wednesday night.. he's really sharp! (Peter)

However, although other network members recognized the importance of the older adult meeting their social and leisure based needs particular after driving cessation, this was not necessarily something which was easily embodies by network members:

"I would love to be able to take her out more, even thought she's a stubborn old mule! I don't like to think of her being stuck indoors.. But in reality, I just can't do it all with everything else I have going on" (Lynette)

\section{Relationship factors}

Relationship factors related to aspects drawn upon by network members, which were specifically related to the relationship between themselves and the older adult, bringing together aspects associated with the older adult and the network member.

Strength/closeness of relationship 
The neighbour of a retired female driver talked about how the closeness and strength of the relationship between herself and her neighbour has acted as a large part of the foundations in terms of how she feels about informal support, and how this influences what support is actually provided. For example:

"I mean I've known Alice for nineteen years, I've lived here nineteen years, and Alice has always been the same you know, they've always been in the garden, she's always had parties for the girls, that's how I remember and what my children remember is having all the parties and the girls in the garden, um, and of course her being independent and out and about you know, so um, we've built up a relationship and a rapport between ourselves" (Anita)

The closeness of the relation was also directly cited by the same participant, in terms of how this influences the provision of informal support:

“.. it's something that you sort of roll into because you've got such a good um relationship with her" (Anita)

The same participant continued to speak about the importance of the strength of the relationship between herself and her neighbour. The length of time the participant had known the older adult was also mentioned as a factor which had provided a type of bonding between both individuals:

".. when you have known someone for that long, you get to know them and know their ways. And like I said I would offer more, and I can see that there's something bothering her then, and I'll say oh what's the matter and she may say 'oh my god the girls are out' and I've said right come on then let's go kind of thing" (Anita)

Other participants drew upon this, and noted that if the older adult which they are involved with wasn't as grateful, or as nice to be around, they would feel and act differently in terms of the provision of informal support:

"I don't think oh my god I have to take her now, it isn't like that at all, it's a good relationship, a good solid foundation then for a relationship you know between each other"

(Damien) 
When drawing upon why informal support was provided, or would be provided in the event of driving cessation, some network members drew upon an element of mutual support between themselves and the older adult. This was often talked about in relation to previous exchanges of support which the older adult had provided to the network member at earlier stages of the life course, or current support. This support ranged from small scale, practical help, through to major levels of support, on a more encompassing, psychosocial level. For example, the adult daughter of a current male driver talked about support being something which she would increase based upon current support which is provided to her older father, as this is something which is owed back to her older parent, due to him embodying the role of sole care provider due to the death of her mother at a young age:

"We lost my mother when we were very young, and he became the mum and the dad in every way then, we know more than anyone what he did, and what he gave up for us, we were his life.. we will never forget that, I will always be thankful, and will always look after him, in whatever way that may be" (Sandra)

A number of other adult children who took part in the research also drew upon this element of repaying their older parents for support which they have received throughout their own lives from them. For the following son of a current older driver, his father had experienced a temporary period of giving up driving over the last few years, due to a serious illness. The participant described how this has led him to provide help, including lift provision, as well as help with other support needs relating to his father's specific health condition, such as keeping abreast of medical appointments and prescriptions. This was something which was talked about as the natural thing to do, due to his perceptions about role reversal between himself \& his father:

"He's been a wonderful father to us, I have had two wonderful parents, they've always been there for me, and I have always appreciated them. But Dad's been ill over the last few years, 
so I have been doing a lot more for him, that's the way it goes when they get older, it's my turn to look after him now, like he looked after me" (Peter)

Other network members felt that the support they provided to the older was a balancing act, being equality weighted by the support the older adult provides to them. However, the nature of support had changed. For example, the neighbour of a retired female driver talked about increasing the amount of support for the older adult since driving cessation occurred, as well as the nature of the type of support changing, compared to when the older adult was driving. In this case, the participant talked about an awareness of the older adult not being able to provide any practical support to her, due to poor health and mobility, However, other types of support are provided, which the participant equally needs, outside of her personal mobility needs. This included financial support, such as the loaning of a sum of money, as well as social support, in relation to providing the network member with company and contact:

"Well it [support] has increased hasn't it, of course it's increased.. it's gone from a chat over the wall, or popping into each other's houses, to playing a far more instrumental role for Alice. I take her to and from work, or shopping or to the hospital, whatever I can do to help. She is equally as good to me! She helps me with money if I need it, or comes in for a chat and a nice drink if I'm feeling a bit down or something" (Anita)

\section{Shared hobbies $\Xi^{2}$ mutual destinations}

Network members talked about having shared hobbies or interests with the older adult as something which acted as a solid basis for the provision of informal support in relation to driving cessation. For example, the best friend of a retired female driver talked about having closely aligned interests with those of the older adult, as something which was an enabler allowing the provision of informal support. This included things such as both enjoying days out discovering new places in the UK, such as historic sights and botanical gardens: 
"Well it obviously helps that we like the same things, we both love discovering new places on days out, visiting quintessential English villages, going for nice meals, we are friends, we have things in common.. so that's all part of it really" (Damien)

This also included having mutually common needs to visit the same destination:

"Well we work together thank the lord! So it isn't as bad because we travel to the same place I dread to think what would have happened if we worked in different places once he had to give up" (Josephine) 


\section{Outcomes of the driving cessation process for informal support network members}

A number of outcomes were identified amongst the informal support network members of current and retired older drivers, relating to their experiences of the driving cessation process. Outcomes were a combination of practical and psychosocial aspects, as well as the implementation of coping strategies.

\begin{tabular}{|c|c|}
\hline Category & Main \& sub-themes \\
\hline $\begin{array}{l}\text { Practical outcomes of the driving } \\
\text { cessation process for informal support } \\
\text { network members }\end{array}$ & $\begin{array}{l}\text { Prioritising \& planning } \\
\text { Incorporating new driving practices } \\
\text {. Discovering new places }\end{array}$ \\
\hline $\begin{array}{l}\text { Psychosocial outcomes of the driving } \\
\text { cessation process for informal support } \\
\text { network members }\end{array}$ & $\begin{array}{l}\text { Guilt } \\
\text {. Frustration } \\
\text {. Stress \& strain } \\
\text {. Sense of purpose/contribution } \\
\text {. Social engagement }\end{array}$ \\
\hline Coping strategies & $\begin{array}{l}\text { Trip chaining } \\
\text {. Utilising personal informal support } \\
\text { network } \\
\text {. Protecting own needs and interests }\end{array}$ \\
\hline
\end{tabular}




\section{Practical outcomes of the driving cessation process for informal support network members}

\section{Prioritising E planning}

The network members of current and retired older drivers both talked about the need to prioritise and plan, in order to meet the needs of the older adult. For example, the daughter of a current male driver mentioned the need to plan her own needs, in order to accommodate the needs of her father, if driving cessation occurred.

"It would be a case of prioritising if Dad was to give up driving wouldn't it!? I work full time, but that doesn't mean to say I wouldn't be able to meet his needs. It would just be a case of making lists, so saying to him, right then Dad, what do you need from the shop today!?..

$$
\text { That type of thing" (Sandra) }
$$

\section{Incorporating/Undertaking new driving practices}

Some network members of retired older drivers talked about undertaking new driving practices, since driving cessation occurred. For example, the wife of a retired male driver mentioned how her husband giving up driving has led to her driving on the motorway for the first time in her driving career, as it was now her responsibility to drive to places, which her husband would have previously driven to:

"Since Ernest gave up driving, I have had to get used to driving on the motorway. I've even got to drive abroad when we go away in a few months, and that's something I am not looking forward to because he has always done all the driving - so I have had to be brave"

$$
\text { (Josephine) }
$$

\section{Discovering new places}

Another practical outcome of driving cessation for the network members of retired older drivers was the discovery of new places, through providing transport to places which the older adult needed, or desired to go to. This was highlighted in the following account provided by the best friend of a retired female driver: 
".. as a result of going out in the car more with Alice, I have discovered a lot more places myself, places where I didn't even know existed.. we recently visited a botanical garden, which I didn't even know was there!" (Damien)

\section{Psychosocial outcomes of the driving cessation process for informal support network members}

\section{Guilt}

Guilt was a common finding amongst informal support network members. For example, when a network member couldn't provide support to an older adult, they reported feelings of guilt, which often caused them distress. For one network member, Yvette, it was stated that when she is not available to provide help to her mother since driving cessation occurred, she goes 'out of herself', and will immediately arrange for other family members to step in and help.

Other network members stated they feel guilt for the older person, because of the situation they are in since driving cessation occurred. For example, the adult daughter of a retired female driver stated:

"I always feel guilty about my mother, I hate to think of her being stuck at home on her own.. which she is a lot now that she can no longer drive"(Abigail)

However, guilt was described in a different way for the niece of a retired female driver. For example, the participant stated that the older adult makes her feel guilty when she does visit, through direct comment which are made. This was illustrated in the following excerpt:

“Whenever I go there she always makes me feel guilty! It's always, oh I haven't seen a soul all day.. she just says it straight to me!" (Lynette) 


\section{Frustration}

Frustration was something which was highlighted by informal support network members, when drawing upon their experiences of the driving cessation process, relating to the older adult. For example, despite the son of a retired female driver stating that he provides a minimum level of support to his mother, when he does provide any help, he sometimes finds this difficult:

"The thing is with mum, she's so indecisive, so if she says would you mind taking me to... wherever... when I actually get there, she doesn't even know where she wants to go herself! I do find that frustrating" (George)

A similar account was provided by the adult daughter of another retired female. In this case, a sense of frustration was felt when the older adult visited multiple places when out on shopping trips, rather than just visit one to meet her needs:

"When we go shopping, it's never just going to one place, there are always loads of places where she wants to go, and it is hard because I'm always so busy myself" (Harriett)

The same participant talked about how the older adult failing to organise her own needs adds to this pressure. For example, the respondent thought it would help matters if her mother was more pro-active. In this case, the participant noted this was soften a source of tension between herself and her older mother:

"I have been telling her for ages, please write lists, it would make life so much easier.. but she doesn't and instead there's always last minute running about, because there's always something she's forgotten.. and when I tell her she goes in a bad mood then!" (Harriett)

\section{Stress Eं strain}

Some network members talked about the element of stress they experienced as a result of providing support to older adults, as an outcome of driving cessation. The was captured by the daughter of a retired female driver:

"In all honestly, I do find it really hard.. I am constantly running about doing something, I don't get any time to look after myself, I look at my friends and I think, if only my life was as easy as yours.. I literally have no time for myself between everything" (Harriett) 
The increased responsibility for providing support to her husband following driving cessation was also noted by the following spouse:

"I do feel a lot more stressed now that I need to see to Ernie's needs in addition to my own.. I find I'm always rushing about for something these days!" (Josephine)

Sense of purpose

Other network members reported positive outcomes of providing support to current or retired older drivers. For example, the neighbour of a retired driver states that when she knows she has helped her neighbour, this gives her a piece of mind:

"I feel like I can settle better in the evenings when I know I have gone out of my way, or helped Alice.. she does really struggle now without the car, and I actually like helping her" (Anita)

\section{Social engagement}

Other network members reported that providing informal support was something which provided the opportunity for social engagement for themselves this was related to be the best friend of a current driver, who provides transport to the older adults during medical appointments, This was something which was done with ease in this case through the participant also being retired:

"I like to spend time with Maida, taking her to the hospital, which I sometimes do when she goes for her eye check-ups, it always turns into a social thing, and it's more of a day out then, it's not a problem to me at all" (Christine)

\section{Coping strategies}

Trip chaining

Network members of retired older drivers talked about 'killing two birds with one stone', on relation to trip chaining, as a way of trying to manage the older persons needs. This included visiting several places within one round trip when taking the older adult out. This was related to the needs of both the older adult, and the network member. For example, the daughter of a retired female driver stated: 
"If I'm picking her up from work or something, I often call into the supermarket on my way home.. we can both pick things up then" (Abigail)

Utilising support from personal support network

Some network members talked about drawing upon informal support from members of their own personal networks. For example, the son of a current driver who provides instrumental and emotional support to his older father since he became ill, stated:

"Gaynor understands,. Dad is a priority.. he comes first. I am lucky that we are on the same page with that, as she is with her parents" (Peter)

This draws upon the importance of others understanding the role of providing informal support. Nevertheless, a contrasting account was provided by the daughter of a retired female driver, who stated that her partner is unsupportive of her role, because this is something he has never experiences himself:

"It's even more difficult for me, because my partner doesn't understand what I do for my mother at all.. he thinks it's all too much, but he has never had to do it.. so maybe that's why!" (Abigail)

"I often talk to my partner about how I feel, to get things off my chest. But it's hard because he's never had the responsibilities that I have with his parents, so he doesn't understand and sometimes gets annoyed with how much I do, because of how stressed I get, and how it affects our relationship” (Abigail)

\section{Protecting own needs and interests}

Some network members drew upon the need to ensure they protected their own interests, when talking about their experiences of the driving cessation process. For the wife of a retired female driver, the importance of ensuring she sets boundaries was noted. This related to her trying to maintain parts of her lifestyle which were apparent before her husband had to give up driving. In this case, the participant 
talked about the need to do this 'for herself, recognising her own needs as important:

"I have to say no to some things, and out my foot down, otherwise I wouldn't do anything for me anymore. So, I always make sure I still do things like go and have my hair done because I've always down that" (Josephine)

However, 'putting boundaries' in place was not something which was possible for other informal support network members, as this related to the previous mentioned feeling of guilt. This was depicted by the daughter of a retired female driver:

"Even though people say to take time for myself, to do things that I want to do, it's never as easy as that.. I feel awful if I don't so something for my mother.. but then my social life is affected" (Abigail) 


\section{Chapter 6: Discussion}

The following chapter draws upon previous theory and literature, along with Musselwhite \& Haddad's (2010) hierarchal model of mobility needs, in order to discuss current findings.

The following chapter consists of four sub-sections, structured around the studies overarching aim and objectives. Specifically, this was: 'to explore the process of driving cessation in later life, amongst older adults and their informal support network members'. The following sections have been included; (1) Independence and driving in later life (2) Driving cessation, loss, and continuity (3) Utilising informal support E feeling like a burden (4) Providing informal support and ambivalence.

Overall, key findings from this present study highlight the fact that driving cessation in later life is a highly nuanced, and deeply complex phenomenon. This complexity is explained by the fact that driving and driving cessation are highly individual, personal experiences. Although this thesis has utilised a thematic analysis, where the aim is to look for commonalities within the data, reflecting the fact that there were shared perceptions and experiences, it is essential to note that each older adult was unique, reflecting the fact that they are not a homogenous group, with multiple, complex experiences, thoughts and feelings. In order to explain these overall findings, and provide clarity, the studies research questions have been returned to, answered below by findings from the present study, in relation to previous empirical and theoretical work undertaken on the process of driving cessation in later life, with a focus upon informal support. Additionally, the following diagram (figure 2) provides a visual example of the research phenomena which was investigated within the current doctoral thesis. In this case, it demonstrates current and retired older drivers, as a group which, for the purpose of this section, have been brought together as older adults, sharing the experience of driving, or giving up driving in later life. This group alone have diverse experiences, outcomes and perceptions of driving and driving cessation. For example, some older adults had positive outcomes of driving 
cessation, whereas others had extremely negative outcomes, as articulated by their own insights relating to their experiences. 


\section{The meaning of driving in later life}

Beginning with research question 1 - what is the meaning of driving to older people, findings from the present study reveal that current and retired older drivers have diverse experiences. Driving was described in the context of 'needs', as well as 'outcomes'. For example, some participants talked about the need to drive, because it allowed them to do certain things, whereas others talked about outcomes that were derived directly from driving. Both concepts capture the essence of what driving 'means' to older adults.

Overall, findings from the present study were to an extent consistent with Musselwhite \& Haddad's (2010) hierarchal model of mobility needs (see figure 1). For example, participants drew upon the importance of driving to meet their basic (utilitarian) needs, as well as driving being something which was part of their selfidentity (affective needs).

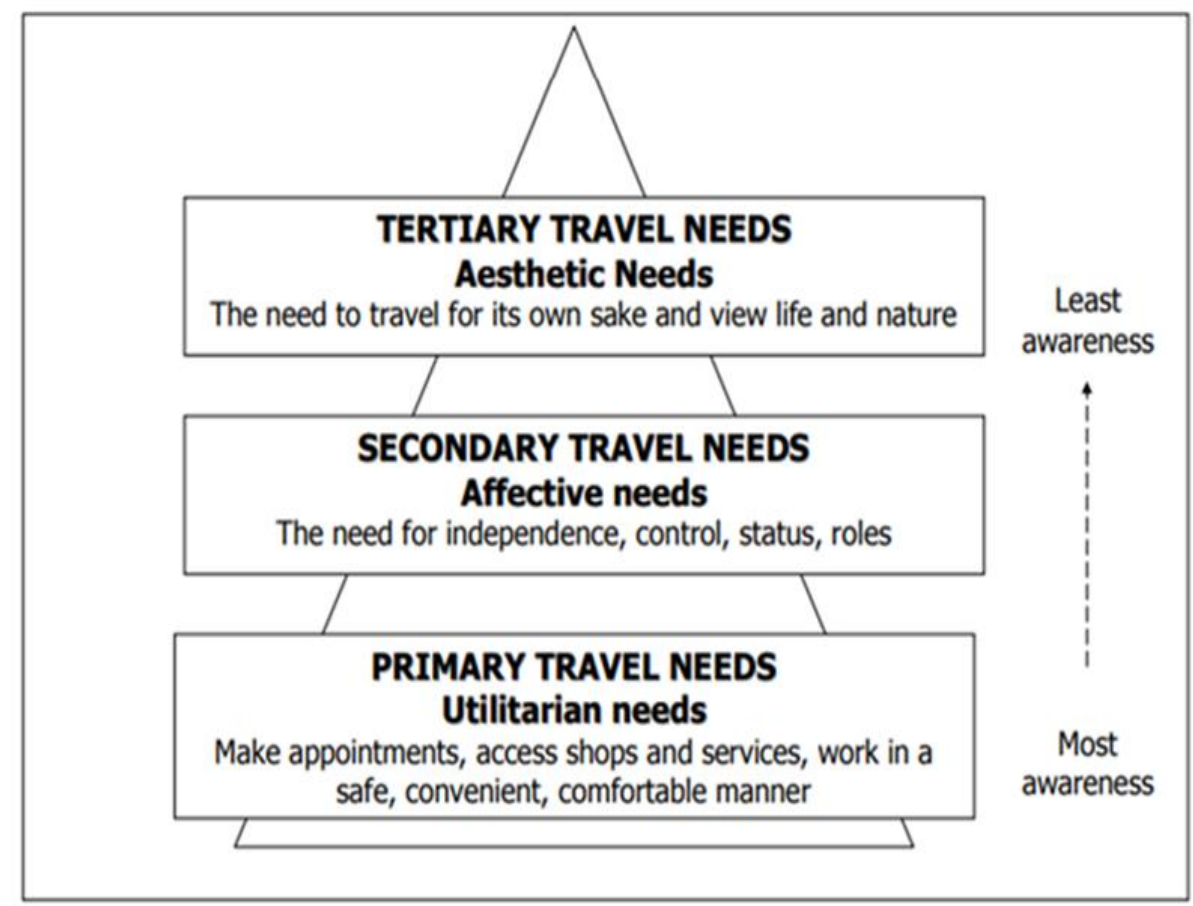

Figure 1: Hierarchal model of mobility needs (Musselwhite छ Haddad, 2010).

However, there were also significant differences between the experiences of current and retired older drivers in the present study, compared to participants in Musselwhite \& Haddad's (2010) study. To explain these differences, a revised model 
has been developed to depict the meaning of driving to older adults, guided by the findings from the present study (see figure 12).

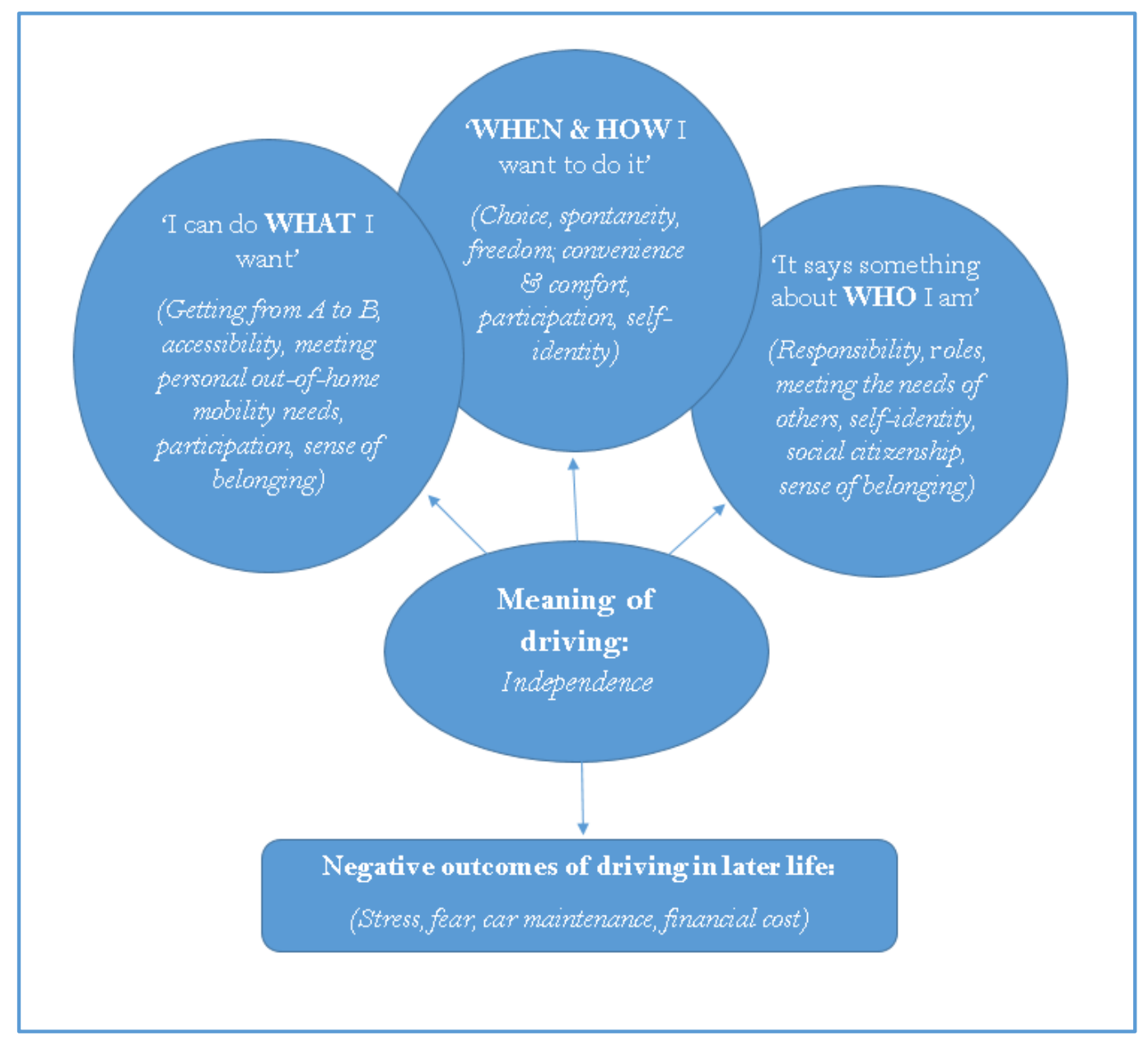

Figure 12: The meaning of driving in later life model

The 'meaning of driving in later life' model has been described in depth below, in relation to the hierarchal model of mobility needs by Musselwhite \& Haddad (2010). Firstly to provide a brief overview, the model is based around 'independence' as the core, key 'meaning' of driving. There are also four sub-categories apparent. Three of these categories are examples of how this sense of independence provided by driving was experienced by participants. These includes 'I can do what I want', 'when $\Xi^{2}$ how I want', and 'it says something about who I am'. Additionally, negative aspects of driving were also part of people's experiences, referred to as outcomes. These findings have been included in the model to illustrate that driving was not always 
something that held positive meanings. However, these negative aspects were overall outweighed by driving meaning independence in later life; hence these outcomes have been placed at the bottom of the model.

\section{Driving means independence}

To begin with, the finding that the overall meaning of driving in later life being independence is consistent with previous research, which has recognised the close linkage between driving and independence. "Independence and driving are often synonymous. For many individuals, personal freedom and independence are reflected in the ability to go from one place to another" (Bauer et al, 2003: 310). The notion of independence is often viewed as the 'pinnacle' within ageing research, emphasizing this as something that older people should be aiming towards, in order to live a successful later life. As previously outlined in the literature review, charitable organisations such as Independent Age add further weight to this issue, through publications and articles that offer advice on remaining independent in later life in relation to a variety of topics, including driving cessation. This is reiterated by one of the slogans outlined on the home page of the website: 'Whatever happens as we get older, we all want to remain independent and live life on our own terms' (Para. 1). The meaning of driving being placed around the central concept of independence is largely consistent with this statement, with current and retired older drivers talking about the importance of driving where they want, when and how they wanted, both of which also say something about who they were. These notions are also highly interlinked with older people's social citizenship, belonging, membership and identity. Each of these concepts were central to the findings from the present study, and have been discussed below relating to the 'meaning of driving in later life' model (figure 12). This greatly differs from the model of older people's mobility needs proposed by Musselwhite \& Haddad (2010), which provides an explanation of mobility needs on a highly individualised level. This previous model does not make reference to social citizenship, belonging, membership or participation, all of which are likely closely related to personal independence for older adults (Lie et al, 2009). This is particularly relevant in today's ageing society, where there is a huge focus upon social inclusion as a way of combatting loneliness and social isolation (Tesch- 
Roemer, 2012). From this perspective, society should ensure inclusiveness of older people through accessible opportunities and resources. Relating to the present study, this related to older people's transport and mobility needs.

Aside from charitable organisations, wider policy drives have also placed a heavy focus upon independence as something which individuals should be striving towards, to live a fulfilling later life. Primarily, the Active Ageing policy framework (WHO, 2002) is often seen as the 'cornerstone' for successful ageing, with a key focus of 'helping people remain independent and active as they age' (WHO, 2002: 5). This framework is based largely around the principles of the activity theory of ageing (Havighurst, 1961), emphasising the importance of older adults undertaking roles and lifestyle practices that are typical in middle age.

Drawing upon the first sub-category within the model, 'I can do what I want', this referred to driving providing the ability to get from $\mathrm{A}$ to $\mathrm{B}$, in order to access places which were necessary or desirable to participants. This was also linked to the concept of choice, where driving provided the ability to visit places out of choice. This is consistent with some of the findings from Musselwhite \& Haddad's (2010) study, which referred to the importance of driving to get from one place to another in order to access basic needs. For example, current and retired older drivers in the present study similarly talked about the need to access practical locations such as supermarkets to purchase essential items, including fresh food, household products and clothing; workplaces; and medical settings, such as GP surgeries, hospital appointments, dentists and opticians. However, findings from the present study differ to Musselwhite \& Haddad (2010), in the sense that current and retired older drivers also placed the same level of importance on accessing places associated with their social or leisure-based needs, as their basic or practical needs. For example, participants talked about the need to drive in order to access 'social spaces', including restaurants, coffee shops, pubs, bingo halls, theatres, cinemas, football stadiums, and gyms. This also included shopping for non-essential based needs, such as browsing in shops and stores, which was often associated with people's hobbies and interests, such as gardening, DIY, and bargain hunting in charity shops. Additionally, this included access to social groups, such as mindfulness classes, IT skills groups and 
slimming classes. It also included accessing voluntary work. Such examples provided by participants are closely related to participation and belonging (Nazroo $E^{\circ}$ Matthews, 2012). For example, volunteering in later life is something that can often act as a substitute for formal employment, once retirement has occurred. A number of studies have found older people to report positive outcomes of volunteering, as it provides a sense of purpose and a feeling of being part of wider society (Davis Smith $\mathcal{E}$ Gay, 2005). This was echoed by Maida, an older female driver in the study, who placed an important emphasis upon the role of volunteering in her life, as this made up part of her weekly routine, whilst also allowing her to provide an important contribution to her local community. As already outlined, accessing social and leisure-based needs was something that was talked about to a much lesser extent by participants in Musselwhite \& Haddad's (2010) study. This was reflected by the majority emphasising the need about getting to places to meet basic, utilitarian needs. Access to social or leisure based destinations was referred to as a 'secondary' need in this previous study.

In addition, current and retired older drivers in the present study emphasised the importance of driving to access natural open spaces, including beaches, lakes, canals, parks, and mountains. This was also perceived to be part of people's 'social' or 'leisure' based needs, rather than being something that represented a distinct category in itself. Instead of this being a separate 'third' level of needs as articulated by participants in Musselwhite \& Haddad's (2010) study. This was interpreted as being of equal importance, compared to basic, social and leisure-based needs, by respondents in the present study. Therefore, the importance of driving to access essential, basic needs, as well as social and leisure-based needs has been placed within the same category of 'I can do what I want', within the revised model of the meaning of driving (figure 12).

The second sub-category of findings relating to driving meaning independence in later life, is 'when and how I want to'. This related to the concept of 'choice', with current and retired drivers drawing upon the importance of having the choice to travel when was most convenient for them, and in a transport mode that provided the most comfort. In support of this finding, previous research has documented the 
closely related link between 'choice' and 'independence', with some scholars suggesting that having choice is a factor that can contribute towards levels of independence (Rabiee, 2013). Metz (2000) also draws upon this aspect of choice, terming this as the 'potential for travel', referring to the ability to travel when and where desired, through making a personal choice. Although these findings were partly drawn upon by Musselwhite \& Haddad (2010), in terms of driving offering convenience and comfort to older adults, these aspects were categorised as primary mobility needs, referring to practical needs only. Also the aspect of choice is not referred to in the hierarchal model. Relating to the present duty, it was revealed that choice, convenience, and comfort that driving offered, held deeper, psychosocial meanings, rather than purely being perceived in a practical nature. Therefore, this category of 'when and how I want' has been placed on the same level of 'what I want'. The third sub-category within the model of the 'meaning of driving' relates to driving representing 'who I am'. In addition to accessing essential or desired places when choosing to, current and retired older drivers talked about driving being part of their self-identity. This was associated largely with playing out roles, including being the transport provider for others. A feeling of responsibility was linked to these roles, leading to an element of self-reliance and independence for oneself and for others. One of the key roles which driving allowed participants to undertaking related to caring. This finding supports previous research outlined in the literature review that also found driving to be an important element when undertake caregiving roles (Bevan et al, 2017). This was illustrated in Daphne's account, as primary carer and transport provider for her dependent husband following his major stroke. Also, Alice referred to the importance of driving before cessation occurred, as this allowed her to provide instrumental support to her older mother, which included lift provision to a variety of places. This caring role was not only something that related to supporting family members through transport provision amongst participants in the present study. As illustrated in the case of Maida, the ability to drive allowed her to provide care and compassion to those in her wider community. This was through undertaking frequent trips to local hospitals, in order to visit patients who were members of her local church or community. This is also an 
example of actively participating in society, which created positive outcomes for this participant, including feeling valued and useful. This finding has been highlighted in previous research on outcomes of volunteering in later life, whereby such feelings have been found to positively improve individual wellbeing (Nazroo $\Xi^{\circ}$ Matthews, 2012).

However, what was important about these experiences of driving was that there was a marked gender difference between participants. For example, all participants who drew upon the need to drive to fulfil caring practices were female. This links with findings outlined from previous research, which also revealed gender specific dimensions of driving in later life (Siren $\Xi$ Hakamies-Blomqvist, 2005). For example and conceptualised through the hierarchal model of mobility needs, Musselwhite \& Haddad (2010) found that car driving was something that was closely linked to roles for females, such as being a mother, grandmother or carer. Suggestions for these consistent findings revolve around sociological theories including the 'gender specific' socialisation process that occurs in childhood, with females being taught behaviour around 'nurturing', and 'caring', whilst males are taught values around 'independence' and 'self-reliance', preparing them for their role as 'breadwinner' (Martin $\Xi^{2}$ Ruble, 2010). This is taught through practices such as encouraging girls playing with kitchens and dolls, and boys playing with cars and garages, for example (Rohlinger $\mathcal{E}^{2}$ Latinsky, 2015). Although Bevan et al. (2017) found no gender differences in relation to driving that allowed the fulfilment of caring roles in later life (as articulated by a male driving caring for his older father), findings from this study revealed clear gender differences. For example, when talking about the need to drive to fulfil roles, current driver Donald talked about providing help to his daughter who was the proprietor of a local rural pub. Having the ability to drive allowed him to get to the pub, in order to undertake the functional role of 'helping out' behind the bar. This was not perceived as a caring role, but something that was associated with the practical provision of support.

In addition to the sub-category of driving providing a sense of 'who I am' relating to the playing out of specific roles in later life, this was also interpreted in terms of driving providing an element of 'self-reliance', also directly linked to the notion of 
independence. For example, current older driver Marianne talked about the value she places upon the ability to meet her own needs, independently of others. 'Driving is my independence, it means I haven't got to bother or run things by other people, I am in charge of my own life'. Schwanen et al. (2012) support this definition of independence. In their study that explored the meaning of independence. In relation to mobility, the authors reported that a sense of independence was derived from not relying upon family and friends in order to achieve physical mobility. Central to this finding is the concept of autonomy, as well as social citizenship and a sense of belonging. Previous authors have reported that independence and autonomy often go hand in hand, with one factor influencing the other (Bowling, 2005). In this case, personal autonomy was achieved through participants having complete control over their mobility practices, based upon when and where they wanted to travel. These experiences influenced how respondents viewed themselves, with driving being recognised as something that is symbolic of self-reliance and personal independence. In relation to driving being related to social citizenship and a sense of belonging, there is a dearth of literature in this particular area. Instead, research has tended to focus upon the relationship between older people's health and social care, as well as income and housing, exploring social citizenship and belonging through these channels instead (insert reference). This explains potentially why Musselwhite \& Haddad's (2010) model of mobility needs does not include these important factors, which, as highlighted in the present study, were significantly related to the meaning of driving in later life. T.H. Marshall (1949) termed social citizenship as "the right to a modicum of economic welfare and security to the right to share to the full in the social heritage and to live the life of a civilized being according to the standards prevailing in society" (cited in Beckett, 2006: 36). Specifically highlighting 'standards prevailing in society' from Marshall's (1949) definition, in this UKspecific context, this would relate to driving, as we are a heavily car-dependent society (insert reference). This is demonstrated by shops and services being increasingly located on the outskirts of towns and cities (insert reference). Therefore, to be a 'driver' in later life means that one is still part of mainstream society, where driving is very much a normal, accepted, and necessary life skill. This was illustrated within the particular research study by Alice, who, when 
comparing her own limited personal mobility following driving cessation to her friends who are still actively driving, stated "I feel like they are 'out there' if that makes any sense, they are part of life.. and I feel like they are actually out there and being a part of life moving around and socialising, and just being involved in life you know" (Alice) Essentially, this example is referring to how the participant no longer feels part of society any more, and feels detached from the social world, based on the loss of independent mobility.

\section{Negative meaning of driving in later life}

Finally, the meaning of driving in later life model differs from the hierarchal model proposed by Musselwhite \& Haddad (2010), because of the sub-section of 'negative outcomes' which were apparent amongst current and retired older drivers. Based upon their lived experiences, participants in the present study explained that driving was not something which was always a positive experience in later life. For example, some individuals reported feelings of stress and fear, as well as problems surrounding the financial cost and maintenance of the car. Nevertheless, it is important to note that although these negative aspects were important in terms of understanding peoples lived experiences of driving, all participants who drew upon negative outcomes reported that the sense of independence which was afforded through driving, outweighed these less positive outcomes overall. Therefore, 'negative outcomes of driving' have been situated at the base of the model, demonstrating that although these aspects need addressing, they were not a 'priority' in terms of understanding the meaning of driving to older participants.

Drawing upon these negative experiences of driving amongst participants, findings relating to fear and car maintenance was something which was only referred to by current and retired female drivers in the study. Fear was related to driving ability in one case, where a current female driver, Molly, had subsequently begun selfregulating her driving practices. This was due to the onset of deteriorating eyesight, including macular degeneration, which had made the driving task extremely difficult in recent years, affecting her confidence and perceived driving ability. Fear was reported in a different sense by another current female driver, who talked about feeling fearful driving during the night time, in rural places which are 
not near her home. This participant talked about feeling a sense of vulnerability through driving alone in these conditions, with a fear of breaking down, with nobody around to help her. This sense of vulnerability was also experienced by Penelope, a retired female driver, although this was in relation to car maintenance. The participant talked about feeling uncomfortable, embarrassed and 'out of her depth' when previously taking her car to garages, before driving cessation occurred. Talking about her experiences of driving, the participant also referred to times where she felt she had been 'ripped off' by car mechanics, who she perceived took advantage of her being an older woman, with a lack of knowledge about cars. Although not referred to in the literature, due to no other previous studies reporting similar outcomes, findings from the present study directly relate to the issue of 'gendered spaces', which is associated with the imbalance of power (Spain, 1993; Rezeanu, 2015). Gendered spaces are described as areas in which particular genders of people, and particular types of gender expression, are considered welcome or appropriate, and other types are unwelcome or inappropriate (Spain, 1993; Rezeanu, 2015). Expanding upon this, within the present context of cars and driving, Lumsdun (2010) suggests that garages are areas which are largely perceived as being 'male domains'. Bridges (2010) suggests that cultural and social imaginary, described as a set of values, institutions, laws, and symbols, has a significant influence upon this perception. In this case, the garage has traditionally been portrayed as being an area which is occupied by males, whether this be home garages, or public car garages. This has also been emphasised through the role of the media, where cars are typically advertised in a way that's appealing to men (Andersson $\mathcal{E}^{2}$ Schytt, 2017). Labour market statistics also support this point, as there is a stark difference in the number of males versus females which are employed within the car industry. For example, only $15.8 \%$ of females held car manufacturing jobs in the UK in 2014, compared to 84\% of males (European Sector Skills Council, 2016). Interestingly, the negative aspects of driving surrounding car maintenance was something which only really had a perceived impact upon females in the study who were unmarried. It was found that although those who were married viewed car maintenance as a negative, undesirable 'chore', these practical tasks were outsourced to their husbands or adult sons, as this was something which was 
perceived as a 'man's job' amongst participants (Bianchi et al, 2000). These findings suggest that traditional normative models of gender identity, which associate femininity with domestic space and home tasks, and masculinity with public space and more practical tasks (Gorman-Murray, 2013), are very much apparent in older people's experiences of driving in later life.

However, other negative outcomes of driving reported by participants were not gender specific, but still held important implications for understanding the meaning of driving in later life.

Referring to the issue of driving creating a sense of financial pressure amongst older participants, it is important to note that there is a dearth of literature which has been published which draws upon the links between driving and finances in later life. Instead, few studies have highlighted links between driving cessation and finances (Rudman et al, 2006), but not about financial implications of driving. Current and retired older drivers talked about the day-to-day expenses of running a car as a problematic outcomes of driving. This mainly related to the cost of petrol, and car parking charges. These financial implications were related to being a 'pensioner' by one current male driver, where in this case, the participant was in receipt of Pension Credit, the government 'top up' for pensioners living below a certain income standard (Gov. UK, undated). The participant mentioned how he does not make as much use of his car as he would like, due to 'money being tight' (Grahame). In this case, the participant talked about spending much of his time at home, despite this not being a desirable outcome, particularly when there is the option for potential mobility (Metz, 2000). This, in part, had left the participant feeling isolated and 'cut off', through the inability to afford to drive the car at certain times of the month. Such examples have important implications for policy, in relation to the continued drive towards active ageing', which highly values notions of independence, participation, and contribution. In this case, although the participant felt that driving provides him with a sense of independence, particularly in terms of self-reliance, the financial costs associated with driving significantly challenge this. Other participants also drew upon driving being a type of financial burden, with two females in the study stating this actually contributed towards their final decision to give up driving. Interestingly, participants 
who drew upon the expense of driving as being something which was problematic, shared common attributes. For example, all had retired from work, and all lived alone, either through divorce or separation.

\section{The meaning of driving cessation for older adults}

The element of independence has been identified as the 'golden thread' in the present thesis, which runs throughout the entire driving cessation process. For example, for participants who had successful outcomes of driving cessation, this was because they still maintained a sense of independence, through the ability to meet their needs through other means, aside from driving.

However, the meaning of driving cessation for participants in the present study was synonymous with the concept of 'loss'. This was expressed through current older driver's pre-conceptions about giving up driving, as well as retired older drivers lived experiences. The notion of 'losing your own independence' stood at the core of this sense of loss. An almost identical overall finding was reported by Bauer et al (2003), who concluded, in their study focusing upon the experiences of six retired female drivers, that 'the experience of being a non-driver represented a loss of independence and spontaneity' (p. 315). Similarly to the findings by Bauer et al (2003), each woman in this study talked about driving cessation resulting in lifestyle changes, including adjustments in social life. This was something which was reported by one retired female driver in the present study, who reported a reduction in contact with her best friend, through lack of convenient transportation (Penelope). However, whereas women in Bauer et al's (2003) study 'rose to the challenge' in terms of finding ways to accommodate losses in independence and spontaneity, female participants in the present study did not all adjust successfully to driving cessation. A potential reason to explain this discrepancy relates to the samples drawn upon in each study. For example, six female participants were recruited from the same demographic area by Bauer et al (2003). It was found that participants used public transport as a way of compensating for the loss of driving, demonstrating that the area which the research was undertaken was well served by public transport. On the other hand, females in the present study were drawn from varied geographical contexts, including rural and 
urban areas, which were found to have important influences upon the meaning of driving cessation for participants. For example, Daphne, a current female driver, talked about the rurality of her area being a significant barrier which led to perceptions of driving cessation being wholly problematic, due to the lack of alternative provision within her area.

Another example of a female in the present study not 'rising to the challenge' of driving cessation, related to Belinda. In this case, the participant's experiences were synonymous with the theory of 'learned helplessness', relating to a condition in which a person suffers from a sense of powerlessness, arising from a traumatic event or persistent failure to succeed (Seligman, 1972). In the case of Belinda, feelings of depression and grief were still strongly apparent, four years on from driving cessation. During the interview, the participant expressed an urge to get back in the driving seat, despite no longer holding a driving licence. However, due to deteriorating vision and overall health status, along with the influence of her family, this was sadly not an option. The participant described how she had since 'gone into herself, since driving cessation occurred, because of this unchangeable situation. The adult daughter and spouse who were also interviewed confirmed this outcome, and talked about how the older adult had become extremely introverted and depressed since losing her ability to drive. The loss of independence experienced through driving cessation, combined with the loss of personal roles, self-identity, and accessibility, had ultimately led to the disengagement of this participant. These negative outcomes are consistent with the proponents of the disengagement theory of ageing (Cumming $\mathcal{E}^{2}$ Henry, 1961). As previously outlined in the literature review, the theory postulates that the most successful, natural pathway in terms of ageing well, is a harmonious, mutual withdrawal between society and an older adult. The outcomes of this study relating to loss are typical of this theory. However, whereas disengagement theory suggests that older adults are passive or even positive in their disengagement, in terms of accepting driving cessation as an inevitable loss associated with ageing, participants in the present study disproved this notion. This was even the case for Belinda, because as already outlined, this participant continued to talk about feeling like she still had the ability to drive. This demonstrates that 
disengagement was not something which was wholly accepted. Many other older adults also supported this finding, which further demonstrates a rejection of disengagement theory, in relation to driving cessation. For example, many participants reported a strong urge, or need to continue with their previous lifestyle practices, which were previously played out through driving. A retired female driver echoed this, stating: “you've got to keep going” (Audrey), referring to her persistent attitude towards life in the post-driving stage, rather than accepting defeat, and loss as an inevitable outcome of the transition.

In contrast to disengagement theory, is continuity theory (Atchley, 1971). This theoretical explanation is more applicable to the current and retired older drivers in the present study, relating to the meaning of driving cessation. For example, Belinda and Alice both felt a sense of depression, sadness, and un-fulfilment, due to not being able to 'continue' with previous lifestyle practices. However, rather than accepting the multiple losses caused by driving cessation, which is what disengagement theory (Cumming $\&$ Henry, 1961) would propose, both participants talked about the need to continue with their previous lifestyle practices. Nevertheless, the extent to which they were able to achieve this pattern of continuity was questionable. These findings have been discussed in further depth below.

However, other older adults in the present study experienced positive outcomes of driving cessation. In this case, Atchley's theory of continuity is relevant, as participants reported positive outcomes, with continuity being at the centre of their transitional experiences. For example, adaptations were made to accommodate for the loss of driving, in order to maintain the same level of independence which was typical when driving. This is something which has been reported in previous research on driving cessation (Musselwhite and Shergold, 2013). Forming part of these adaptations, was the utilisation of alternative modes of transport, such as walking, and the use of the bus. Interventions, such as the free bus pass were drawn upon as important factors in terms of bus use as an alternative to driving. The element of affordability which the bus pass provides was mentioned by Penelope, who frequently uses the bus to travel to and from her local town centre. These benefits have been outlined in previous research, which has found positive links between the use of the 
bus in later life, and levels of independence and wellbeing (Coronini-Cronberg et al, 2012). However, with government austerity, and the uncertain future of the UK economy in relation to Brexit, the sustainability of this intervention comes into question. This is evidenced by the fact that there has been a persistent, underlying threat to withdraw the free bus pass for older people in England and Wales (Andrews, 2012), for several continual years.

However, for many older adults in the study, limited health and mobility status impacted upon their abilities to use these alternative transport modes. In these cases, informal support, referring to the support provided by family, friends and community members, was largely drawn upon. This has also been discussed further in this chapter (See section 6c).

Referring back to those participants who experienced the most positive outcomes of driving cessation, another alternative method drawn upon to meet their needs was the internet. This was illustrated by Penelope, who talked about occasionally undertaking a food shop online, to purchase heavy items, such as several bottles of wine on a Christmas time. This compensated for previously driving to the supermarket, with the option of having the car parked nearby. This is often referred to as the concept of 'virtual mobility' (Parkhurst et al., 2014). An earlier study by Rosse et al (2013) draws upon this finding, stating that technology such as the internet could provide opportunities for social engagement, to those with limited mobility, who may spend prolonged periods of time at home. Further research again has found that internet usage has been shown to improve social capital, in the sense of increasing communication with friends and family, and enhancing feelings of connectedness to the community (Hogeboom et al, 2010; Sum et al, 2009). Participants within the present study specifically reflected this finding, through talking about the perceived benefits which they experienced through using social media. This was referred to by current and retired older drivers, when drawing upon both perceptions and lived experiences of driving cessation.

However, as documented within the findings of the present study, the usage of the internet as an alternative to driving was not something which was viewed in a 
positive light by all participants. This was due to a number of reasons, including the lack of physical social interaction which would occur, through usage of this alternative method. This support previous research, which has found that the use of ICT's can further exacerbate issues of social isolation and loneliness in later life, through the decline of human relations, including face-to-face and physical contact (Adams, 2000; Cornwell and Lundgren, 2001; Kenyon et al, 2003). An important point was raised by Alice, a retired older driver. Although the participant stated the advantages of using social media as an alternative to driving, this was a type of 'double edged sword'. For example, Alice stated that through viewing the lives of other people online, this often further exacerbated her feelings of isolation and detachment. In this case, viewing other peoples busy social lives made the participant question her own reality, viewing this as a depressing state of affairs, since driving cessation occurred.

Additionally, other participants talked about the internet not being a realistic alternative to driving, due to their either minimal, or complete lack of knowledge of how to use online sources. However, for one older gentleman, Derek it wasn't a complete lack of knowledge which acted as a barrier. Instead, the participant expressed a complete reluctance to using these methods due to wholly negative perceptions surrounding the safety and security of using the internet. Findings from the present study draw attention to the fact that older participants were nowhere near homogeneous, in terms of their lived experiences, and perceptions of the driving cessation process. These findings begin to address an important gap in knowledge, which was outlined by Musselwhite (2018), 'modern technologies are a poor substitute for literally being outdoors.. little is understood as to why this is' (p. 197).

Another essential point to make in relation to understanding older peoples experiences of driving cessation, is that both female participants who reported the most successful outcomes of driving cessation were those who made the decision to voluntarily give up driving. Previous research supports this finding. For example, Bauer et al (2003) reported that older women who successfully adapted to life after driving, were those who made the decision voluntarily. On the other hand, the remaining five participants who had already given up driving in the present study 
did so 'involuntarily'. This related to the experiences of those who gave up through necessity, rather than through choice, due to sudden onset of health problems. For these participants, driving cessation was mostly negative on the whole, compared to those who made the decision to give up driving through personal choice. This finding largely goes back to the concept of independence which driving affords people in later life (Bauer et al , 2003). As demonstrated by the experiences of older adults in the present study, this sense of independence is largely eroded when driving cessation occurs, when this is not something which is undertaken through choice. This finding relates to the concept of the 'locus of control' (Rotter, 1954), suggesting that when an element of control or autonomy is removed from an individual, relating to decision making, the outcomes are usually negative. Whereas if an individual is involved in their own decision-making, outcomes are usually positive. This was also something drawn upon by current older drivers in the study, when expressing their perceptions of driving cessation. For example, Derek reported that he would 'know himself', when the time was right to give up driving, emphasising the importance of making this decision himself, independently. This supports previous findings on driving cessation, which has found a direct link between staying 'in charge' of the decision to give up driving, and experiencing successful outcomes (Windsor et al, 2007). However, other males in the study talked about not wanting to think proactively about driving cessation, with one participant mentioning that he hoped to continue driving until he passed away. Other research (Musselwhite \& Shergold, 2013) has also highlighted a sense of reluctance relating to older people's attitudes towards driving cessation, with males being found to hold similar attitudes as those within the present study. On the other hand, other male drivers in the study seemed to have more 'realistic attitudes' towards driving cessation. For example, Barry, a current male driver, talked about the probability of declining health meaning that he will need to retire from driving in the future. However, this was something which the participant did not feel the need to plan for. Stating that he would 'cross that bridge when it comes to it'. This role of planning, however, was something that was referred to be Alice, a retired female driver. The participant mentioned that if she was to provide any advice to other current older drivers, this would be to be proactive, and make plans to give up driving, rather than run the risk of finding yourself in the same position she was in, 
with the experience of driving cessation being taken out of her hands. The participant suggested that undertaking pro-active steps, such as using public transport whilst still able to drive, would be beneficial for older people, to better prepare themselves for life after driving. Previous research has supported this finding (Liddle et al, 2014 Liddle et al, 2007), identifying that when driving cessation is prepared for, older adults experience more positive outcomes, compared to those who are more 'reactive' to the event.

\section{Older adults experiences of informal support throughout the process of driving cessation}

Older people's experiences of informal support, in relation to the process of driving cessation, were highly diverse, consisting of both positive and negative aspects. Participants talked about reasons for using, or not using informal support, as well as outcomes which were derived from these decisions. Both reasons and outcomes of informal support were interlinked in many cases.

Firstly, some participants were positive when drawing upon their perceptions of utilising informal support as an alternative to driving. For example, Donald talked about not having a problem asking his adult children for support if he gave up driving. This is illustrated through the following comment; "the way I see it, is I gave to them, and still give to them now.. so it's time for them to give something back to me". The participant explained how he has provided continual channels of support to his adult children throughout his life course, and this support is still ongoing. This therefore acted as a basis for receiving support back. Similarly, Maida, a current female driver, also expressed feelings of ease in terms of utilising members of her informal support network, if and when driving cessation occurs. In this case, the participant reported a level of confidence and reassurance through knowing that members of her local church who lived nearby, as well as other good friends, would help her if she gave up driving, and needed a lift. These findings are largely consistent with social exchange theory, which, as previously outlined, has reciprocation built in as a core principle, and previous research has highlighted how reciprocation can mediate relationships between people as they age and their maintaining their activity (Thompson, 2016; Tomini et al, 2016; Wharendorf et al, 
2010). As previously outlined, Maida currently provides support to others at present, through her ability to drive, such as visiting church members whilst they are in hospital. However, it is important to note that those who reported the most positive perceptions about informal support, were those who were currently still driving. This meant they were still completely independent, in terms of meeting their own mobility needs.

On the other hand, those who held more negative perceptions about informal support were retired drivers, and often those who had a 'higher level' of informal support needs. This was largely due to the fact that these older adults were not able to use alternative modes of transport, such as walking or cycling, due to having significant health and mobility problems. This was also the reason why driving cessation had occurred. This trend or outcome, based on the findings from the present study, are illustrated in figure 9, within the methodology chapter of the thesis. The image of the overall sample set clearly shows that those who were currently driving had less informal support network members around them, currently providing them with support $(n=5)$. On the other hand, those who had retired from driving referred more network members $(n=10)$, reflecting the increased amount of support which occurs at this stage of the driving cessation process.

Drawing upon some of the negative experiences reported by current and retired older drivers, the issue of burden stood as the most central issue. Most retired drivers talked about this being something which they experienced, acting as a complete deterrent for some people utilising this type of support. For example, although the grandson of Christopher frequently calls and offers him support, the participant talked about not wanting to accept any instrumental help, because he would prefer his grandson to focus on his career, rather than becoming a burden to him. This is despite the fact that the participant needs help, due to significant mobility restrictions, through his complete loss of eyesight, and subsequent severe mobility restrictions. This finding supports previous research, which has also reported older people feeling like a burden to their informal networks, in relation to their mobility and transport needs (Azad et al, 2002; Musselwhite \& Shergold, 2013). 
However, no research has found the feeling of being a burden as a complete deterrent for older people meeting their mobility needs, on the event of driving cessation, as was found here. This has important implications for support interventions, as discussed in Chapter 7, the conclusion. This example rejects the principles of social exchange theory, as in this case, the participant talked about not only providing lifts to his grandson previously, when he was able to drive, but he also more recently bought a house for his grandson. Despite this, the feeling of being a burden overrode the provision of support. Similar findings were reported by Penelope, another retired female driver. In this case, the participant talked about providing intense childcare to her adult son's children, in order for him and his wife to go to work. Based upon social exchange theory, this would suggest that support would be reciprocated to the older adult, in times of need. In this case, this would be through the provision of a lift, to take her home, after providing childcare all day, particularly during night time and in bad weather conditions. Nevertheless, there was no 'reward' reported for the participant. This was demonstrated by not receiving a lift home, or even a thank you for her help. The participant described how this support was not offered, and she felt very uncomfortable asking for a lift, due to an awareness of her son already experiencing strain, through working full time and balancing family life. Social exchange theory would suggest that because the costs potentially outweigh the benefits in Penelope's case, the provision of childcare would cease. However, the provision of childcare continued, despite the fact that aside from having the opportunity to spend time with her grandchildren, little benefits were experienced, particularly relating to her practical mobility needs. This suggests the participant was instead, acting on the basis of altruism, with support being provided out of pure selflessness, and love for her son and grandchildren. This supports findings from previous social gerontology literature, which has also found that care for grandchildren is provided through altruistic behaviour (Sun, 2015). Although studies on altruism suggests that this often has a positive influence on older peoples quality of life (Kahana et al, 2013), this was not relevant in Penelope's case, as she was essentially left with an unmet mobility need, by 'fending for herself, in terms of finding her own way home despite tough environmental conditions, and feelings of fatigue after the provision of childcare. 
Older people felt like they could only ask network members to provide support for them to meet their 'essential', or 'basic' needs. Participants reported that asking for this type of help was justified, because these needs were ultimately associated with their basic, survival-based needs. In this case, support was 'justified'. This was illustrated by Beatrice, when she talked about not feeling 'so bad' about asking her niece for a lift a medical appointment. On the other hand, she did not feel that asking for a lift to access places associated with her social and leisure based needs was warranted. 'I couldn't just ring her up and say 'oh, will you come and get me to take me down the front to have an ice cream, I think she'd be annoyed if'I was getting her to drive all that way to take me out for that". This is something Musselwhite (2017) has found, and relates clearly to the category of "where I want" in the model derived from the findings in this thesis (figure 2), suggesting informal support reduces independence in accessing places they want to go to. However, this finding does have important connotations for understanding the limitations associated with informal support, as an alternative to driving in later life.

Alternatively, other older participants did talk about some of their more social and leisure based needs getting met through informal support. However, this was largely the case when network members offered support, rather than the older adult ask for support, something not previously found in the literature. In this instance, it was often the case that transport provision to meet the older adults social and leisure based needs was something which was already built into the relationship between the older adult and the network member, even when the older adult still had the ability to drive. For example "We go on day's out when Sandra is off from work, different places all the time, it was a drive up through the valley the last time" (Derek). Current and retired older drivers talked extensively about how much they valued going out for social and leisure based purposes, with one retired older driver, Alice, talking about how visits to the beach, and places which are situated near water have always provided her with a sense of revival and refreshment, which was even more poignant in recent years since experiencing depression, following driving cessation. "I have always found that being near the water helps to blow the cobwebs away, and I love to get there as often as I can, when somebody takes me”. This finding has 
received significant research attention in recent years, with scholars reporting upon the advantages of older adults connecting with nature. For example, Wolf \& Housley (2016) reported that older individuals with access to nearby nature showed improved mental health and cognitive function and an increase in social interaction with those around them and their community. However, if older people cannot ask their support network for help in accessing such places, and are reliant on the good will of their support network, it may mean they cannot improve their mental health and cognitive function when they need too.

Even when some of the social and leisure based out-of-home mobility needs of older adults in the present study were met through informal support, the ability to do this 'when' they wanted was completely compromised after driving cessation. This related to the second sub-category on the model of 'driving means independence', relating to 'when and how I want' in the model (figure 12), derived from the findings of this thesis. This was because using informal support as an alternative to driving one's own car was something which was largely based around the lifestyles of informal network members, such as working hours, and their own social lives. As outlined in the findings chapter, this led to a feeling of frustration for Ernest, a retired male driver. This was illustrated through the participant describing everything being a matter of 'waiting', relating to the reliance upon his spouse for his mobility needs. This finding reiterates the importance of the potential for travel the car provides, as outlined by Metz (2000) and Parkhurst et al. (2014), but adds the dimension that informal support does not overcome this.

The 'how' part of the sub-category, in the model derived from the thesis (figure 12), however, does get met to an extent, as older people still view travelling in a car as the most convenient and comfortable transport mode, even when this is as a car passenger.

Finally, the category of the model 'it says something about who I am' (figure 12) relating directly to the older persons identity, is also largely compromised through the usage of informal support. This is because driving means complete independence, which is largely experienced through the playing out of roles, and 
having responsibilities, with complete self-reliance and autonomy over one's life. Using informal support often shifts the feeling of 'independence', to 'dependence', despite some network members attempts to 'empower' the older adult, with the aim of trying to preserve an element of independence for them. This factor has been discussed in depth in part $6 \mathrm{~d}$ of the discussion chapter, referring to the experiences of the driving cessation process, for informal support network members. Musselwhite (2018) touches upon this, suggesting psychosocial needs in Musselwhite and Haddad (2010) model are not met when receiving lifts from others.

Another important finding relating to older peoples experiences of informal support, drew upon a significant gender difference. This relates to the diversity of older adult's informal support networks. For example, female participants largely talked about utilising multiple people in their informal support networks, either currently, or something which was perceived would occur if and when driving cessation occurs. This included family members, friends, neighbours, and wider community members. Alice, for example, utilised support from her adult daughters, neighbour, best friend, other friends, and work colleagues. In this case, this was talked about as a coping strategy, in order to sustain informal support. This refers to the participant talking about 'rationing support', where she was aware of not placing too much responsibility upon one network member only. This finding has not been found in previous research, particularly in the context of older people utilising informal support in relation to driving cessation.

However, there was a significant age difference relating to older peoples informal support networks. For example, older female participants talked about no longer having friends around them, due to the fact that these individuals had gradually passed away. Previous authors have published research on this topic, recognising that losing friends is part of the natural pathway for people in later life (Roberto $\mathbb{E}^{\circ}$ Stanis, 1994). In a study on older women's experiences of loss in later life, Robert \& Stanis (1994) note that participants included in the study propose advice to other older adults, in terms of how to deal with this loss. This included "advice to others 
who had lost a close friend was to remember their friend, seek out new friendships, and be active" (p. 21).

However, males in the present study reported a completely opposing account. For example, one retired male driver talked about his only transport provision being his spouse, since driving cessation occurred. In this case, the participant did talk about his own sisters, and his sister-in-law's offering him transport to undertake any duties which he needed to, although these offers were rejected immediately. This suggests an intense level of pride for this participant, with him not wanting to seem like he was dependent upon others. This links to theories of masculinity, linking to self-identity. Other males echoed this, also talking about only drawing upon one person for informal support. Research suggests that females are both more likely to give and to receive social support throughout the life course and this continues into older age (Luckow et al., 1998; Tamres et al., 2002), though this has not been studied in terms of driving cessation previously.

Another male also drew upon only one informal support network member, who was also his primary supporter. Despite the fact that the participant was still driving, he had recently experienced severe health problems, relating to heart failure. This had resulted in him spending periods in hospital, although the hospital was within the next county over from where he lived. In this case, the participant talked about how his pub landlord provided him with transport to and from the hospital, and provided him with other support needs, including 'meals on wheels', made by his wife, as well as transport to take him to and from the pub, to ensure he was 'getting out'. This finding suggests that rural areas consist of much 'closer-knit' communities, compared to urban areas; therefore have greater social capital (Parkhurst et al, 2014). This agrees with previous research where strong local social capital appears important in conferring mobility on certain social groups, especially those without access to a car (Gray et al, 2006), although this has again, not been found in the specific context of driving cessation.

Another very similar account was provide by Gerald, another current male driver, who reported the need for informal support over the past 12 months, also due to 
becoming unwell with an infected leg ulcer. The participant talked about how he had relied upon his brother and sister, although they lived 2 hours drive away, during this period. The participant did not have any contact with either of his adult children, through a complete relationship breakdown, and was divorced many years ago. Also, he had not long moved to the area, and felt like his neighbours were unsupportive and not very welcoming of him. This account raises several important points. For example, it draws upon the changing nature of informal support, relating to no longer having contact with adult children, and living in an area away from family members which relates to modernisation theory, the dispersed nature of families as they seek work. It also draws upon neighbourhoods 'not being like they used to be', through the participant talking about factors which were synonymous of social exclusion. This included neighbours not saying hello to him, despite living in the same block of flats. This relates to wider social gerontology research, looking at the impact of community cohesion on older people's wellbeing, and again social capital. Puntham (2000) suggests that social capital is cyclical and is waning at present, and Held (1996) suggests it is merely changing, as technology exchanges social capital in situ to more virtual patterns of social capital that technology enables at distance, which both fit the pattern Gerald refers to. The influence on how cohesive a community is in terms of integration has received attention in recent years, through agendas such as the loneliness and prevention of social isolation in later life drive. For example, Age UK (2018) produced an article on their website about 'discovering how lonely your neighbourhood is'. However, greater integration of mobility and driving cessation as part of the loneliness and isolation agenda is suggested as being important moving forwards. 


\section{Informal support network members and the process of driving cessation}

Informal support network members of current and retired older drivers presented varied accounts, based on their lived experiences of being a network member of an older adult, who was within the process of driving cessation. This included network members lived experiences of those older people who were currently driving, but may receive occasional support, to those who were reducing driving, and those who had completely ceased driving.

One of the overall findings was that those who reported the most negative outcomes of being involved with the driving cessation process, were those who were providing the most intense support. This also included an all-encompassing nature of the support, ranging from lifts, to the provision of emotional or social support to the older adult. Interestingly, these participants were all kin members. This included the wife of a retired male driver, two daughters of a retired female driver, and the niece of a retired female driver. Negative experiences ranged from feelings of stress, strain, and guilt. On the other hand, other network members who played more of an intermittent role in terms of the provision of informal support, reported more positive outcomes. There were a number of factors which influenced the experiences of informal support network members, in relation to the driving cessation process of the older adult.

Social exchange theory, as previously outlined, suggests that individuals make rational choices, and act accordingly, based upon a cost-benefit analysis of a particular circumstance, relating to social relationships (Homans, 1958). The theory is built upon reciprocity, not necessarily between the two parties involved, but in the sense that the person 'putting in', or providing support will get something back. In this case, this may refer to aspects of reciprocity which 'come from within', or are intrinsic, independent of the older person, or from the older person themselves. For example, financial rewards, or displaying gratitude and appreciation. The theory states that when the benefits of providing support outweigh any negative connotations, this results in the most successful outcomes. Applied to this context, this would refer to the continued provision of informal support, with positive outcomes for the provider 
and receiver of informal support. Social exchange theory can be applied to part of the findings from the present study. In this case, the phenomena under study which the cost-benefit analysis related to is the provision of informal support, which was found to be multi-faceted in nature. This included practical help, such as the provision of transport, or delivering goods to the older adult, through to psychosocial support, such as spending time with the older adult throughout the process of driving cessation, to provide company, guidance and advice.

Social exchange theory has been useful to an extent, to explain some of the motivations for why network members provide support to older adults throughout the process of driving cessation. For example, despite the 'costs' associated with the provision of support, such as network members time, effort and resources, the 'benefits' of helping the older adult outweighed the costs for some, hence these individuals reported positive outcomes, and continued to provide support to the older adult. These benefits included the feeling of reassurance, through to personal gains, including social engagement, having a sense of purpose, and feeling valued and appreciated (Anita, Christine, Damien, Yvette). Explanations for the more 'positive' experiences, as reported by the non-kin network members within this study, are varied. Importantly, this study also found that even for those network members who reported the most positive outcomes, this was related to the employment of coping strategies, relating to the provision of informal support. This related to practicalities, and psychosocial factors of providing informal support, such as availability and willingness to help. For example, participants talked about practical tactics which they adopted, which also helped to reduce any negative psychosocial connotations which could potentially be experienced, such as strain and stress. This included organising and prioritising their personal needs, along with the needs of the older person. This also included utilising support from other informal support network members, and trip chaining, referring to meeting a multiple number of personal needs, or the needs of the older person, during one out of home trip. For these individuals, a key aspect to ensure the continued provision of informal support was balance, between their own needs, and the needs of the older adult. The importance of balance when providing informal support has also been found in wi]er 'caring - 
based' literature (Plaisier et al, 2015). Nevertheless, this was not something which was easily achieved for some.

On the other hand, other findings from the present study contradict certain facets of the theory. Some network members continued to provide support to older adults, even when the negative outcomes outweighed the positive aspects associated with the provision of support. For example, Harriett, the daughter of a retired driver, talked about feeling a sense of reassurance through supporting her older mother since she gave up driving. However, the costs of providing this support largely overshadowed reassurance. Costs included feelings of extreme pressure, stress, burden, guilt, conflict and resentment. This was largely related to the participant not having a 'balance' between her own needs, and the needs of the older person, despite employing coping strategies to help with this. These negative feelings were related to the participant experiencing role strain, where she was juggling a pressurised full time job, a wide circle of friends, as well as childcare for her long term partner's child. This finding related to the fact that in reality, the participant had limited availability to provide her mother with the support which was required. This finding highlights a criticism of social exchange theory. For example, the theory is based upon the concept of 'rational choice', not taking into account wider influences which can affect relationships between two or more parties. Another way in which this finding differs from social exchange theory, is that Harriett continues to provide support to her older mother, despite this feeling of ongoing strain. In this case, this was largely down to the older adult being dependent upon informal support, through poor health which significantly restricts her ability to be independently mobile. Previous research has drawn upon the concept of 'obligation', in order to explain why kin members provide support to older adults (Henretta, et al., 1997; Silverstein, et al., 2002). This refers to network members experiencing a sense of duty for an older relative, which is largely based upon social, moral, and cultural expectations (Silverstein et al, 2006).

Other kin-network members drew upon similar experiences, reporting negative experiences of the driving cessation process. For example, Lynette, the niece of a retired female driver, also expressed feelings of stress, anxiety and pressure through providing support to her older aunty since she gave up driving. A sense of obligation 
was also felt in this case, through the participant explaining that the older adult had nobody else to help her, through never having children of her own. Research has often showed the obligation felt by children (Silverstein et al., 2002, 2006), but this shows wider family members can also feel this sense of obligation. Further research capturing the experiences of wider family members may shed more light upon this finding.

Another participant, Josephine, also talked about feeling a sense of obligation, through providing her husband with transport for all of his needs since driving cessation occurred. Feelings of stress were also documented in this case. These findings are partly supported by previous research. For example, a Spanish study (del-Pino-Casado et al, 2011) focusing upon cultural caregiving motives and subjective burden in informal caregivers of disabled older people, found that this sense of obligation was greatest amongst spouses involved in the research. However, findings from this previous study also differ from the present study, in part. This is because del-PinoCasado et al (2011) reported that the sense of obligation was only evident amongst spouses, and not amongst other relatives and non-relatives. In contrast to this, the present research study found that feelings of obligation were in fact experienced by wider family members and friends of current and retired older drivers.

Some adult children in the present study reported a sense of filial obligation, in relation to explaining their motivations for providing their older parents with informal support, throughout the process of driving cessation. This is also something which has been found in previous studies which have specifically included the views of adult children of older adults, in relation to driving reduction and cessation. For example, in a study on the views of adult children on the driving reduction and cessation process of their older parents, one participant stated “.. they're the parent, and we respect that.. I have to give up my freedom because I'm going to have to take mom or dad wherever.. it's a drain.. but it is a responsibility on us and we need to take care of our parents" (Connell et al, 2012: 984).

However, even for the adult children in the present study which did report more positive outcomes, this was largely because they were interviewed whilst their older 
parent was still driving, therefore still having independence. It would be interesting to see if these perceptions changed, if and when driving cessation occurred, to investigate whether perceptions matched experiences. However, these participants did also report some negative aspects of the driving cessation process. This was captured by Peter, the son of a current older driver. He talked about having a highly stressful job, which takes up a lot of his time. The participant mentioned that providing help to his father, which includes instrumental support such as lifts to social and practical destinations, as well as emotional support, in the form of company and social contact, does also create feelings of strain. In this case, however, Peter talked about how he balances this through the employment of coping strategies. For example, the participant mentioned having a good, solid relationship with his wife, where she fully understands that his father is the 'top priority'. This understanding allows the participant to balance these multiple roles. He also talked about how he often takes his son along to his fathers with him, ensuring time is spent with his father and his son, overcoming any negative feelings of obligation. Comparing this example to the account of Abigail, the daughter of a retired female driver, is interesting. For example, Abigail talked about feeling extreme strain and stress through providing her older mother with informal support, as a result of driving cessation. This was related to her partner not understanding the needs of the older adult, which makes him feel neglected, and a lesser priority. These findings outline the importance of network members own personal networks understanding their role as an informal supporter. It also has implications for policy, which needs to recognise the burden which individuals feel, through the increase in support which is provided once an older adult gives up driving.

Referring back to the experiences of informal support throughout the process of driving cessation, an important finding related to non-kin family members experiencing more positive outcomes, compared to kin-members. For example, the account provided by the neighbour of a current older driver, Anita, captured this finding. The participant reported that providing support to the older adult following driving cessation is by no means a chore to her. Instead, it was reported that she did not provide an intense amount of support, and perceived her role as just 'filling in the 
gaps' when the older adults other family members are unavailable to help. This finding is supported by Finch \& Mason (1993), who found that whereas familial caregiving in later life is often based on obligation and duty, help provided by friends and neighbours is based on a different kind of motivation, which is often influenced by type and level of familial support which older adults may already receive.

As part of the outcomes of providing informal support in response to an older adults driving cessation, practical outcomes were drawn upon, which often held a deeper, more psychosocial meaning for participants. For example, the daughter of a retired female driver mentioned how she often cancels plans to have coffee with friends to accommodate the needs of her mother, since driving cessation occurred. This places further strain upon the network member, through sacrificing her own social life in favour of meeting her older mother's needs. Other practical outcomes of driving cessation on the lives of informal support systems have been documented in previous studies. For example, Freund \& Szinovacz (2002) found that caregivers often missed or reduced work, or gave up working altogether, in order to care for their elderly loved ones. Informal support network members in the present study reported some similar outcomes, although this was more about making adaptations to their working patterns, rather than missing or ceasing work altogether. For example, two adult daughters of both current and retired drivers talked about the value they placed upon working in a department which offers a 'flexi' system. Both participants reported that without this element of flexibility, informal support would be difficult to provide to the older adult. This suggests the value in government policies which partly recognise the importance of a 'work-life balance'. On the other side of the coin, flexible working was not possible for another daughter of an older driver, due to being the landlady of a village pub. In this instance, the participant talked about the need to always be present within her work premises, resulting in difficulty finding the time to provide informal support.

This last point relates to the policy backdrop upon which this study took part against. For example, through the continual rolling back of the welfare state in the UK since the 1970's, this has seen less and less welfare support being provided. In recent years, this has been reiterated through Conservative Party agenda's, such as the Big Society, 
where the focus has been upon 'community first'. This translates to the government removing their role in the welfare of their citizens, transferring this responsibility to individuals and local communities to support one another. In this case, such agenda's would assume that older people will be able to either $(a)$ independently meet their needs in later life, or (b), rely upon informal support networks. This has been echoed in the UK with little support being provided for carers, particularly in the context of older people's mobility and transport needs. Although in recent years, there have been 'carer's drives', where there has been more of a focus upon recognising the important role of informal support providers. Nevertheless, this has largely come from a third sector standpoint, such as Carers UK. On the whole, it could be argued that the government provide little support. This is apparent through the current Carers Allowance benefit which is available to people in the UK. The criteria for providing this benefit is highly restrictive, in the sense that the person providing 'care', needs to be undertaking this role for at least 35 hours per week, This does not take into account those informal support network members who perhaps provide significant transport and other associated support for older people after driving cessation, for less than the required 35 hours.

Overall, referring to the type of informal support which was provided to older adults, network members largely focused their support provision around essential needs, resulting in social and leisure based needs often going unmet, as noted in section 6c. However, social and leisure based needs were sometimes built in. This was largely because the family, friends and neighbours of older people involved in the study valued the concepts of activity and independence. In this case, these individuals often acted as 'bodyguards', trying to ward off detachments of the older adult, fearing the potential of isolation. This was about an understanding of the older adults support needs, and also of the actual, or perceived impact of driving cessation. However, a finding from a previous study on the perspectives of adult children about the driving cessation of their older parents revealed opposing findings, with one participant questioning the mobility needs of her older parent "where does he want to go at the age of 85?" (Rosenbloom, 2010). This finding holds an important message, in terms of how well informal support network members understand the needs of older adults. 
Possibly, if the network member and the older adult both had a mutual understanding of each other's needs, this could pave the way for a more positive experience of informal support, in relation to driving cessation, as well as wider areas of ageing. However, the extent to which these social and leisure based needs could be met was restricted in a lot of cases, due to the availability of network members, as well as the willingness to provide support. This is illustrated in the case of Lynnette, the niece who feels completely unappreciated by her older aunt, and experiences negative outcomes when she does visit her.

Another important finding from the present study related to some network members empowering the older adult, in an attempt to reduce the feeling of burden which was often experienced by current and retired older drivers. In this case, some individuals wanted to ensure the older adult preserved as much of their independence as possible. This also relates to the concept of 'perceived control'. The element of empowerment was played out through some network members carefully intertwining their knowledge about the older adult feeling like a burden, with tactics which tried to eliminate those feelings. For example, Damien, the best friend Alice, a retired female driver, asks the older adult where she wants to go, and actively offers to take her places. Also, Sandra, the daughter of a current male driver, talked about ensuring her older father is involved in important decisions, so that he feels a sense of contribution and empowerment, rather than feeling like a burden when joining his daughter and her family on days out, for example. The role of empowerment was essentially about the network member 'putting the ball in the court' of the older adult. However, this was not something which was easily achievable, or a reality for some network members. This was largely down to time restraints and role strain for primarily family members, who were often already experiencing difficulty trying to balance multiple roles. Nevertheless, this element of empowerment holds important meanings, documented by the concept being applied to experiences of informal support in relation to wider issues associated with ageing. For example, for older adults who need help with their personal care, or care in the community (Joseph Rowntree Foundation, 2010). However, this concept has not previously been applied to the field of driving cessation, which therefore warrants further investigation into the 
phenomena of informal support throughout the process of driving cessation. This would allow for the identification of best practice examples, whilst essentially responding to the needs of older adults and their network members who are experiencing this major later life transition. 


\section{Chapter 7: Conclusion}

The following chapter draws upon conclusions from the overall study. This includes; key messages from study, limitations and directions for future research, key contributions to knowledge, recommendations for policy $\mathcal{F}^{\circ}$ practice, $\Xi$ dissemination of research

\section{Key messages from study}

The process of driving cessation and informal support is a multi-faceted and unique phenomena, which cannot be explained or conceptualised through one single theoretical lens. The topic has been found to be far more complex than that, which is also recognised by the multiple academic disciplines upon which the study spans. Although frameworks (figure 1) and theories incorporated within the early stages of the research have been drawn upon in order to provide foundation knowledge for the present thesis, findings have shown that these initial starting points are insufficient, in terms of detailing the complexity of the phenomena. This is also to do with the fact that driving cessation and informal support is something which has received scant attention in previous literature, which largely guided the focus of the study.

Combining the findings chapter with the discussion, a number of key messages have arose from the study. These have been listed below:

. Driving in later life is closely linked with older adults' subjective independence

. Driving cessation is associated with loss, along with the notion of dependency

. Not all older adults are able to successfully meet their transport and mobility needs independently once driving cessation occurs. This may result in the need for informal support . Informal support is a partial, yet far from complete alternative to driving cessation in later life

. Although there have been some positive aspects of informal support outlined, experiences of burden and strain largely dominate

. Informal support networks do not have recognition of the support they give in this area 


\section{Limitations and directions for future research}

Although the research has a number of strengths, there are also a number of limitations which need to be addressed. These points have been drawn upon, and responded to, in relation to suggestions for future research, in order to address these limitations.

Firstly, it could be argued that findings are limited due to the small sample size. Although the utilisation of smaller sample sizes are favoured in qualitative research, for their ability to provide quality over quantity, and depth over breadth, the findings are not generalisable to wider populations. The findings are relevant for the study site that involved urban and rural participants in the United Kingdom. However, the context specific nature of transport provision and support may mean it is hard to generalise to other populations. Hence, patterns which emerged relating to interesting gender differences are also limited in terms of application to other populations. However, this limitation could be addressed by future research, by using a larger sample size, in a variety of different contexts.

The study was also 'local', in terms of it being centred to the context of South West Wales, representing the experience of the driving cessation process in a highly Westernised culture, which is car dependent. It would be interesting for further research to be undertaken in wider contexts, on a global basis, to study how different cultures and societies may respond to driving cessation, and whether informal support is experienced in a similar way.

As already outlined, the utilisation of a word of mouth snowball sample has also been criticised as a strategy for obtaining participants for research. This is due to the element of bias which can be built in using this technique. However, it has been outlined in the methods chapter that this element of bias was eliminated as much as possible, based upon aspects such as researcher professionalism, and reflexivity. It could be argued that older adults referring those network members who they perceived to be suitable, or relevant to the study, could be a misinterpretation of what the phenomena of driving cessation and informal support is actually about. However, as outlined, this method was used, as the primary starting point in the research study, to gather the lived experiences of current and retired older drivers, with informal 
support being part of the multi-faceted experience of driving cessation. Therefore, it was essential that the older adult remained as a 'gatekeeper' to this second group of participants. However, future studies could look to recruit network members through different methods, such as public advertisements, to gather people in focus groups to talk about their experiences of an older adult going through the driving cessation process. Thus, shifting the focus from the older individual to the network member first and foremost.

Another disadvantage of the research was that it was undertaken in a cross-sectional manner with one specific sample, reflecting one particular moment in time. Although this approach is consistent with Heideggarian phenomenology, in terms of drawing out the lived experience of people's lives as the basis for understanding social phenomena, it would be interesting to have followed participants at several times, to map out how participants were experiencing the process over a longer period of time. It would be even more desirable to undertake this study over an even longer period of time, with no time restrictions as were apparent within the present doctoral study.

Although the present study is not generalizable or replicable, due to the in-depth richness of data collected, focusing upon quality over quantity, findings have important implications for future research. Firstly, there is scope for a similar phenomenon to be investigated in future years, taking into account a different cohort of older adults and informal support providers, within a different context. This would naturally take into account different political and economic circumstances, which could substantially influence the experiences of older adults and informal support providers relating to informal support.

Other future research directions relate to more exploration being undertaken into combining the experiences of older people and informal support network members, to build upon the present research. Future research questions could include aspects such as; does the demand for informal support meet provision of informal support. Although this study has eluded to this, this has found this to be a highly complex phenomena, which is made up of individual factors, as well as relational factors. Future research could explore this aspect using systematic methods, such as quantitative research, 
providing statistics, which could be demonstrated visually, to be clearly presented to policy makers and wider audiences.

Finally, the advent of new technologies, such as driverless cars, could make independent mobility a reality for people much later in life, despite having cognitive or physiological difficulties that stop people driving. How such technologies might alter the mobility and support network surrounding the older person needs further investigation.

\section{Key contributions to knowledge}

The present thesis has provided a number of key contributions to knowledge. For example, to my knowledge, this study is the first piece of research which has provided a holistic approach to studying the process of driving cessation amongst older adults and informal network members. As previously outlined, research on driving cessation is vast, although there is a stark lack of knowledge which has specifically focused upon informal support as an aspect of this process, despite the fact it has been highlighted as a fundamental factor which has important outcomes for current and retired older drivers (Johnson, 2008; Schryer, 2017; Taylor \& Tripodes, 2001).

To summarise, this project has contributed:

. A new model to explain the meaning of driving to older adults

. Snowball sampling as a tested method of best practice

. Adaption of Braun $E^{2}$ Clarkes six-step data analysis process

. An interdisciplinary approach to a understanding a complex phenomena, resulting in outcomes and recommendations within multiple areas, aside from just policy and practice recommendations

. A holistic approach towards the definition of informal support, recognising the changing nature of this concept (network members were not restricted to family members only)

\section{7d. Recommendations for policy \& practice}

To enlighten and encourage support in driving cessation through informing the public of the importance of driving cessation and support in the driving process, the 
DVLA should be acting as a point of contact for older adults, once driving cessation occurs. Findings from the present study, alongside previous research, have found that driving cessation often results in isolation and social disengagement. To date, there is no 'safety' net for older people to lean on when this transition occurs. Therefore, when an older adult surrenders their driving licence to the DVLA, this should trigger the provision of information on 'driving cessation'. I recommend that information leaflets should include advice and guidance for older adults, as well as for informal support network members. The information should be made available online, for those with access to the internet, although a manual letter should be issued automatically via a computer based system. This would ensure that nobody is missed, in terms of support interventions.

Points of contact for current and retired older drivers need to be more 'age friendly'. For example, information which is available on current and retired older drivers is often based online. The research has shown that older people in the study do not all use the internet to communicate. Despite efforts by government etc. there is still a 'digital divide' which needs to be recognised., and addressed.

It is suggested that the government should play an active role in working with employees, across the entire labour market, with an aim to roll out more flexible working practices. Findings from this study have shown that where 'flexi' systems are in place, this often acts as an enabler for individuals to provide informal support.

There should be more support for non-car modes of transport and more encouragement across the life course to use other modes of transport, so people are not wedded to their vehicles in later life. Accessible public and community transport was found to be a lifeline for many participants and could overcome the need for support when giving up driving. However, cuts to local bus services and the lack of coordination between bus and rail networks can make even short journeys difficult for older people. Poor quality signage, seating and public toilets can also make older people feel less confident about public travel.

With the rise of formalised support for older people to reduce isolation and loneliness with clubs and societies, providers of these interventions need to make sure transport 
is coordinated for people to be able to access them. When events are planned for older people, there needs to be more done to help them use alternative modes of transport. Events should have good public transport access or specialist services through community transport run to them.

The role of training and education in both helping older people assess and develop their driving skills, such as driver assessment centres, should consider becoming mobility centres that help older people explore alternatives to driving, as well as simply assessing their driver performance. As Musselwhite (2010) notes, this is best done through a social travel group and planning should include both practical and psychosocial support and could align with Queensland model, CarFreeMe, which provides psychological, social and practical peer support for older people in groups.

Since the 1970's the UK has witnessed a continued 'rolling back of the welfare state', in terms of shifting the focusing from government intervention, to individuals and communities themselves. A number of agendas have recognised this, such as 'communities first', or the 'big society agenda'. In addition, carers can become invisible. This study shows the amount of effort and time informal network members, as carers, put into supporting older peoples' transport needs that can go unrewarded, leading to feelings of burden, guilt and shame. This is a huge area for social policy, particularly when considering the present context in the UK, with the unknown implications of a very uncertain Brexit, along with austerity cuts, and asks the question as to whether actually should proper paid provision should occur supporting older people with transport needs. 


\section{Dissemination}

The following table outlines research based achievements achieved throughout the duration of the present doctoral study:

\section{Research specific achievements \& contributions - relating to $\mathrm{PhD}$} 2019

- $\quad$ Published journal article - 'Older peoples' experiences of informal support after giving up driving', Research in Transportation Business \& Management

- $\quad$ Outstanding Achievement to Public Engagement award

- $\quad$ Blog post - Centre for Innovative Ageing

2018

- $\quad$ Research As Art award

- $\quad$ Reaching Wider educational day event; Swansea University

- $\quad$ BSG conference oral presentation; University of Manchester

2017

- $\quad$ Research poster presentation-CADR conference; Cardiff City Hall

- $\quad$ BSG conference oral presentation; Swansea University

- $\quad$ CADR mini conference oral presentation; Swansea University

2016

- $\quad$ PGR oral conference presentation; Swansea University

2015

- $\quad$ Blog post - Campaign to End Loneliness

- $\quad$ Conference presentation - Campaign to End Loneliness; Cardiff City Hall

- $\quad$ PGR oral conference presentation; Swansea University

\section{Relevant teaching related to doctoral research}

- Teaching has been undertaken on a number of modules across Swansea University, across the past 4 years, during doctoral study.

. In relation to the present $\mathrm{PhD}$ research, I have taught as module lead \& guest lecturer on several Social Policy \& Social Research Methods modules, drawing upon $\mathrm{PhD}$ findings, implications, \& research approaches. 


\section{Bibliography}

Aboderin, I. (2004). Modernisation and ageing theory revisited: current explanations of recent developing world and historical Western shifts in material family support for older people. Ageing \& Society, 24(1), 29-50

Abrams, D., Russell, P., Vauclair, M, \& Swift, H. (2011). Ageism in Europe: Findings from the European Social Survey. Technical report. Age UK

Adler, G. \& Rotunda, S. (2006). Older adults' perspectives on driving cessation, Journal of Aging Studies, 20, 227-235. doi:10.1016/j.jaging.2005.09.003

Ahern, A., \& Hine, J. (2010). Transport for older people in rural areas. CARDI (Centre for Ageing Research and Development in Ireland). Retrieved from: https://pure.ulster.ac.uk/en/publications/transport-for-the-elderly-what-happensin-rural-areas-3, accessed 5.2.19

Al-Hassani, S. B., \& Alotaibi, N. M. (2014). The impact of driving cessation on older Kuwaiti adults: Implications to occupational therapy. Occupational therapy in health care, 28(3), 264-276

Alsnih, R. \& Hensher, D. (2003). The mobility and accessibility expectations of seniors in an aging population. Transportation Research Part A: Policy and Practice. $37(10), 903-916$

Andersson, H. \& Schytt, E. (2017). Sexism in Advertising: A Qualitative Study of the Influence on Consumer Attitudes Towards Companies (Master's thesis). Jonkoping, Sweden. Jonkoping University

Andrews, G. (2012). Just the ticket? Exploring the contribution of free bus fares policy to quality of later life (Doctoral thesis). Bristol, England. University of the West of England 
Anstey, K., Windsor, T., Luszcz, M. \& Andrews, G. (2005). Predicting Driving Cessation over 5 Years in Older Adults: Psychological Well-Being and Cognitive Competence Are Stronger Predictors than Physical Health. Journal of the American Geriatrics Society, 54(1), 121-126. doi: 0.1111/j.1532-5415.2005.00471.x

Andrews, M., Squire, C., \& Tamboukou, M. (Eds.). (2013). Doing narrative research. Sage.

Anstey, K., Windsor, T., Luszcz, M. \& Andrews, G. (2005). Predicting Driving Cessation over 5 Years in Older Adults: Psychological Well-Being and Cognitive Competence Are Stronger Predictors than Physical Health. Journal of the American Geriatrics Society, 54(1), 121-126. doi: 0.1111/j.1532-5415.2005.00471.x

Antonucci, T.C. (2001). Social relations: An examination of social networks, social support, and sense of control. In J. E. Birren \& K. W. Schaie (Eds.), Handbook of the psychology of aging (pp. 427-453). San Diego, CA, US: Academic Press.

Siren, A. K., \& Haustein, S. (2015). Driving licences and medical screening in old age: Review of literature and European licensing policies. Journal of Transport $\mathcal{E}^{2}$ Health, 2(1), 68-78 doi: 10.1016/j.jth.2014.09.003

Anu, S. \& Meng A. (2012). Cognitive screening of older drivers does not produce safety benefits. Accident Analysis and Prevention. 45, 634-638. doi: 10.1016/j.aap.2011.09.032

Atchley, R. C. (1994). Social forces and aging (7th ed.). Belmont, CA: Wadsworth.

Atchley, R. (1975). Adjustment to Loss of Job at Retirement. The International Journal of Aging and Human Development, 6(1), 17-27. doi: 10.2190/EHU3-VCRV-VCRJO4NU

Atkinson, R., \& Flint, J. (2001). Accessing hidden and hard-to-reach populations: Snowball research strategies. Social research update, 33(1), 1-4 
Austin, Z., \& Sutton, J. (2014). Qualitative research: getting started. The Canadian journal of hospital pharmacy, 67(6), 436-440. doi:10.4212/cjhp.v67i6.1406

Azad, N., Byszewski A., Amos, S. \& Molnar, F. (2002). A survey of the impact of driving cessation on older drivers. Journal of the Canadian Geriatrics Society, 5(4), 170174

Bailey, J. (2008). First steps in qualitative data analysis: transcribing, Family Practice, 25(2), 127-131, doi: 10.1093/fampra/cmn003

Baltes, M. M., \& Carstensen, L. L. (1996). The process of successful ageing. Ageing $\S^{2}$ Society, 16(4), 397-422

Baltes, P. B. (1997). On the incomplete architecture of human ontogeny: Selection, optimization, and compensation as foundation of developmental theory. American psychologist, 52(4), 366

Baltes, P. B., \& Baltes, M. M. (1990). Psychological perspectives on successful aging: The model of selective optimization with compensation. Successful aging: Perspectives from the behavioral sciences, 1(1), 1-34

Bamford, C., Gregson, B., Farrow, G., Buck, D., Dowshell, T., McNamee, P. \& Bond, J. (1998). Mental and physical frailty in older people: the costs and benefits of informal care. Ageing and Society, 18(3), 317-354

Barker, J. (2002). Neighbors, Friends, and Other Nonkin Caregivers of CommunityLiving Dependent Elders. The Journals of Gerontology. 57(3), 158-167. doi: $\underline{10.1093 / \text { geronb/57.3.S158 }}$

Barrett, A. \& Gumber, C. (2019). Feeling Older and Driving Less: The Effect of Age Identity on Older Adults' Transition from Driving. Innovation in aging, 3(1), doi:10.1093/geroni/igzo04 
Bauer, M., Rottunda, S. \& Adler, G. (2003). Older Women and Driving Cessation. Qualitative Social Work, 2(3), 309-325

Bazeley, P., \& Richards, L. (2000). The NVivo qualitative project book. Sage Research Methods. doi: https://dx.doi.org/10.4135/9780857020079

BBC News. (2019, January 18). Older drivers: Is age a factor behind the wheel?. Retrieved from: https://www.bbc.co.uk/news/uk-46916429, accessed 2.2.19

Berkman L., Sekher, T., Capistrant, B, et al. (2012). Social Networks, Family, and Care Giving Among Older Adults in India. In: National Research Council (US) Panel on Policy Research and Data Needs to Meet the Challenge of Aging in Asia; Aging in Asia: Findings From New and Emerging Data Initiatives. Washington (DC): National Academies Press (US). 11. Retrieved from: https://www.ncbi.nlm.nih.gov/books/NBK 109207/

Bevan, M., Andrews, E., Attuyer, K., Cambridge, H., Cinderby, S., Croucher, K., Edwards, A., Gilroy, R., Lewis, A., Mathews, B., McInnes, L., Petrie, H., Power, C., Swallow, D. and Tunstall, B. (2017) Co-Motion: Mobility and wellbeing in later life. Summary of key findings and recommendations. York: University of York.

Bhatti, M. (2006). 'When I'm in the garden I can create my own paradise': Homes and gardens in later life. The Sociological Review, 54(2), 318-341

Bianchi, S., Milkie, M., Sayer, L. \& Robinson, J. (2000). Is anyone doing the housework? Trends in the gender division of household labor. Social Forces, 79, 191228

Blood, I. (2010). Older people with high support needs: how can we empower them to enjoy a better life (Research Report No. 2543). Retrieved from: https://www.jrf.org.uk/report/older-people-high-support-needs-round-evidence, accessed 2.1.19

Bloomberg, L. \& Volpe, M. (2016). Completing your qualitative dissertation, $3^{\text {rd }}$ edition. SAGE, California. 
Bonder, B., \& Dal Bello-Has. V. (2009). Functional performance in older adults. Philadelphia: F.A. Davis Co.

Bonnel, W. B. (1999). Giving up the car: older women's losses and experiences. Journal of psychosocial nursing and mental health services, 37(5), 10-15

Bowers, H., Clark, A., Crosby, G., Easterbrook, L., Macadam, A., MacDonald, R., ... \& Oshinaike, T. (2009). Older people's vision for long-term care. York: Joseph Rowntree Foundation.

Bowling, A. (2002). Research Methods in Health: Investigating health and health services. Second Edition. Buckingham, Open University Press. Retrieved from: http://www.dphu.org/uploads/attachements/books/books 2615 0.pdf, accessed 2.1.19

Bowling. A. (2008). Enhancing later life: How older people perceive active ageing. Aging and Mental Health. 12(3), 293-301. doi: 10.1080/13607860802120979

Boudiny, K. (2013). 'Active ageing': from empty rhetoric to effective policy tool. Ageing and society, 33(6), 1077-1098. doi: 10.1017/So 144686X1200030X

Braitman, K., Bevan B. Kirley, Susan Ferguson \& Neil K. Chaudhary (2007) Factors Leading to Older Drivers' Intersection Crashes, Traffic Injury Prevention, 8:3, 267274, doi: $\underline{10.1080 / 15389580701272346}$

Braun, V. \& Clarke, V. (2006). Using thematic analysis in psychology, Qualitative Research in Psychology, 3(2), 77-101. doi: 10.1191/1478088706qp0630a

Breen, D. A., Breen, D. P., Moore, J. W., Breen, P. A., \& O'Neill, D. (2007). Driving and dementia. Bmj, 334(7608), 1365-1369

Bridges, T. (2013, January 3). Inequality by (Interior) Design: A Brief History of the Masculinization of the Garage. Retrieved from: 
https://inequalitybyinteriordesign.wordpress.com/2013/01/03/a-brief-history-ofthe-masculinization-of-the-garage/, accessed 2.1.19

Bryanton, O., Weeks, L. E., \& Lees, J. M. (2010). Supporting older women in the transition to driving cessation. Activities, Adaptation \& Aging, 34(3), 181-195

Bryman, A. (2008). "Of methods and methodology". Qualitative Research in Organizations and Management: An International Journal,3(2), 159-168. doi: $\underline{10.1108 / 17465640810900568}$

Bryman, A. (2016). Social research methods. Oxford. Oxford University Press.

Buckholz, M. (1978). Informal Support Systems for the Aged: Limitations and Issues. Journal of Sociology \& Social Welfare, 5(6), 773-780

Burholt, V., Sardani, A., Evans, E. \& Murray, A. (2018). Unveiling the story: Wellbeing of Wales 2016-17 for older people. (Unpublished) Retrieved from: file:///C:/Users/Amy/Downloads/WoW\%20in\%20Later\%20Life\%2oReport\%20\%20merged\%20V6\%20(1).pdf, accessed 1.1.19

Burkhardt, J., Berger, A., 1997. The mobility consequences of the reduction or cessation of driving. Paper presented at the 1997 Annual Meeting of the Transportation Research Board.

Burkhardt, J. E. (1999). Mobility changes: Their nature, effects, and meaning for elders who reduce or cease driving. Transportation Research Record, 1671(1), 11-18

Burkhardt, J., Berger, A. M., \& McGavock, A. T. (2000, January). The mobility consequences of the reduction or cessation of driving by older women. In Women's Travel Issues Second National Conference Drachman Institute of the University of Arizona; Morgan State University; Federal Highway Administration.

Butcher, L. (2017). Older drivers. Briefing paper Number SN409, House of Commons library, UK. 
Buys, L. R., \& Carpenter, L. (2002). Cessation of driving in later life may not result in dependence. Australasian Journal on Ageing, 21(3), 152-155

Cal, A. \& Tehmarn, A. (2016). "Phenomenological Epistemology Approaches and Implications for HRD Research and Practice”. UFHRD, University Forum of Human Resource Development, Manchester, England.

Cantor, M. H. (1979). Neighbors and friends: An overlooked resource in the informal support system. Research on Aging, 1, 434-463

Carr, K. (2008). Qualitative Research to Assess Interest in Public Transportation for Work Commute. Journal of Public Transportation, 11,(1), 1-16. doi: http://doi.org/10.5038/2375-0901.11.1.1

Carter, S. M., \& Little, M. (2007). Justifying knowledge, justifying method, taking action: Epistemologies, methodologies, and methods in qualitative research. Qualitative health research, 17(10), 1316-1328

Centre for Policy on Ageing (2014, July). The care and support of older people - an international perspective. Retrieved from: https://www.ageuk.org.uk/Documents/EN-GB/Forprofessionals/Research/CPA-

International care and support of older people.pdf? dtrk=true, accessed 2.1.19

Chacko, E. E., Wright, W. M., Worrall, R. C., Adamson, C., \& Cheung, G. (2015). Reactions to driving cessation: a qualitative study of people with dementia and their families. Australasian Psychiatry, 23(5), 496-499

Chan, N., Anstey, K., Windsor, T. \& Luszcz, M. (2011). Disability and Depressive Symptoms in Later Life: The Stress-Buffering Role of Informal and Formal Support. Gerontology, 57, 180-189. doi: 10.1159/000314158 
Chihuri, S., Mielenz, T. J., DiMaggio, C. J., Betz, M. E., DiGuiseppi, C., Jones, V. C., \& Li, G. (2016). Driving cessation and health outcomes in older adults. Journal of the American Geriatrics Society, 64(2), 332-341

Chipman, M. L., Payne, J., \& McDonough, P. (1998). To drive or not to drive: The influence of social factors on the decisions of elderly drivers. Accident Analysis \& Prevention, 30(3), 299-304

Choi, M., Adams, K. B., \& Kahana, E. (2012). The impact of transportation support on driving cessation among community-dwelling older adults. Journals of Gerontology Series B: Psychological Sciences and Social Sciences, 67(3), 392-400

Choi, M., Adams, K. B., \& Mezuk, B. (2012). Examining the aging process through the stress-coping framework: application to driving cessation in later life. Aging $\mathbb{E}$ mental health, 16(1), 75-83

Choi, M., Mezuk, B., \& Rebok, G. W. (2012). Voluntary and involuntary driving cessation in later life. Journal of Gerontological Social Work, 55(4), 367-376

Cicirelli, V. G. (1993). Attachment and obligation as daughters' motives for caregiving behavior and subsequent effect on subjective burden. Psychology and aging, 8(2), 144

Cohen, M. Z., \& Omery, A. (1994). Schools of phenomenology. In J. M. Morse (Ed.), Critical issues in qualitative research (pp. 136-156). Thousand Oaks, CA: Sage.

Congdon, J.D., Drawer, P.O., \& Dunham, A.E. (1999). Defining the beginning: the importance of research design. Retrieved from: https://www.semanticscholar.org/paper/Defining-the-beginning\%3A-theimportance-of-research-Congdon-

Drawer/85b012169615a440d0c48d87c6d83657b8d2a3df, accessed 5.2.19 
Connell, C., Harmon, A., Janevic, M. \& Kostyniuk, L. (2012). Older Adults' Driving Reduction and Cessation: Perspectives of Adult Children. Journal of Applied Gerontology. 32(8), doi: $10.1177 / 0733464812448962$

Coughlin, J. (2001). Transportation and older persons: Perceptions and preferences: A report on focus groups.

Coughlin, J. F. (2001). Beyond health and retirement: Placing transportation on the aging policy agenda.

Cowgill, D.O. (1972). A theory of aging in cross-cultural perspective. In Cowgill, D. O. and Holmes, L. D. (eds), Ageing and Modernization. Appleton-Century-Crofts, New York, 1-14

Creswell, J. W. (2013). Qualitative Inquiry \& Research Design: Choosing among Five Approaches (3rd ed.). Thousand Oaks, CA: SAGE.

Creswell, J. (2015). 30 essential skills for the qualitative researcher. Los Angeles, CA: SAGE.

Cronin, P., Ryan, F., \& Coughlan, M. (2008). Undertaking a literature review: a stepby-step approach. British journal of nursing, 17(1), 38-43

Cumming, E. \& Henry, W.E. (1961). Growing old: The process of disengagement. New York, NY: Basic Books.

Curl, A. \& Davison, L. (2014). Transport geography: perspectives upon entering an accomplished research sub-discipline. Journal of Transport Geography, 38, 100-105. doi: 10.1016/j.jtrangeo.2014.05.018

Curl, A. L., Proulx, C. M., Stowe, J. D., \& Cooney, T. M. (2015). Productive and social engagement following driving cessation: A couple-based analysis. Research on aging, 37(2), 171-199 
Curl, A., Stowe, J., Cooney, T. \& Proulx, C. (2013). Giving Up the Keys: How Driving Cessation Affects Engagement in Later Life, The Gerontologist, 54(3), 423-433. doi: $\underline{10.1093 / \text { geront/gnto37 }}$

Curro, M. (2012). Seniors' perceptions around driving cessation: a multi-ethnic, multicultural perspective (Doctoral dissertation, University of British Columbia).

Cvitkovich, Y., \& Wister, A. (2001). The importance of transportation and prioritization of environmental needs to sustain well-being among older adults. Environment and Behavior, 33(6), 809-829

D’Ambrosio, L. A., \& Gilbert, J. (2004). Who drives older drivers' decisions? (Report from the MIT AgeLab and Hartford Financial Services Group. Retrieved from: http://web.mit.edu/coughlin/agelabsite/news_events/pdfs/AgeLab_ driver_decision.pdf, accessed 1.1.19

Daher, M., Carre, D., Jaramillo, A., Olivares, H. \& Tomicic, A. (2017). Experience and Meaning in Qualitative Research: A Conceptual Review and a Methodological Device Proposal. Forum: Qualitative Social Research, 18(3), 1-96. doi: http://dx.doi.org/10.17169/fqs-18.3.2696.

Davis Smith, J. \& Gay, P. (2005). Active ageing in active communities - volunteering and the transition to retirement, Joseph Rowntree Foundation. Retrieved from: https://www.jrf.org.uk/sites/default/files/jrf/migrated/files/1861347626.pdf, accessed 4.12.19

Dellinger, A. M., Sehgal, M., Sleet, D. A., \& Barrett-Connor, E. (2001). Driving cessation: What older former drivers tell us. Journal of the American Geriatrics Society, 49(4), 431-435

DeLiema, M. \& Bengtson, V. (2015). Activity Theory, Disengagement Theory, and Successful Aging. Encyclopedia of Geropsychology. doi: 10.1007/978-981-287-0803_102-1 
del-Pino-Casado, R., Frias-Osuna, A. \& Palomino-Moral, P. (2011). Subjective Burden and Cultural Motives for Caregiving in Informal Caregivers of Older People. Journal of Nursing Scholarship. 43(3), 282-291. doi: 10.1111/j.1547$5069.2011 .01407 . \mathrm{x}$

Department for Transport. (2018). Statistical data set: Driving licence holding and vehicle availability. Retrieved from: https://www.gov.uk/government/statistical-datasets/nts02-driving-licence-holders

Devers, K. J., \& Frankel, R. M. (2000). Study design in qualitative research--2: Sampling and data collection strategies. Education for health, 13(2), 263

DiCicco-Bloom B, \& Crabtree BF. (2006). The qualitative research interview. Medical Education, 4O(4), 314-321

Dickerson, A., Molnar, L., Bédard, M., Eby, D., Berg-Weger, M., Choi, M., Grigg, J., Horowitz, A., Meuser, T., Myers, A., O’Connor, M., Silverstein, M. (2019) Transportation and Aging: An Updated Research Agenda to Advance Safe Mobility among Older Adults Transitioning From Driving to Non-driving, The Gerontologist, 59(2), 215-221. Doi: 10.1093/geront/gnx 120

Dickson-Swift, V., James, E., Kippen, S. \& and Liamputtong, P. (2008). Risk to Researchers in Qualitative Research on Sensitive Topics: Issues and Strategies. Qualitative Health Research. 18, 133-144

Diendl, C. \& Brandt, M. (2017). Support networks of childless older people: informal and formal support in Europe. Ageing $\S^{2}$ Society, 37(8), 1543-1567. doi: $10.1017 /$ So $144686 \mathrm{X} 16000416$

Donorfio, L., Mohyde, M., Coughlin, J. \& D'Ambrosio, L. (2008). A Qualitative Exploration of Self-Regulation Behaviors Among Older Drivers, Journal of Aging \& Social Policy, 20:3, 323-339, doi: $\underline{\text { 10.1080/08959420802050975 }}$ 
Duner, A. \& Nordstrom, M. (2007). The roles and functions of the informal support networks of older people who receive formal support: a Swedish qualitative study, Ageing \& Society, 27, 67-85. doi: 10.1017/S0144686X06005344

Durant, T. \& Christian, O. (2006). Caregiving to aging parents. Forum on Public Policy. Retrieved from https://www.questia.com/library/journal/1G1244026560/caregiving-to-aging-parents, accessed 1.1.19

Dwyer, K. (2017, May 16). Driving Dilemmas: Risk vs. Independence. Retrieved from: $\quad$ https://caregiver.com/articles/driving-dilemmas-risk-vs-independence/, accessed 6.2.19

Dykstra, P. (2015). Aging and Social Support. The Blackwell Encyclopedia of Sociology. doi: https://doi.org/10.1002/9781405165518.wbeosa033.pub2

Easton, K., McComish, J. \& Greenberg, R. (2000). Avoiding Common Pitfalls in Qualitative Data Collection and Transcription. Qualitative Health Research, 10(5), 703-707. doi: 10.1177/104973200129118651

Eby, D., Molnar, L., Kostyniuk, L., St Louis, R. \& Zanier, N. (2017). Characteristics of informal caregivers who provide transportation assistance to older adults. Public Library of Science. 12(9). doi: 10.1371/journal.pone.0184085

Edirisingha, P. (2012). Interpretivism and Positivism (Ontological and Epistemological Perspectives). Retrieved from: https://prabash78.wordpress.com/2012/03/14/interpretivism-and-postivismontological-and-epistemological-perspectives/, accessed 6.2.19

Edwards, J., Ross, L., Ackerman, M., Small, B., Ball, K. , Bradley, S., \& Dodson, J. (2008). Longitudinal predictors of driving cessation among older adults from the ACTIVE clinical trial. The Journals of Gerontology Series B: Psychological Sciences and Social Sciences, 63(1), 6-12. doi: 10.1093/geronb/63.1.p6 
Edwards, R. \& Holland, J. (2013). What is qualitative interviewing? London, Bloomsbury

Eisenhandler, S. (1990). The asphalt identikit: old age and the driver's license. International Journal of Aging and Human Development, 30(1), 1-14

Ellaway, A., Macintyre, S., Hiscock, R. \& Kearns, A. (2003). In the driving seat: psychosocial benefits from private motor vehicle transport compared to public transport. Transportation Research Part F. 6, 217-231. doi: 10.1016/S13698478(03)00027-5

Elwood, S. \& Martin, G. (2000). "Placing” Interviews: Location and Scales of Power in Qualitative Research. The Professional Geographer, 52(4), 649-657. doi: $10.1111 / 0033-0124.00253$

Emerson, R. M. (1976). Social exchange theory. Annual review of sociology, 2(1), 335362

Enterlante, T. M., \& Kern, J. M. (1995). Wives' reported role changes following a husband's stroke: a pilot study. Rehabilitation Nursing, 2O(3), 155-160

Estes, C. L. (2001). Social policy and aging: A critical perspective. Sage.

Alkassim, R., \& Abubakar, S. (2016). Comparision of snowball sampling and sequential sampling technique. Biometrics and Biostatistics International Journal, 3(1), 55

European Commission, European Sector Skills Council, Blueprint for Sectoral Cooperation on Skills - European Sector Skills Councils: Automotive (2016): 36-46. Retrieved from: https://ec.europa.eu/social/main.jsp?catId=1415\&intPageId=5062, accessed 6.2.19

European Commission. (2010). 2012 to be European year for active ageing. DG Employment Social Affairs and Inclusion: Retrieved from 
http://ec.europa.eu/social/main.jsp?langId=en\&catId=89\&newsId=860, accessed 6.2.19

European Social Survey. (2012). Experiences and Expressions of Ageism: Topline Results (UK) from Round 4 of the European Social Survey: London. Retrieved from: https://www.europeansocialsurvey.org/docs/findings/ESS4 gb toplines experien ces_and_expressions_of_ageism.pdf , accessed 5.2.19

Ferrari, R. (2015). Writing narrative style literature reviews. Medical Writing, 24(4), 230-235

Finch, J. \& Mason, J. (1993). Negotiating Family Responsibilities. Tavistock/Routledge, London.

Finlayson, M., \& Kaufert, J. (2002). Older women's community mobility: a qualitative exploration. Canadian Journal on Aging/La Revue canadienne du vieillissement, 21(1), $75-84$

Fiske, A., Wetherell, J. L., \& Gatz, M. (2009). Depression in older adults. Annual review of clinical psychology, 5, 363-389

Fonda, S. J., Wallace, R. B., \& Herzog, A. R. (2001). Changes in driving patterns and worsening depressive symptoms among older adults. The Journals of Gerontology Series B: Psychological Sciences and Social Sciences, 56(6), 343-351

Frankel, R. \& Devers, K. (2000). Study design in qualitative research--1: Developing questions and assessing resource needs. Education for health, 13(2), 251

Freund, B. \& Szinovacz, M. (2002) Effects of cognition on driving involvement among the oldest old: Variations by gender and alternative transportation opportunities. The Gerontologist. 42, 62 1-633. doi: 10.1093/geront/42.5.621

Froster, L. \& Walker, A. (2015). Active and Successful Aging: A European Policy Perspective. The Gerontologist, 55(1), 83-90. doi:10.1093/geront/gnu028 
Frost-Steward, J. (2015). "It seems like it should be so simple": The role of the family in elder driving retirement. (Doctoral dissertation). Manhattan, Kansas: Kansas State University.

Fuller, R. (2005). Towards a general theory of driver behaviour. Accident analysis $\S^{\circ}$ prevention, 37(3), 461-472

Gadamer, H. (1976). Philosophical Hermeneutics. London. University California Press.

Gallo, J. J., Rebok, G. W., \& Lesikar, S. E. (1999). The driving habits of adults aged 60 years and older. Journal of the American Geriatrics Society, 47(3), 335-341

Gardezi, F., Wilson, K. G., Man-Son-Hing, M., Marshall, S. C., Molnur, F. J., Dobbs, B. \& Tuokko, H. 2006. Qualitative research on older drivers. Clinical Gerontologist, 30, 1, 5-22. doi: 10.1300/Jo18v30no1_02

Gardiner, C., Geldenhuys, G. \& Gott, M. (2018). Interventions to reduce social isolation and loneliness among older people: an integrative review. Health and Social Care in the Community, 26(2), 147-157 doi: 10.1111/hsc.12367

Gearing, R. (2004). Bracketing in research: A typology. Qualitative health research, 14(10), 1429-1452

Gilhooly, M., Hamilton, K., Age Concern Scotland, Gow, J., Webster, N., Pike, F., Bainbridge, K. (2004). Transport and Ageing: Extending Quality of Life for Older People Via Public and Private Transport, 2000-2001. UK Data Service. SN: 5035, http://doi.org/10.5255/UKDA-SN-5035-1

Gillins, L. (1990). Yielding to age: When the elderly can no longer drive. Journal of gerontological nursing, $16(11), 12-15$

Given, L. (2008). The SAGE encyclopedia of qualitative research methods (Vols. 1-0). Thousand Oaks, CA: SAGE Publications, Inc. doi: 10.4135/9781412963909 
Glasgow, N., \& Blakely, R. (2000). Older nonmetropolitan residents' evaluations of their transportation arrangements. Journal of Applied Gerontology, 19(1), 95-1 16

Gorman-Murray, A. (2013) Urban homebodies: embodiment, masculinity, and domesticity. Geographical Research. 51(2), 137-1447 doi: 10.1111/j.1745$\underline{5871.2011 .00750 . \mathrm{x}}$

Gov.UK. (undated). Pension Credit. Retrieved from: https://www.gov.uk/pensioncredit/eligibility, accessed 2.2.19

Gray, D., Shaw, J \& Farringdon, J. (2006). Community transport, social capital and social exclusion in rural areas, Area, 38(1), 89-98

Green, B., Johnson, C. \& Adams, A. (2006). Writing narrative literature reviews for peer-reviewed journals: secrets of the trade. Journal of Chiropractic Medicine, 5(3), 101117. doi: 10.1016/S0899-3467(07)60142-6

Green, J., Jones, A., \& Roberts, H. (2014). More than A to B: the role of free bus travel for the mobility and wellbeing of older citizens in London. Ageing Eீ Society, 34(3), $472-494$

Green, J., Willis, K., Hughes, E., Small, R., Welch, N., Gibbs, L. \& Daly, J. (2007). Generating best evidence from qualitative research: the role of data analysis. Australian And New Zealand Journal Of Public Health, 31 (6), 545-550

Griffiths, P., Gossop, M., Powis, B. \& Strang, J. (1993). Reaching hidden populations of drug users by privileged access interviewers: methodological and practical issues, Addiction, 88, 1617-1626

Groessl, E., Kaplan, R., Rejeski, W., Katula, J., King, A. \& Frierson, G. (2007). Healthrelated quality of life in older adults at risk for disability, American Journal of Preventive Medicine. 33, 214-218. doi: 10.1016/j.amepre.2007.04.031

Grosvenor, T. (2000). Qualitative research in the transport sector (No. E-Co08,) 
Guest, G. (2012). Applied thematic analysis. Thousand Oaks, California: Sage.

Guest, G., Bunce, A. \& Johnson, L. (2006). 'How many interviews are enough? An experiment with Data Saturation and Variability'. Field Methods, 18, 59-82

Hakamies-Blomqvist, L., \& Wahlström, B. (1998). Why do older drivers give up driving?. Accident Analysis \& Prevention, 30(3), 305-312

Hanson, T. \& Hildebrand, E. (2011). Can rural older drivers meet their needs without a car? Stated adaptation responses from a GPS travel diary survey. Transportation, 38(6), 975-992

Hart, C. (2018). Doing a literature review: Releasing the research imagination. Sage.

Havighurst, R. (1961). Successful aging. The Gerontologist, 1, 8-13. doi: $10.1093 /$ geront/1.1.8

The Hawthorne effect. (2004). In Payne, G., \& Payne, J. Sage key Concepts: Key concepts in social research (pp. 108-111). London: SAGE Publications, Ltd doi: $10.4135 / 9781849209397$

Heidegger, M. (1962). Being and time (J. Macquarrie \& E. Robinson, Trans.). New York: Harper and Row

Heinz, M., Cone, N., da Rosa, G., Bishop, A. \& Finchum, T. (2017). Examining Supportive Evidence for Psychosocial Theories of Aging within the Oral History Narratives of Centenarians. Societies, 7(8). doi:10.3390/soc7020008

Held D (1996) Democracy and the global order: from the modern state to cosmopolitan governance Polity Press, Oxford

Henretig, F., Durbin, D., Kallan, M. \& Winston, F. (2011). Grandparents driving grandchildren: an evaluation of child passenger safety and injuries. Pediatrics-English Edition, 128(2), 289-295. doi: 10.1542/peds.2011-0046 
Henretta, J., Hill, M., Li, W., Soldo, B. \& Wolf, D. (1997). Selection of children to provide care: The effect of earlier parental transfers. Journal of Gerontology, Series BPsychological Sciences and Social Sciences, 52, 110-119

Hogeboom, D., McDermott, R., Perrin, K., Osman, H. \& Bell Ellison, B. (2010). Internet use and social networking among middle aged and older adults. Educational Gerontology, 36, 93-111. doi:10.1080/03601270903058507

Hirai, H., Ichikawa, M., Kondo, N., \& Kondo, K. (2019). The risk of functional limitations after driving cessation among older Japanese adults: the JAGES cohort study. Journal of Epidemiology, JE20180260.

Hjortold, R. (2013). Transport resources, mobility and unmet transport needs in old age. Ageing E Society, 33, 1190-1211. doi: 10.1017/SO 144686X12000517

Holland, S., Greenberg, J., Tidwell, L., Malone, J., Mullan, J., \& Newcomer, R. (2005). Community-based health coaching, exercise, and health service utilization. Journal of Aging and Health, 17(6), 697-716

Holley-Moore, G., \& Creighton, H. (2015). The future of transport in an ageing society. London, UK: International Longevity Centre-UK.

Homans, G. (1958). Social Behavior as Exchange. American Journal of Sociology, 63(6), 597-606

Hooyman, N., \& Kiyak, H. A. (1996). Social gerontology: A multidisciplinary perspective (4th ed.). Needham Heights, MA: Allyn \& Bacon

Horowitz, A., Boerner, K., \& Reinhardt, J. P. (2002). Psychosocial aspects of driving transitions in elders with low vision. Gerontechnology. 1(4), 262-273. Doi: $10.4017 /$ gt.2002.01.04.005.00

Hoschild, A. (1975). Disengagement theory: a critique and proposal. American Sociological Review, 40(5), 553-69 
House of Lords. (2018, April 18). The Ties that Bind: Citizenship and Civic Engagement in the $21 \mathrm{st}$ Century. Retrieved from: https://publications.parliament.uk/pa/ld201719/ldselect/ldcitizen/118/118.pdf, accessed 4.12 .19

Husserl, E. (1970). The crisis of European sciences and transcendental phenomenology: An introduction to phenomenological philosophy. Northwestern University Press.

Ichikawa, M., Nakahara, S. \& Takahashi, H. (2016). The impact of transportation alternatives on the decision to cease driving by older adults in Japan. Transportation. $43(3), 443-453$

Illario, M., Vollenbroek-Hutten, M., Molloy, D., Menditto, E., Iaccarino, G. \& Eklund, P. (2016). Active and Healthy Ageing and Independent Living 2016. Journal of aging research, 8062079. doi:10.1155/2016/8062079

Jette, A. \& Branch, L. (1992). A ten-year follow-up of driving patterns among the community-dwelling elderly. Human factors, 34(1), 25-31

Jetten, J. \& Pachana, N. (2012). Not wanting to grow old: A Social Identity Model of Identity Change (SIMIC) analysis of driving cessation among older adults. In J. Jetten, J, Haslam, C. \& Haslam. S. (Eds.). The social cure: Identity, health and well-being, 97-1 13. Psychology Press.

Joanisse, M., Gagnon, S. \& Voloaca, M. (2012). The impact of Stereotype Threat on the simulated driving performance of older drivers. Accident; analysis and prevention. 50, 530-538. doi: 10.1016/j.aap.2012.05.032

Johnson, C. \& Keltner, J. (1983). Incidence of visual field loss in 20,000 eyes and its relationship to driving performance. Archives of Ophthalmology, 101(3), 371-375

Johnson, J. (1998). Older rural adults and the decision to stop driving: The influence of family and friends. Journal of community health nursing, 15(4), 205-216. https://doi.org/10.1207/s15327655jchn1504_2 
Johnson, J. (2008). Informal social support networks and the maintenance of voluntary driving cessation by older rural women. Journal of Community Health Nursing, 25(2), 65-72. https://doi.org/10.1080/07370010802017034

Johnson, N. (2009). The role of self and emotion within qualitative sensitive research: a reflective account. Enquire. 2(2), 191-214

Kahana, E., Bhatta, T., Lovegreen, L., Kahana, B., \& Midlarsky, E. (2013). Altruism, helping, and volunteering: pathways to well-being in late life. Journal of aging and health, 25(1), 159-187. doi:10.1177/0898264312469665

Kahvedzic, A. (October 2013). International re-licensing models of older drivers. Royal College of Physicians of Ireland. Retrieved from: https://rcpi-livecdn.s3.amazonaws.com/wp-content/uploads/2016/02/4_International-Re-

Licensing-Models-of-Older-Drivers-1.pdf, accessed 28.6.19

Kaufman, S. R. (1994). The ageless self: Sources of meaning in late life. University of Wisconsin Press.

Kelley, H. \& Thibaut, J. (1978). Interpersonal relations: A theory of interdependence. New York: Wiley.

Kenyon, S., Rafferty, J. and Lyons, G. (2003) Social exclusion and transport: A role for virtual accessibility in the alleviation of mobility related social exclusion? Journal of Social Policy, 32 (3), 317-338. doi: 10.1017/So047279403007037

Keltner, J. \& Johnson, C. (1987). Visual function, driving safety, and the elderly. Ophthalmology, 94(9), 1180-1188

Keltner, J. \& Johnson, C. (1992). Visual function and driving safety. Archives of Ophthalmology, 110(12), 1697-1698 
Khan, Z., Braich, P., Rahim, K., Rayat, J., Xing, L., Iqbal, M. \& Almeida, D. (2016). Burden and depression among caregivers of visually impaired patients in a Canadian population. Advances in medicine. 1-8. doi: 10.1155/2016/4683427

Kim, H. \& Richardson, V. (2006). Driving cessation and consumption expenses in the later years. The Journals of Gerontology Series B: Psychological Sciences and Social Sciences, 61(6), 347-353

Kim, Y. (2010). The Pilot Study in Qualitative Inquiry Identifying Issues and Learning Lessons for Culturally Competent Research. Qualitative Social Work, 10(2), 190-206. doi: 10.1177/1473325010362001

Kington, R., Reuben, D., Rogowski, J., \& Lillard, L. (1994). Sociodemographic and health factors in driving patterns after 50 years of age. American journal of public health, 84(8), 1327-1329

Książkiewicz, S. (2012). Quantitative or qualitative transport planning? An interdisciplinary geographic perspective. Prace Geograficzne, (130), 131-139

Lambert, C., Jomeen, J. \& McSherry, W. (2015). Reflexivity: a review of the literature in the context of midwifery research. British Journal of Midwifery, 18(5). doi: $\underline{10.12968 / \text { bjom.2010.18.5.47872 }}$

Law, M., Stewart, D., Letts, L., Pollock, N., Bosch, J., \& Westmorland, M. (1998). Guidelines for critical review of qualitative studies. McMaster University occupational therapy evidence-based practice research Group.

Lehtinen, V., Näsänen, J., \& Sarvas, R. (2009, September). A little silly and emptyheaded: older adults' understandings of social networking sites. In Proceedings of the 23rd British HCI Group Annual Conference on People and Computers: Celebrating People and Technology (pp. 45-54). British Computer Society.

LeVasseur, J. (2003). The problem of bracketing in phenomenology. Qualitative health research, 13(3), 408-420 
Liang, P., Gustafsson, L., Liddle, J. \& Fleming, J. (2014). Family members' needs and experiences of driving disruption due to health conditions or ageing, Journal of Disability and Rehabilitation, 37(22), 2114-2129

Liddle, J. \& McKenna, K. (2003). Older Drivers and Driving Cessation. British Journal of Occupational Therapy, 66(3), 125-132. doi: 10.1177/030802260306600307

Liddle, J., Gustafsson, L., Bartlett, H., \& McKenna, K. (2012). Time use, role participation and life satisfaction of older people: Impact of driving status. Australian Occupational Therapy Journal, 59(5), 384-392

Liddle, J., Gustafsson, L., Mitchell, G. \& Pachana, N. (2016). A Difficult Journey: Reflections on Driving and Driving Cessation From a Team of Clinical Researchers, The Gerontologist, 57(1), 82-88. doi: 10.1093/geront/gnw079

Liddle, J., Hayes, R., Gustafsson, L., \& Fleming, J. (2014). Managing driving issues after an acquired brain injury: Strategies used by health professionals. Australian occupational therapy journal, 61(4), 215-223

Liddle, J., Reaston, T., Pachana, N., Mitchell, G., \& Gustafsson, L. (2014). Is planning for driving cessation critical for the well-being and lifestyle of older drivers?. International psychogeriatrics, 26(7), 11111-1120

Lie, M., Baines, S. \& Wheelock, J. (2009). Citizenship, Volunteering and Active Ageing. Social Policy and Administration. 43(7), 702-718. doi: 10.1111/j.14679515.2009.00690.x

Lincoln, Y. S., \& Guba, E. G. (2000). Paradigmatic controversies, contradictions, and emerging confluences. In N. K. Denzin, \& Y. S. Lincoln (Eds.), The handbook of qualitative research (2nd ed., pp. 1065-1 122), Thousand Oaks, CA: Sage Publications.

Lopez. K. \& Willis, D. (2004). Descriptive Versus Interpretive Phenomenology: Their Contributions to Nursing Knowledge, Qualitative Health Research, 14, 726-735. doi: $10.1177 / 1049732304263638$ 
Lorca, M., \& Ponce, M. (2015). Normative, Structural, and Individual Factors that Predispose Adult Children to Provide Social Support to Their Elderly Parents. Journal of Comparative Family Studies, 4, 517-540

Loughran, D., Seabury, S. \& Zakaras, L. (2007). What Risks Do Older Drivers Pose to Traffic Safety?. Santa Monica, CA: RAND Corporation. Retrieved from: https://www.rand.org/pubs/research_briefs/RB9272.html

Lucas, K. (2013). Qualitative methods in transport research: the 'action research' approach. In: Zmud, J, Lee-Gosselin, M and Carrasco, JA, (eds.) Transport Survey Methods: Best practice for decision making. Emerald Publishing

Luckow, A., Reifman, A., \& McIntosh, D. (1998). Gender differences in coping: A meta-analysis. Poster presented to the annual meetings of the American Psychological Association, San Francisco, CA

Luiu, C., Tight, M. \& Burrow, M. (2018). Factors Preventing the Use of Alternative Transport Modes to the Car in Later Life. Sustainability, 10(6), 1982

Lumsden, K. (2010). Gendered performances in a male-dominated subculture: 'girl racers', car modification and the quest for masculinity. Sociological Research Online, 15 (3). doi: $10.5153 /$ sro.2123

Lyman, J., McGwin Jr, G. \& Sims, R. (2001). Factors related to driving difficulty and habits in older drivers. Accident Analysis \& Prevention, 33(3), 413-42 1

Lyons, G. (2004). Transport and society. Transport Reviews, 24(4), 485-509

Lyons, G., Jain, J., \& Holley, D. (2007). The use of travel time by rail passengers in Great Britain. Transportation Research Part A: Policy and Practice, 41(1), 107-120

MacLeod, K., Satariano, W. \& Ragland, D. (2014). The Impact of Health Problems on Driving Status among Older Adults. Journal of transport \& health, 1(2), 86-94. doi: $10.1016 /$ j.jth.2014.03.001 
Maharaj, N. (2016). Using field notes to facilitate critical reflection. Journal of Reflective Practice: International and Multidisciplinary Perspectives, 17(2), 114-124. doi: $\underline{10.1080 / 14623943.2015 .1134472}$

Malhotra, C., Malhotra, R., Ostbye, T., Matchar, D. \& Chan, A. (2012). Depressive symptoms among informal caregivers of older adults: insights from the Singapore Survey on Informal Caregiving. International Psychogeriatrics. 24(8), 1335-46. doi: $10.1017 / \mathrm{S} 1041610212000324$

Many older drivers concerned about loss of identity and independence if they have to stop driving, new survey reveals (2017, September 11). Retrieved from: https://www.independentage.org/news-media/press-releases/many-older-driversconcerned-about-loss-of-identity-and-independence-if, accessed 5.2.19

Marottoli, R. (1993). Driving safety in elderly individuals. Connecticut medicine, 57(5), $277-280$

Marottoli, R. \& Drickamer, M. (1993). Psychomotor mobility and the elderly driver. Clinics in geriatric medicine, 9(2), 403-411

Marottoli, R. A., De Leon, C. F. M., Glass, T. A., Williams, C. S., Cooney Jr, L. M., Berkman, L. F., \& Tinetti, M. E. (1997). Driving cessation and increased depressive symptoms: prospective evidence from the New Haven EPESE. Journal of the American Geriatrics Society, 45(2), 202-206

Marottoli, R., Ostfeld, A., Merrill, S., Perlman, G., Foley, D. \& Cooney Jr, L. (1993). Driving cessation and changes in mileage driven among elderly individuals. Journal of gerontology, 48(5), 255-260

Mars, L., Arroyo, R. \& Ruiz, T. (2016). Qualitative Research in Travel Behavior Studies. Transportation Research Procedia, 18, 434-445. doi: 10.1016/j.trpro.2016.12.057 
Martin, C. \& Ruble, D. (2010). Patterns of gender development. Annual review of psychology, 61, 353-381. doi:10.1146/annurev.psych.093008.100511

Maxwell, J. A. (2012). Qualitative research design: An interactive approach (Vol. 41). Sage publications.

McHugh, K. (2003). Three faces of ageism: society, image and place. Ageing $\mathcal{E}^{2}$ Society, 23(2), 165-185

McInerney, S. (2009). Driving cessation and quality of life for older adults. California State University, Long Beach.

Medical Research Council. (2003). Personal Information in Medical Research: London. Retrieved from: https://mrc.ukri.org/documents/pdf/personal-information-inmedical-research/, accessed 5.2.19

Melenhorst, A., Rogers, W. \& Bouwhuis, D. (2006). Older adults' motivated choice for technological innovation: Evidence for benefit-driven selectivity. Psychology and aging, 21(1), 190

Metz, D. (2000). Mobility of older people and their quality of life. Transport Policy, 7 , $149-52$

Mezuk, B. \& Rebok, G. (2008). Social integration and social support among adults following driving cessation. Journal of Gerontology. 63(B), 298-303. doi: 10.1093/geronb/63.5.s298

Milena, Z., Dainora, G. \& Stancu, A. (2008). Qualitative Research Methods: A Comparison Between Focus-Group And In-Depth Interview. Annals of Faculty of Economics. 4, 1279-1283

Mills, J., \& Birks, M. (2014). Qualitative methodology: A practical guide. Sage. 
Mitchell, C. (2008). The licensing of older drivers in Europe - a case study. Traffic Injury Prevention. 9(4), 360-366. doi: 10.1080/15389580801895160.

Mitchell, C. (2018). Gender Differences in the Behaviour of Older Drivers: Maintaining mobility and safety. Retrieved from: https://www.racfoundation.org/wp-content/uploads/Gender-Differences-in-theBehaviour-of-Older-Drivers September2018.pdf, accessed 8.2.19

Mitchell, C. (2008). The licensing of older drivers in Europe-a case study. Traffic Injury Prevention. 9, 360-366.

Mitchell, C. (2017). Are Older People Safe Drivers on the Roads, Testing and Training? In C.Musselwhite (ed.) Transport, Travel and Later Life (pp. 37-63). Bingley: Emerald Publishing Limited.

Mruck, K., \& Mey, G. (2007). Grounded theory and reflexivity. In Bryant, A. \& Charmaz, K. (Eds.) The Sage handbook of grounded theory (pp. 515-538). London, UK, Sage

Murray, A. \& Musselwhite, C. (2019). Older peoples' experiences of informal support after giving up driving. Research in Transportation Business \& Management, 1-9. doi: $\underline{10.1016 / j . r t b m .2019 .100367}$

Musselwhite, C. \& Haddad, H. (2010). Mobility, accessibility and quality of later life. Quality in Ageing and Older Adults. 11(1), 25-37

Musselwhite, C. \& Haddad, H. (2018). Older people's travel and mobility needs: a reflection of a hierarchical model 10 years on. Quality in Ageing and Older Adults. 19(2), 87-105. doi: 10.1108/QAOA-12-2017-0054.

Musselwhite, C. (2017). Exploring the importance of discretionary mobility in later life. Working with Older People, 21(1), 49-58 
Musselwhite, C. (2017). Public and community transport. In Transport, Travel and Later Life (pp. 117-128). Emerald Publishing Limited.

Musselwhite, C. \& Haddad, H. (2007). Prolonging the Safe Driving of Older People through Technology. Final report, October 2007. Centre for Transport \& Society, University of the West of England, Bristol.

Musselwhite, C. (2011) The importance of driving for older people and how the pain of driving cessation can be reduced. Signpost: Journal of Dementia and Mental Health Care of Older People, 15(3), 22-26

Musselwhite, C. \& Shergold, I. (2013). Examining the process of driving cessation in later life. European Journal of Ageing, 10(2), 89-100. doi: 10.1007/s 10433-012-0252-6

Musselwhite, C. (2018). Transport and Travel in Later Life. Bingley, Emerald Publishing

Naveed, A., Sakata, N., Kafallinou, A., Young, S. \& Anand, K. (2017). Understanding, embracing and reflecting upon the messiness of doctoral fieldwork. Compare: $A$ Journal of Comparative and International Education. 47(5), 773-792. doi: 10.1080/03057925.2017.1344031

Nazroo, J. \& Matthews, K. (2012). The impact of volunteering on well-being in later life. A report to WRVS. Retrieved from: https://www.royalvoluntaryservice.org.uk/Uploads/Documents/Reports\%20and\% 20Reviews/the_impact_of_volunteering_on_wellbeing_in_later_life.pdf, accessed 4.12 .19

Nocon, A. \& Pearson, M. (2000). The roles of friends and neighbours in providing support for older people. Ageing and Society. 20, 341-367

Nordbakke, S. (2013). Capabilities for mobility among urban older women: barriers, strategies and options. Journal of Transport Geography, 26, 166-174 
Noy, C. (2008). Sampling knowledge: The hermeneutics of snowball sampling in qualitative research. International Journal of social research methodology, 11(4), 327-344

Office for National Statistics. (2018). Overview of the UK population. Retrieved from: https://www.ons.gov.uk/peoplepopulationandcommunity/populationandmigration /populationestimates/articles/overviewoftheukpopulation/november2018, accessed 5.1 .19

Older people with high support needs: how can we empower them to enjoy a better life. (2010, October). Retrieved from file:///C:/Users/Amy/Downloads/supporting-older-people-summary.pdf , , accessed 6.1.19

Oliver, D., Serovich, J. \& Mason, T. (2005). Constraints and Opportunities with Interview Transcription: Towards Reflection in Qualitative Research. Social forces; $a$ scientific medium of social study and interpretation, 84(2), 1273-1289. doi:10.1353/sof.2006.0023

O'Neill, D., Bruce, I., Kirby, M., \& Lawlor, B. (2000). Older drivers, driving practices and health issues. Clinical Gerontologist, 22(1), 47-54

O’Neil, J., Bull, M., Slaven, J. \& Talty, J. (2012). Grandparents and child passenger safety. Accident Analysis \& Prevention, 49, 354-359

Ormerod, M., Newton, R., Phillips, J., Musselwhite, C., McGee, S. \& Russell, R. (2015). How can transport provision and associated built environment infrastructure be enhanced and developed to support the mobility needs of individuals as they age? Future of an ageing population: evidence review. Foresight report, Government Office for Science, UK.

Owton, H. and Allen-Collinson, J. (2013) Close but not too close: friendship as method(ology) in ethnographic research encounters. Journal of contemporary ethnography. 43(3), 283-305. doi: 10.1177/0891241613495410 
Oxley, J., Charlton, J., Koppel, S., Scully, J., \& Fildes, B. (2005). Crash risk of older female drivers--contributing factors. Annual proceedings. Association for the Advancement of Automotive Medicine, 49, 345-360

Pachana, N. Jolanda, J. (2017). Social Identity Change and Driving in Later Life, In: Pachana N.A. (eds) Encyclopedia of Geropsychology. Springer, Singapore

Palaganas, E., Sanchez, M., Molintas, M. \& Caricativo, R. (2017). Reflexivity in Qualitative Research: A Journey of Learning. The Qualitative Report, 22(2), 426-438. Retrieved from https://nsuworks.nova.edu/tqr/vol22/iss2/5

Payne, G. \& Payne, J. (2004). The hawthorne effect. In Sage key Concepts: Key concepts in social research (108-111). London: SAGE Publications. doi: $10.4135 / 9781849209397$

Pellerito, J. (2008). Driving retirement and the quality of life of older men and women in metropolitan Detroit. (Doctoral dissertation). Detroit, Michigan: Wayne State University

Persson, D. (1993). The elderly driver: Deciding when to stop. The Gerontologist, 33, $88-91$

Pike, F., Bainbridge, K., Gow, J., Hamilton, K., Gilhooly, M. \& Webster, N. (2004). Transport and Ageing: Extending Quality of Life for Older People Via Public and Private Transport, 2000-2001. UK Data Service. SN: 5035, http://doi.org/10.5255/UKDA-SN-5035-1

Plaisier, I., van Groenou, B. \& Keuzenhamp, S. (2015). Combining work and informal care: the importance of caring organisations. Human resource management journal, 25(2), 267-280. doi: $10.1111 / 1748-8583.12048$

Putnam R (2000) Bowling alone: the collapse and revival of American community Simon \& Schuster, New York 
Rabiee, P. (2012). Exploring the Relationships between Choice and Independence: Experiences of Disabled and Older People. British Journal of Social Work, 43, 872-888 doi: $10.1093 / \mathrm{bjsw} / \mathrm{bcs} 022$

Ragland, D., Satariano, W. \& MacLeod, K. (2005). Driving cessation and increased depressive symptoms. The Journals of Gerontology Series A: Biological Sciences and Medical Sciences, 60(3), 399-403

Ralston, L., Bell, S., Mote, J., Rainey, T., Brayman, S. \& Shotwell, M. (2001). Giving up the car keys: Perceptions of well elders and families. Physical \& Occupational Therapy in Geriatrics, 19(4), 59-70

Ranney, M., Meisel, Z., Choo, E., Garro, A., Sasson, C. \& Guthrie, K. (2015). Interview-based Qualitative Research in Emergency Care Part II: Data Collection, Analysis and Results Reporting. Research Methods E Statistics. 22(9), 1103-1112. doi: $10.1111 /$ acem. 12735

Reichstadt, J., Sengupta, G., Depp, C., Palinkas, L. \& Jeste, D. (2010). Older adults' perspectives on successful aging: Qualitative interviews. The American Journal of Geriatric Psychiatry, 18(7), 567-575

Reybold, L., Lammert, J. \& Stribling, S. (2013). Participant selection as a conscious research method: Thinking forward and the deliberation of 'emergent' findings. Qualitative Research, 13(6), 699-716

Rezeanu, C. (2015). The relationship between domestic space and gender identity: Some signs of emergence of alternative domestic femininity and masculinity. Journal of Comparative Research in Anthropology \& Sociology, 6(2), 9-29

Roberto, K. \& Stanis, P. (1994). Reactions of Older Women to the Death of Their Close Friends. Journal of Death and Dying, 29(1). Doi: 10.2190/KKGD-HR3F-CKY4$\underline{58 P M}$ 
Rosenbloom, R., \& Ståhl, A. (2002). Automobility Among The Elderly; The Convergence of Environmental, Safety, Mobility and Land Use Issues.

Rosenbloom, S. (2010). How adult children in the UK and the US view the driving cessation of their parents: Is a policy window opening?. Journal of Transport Geography, 18(5), 634-641

Rosso, A., Taylor, J., Tabb, L. \& Michael, Y. (2013). Mobility, disability, and social engagement in older adults. Journal of aging and health, 25(4), 617-637. doi: $10.1177 / 0898264313482489$

Rothe, J. P. (1990) The Safety of Elderly Drivers. Transaction Publishers, London.

Rotolo, T., \& Wilson, J. (2006). Substitute or complement? Spousal influence on volunteering. Journal of Marriage and Family, 68(2), 305-319

Rotter, J. (1954). Social Learning and Clinical Psychology, Prentice-Hall, Englewood Cliffs. NI.

Roulston, K. (2010). Considering quality in qualitative interviewing. Qualitative research, 10(2), 199-228

Rudman, D., Friedland, J., Chipman, M. \& Sciortino, P. (2006). Holding On and Letting Go: The Perspectives of Pre-seniors and Seniors on Driving Self-Regulation in Later Life. Canadian Journal on Aging, 25(1), 65-76

Rusbult, C. \& Buunk, B. (1993). Commitment processes in close relationships: An interdependence analysis. Journal of Social and Personal Relationships, 10(2), 175-204. doi: $10.1177 / 026540759301000202$

Sanford, S., Naglie, G., Cameron, D. \& Rapoport, M. (2018). Subjective experiences of driving cessation and dementia: A meta-synthesis of qualitative literature. Clinical gerontologist, 1-20 
Sanford, S., Rapoport, M., Tuokko, H., Crizzle, A., Hatzifilalithis, S. \& Laberge, S. (2018). Independence, loss, and social identity: Perspectives on driving cessation and dementia. Dementia, 18, 7-8. Doi: 10.1177/1471301218762838.

Schryer, E., Boerner, K., Horowitz, A., Reinhardt, J. \& Mock, S. (2017). The social context of driving cessation: understanding the effects of cessation on the life satisfaction of older drivers and their social partners. Journal of applied gerontology. 38(12), 1661-1686. doi: 10.1177/0733464817741683.

Schwanen, T. \& Antonio Páez, A. (2010). The mobility of older people - An introduction. Journal of Transport Geography. 18(5), 591-595

Schwanen, T., Banister, D. \& Bowling, A. (2012). Independence and mobility in later life. Geoforum, 43(6), 1313-1322. doi: 10.1016/j.geoforum.2012.04.001Get rights and content

Scotland, J. (2012). Exploring the Philosophical Underpinnings of Research: Relating Ontology and Epistemology to the Methodology and Methods of the Scientific, Interpretive, and Critical Research Paradigms, English Language Teaching, 5(9), 9-16. doi: 10.5539/elt.v5n9p9

Seligman, M. (1972). Learned Helplessness. Annual Review of Medicine, 23(1), 407412

Selwyn, C. (2014). Age, Health, and Driving Ability: Perceptions of Older Adults (masters thesis) Georgia State University, Atlanta, Georgia.

Silverman, D. (2006b). The Relevance of Qualitative Research. In D. Silverman (Ed.), Interpreting Qualitative Data. London: Sage.

Silverstein, M., Conroy, S. \& Gans, D. (2012). Beyond solidarity, reciprocity and altruism: moral capital as a unifying concept in intergenerational support for older people. Ageing E̊ Society, 32(7), 1246-1262 
Silverstein, M., Conroy, S., Wang, H., Giarrusso, R., \& Bengtson, V. (2002). Reciprocity in parent-child relations over the adult life course. Journal of Gerontology: Social Sciences, 57, 3-13

Silverstein, M., Gans, D. \& Yang, F. (2006). Intergenerational Support to Aging Parents: The Role of Norms and Needs. Journal of Family Issues, 27(8), 1068-1084. doi:10.1177/0192513X06288120

Siren, A. \& Hakamies-Blomqvist, L. (2005). Sense and sensibility: a narrative study of older women's car driving. Transportation Research, Part F: Traffic Psychology and Behaviour, 8, 213-28. doi: 10.1016/j.trf.2005.04.008

Siren. A. \& Haustein, A. (2015). Driving licences and medical screening in old age: Review of literature and European licensing policies. Journal of Transport $\S^{2}$ Health, 2(1), 68-78. doi: 10.1016/j.jth.2014.09.003

Skinner, B. F. (1983). Intellectual self-management in old age. American Psychologist, 38(3), 239

Stanford Encyclopedia of Philosophy. (2016, November 1). Edmund Husserl. Retrieved from: https://plato.stanford.edu/entries/husserl/ , accessed 1.2.19

Stanford Encyclopedia of Philosophy. (2013, December 16). Phenomenology. Retrieved from: https://plato.stanford.edu/entries/phenomenology/. , accessed 2.2.19

Spain, D. (1993). Gendered Spaces and Women's Status. Sociological Theory, 11(2), $137-151$

Steg, L. (2005). Car use: lust and must. Instrumental, symbolic and active motives for car use. Transportation Research Part A, 39,147-162

Straight, A. K. (1997). Community transportation survey. Public Policy Institute, Research Group. 
Strawbridge, W., Wallhagen, M. \& Cohen, R. (2002). Successful aging and wellbeing: Self-rated compared with Rowe and Kahn. The Gerontologist, 42(6), 727-733

Stubbins, J. (Ed.). (1977). Social and psychological aspects of disability: A handbook for practitioners. Baltimore, MD, US: University Park Press.

Suanet, B., Broese van Groenou, M. \& van Tilburg, T. (2012). Informal and formal home-care use among older adults in Europe: can cross-national differences be explained by societal context and composition? Ageing \& Society, 32, 3, 491-515

Sullivan, C., \& Buckley, S. (2013). A survey examining the impact of driving cessation on people with epilepsy in Ireland. British Journal of Occupational Therapy, 76(9), 399408

Sum, S., Mathews, R., Hughes, I. \& Campbell, A. (2008). Internet use and loneliness in older adults. Cyber Psychology \& Behavior, 1 1, 208-21 1. doi: 10.1089/cpb.2007.0010

Sun, J. (2015). Altruism or reciprocity? Effects of grandchildren caring on the quality of life o older people in China. The Gerontologist, 55(2), doi: $10.1093 /$ geront/gnv346.18

Swansea University. (2014, August 26). Ageing Studies: Fully-funded PhD Studentship Announced. Retrieved September 6, 2018, from https://www.swansea.ac.uk/humanandhealthsciences/news-and-events/latestresearch/ageingstudiesfully-fundedphdstudentshipannounced.php

Symon, G., \& Cassell, C. (2012). Assessing Qualitative Research. In Qualitative organizational research: Core methods and current challenges, 204. Sage.

Tamres, L., Janicki, D. \& Helgeson, V. (2002). Sex differences in coping behavior: A meta-analytic review and an examination of relative coping. Personality and Social Psychology Review, 6, 2- 30 
Taylor, B. \& Tripodes, S. (2001). The effects of driving cessation on the elderly with dementia and their caregivers. Accident Analysis and Prevention. 33, 519-528

Tesch-Roemer, C. (2012). Promoting Participation, Social Inclusion and NonDiscrimination of Older Persons. Retrieved from: https://www.unece.org/fileadmin/DAM/pau/age/Ministerial_Conference_Vienna /Information/Speeches/Others/C.Tesch-Romer_keynote_speech.pdf, accessed 4.12 .19

Thoits, P. (2011). Mechanisms linking social ties and support to physical and mental health. Journal of Health and Social Behavior 52, 145-61. doi: $10.1177 / 0022146510395592$

Thompson, S. (2016). Promoting Reciprocity in Old Age: A Social Work Challenge. Social Work in Action, 28(5), 341-355. doi: 10.1080/09503153.2015.1135892

Thurley, D. \& Keen, R. (2017). State pension age review (House of Commons Library No. 16). London: House of Commons.

Tolkacheva, N., Van Groenou, M. B., De Boer, A., \& Van Tilburg, T. (2011). The impact of informal care-giving networks on adult children's care-giver burden. Ageing \& Society, 31(1), 34-51

Tufford, L. \& Newman, P. (2010). Bracketing in Qualitative Research. Qualitative Social Work, 11(1), 80-96. doi: 10.1177/1473325010368316

Utz, R. L., Carr, D., Nesse, R., \& Wortman, C. B. (2002). The effect of widowhood on older adults' social participation: An evaluation of activity, disengagement, and continuity theories. The Gerontologist, 42(4), 522-533

van den Berg, P., Kemperman, A., de Kleijn, B. \& Borgers, A. (2016). Ageing and loneliness: The role of mobility and the built environment. Travel Behaviour and Society, 5, 48-55. doi: 10.1016/j.tbs.2015.03.001 
van Groenou, M. I. B., \& De Boer, A. (2016). Providing informal care in a changing society. European Journal of Ageing, 13(3), 271-279

van Groenou, M. I. B., \& De Boer, A. (2016). Providing informal care in a changing society. European Journal of Ageing, 13(3), 271-279

van Wijk, E. \& Harrison, T. (2013). Managing Ethical Problems in Qualitative Research Involving Vulnerable Populations, Using a Pilot Study. International Journal of Qualitative Methods, 570-586. doi: 10.1177/160940691301200130

Vanderstoep, S. \& Johnson, D. (2008). Research methods for everyday life: Blending qualitative and quantitative approaches (Vol. 32). John Wiley \& Sons.

Warren, C. (2001). Qualitative interviewing. In Gubrium, J. \& Holstein, J. Handbook of interview research (pp. 83-102): SAGE. doi: 10.4135/9781412973588

Weber, S., Porter, M. \& Menec, V. (2010). Mobility in Older Adults: A Comprehensive Framework. The Gerontologist. 50(4), 443-450. doi: $\underline{10.1093 / \text { geront/gnq013 }}$

Whitehead, B., Howie, L. \& Lovell, R. (2006). Older people's experience of driver licence cancellation: A phenomenological study. Australian Occupational Therapy Journal. 53(3), 173-180. doi: 10.1111/j.1440-1630.2006.00564.X

Windsor, T., Anstey, K., Butterworth, P., Luszcz, M. \& Andrews, G. (2007). The Role of Perceived Control in Explaining Depressive Symptoms Associated With Driving Cessation in a Longitudinal Study, The Gerontologist, 47(2), 215-223. doi: $10.1093 /$ geront/47.2.215

Wojnar, D. \& Swanson, K. (2007). Phenomenology: An Exploration. Journal of Holistic Nursing, 25(3), 172-180. doi: 10.1177/0898010106295172

Wolf, K. \& Housley, E. (2016). The Benefits of Nearby Nature in Cities for Older Adults. Annapolis, MD: The TKF Foundation. 
World Health Organisation. (2019). Active ageing: a policy framework. Retrieved from: https://www.who.int/ageing/publications/active ageing/en/,accessed 5.2.19

Ward, M., Somerville, P., \& Bosworth, G. (2013). 'Now without my car I don't know what I'd do': The transportation needs of older people in rural Lincolnshire. Local Economy, 28(6), 553-566

Whitehead, B., Howie, L. \& Lovell, R. (2006). Older people's experience of driver licence cancellation: A phenomenological study. Australian Occupational Therapy Journal. 53(3), 173-180. doi: 10.1111/j.1440-1630.2006.00564.X

Windsor, T. \& Anstey, K. (2006). Interventions to reduce the adverse psychosocial impact of driving cessation on older adults. Clinical interventions in aging, 1(3), 205

Windsor, T., Anstey, K., Butterworth, P., Luszcz, M. \& Andrews, G. (2007). The Role of Perceived Control in Explaining Depressive Symptoms Associated With Driving Cessation in a Longitudinal Study, The Gerontologist, 47(2), 215-223. doi: 10.1093/geront/47.2.215

Wirth, L. (1938). Urbanism as a way of life. American Journal of Sociology, 44(1), 1-24 Wolf, D. (1997). Selection of children to provide care: The effect of earlier parental transfers. Journal of Gerontology, Series B-Psychological Sciences and Social Sciences, 52, $110-119$

World Health Organisation. (2019). Active ageing: a policy framework. Retrieved from: https://www.who.int/ageing/publications/active_ageing/en/

Wright, R., Brand, R., Dunn, W. \& Spindler, K. (2007). How to write a systematic review. Clinical Orthopaedics and Related Research (1976-2007), 455, 23-29

Xie, B., Watkins, I., Golbeck, J., \& Huang, M. (2012). Understanding and changing older adults' perceptions and learning of social media. Educational gerontology, 38(4), 282-296 
Ziegler, F. \& Schwanen, T. (2011). 'I like to go out to be energised by different people': an exploratory analysis of mobility and wellbeing in later life. Ageing $\mathcal{E}^{2}$ Society, 31(5), 758-781. doi: 10.1017/So 144686X10000498 


\section{Appendices}

\section{Appendix 1: Ethical Application}

\section{Application for Standard Ethical Approval}

\section{PLEASE COMPLETE THE FORM USING TYPESCRIPT}

(hand-written applications will not be considered)

\begin{tabular}{|c|c|}
\hline $\begin{array}{l}\text { Principal } \\
\text { Investigator }\end{array}$ & Miss Amy Murray \\
\hline Date & 13th August 2015 \\
\hline School & $\begin{array}{l}\text { Centre for Innovative Ageing: College of Human and Health } \\
\text { Sciences }\end{array}$ \\
\hline E-mail address & 554084@swansea.ac.uk \\
\hline $\begin{array}{l}\text { Title of Proposed } \\
\text { Research }\end{array}$ & $\begin{array}{l}\text { Examining the driving cessation process amongst current and } \\
\text { retired older drivers and their informal social network members }\end{array}$ \\
\hline $\begin{array}{l}\text { Type of } \\
\text { Researcher }\end{array}$ & Postgraduate student \\
\hline Name of supervisor & Dr Charles Musselwhite \\
\hline
\end{tabular}

1. Briefly describe the main aims of the research you wish to undertake. Please use non-technical language wherever possible.

This research project will explore the process of driving cessation amongst current and retired older drivers and their informal social network members.

The main aims of the study are:

. To uncover how the transition from driver to non-driver can be made successfully, in order for older people to remain mobile and to maintain their quality of life and level of wellbeing without the car. 
- To uncover how older peoples informal social network members undergo the process of driving cessation, by focusing upon the role they play, and how older persons' transition from driver to non-driver is experienced by the informal social network members.

. To design a toolkit for older current and retired drivers, and their informal social network members to aide them in this later life transition.

. To inform policy and practice of the findings and to collaborate with local agencies or policy makers to design bottom-up, innovative interventions which help older people remain as mobile as possible once they are unable to drive.

Each aim will be dependent upon research findings to provide a strong evidence base.

2. Briefly describe the overall design of the project

A qualitative, explorative study on giving up driving in later life, utilising individual interviews amongst four separate groups through a case-study approach.

Group 1: current older drivers

Group 2: informal social network members of current older drivers

Group 3: retired older drivers

Group 4: informal social network members of retired older drivers

3. Briefly describe the methods of data collection and analysis. Please describe all measures to be employed. If questionnaire or interviews are to be used, please provide the questionnaire / interview questions and schedule - if available.

For data collection, semi-structured interviews will be used with each individual participant.

See appendices 1-4 for interview prompts for each of the four separate groups. Each topic area will begin with an open question, and the following questions will act as prompts if they are not covered in the response from the participant to the opening question. 
A thematic analysis approach will be adopted to analyse the research findings following the transcription of each interview.

4. Location of the proposed research (i.e., Departmental labs, schools, etc)

The home of the participant or public place, for example a coffee shop (to be as secluded as possible). The location of the interview will be confirmed by each participant.

5. Describe the participants: give the age range, gender, inclusion and exclusion criteria, and any particular characteristics pertinent to the research project.

As outlined above, the study will include four separate groups. The inclusion and exclusion criteria for each group are outlined below.

\section{Group 1: Current older drivers}

\begin{tabular}{|l|l|}
\hline Inclusion Criteria & Exclusion criteria \\
\hline Over 65 years old & Under 65 years old \\
\hline $\begin{array}{l}\text { Holds a full valid UK } \\
\text { driving licence }\end{array}$ & $\begin{array}{l}\text { Does not hold a full valid UK } \\
\text { driving licence }\end{array}$ \\
\hline $\begin{array}{l}\text { Able to communicate in } \\
\text { English }\end{array}$ & $\begin{array}{l}\text { Not able to communicate in } \\
\text { English }\end{array}$ \\
\hline $\begin{array}{l}\text { No serious physical or } \\
\text { cognitive health issues }\end{array}$ & $\begin{array}{l}\text { Serious health issues } \\
\text { affecting participation }\end{array}$ \\
\hline $\begin{array}{l}\text { Willing to participate in } \\
\text { study and share } \\
\text { information }\end{array}$ & $\begin{array}{l}\text { Not willing to participate in } \\
\text { study or share information }\end{array}$ \\
\hline $\begin{array}{l}\text { Living in South West } \\
\text { Wales (Swansea and } \\
\text { Carmarthen specifically) }\end{array}$ & $\begin{array}{l}\text { Living outside of South West } \\
\text { Wales (Swansea and } \\
\text { Carmarthen specifically) }\end{array}$ \\
\hline
\end{tabular}




\begin{tabular}{|c|c|}
\hline Inclusion criteria & Exclusion criteria \\
\hline $\begin{array}{l}\text { Has been referred via the } \\
\text { older current driver }\end{array}$ & $\begin{array}{l}\text { Has not been referred via } \\
\text { the older current driver }\end{array}$ \\
\hline $\begin{array}{l}\text { Willing to participate in } \\
\text { study and share information }\end{array}$ & $\begin{array}{l}\text { Not willing to participate } \\
\text { in study or share } \\
\text { information }\end{array}$ \\
\hline $\begin{array}{l}\text { Written informed consent } \\
\text { given }\end{array}$ & $\begin{array}{l}\text { No written informed } \\
\text { consent given }\end{array}$ \\
\hline $\begin{array}{l}\text { Able to communicate in } \\
\text { English }\end{array}$ & $\begin{array}{l}\text { Not able to communicate } \\
\text { in English }\end{array}$ \\
\hline $\begin{array}{l}\text { No serious physical or } \\
\text { cognitive health issues }\end{array}$ & $\begin{array}{l}\text { Serious physical or } \\
\text { cognitive health issues }\end{array}$ \\
\hline Over 18 years old & Under 18 years old \\
\hline $\begin{array}{l}\text { Lives in an area } \\
\text { accessible/in reach of the } \\
\text { researcher }\end{array}$ & $\begin{array}{l}\text { Does not live in an areas } \\
\text { accessible/in reach of the } \\
\text { researcher }\end{array}$ \\
\hline
\end{tabular}




\begin{tabular}{|c|c|}
\hline \multicolumn{2}{|l|}{ Group 3: Retired older drivers } \\
\hline \begin{tabular}{|l|} 
Inclusion criteria \\
\end{tabular} & Exclusion criteria \\
\hline Over 65 years old & Under 65 years old \\
\hline $\begin{array}{l}\text { No longer holds a valid UK } \\
\text { driving licence }\end{array}$ & $\begin{array}{l}\text { Holds a valid UK driving } \\
\text { licence }\end{array}$ \\
\hline $\begin{array}{l}\text { Able to communicate in } \\
\text { English }\end{array}$ & $\begin{array}{l}\text { Unable to communicate } \\
\text { in English }\end{array}$ \\
\hline $\begin{array}{l}\text { No serious physical or } \\
\text { cognitive health issues }\end{array}$ & $\begin{array}{l}\text { Serious health issues } \\
\text { affecting participation }\end{array}$ \\
\hline $\begin{array}{l}\text { Willing to participate in } \\
\text { study and share information }\end{array}$ & $\begin{array}{l}\text { Not willing to } \\
\text { participate in study or } \\
\text { share information }\end{array}$ \\
\hline $\begin{array}{l}\text { Written informed consent } \\
\text { given }\end{array}$ & $\begin{array}{l}\text { No written informed } \\
\text { consent receive }\end{array}$ \\
\hline $\begin{array}{l}\text { Living in South West Wales } \\
\text { (Swansea and Carmarthen } \\
\text { specifically) }\end{array}$ & $\begin{array}{l}\text { Living outside of South } \\
\text { West Wales (Swansea } \\
\text { and Carmarthen } \\
\text { specifically) }\end{array}$ \\
\hline
\end{tabular}




\section{Group 4: Informal Support Network members}

\begin{tabular}{|l|l|}
\hline Inclusion criteria & Exclusion criteria \\
\hline $\begin{array}{l}\text { Has been referred via the } \\
\text { older current driver }\end{array}$ & $\begin{array}{l}\text { Has not been referred via } \\
\text { the older current driver }\end{array}$ \\
\hline $\begin{array}{l}\text { Willing to participate in } \\
\text { study and share information } \\
\text { Written informed consent } \\
\text { given }\end{array}$ & $\begin{array}{l}\text { Not willing to } \\
\text { share information }\end{array}$ \\
\hline $\begin{array}{l}\text { Able to communt given } \\
\text { English }\end{array}$ & $\begin{array}{l}\text { Not able to communicate } \\
\text { in English }\end{array}$ \\
\hline $\begin{array}{l}\text { No serious physical or } \\
\text { cognitive health issues }\end{array}$ & $\begin{array}{l}\text { Serious physical or } \\
\text { cognitive health issues }\end{array}$ \\
\hline Over 18 years old & Under 18 years old \\
\hline reach of the researcher & $\begin{array}{l}\text { Does not live in an areas } \\
\text { researcher }\end{array}$ \\
\hline
\end{tabular}

\section{How will the participants be selected and recruited?}

The recruitment and selection of study participants is based on a word of mouth approach.

Groups 1 and 3 (initial case-study participants - current and retired older drivers) will be selected in the urban and rural area (Swansea and Carmarthen) using the same recruitment technique. The researcher will use her informal personal network to identify initial participants who fit the inclusion criteria, employing a snowball sample design after the initial interviews in each area with the original participants, in order to identify 
other potential participants who also fit the studies inclusion criteria, who may otherwise not be accessible.

The second selection and recruitment technique which could potentially be adopted (following the success rate of the word of mouth/snowball sample) will utilise Swansea Universities OPAN list of contacts, to identify those who fit the inclusion criteria.

To recruit the informal social network members of the current and retired older drivers (Groups 2 and 4) the researcher will address the topic area of informal social networks with the older participant during the semi-structured interviews. (See appendix $\mathbf{1}$ section $\mathbf{C}$ and appendix 3 section $\mathbf{D}$ ). This topic area will ask the older person to identify all members in their informal social networks (such as a spouse, relatives, friends, neighbours etc.) and state who currently helps them with all types of needs including help with transport, and practical and emotional support). From here, the researcher will identify with the older participant who the most important informal social network members are, and will ask which of these members would likely be willing to participant in the study.

In the case of an older participant having no informal social network members which they consider to help and support them, the case-study will remain with only the older participant - and this will be recorded in the findings.

\section{What procedures (e.g., interviews, computer-based learning tasks, etc.) will be carried out on the participants?}

Each group will be asked to complete an information sheet prior to each interview to gather basic background information. The sheet can be completed by the participant - or by the researcher (following responses from each participant) depending on each interviewee's preference. (See appendix 5)

Each individual will then take part in a semi-structured interview which will last approximately 1 hour.

\section{What potential risks to the participants do you foresee and how do you propose to ameliorate/deal with potential risks?}

Potential risks of study participants include:

(a) Emotional risks: Participants could potentially be uncomfortable talking about certain topics covered by each interview prompt sheet. For example, the impact of driving cessation or their marital status. The researcher is aware that some participants maybe suffering from depression or loneliness, given the study being based on driving cessation, a major later life transition which has been proven to 


\begin{tabular}{|c|c|}
\hline & $\begin{array}{l}\text { increase the risk of depression etc. (Fonda et al, 2001; Marattoli et al, 1997). } \\
\text { Likewise, there could be emotional risks amongst informal social network } \\
\text { members - particularly if they have a heavy responsibility for the current or } \\
\text { retired older driver and could consequently be suffering from stress or depression } \\
\text { (Durant and Christian, 2006). To ameliorate such risks, the researcher will take } \\
\text { extra care and remain empathetic when conducting interviews with each member } \\
\text { of each of the four groups. The researcher may also suggest a break or a } \\
\text { reschedule of an interview if the participant is in any way distressed or } \\
\text { uncomfortable, in order to minimise any emotional harm to each interviewee. } \\
\text { Additionally, the researcher will remind each participant of the option to } \\
\text { withdraw from the study, in which case any data collected relating to that } \\
\text { individual will be destroyed. }\end{array}$ \\
\hline & $\begin{array}{l}\text { Fear of disclosure: Older current and retired drivers, and/or their informal } \\
\text { social network members could potentially be fearful that the researcher will } \\
\text { report any information collected during the interview to a government } \\
\text { organisation such as the DVLA regarding their ability to drive or hold a valid UK } \\
\text { driving licence. The researcher will confirm on the participant information sheets } \\
\text { (briefing letter) and during each interview that no information will be passed onto } \\
\text { any government organisation regarding the driving abilities or health status of } \\
\text { each participant. The study is purely to explore the perceptions and lived } \\
\text { experiences of each group regarding driving cessation, and to identify how the } \\
\text { driver to non-driver status can be made successfully to avoid negative outcomes, } \\
\text { such as depression, loneliness and social isolation. Findings could potentially be } \\
\text { used to inform policy and practice of suggestions and recommendations, although } \\
\text { no personal information such as names of participants or specific locations will be } \\
\text { disclosed at any point during or following the study, in compliance with the Data } \\
\text { Protection Act (1998) and Swansea universities ethical procedures for social } \\
\text { research. }\end{array}$ \\
\hline $\begin{array}{ll}\text { (c) } & \\
\mathrm{c} \\
\mathrm{c} \\
\mathrm{e} \\
1 \\
\mathrm{~T} \\
\mathrm{c} \\
\mathrm{t} \\
\mathrm{i} \\
\mathrm{p}\end{array}$ & $\begin{array}{l}\text { Fear of judgement: Participants in each of the four groups included in the study } \\
\text { could be fearful of being judged by the researcher. For example, retired older } \\
\text { drivers could be embarrassed to open-up and share information regarding their } \\
\text { experience of giving up driving. Research has shown this issue is particularly } \\
\text { linked to males - where driving is often linked to status, power and roles } \\
\text { (Musselwhite and Haddad, 2010). The researcher will ensure each participant (male } \\
\text { or female) who could be embarrassed regarding their driving status and lifestyle } \\
\text { that no judgements are being placed upon them and the research is purely } \\
\text { intended to explore how their mobility, and wider needs can be achieved as far as } \\
\text { possible, without a car. }\end{array}$ \\
\hline $\begin{array}{l}\text { Informa } \\
\text { as quest } \\
\text { thought } \\
\text { example }\end{array}$ & $\begin{array}{l}\text { al social network members may also be fearful of being judged by the researcher } \\
\text { tions will include topics related to level of support they provide, and their } \\
\text { ts and feelings around potential increased responsibilities for the older person, for } \\
\text { le. The researcher will again emphasize that responses to such topics will not be }\end{array}$ \\
\hline
\end{tabular}


used against each participant in any way, and they will not be judged as the researcher will remain neutral for the entire duration of the study and after completion. Any information received will be used to add to the field of research relating to older people and driving, and to improve the outcomes of current and retired older drivers in the study, and for informal social network members like themselves. This applies not only to those included in this particular study, but also to wider society.

(d) Mistrust of the researcher: Each participant could potentially be reluctant, or mistrusting of the researcher, especially when considering the sensitive and personal nature of qualitative research which aims to uncover in depth meanings and experiences of research participants. The researcher will ensure there are several opportunities for contact will all participants prior to commencement of each interview in order for each interviewee to familiarise themselves with the researcher, and to minimise the feeling of mistrust. Participants could be fearful that the researcher isn't who they say they are. To ensure participants that the research is genuine, the researcher will wear her Swansea University photographic ID card around her neck at all times ensuring it is visible to all participants. Also, if any person would like to check the contact details of the researcher or study supervisor, these would have been outlines clearly on several documents before commencement of the study. Additionally, participants will be given the opportunity to express any concerns regarding fear of mistrust or misuse of their personal information before, during and following each interview.

\section{What potential risks to the interests of the researchers do you foresee and how will you ameliorate/deal with potential risks?}

Participants will be given the choice of venue for where they would like the interview to take place. If the researcher is required to conduct the interview at the home of each participant, this poses lone working interviews where the safety of the researcher is a potential risk. To ensure this risk is minimised, the researcher will follow the Centre of Innovative Ageing's 'Personal safety guidelines for researchers and interviewers' and will take extra precautionary measures to offset such issues, such as carrying a fully charged mobile phone which is accessible at all times, and by informing one family member, and personal supervisor (or second supervisor - dependant on availability) of the location and precise time of each interview in the event of an emergency. The researcher will contact the one selected family member and supervisor, via text or email to confirm the ending of each interview and safe return home.

To further ensure the researcher is dealing with the correct participant, contact will have been made several times with each individual before the commencement of each interview. For example, initial recruitment by contacting each potential participant either by phone, email or letter following a recommendation by word of mouth and 
through the snowballing sampling method. Participants would have received a participant information sheet, informed consent form, and debriefing sheet which will also be issued via the researcher. After administering all information and following receipt of the participant's informed consent forms, the researcher will contact each participant to arrange a suitable time, date and location for the interview to take place. If this is to be at the participant's home, safety questions will be asked at this stage to enable the researcher to prepare herself before visiting. For example, are there any pets in the home and are there any other people living in the home.

If each participant would rather the interview be conducted at a public place, for example, a coffee shop, the researcher will emphasize the importance of confidentiality, and will try, to the best of her ability, to conduct the interview without any distractions from other customers, and to sit somewhere which is as secluded as possible to avoid other customers or staff over-hearing the conversation, and to also protect the researcher and participants identity.

In addition to the above safety precautions and practicalities, the researcher will call or text each participant (to be specified by each interviewee) approximately 1 hour before visiting at their home or meeting them at a public place, to confirm the details and ensure they are able to go ahead with the pre-arranged interview. 


\section{Appendix 2: Briefing letter - Study invitation}

Dear

I am writing to invite you to take part in the PhD study which I am currently undertaking at Swansea University within the Centre for Innovative Ageing. The title of the research project is:

"Examining the driving cessation process amongst current and retired older drivers and their informal social network members".

The aim of the study is to explore the process of driving cessation, to identify how the transition from driver to non-driver can be made successfully.

I intend to undertake semi-structured interviews with four separate groups, including current drivers over 60 years old, retired drivers over 60 years old, and the informal social network members of both current and retired older drivers. For example, relatives, friends, neighbours etc.

The interviews are intended to take approximately 1 hour with each participant and a tape recorder will be used to enable later transcription of information gathered, ensuring that the researcher does not miss anything said during the interview.

Recordings will be written up and anonymised so that there are no identifying names or places in the record. These will be analysed and written up in a final academic report, journal article and conference presentation. Your answers may be used in these publications along with other interviewee's answers, but will still be anonymous and not traceable to you. If you'd like a copy of any publications, then please let me know.

If you do not want to answer any of the questions during the interview, or if you would like to take a break or even reschedule the interview, then please let the researcher know. It is also essential to note that any information given during interviews is purely to answer the aims and objectives of the research project, and the researcher will not disclose any information to any outside organisations, such as the DVLA. All information relating to each participant will be kept confidential and securely stored on a password protected computer at all times during the course of the study.

Each participant has a choice of where they would like the interview to take place, which could include your own home or a public place, such as a coffee shop, although it is worth considering privacy issues if this is the preference.

It is important to note that you have no obligation to take part in this research. Participation is entirely voluntary and you are free to withdraw at any time, without 
explanation and without being disadvantaged in anyway. However, if you do decide to take part, your participation will be greatly valued and your knowledge and experiences will be extremely important in terms of shaping the outcomes of the study. Findings from the study could also potentially inform policy and practice.

If you have any questions or concerns in relation to any part of this letter, please feel free to contact the researcher or study supervisor. Contact details have been provided below.

If you are satisfied that this letter has provided enough information, and you are happy to take part in the study, please contact the researcher by letter, phone or email. Alternatively, in a few days after sending this letter, the researcher will contact you either by phone or email to confirm if you would like to participate in the study. If so, a time, date and location will be arranged for the interview to take place. However, if you would rather not take part, then you are very welcome to let the researcher know, although your participation would be greatly valued.

This study has received ethical approval from the Swansea University ethics committee.

Many thanks for taking your time to read this letter.

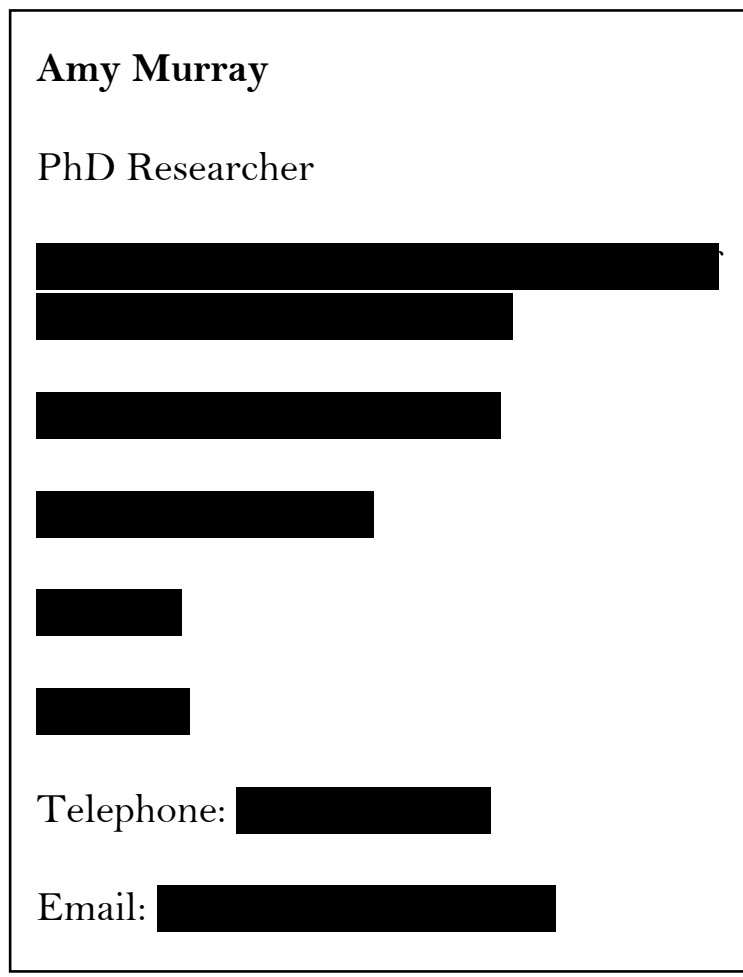

\section{Supervisor: Dr Charles Musselwhite}

Associate Professor

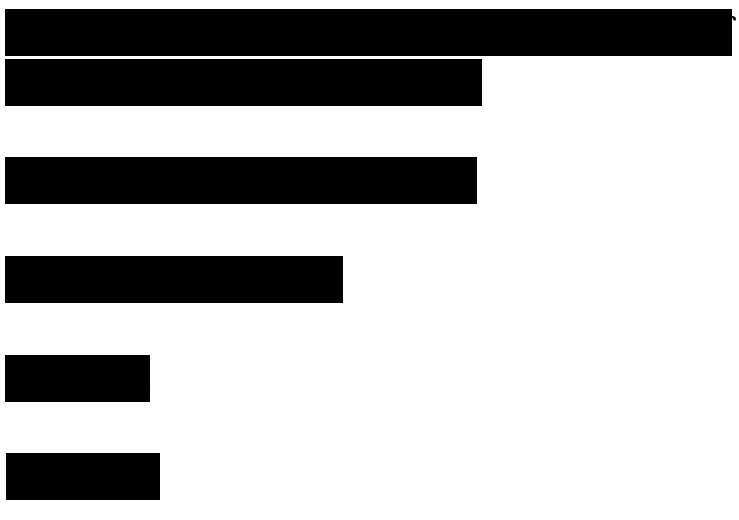

Telephone:

Email: 


\section{Appendix 3: Written consent form for all participants}

Research title: "Examining the driving cessation process amongst current and retired older drivers and their informal social network members"

I consent to participating in a semi-structured interview, which will last approximately 1 hour regarding the topic of giving up driving in later life. I agree to provide a personal viewpoint on my perceptions and experiences relating to the process of driving cessation. (Please tick and sign).

An explanation of the research aims and objectives have been outlined by the research facilitator, and I have been given the opportunity to express any concerns which I may have. (Please tick and sign).

I have been made fully aware that any information given in the interview will be treated with the highest degree of confidentiality and anonymity. (Please tick and sign).

I agree to the interview being tape-recorded and written notes being taken by the facilitator, which will be destroyed after completion of the research project. I understand that information gathered will be used in research, and that this information will be accessible to all once the study has been completed, although my name will not appear in the research. (Please tick and sign).

I understand I am allowed to withdraw my consent for participating in this research at any point during the research process and that I know how to do this. In this case, all information given will be destroyed. I am also aware that I can deny any answers 
which I do not want to respond to during the interview.

(Please tick and sign).

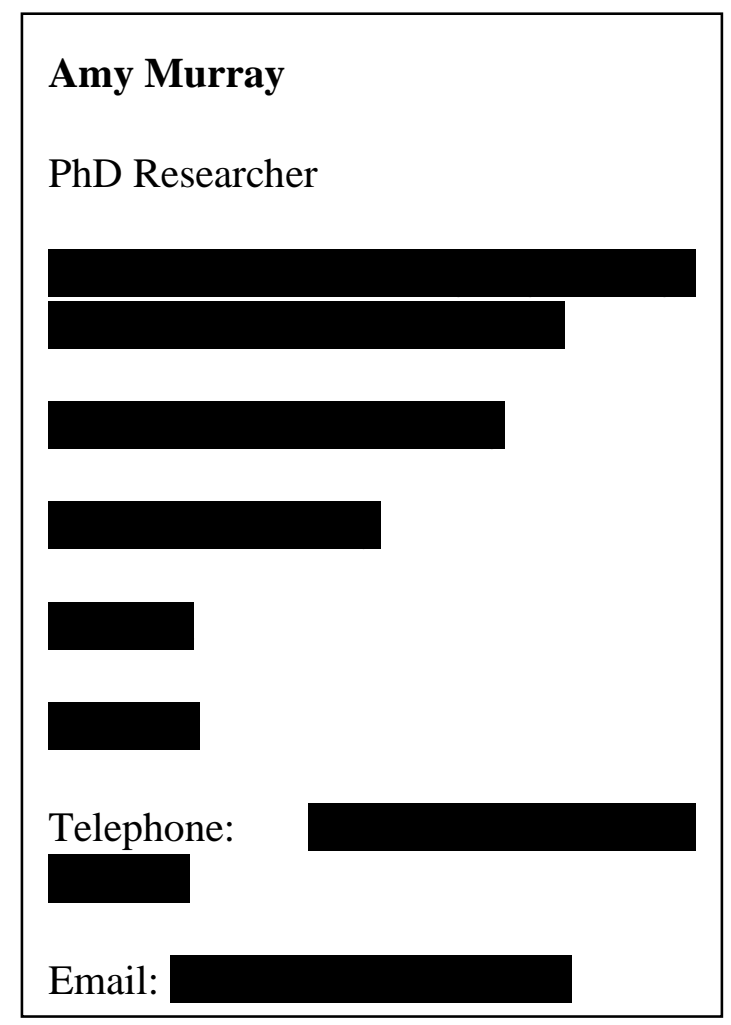

Supervisor: Dr Charles Musselwhite

Associate Professor
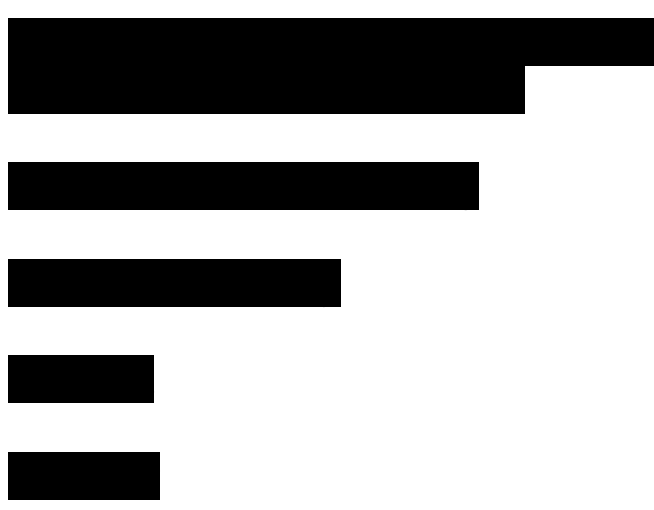

Telephone:

Email:

Date

Signature of participant:

Signature of researcher: 


\section{Appendix 4: Example of interview transcribed verbatim}

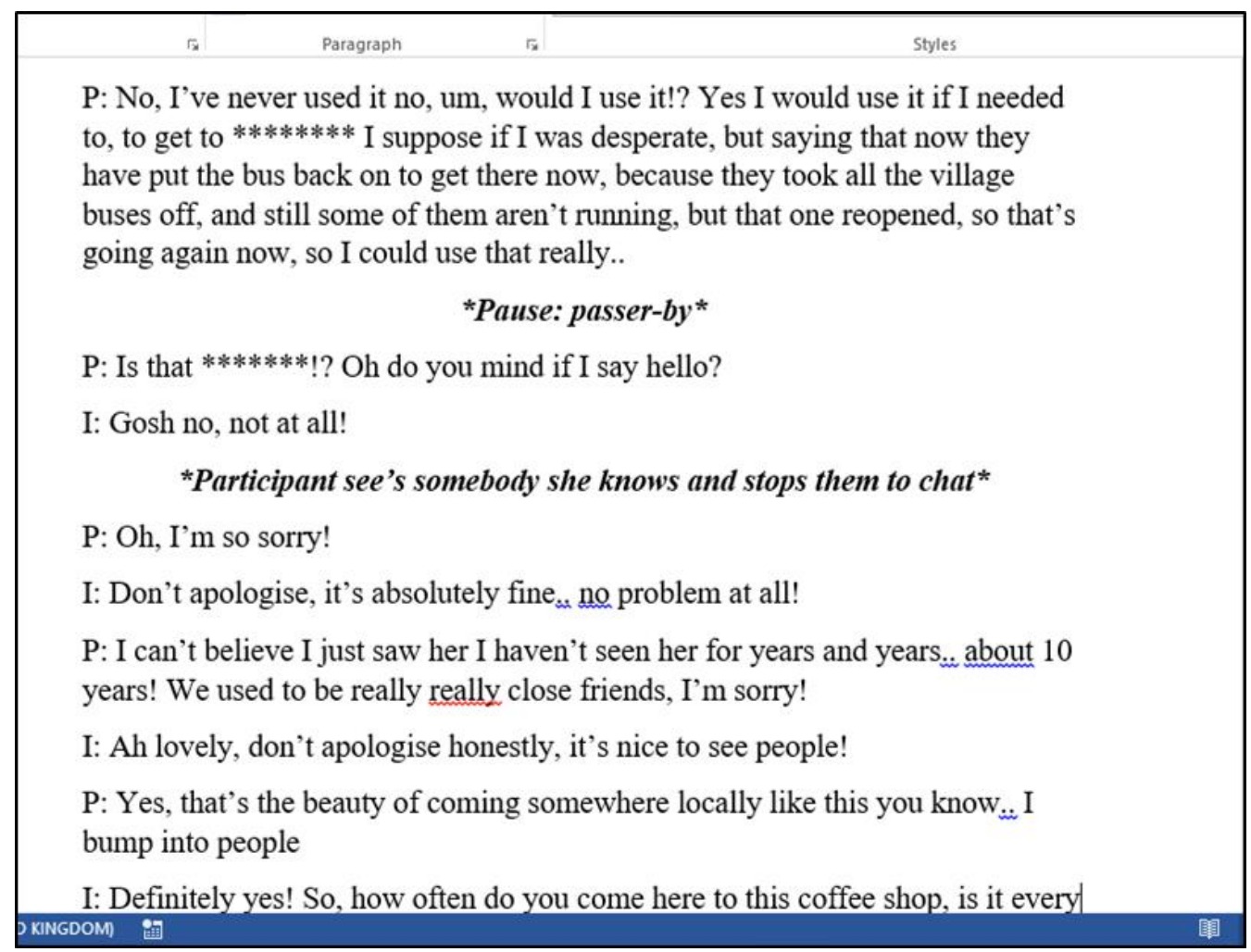


Appendix 5: Participant information sheet

\begin{tabular}{|c|c|}
\hline Name & \\
\hline Age & \\
\hline Gender & Male/Female \\
\hline $\begin{array}{l}\text { Area of } \\
\text { residence }\end{array}$ & $\begin{array}{l}\text { Location: } \\
\text { Rural/Urban/Semi rural/urban }\end{array}$ \\
\hline Marital status & $\begin{array}{l}\text { Married/Civil } \\
\text { Partnership/Cohabiting/Single/Widowed/Divorced }\end{array}$ \\
\hline Children & $\begin{array}{l}\text { Yes/No } \\
\text { Gender: } \\
\text { Ages: }\end{array}$ \\
\hline $\begin{array}{l}\text { Employment } \\
\text { status }\end{array}$ & $\begin{array}{l}\text { Employed (full-time, part-time) Unemployed, retired, full- } \\
\text { time education } \\
\text { Main job/s or profession/s throughout lifetime: }\end{array}$ \\
\hline $\begin{array}{l}\text { Highest } \\
\text { educational } \\
\text { qualification }\end{array}$ & \\
\hline $\begin{array}{l}\text { Valid UK driving } \\
\text { licence }\end{array}$ & Yes/No \\
\hline
\end{tabular}




\begin{tabular}{|c|c|}
\hline & Length of time held licence: ___ years \\
\hline $\begin{array}{l}\text { Average amount } \\
\text { of driving } \\
\text { (currently or } \\
\text { prior to giving- } \\
\text { up driving) }\end{array}$ & No of miles _ per week \\
\hline $\begin{array}{l}\text { Use \& frequency } \\
\text { of other } \\
\text { transport modes }\end{array}$ & 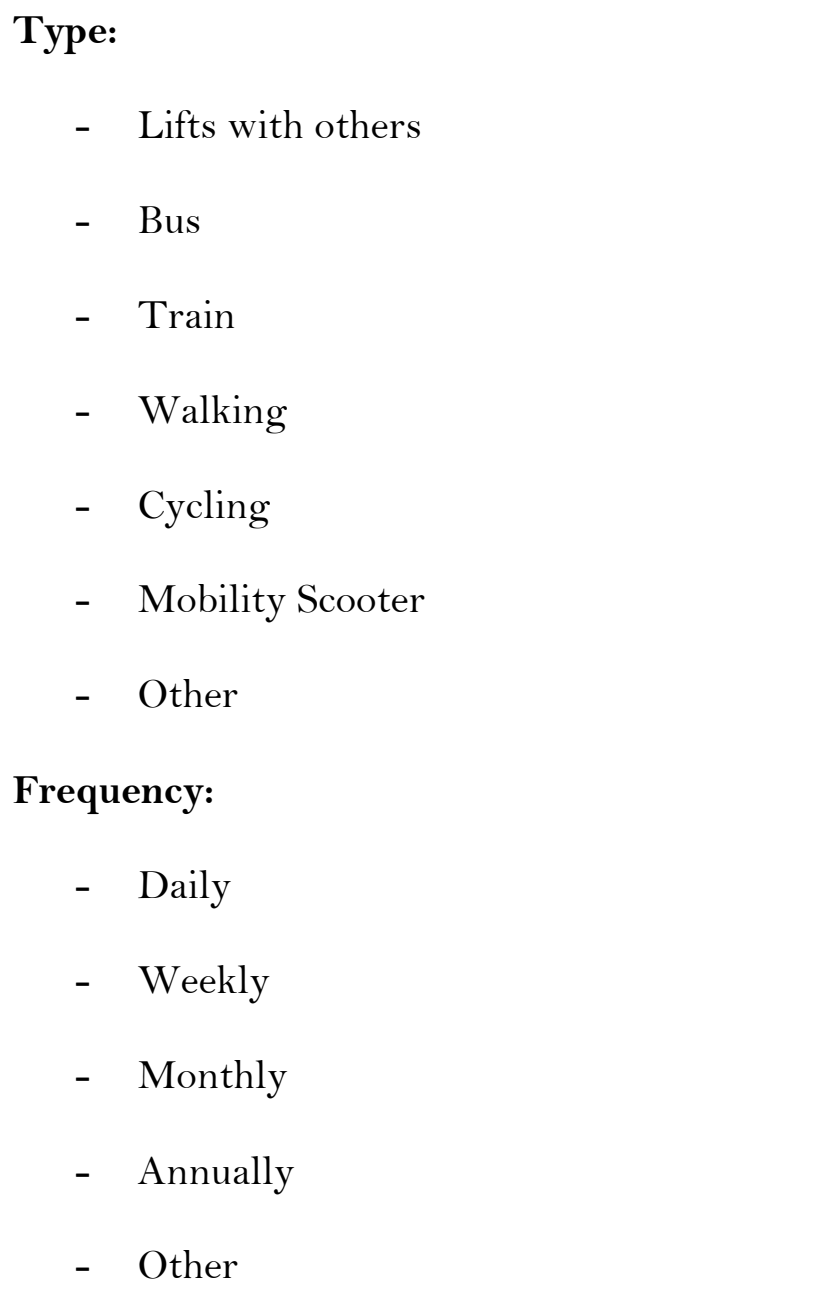 \\
\hline Health & Very good / good / adequate / poor / very poor \\
\hline
\end{tabular}


Appendix 6: Participant information sheet: Informal support network members

\begin{tabular}{|l|l|}
\hline Name & \\
\hline Age & \\
\hline Gender & Male/Female \\
\hline Area of residence & \\
\hline Marital status & Married/Co-habiting/Single/Widowed/divorced \\
\hline Children & Yength of time held licence: \\
\hline qualification & Yes/No good / good / adequate / poor / very poor \\
\hline Employment status & $\begin{array}{l}\text { Employed (full-time, part-time) Unemployed, } \\
\text { retired, full-time education }\end{array}$ \\
\hline
\end{tabular}


Appendix 7: Interview prompt: Current older drivers

\begin{tabular}{|c|c|}
\hline Section & Topic \\
\hline A & $\begin{array}{l}\text { Driving History: } \\
\text { Can you tell me about your driving history? } \\
\text {. When did you first start driving? } \\
\text {. For what purpose did you start? } \\
\text {. What was the first car you had? }\end{array}$ \\
\hline B & $\begin{array}{l}\text { The meaning of driving: } \\
\text { What does being able to drive mean to you? } \\
\text { Why do you/do you not enjoy driving? } \\
\text { What are your hobbies and interests? Is driving related to these in } \\
\text { anyway? }\end{array}$ \\
\hline D & $\begin{array}{l}\text { Perceptions of giving up driving: } \\
\text { How do you feel about the thought of giving up driving? } \\
\text { Is this something you have thought about? }\end{array}$ \\
\hline
\end{tabular}




\begin{tabular}{|c|c|}
\hline & How do you think you would cope without a car? \\
\hline $\mathbf{C}$ & $\begin{array}{l}\text { Informal Support Network Members: } \\
\text { Can you tell me about your informal support network? (By this, I mean } \\
\text { family, friends, neighbours, or wider community members) } \\
\text { Do you receive support of any of these individuals? } \\
\text { Do you think any of these people would support you in the case of } \\
\text { driving cessation? } \\
\text { *For the purpose of the present study, I am recruiting members } \\
\text { of current and retired older drivers informal networks. Out of } \\
\text { those people talked about, would you be happy for any of them } \\
\text { to speak to me about your driving and driving cessation?* }\end{array}$ \\
\hline $\mathbf{F}$ & $\begin{array}{l}\text { Views on alternative transport: } \\
\text { What are your thoughts on public transport e.g. buses छ̊ trains? }\end{array}$ \\
\hline $\mathbf{G}$ & $\begin{array}{l}\text { Views on support for driving cessation } \\
\text { Do you think there should be support for older people driving, and } \\
\text { giving up driving? } \\
\text { If so, what type of support, and why? }\end{array}$ \\
\hline
\end{tabular}


Appendix 8: Interview prompt: Retired older drivers

\begin{tabular}{|c|c|}
\hline Section & Topic \\
\hline $\mathbf{A}$ & $\begin{array}{l}\text { Driving History: } \\
\text { Can you tell me about your driving history? } \\
\text {. When did you first start driving? } \\
\text {. For what purpose did you start? } \\
\text {. What was the first car you had? }\end{array}$ \\
\hline B & $\begin{array}{l}\text { The meaning of driving: } \\
\text { What did driving mean to you? } \\
\text { Did you enjoy driving? } \\
\text { What are your hobbies and interests? Was driving related to these in } \\
\text { anyway? }\end{array}$ \\
\hline D & $\begin{array}{l}\text { Perceptions of giving up driving: } \\
\text { How has the experience of giving up driving been for you? } \\
\text { Have you experiences any changes in your life? }\end{array}$ \\
\hline
\end{tabular}




\begin{tabular}{|c|c|}
\hline & How are you coping without a car? \\
\hline $\mathbf{C}$ & $\begin{array}{l}\text { Informal Support Network Members: } \\
\text { Can you tell me about your informal support network? (By this, I mean } \\
\text { family, friends, neighbours, or wider community members) } \\
\text { Do you receive support of any of these individuals? } \\
\text { Have any of these individuals been important in relation to you giving up } \\
\text { driving? } \\
\text { * For the purpose of the present study, I am recruiting members of } \\
\text { current and retired older drivers informal networks. Out of those } \\
\text { people talked about, would you be happy for any of them to speak } \\
\text { to me about your driving and driving cessation?* }\end{array}$ \\
\hline $\mathbf{F}$ & $\begin{array}{l}\text { Views on alternative transport: } \\
\text { What are your thoughts on public transport e.g. buses \& trains? }\end{array}$ \\
\hline $\mathbf{G}$ & $\begin{array}{l}\text { Views on support for driving cessation } \\
\text { Do you think there should be support for older people driving, and giving } \\
\text { up driving? } \\
\text { Have you received any support? } \\
\text { If so, what type of support, and why? }\end{array}$ \\
\hline
\end{tabular}


Appendix 9: Interviews prompt: Informal support network members

\begin{tabular}{|c|c|}
\hline Section & Topic \\
\hline $\mathbf{A}$ & $\begin{array}{l}\text { Relationship with Older adult } \\
\text { What is your relationship to the } \mathbf{X} \text { ? } \\
\text { How much, and what type of contact do you have with } \\
\text { them? } \\
\text { Do you currently provide any help or support to X? (E.g. } \\
\text { physical/practical such as transport, shopping, social support } \\
\text { healthcare, DIX, emotional support?) }\end{array}$ \\
\hline $\mathbf{B}$ & $\begin{array}{l}\text { Typical routine/lifestyle } \\
\text { Could you tell me your typical week starting from } \\
\text { Monday? } \\
\text { Do you have any roles and responsibilities? } \\
\text {. How you manage your own needs (E needs of OP - if } \\
\text { appropriate)? }\end{array}$ \\
\hline $\mathbf{C}$ & $\begin{array}{l}\text { Views on } \mathbf{X} \text { and driving } \\
\text { How do you/did you feel about } \mathbf{X} \text { driving? } \\
\text { Did this have any implications for yourself?. }\end{array}$ \\
\hline $\mathbf{D}$ & Perceptions of $\mathrm{X}$ giving up driving \\
\hline
\end{tabular}




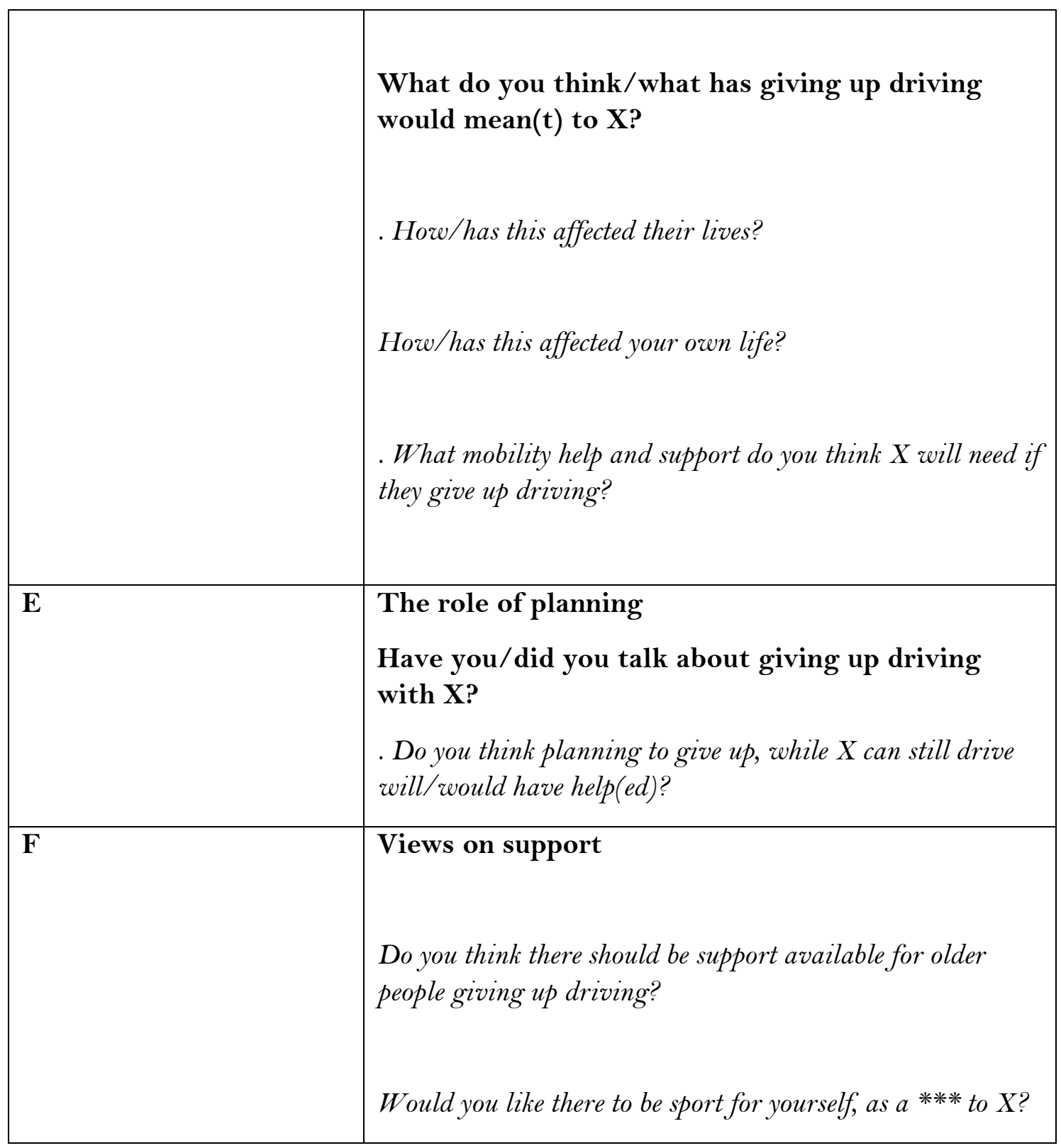


Appendix 10: Online support for current and retired older drivers

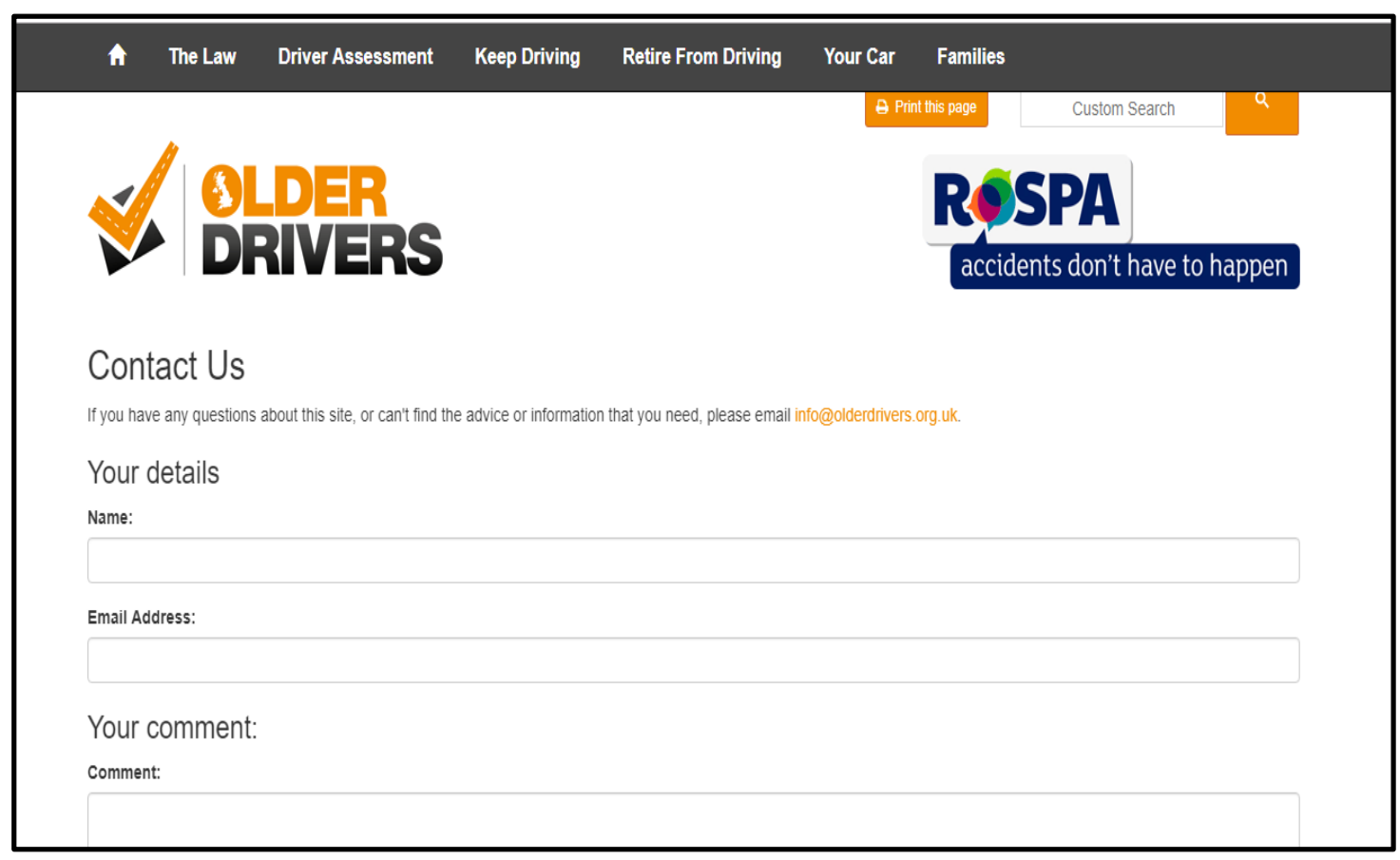


Appendix 11: Information Sheet: Current and retired older drivers

\begin{tabular}{|c|c|}
\hline Support/Service & Contact information \\
\hline Alternative Transport & \\
\hline Bus service & $\begin{array}{l}\text { South Wales Transport } \\
\text { Contact number: } 01792799575 \\
\text { Postal address: Unit 2, Ferryboat Close, Swansea } \\
\text { Enterprise Park, Llansamlet, Swansea, SA6 8QN } \\
\text { Email address: } \underline{\text { info@southwalestransport.com }} \\
\text { Website: } \underline{\text { https://www.southwalestransport.com/ }}\end{array}$ \\
\hline Train service & $\begin{array}{l}\text { Great Western Railway } \\
\text { Website: https://www.gwr.com/ } \\
\text { Contact number: } 03457000125 \\
\text { Postal address: Freepost GWR CUSTOMER } \\
\text { SUPPORT } \\
\text { The Train Line } \\
\text { Website: https://www.thetrainline.com/train-times }\end{array}$ \\
\hline Community transport & $\begin{array}{l}\text { Contact number: } \\
\text { Postal address: } \\
\text { Email address: mail@dansa.org.uk }\end{array}$ \\
\hline
\end{tabular}




\begin{tabular}{|c|c|}
\hline & Website: http://www.dansa.org.uk/ \\
\hline Local taxi service: & $\begin{array}{l}\text { Contact number: } \\
\text { Postal address: } \\
\text { Email address: }\end{array}$ \\
\hline Walking groups & $\begin{array}{l}\text { Contact number: } \\
\text { Postal address: } \\
\text { Email address: } \\
\text { Website: }\end{array}$ \\
\hline Cycling groups & $\begin{array}{l}\text { Contact number: } \\
\text { Postal address: } \\
\text { Email address: } \\
\text { Website: }\end{array}$ \\
\hline Support information & \\
\hline Citizens Advice Bureau & $\begin{array}{l}\text { Contact number: } \underline{03444772020} \\
\text { Website: } \underline{\text { https://www.citizensadvice.org.uk/wales/ }} \\
\text { Postal address: Citizens Advice, 3rd Floor North, } 200 \\
\text { Aldersgate, London, EC1A 4HD } \\
\text { Email address: info@citizensadvicesnpt.org.uk }\end{array}$ \\
\hline
\end{tabular}




\begin{tabular}{|c|c|}
\hline Age UK & $\begin{array}{l}\text { Contact number: } 08006781602 \\
\text { Website: www.ageuk.org.uk/contact-us/ } \\
\text { Postal address: Age UK, Tavis House, 1-6 Tavistock } \\
\text { Square, London WC1H 9NA } \\
\text { Email address: contact@,ageuk.org.uk }\end{array}$ \\
\hline ROSPA & $\begin{array}{l}\text { Contact number: } \underline{01212482000} \\
\text { Website: } \underline{\text { https://www.rospa.com/ }} \\
\text { Email address: help@rospa.com. } \\
\text { Postal address: } \\
\text { 2nd Floor, } 2 \text { Cwrt-y-Parc, Parc Ty Glas, Cardiff } \\
\text { Business Park, Llanishen, Cardiff, CF 14 5GH, UK }\end{array}$ \\
\hline Brake & 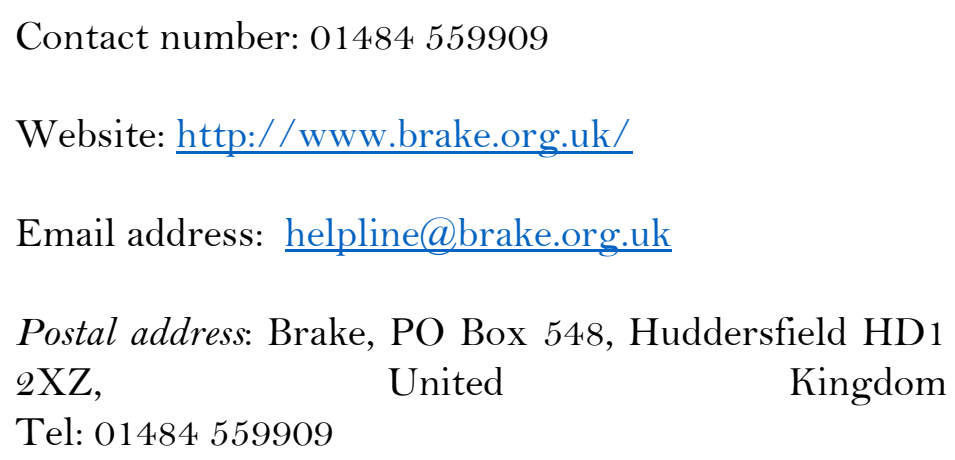 \\
\hline
\end{tabular}




\section{Appendix 12: Information sheet for informal support network members}

\begin{tabular}{|c|c|}
\hline Support/Service & Contact information \\
\hline Carers UK - Carers Assessment & $\begin{array}{l}\text { Website: } \\
\text { https://www.carersuk.org/help-and- } \\
\frac{\text { advice/practical-support/getting-care- }}{\text { and-support/carers-assessment }} \\
\text { Contact number: 020 } 73784999 \\
\text { Email address: info@carersuk.org } \\
\text { Postal address: Carers UK, 20 Great } \\
\text { Dover Street, London SE1 4LX }\end{array}$ \\
\hline AGE UK - Support for carers & $\begin{array}{l}\text { Website: } \\
\text { https://www.ageuk.org.uk/services/in- } \\
\text { your-area/carers-support/ } \\
\text { Postal address: Age UK, Tavis House, 1- } \\
6 \text { Tavistock Square, London WC1H } \\
\text { 9NA } \\
\text { Contact number: } 08006781602\end{array}$ \\
\hline $\begin{array}{l}\text { Older Drivers -Information for } \\
\text { families }\end{array}$ & $\begin{array}{l}\text { Website: } \\
\text { https://www.olderdrivers.org.uk/ } \\
\text { Email address: info@olderdrivers.org.uk }\end{array}$ \\
\hline Older Drivers Forum & $\begin{array}{l}\text { Website: } \\
\underline{\text { https://olderdriversforum.com/ }} \\
\text { Direct contact - email: } \\
\underline{\text { https://olderdriversforum.com/contact- }} \\
\underline{\text { us/ }}\end{array}$ \\
\hline
\end{tabular}




\section{Appendix 13: Coloured coding in word document - alternative transport example}

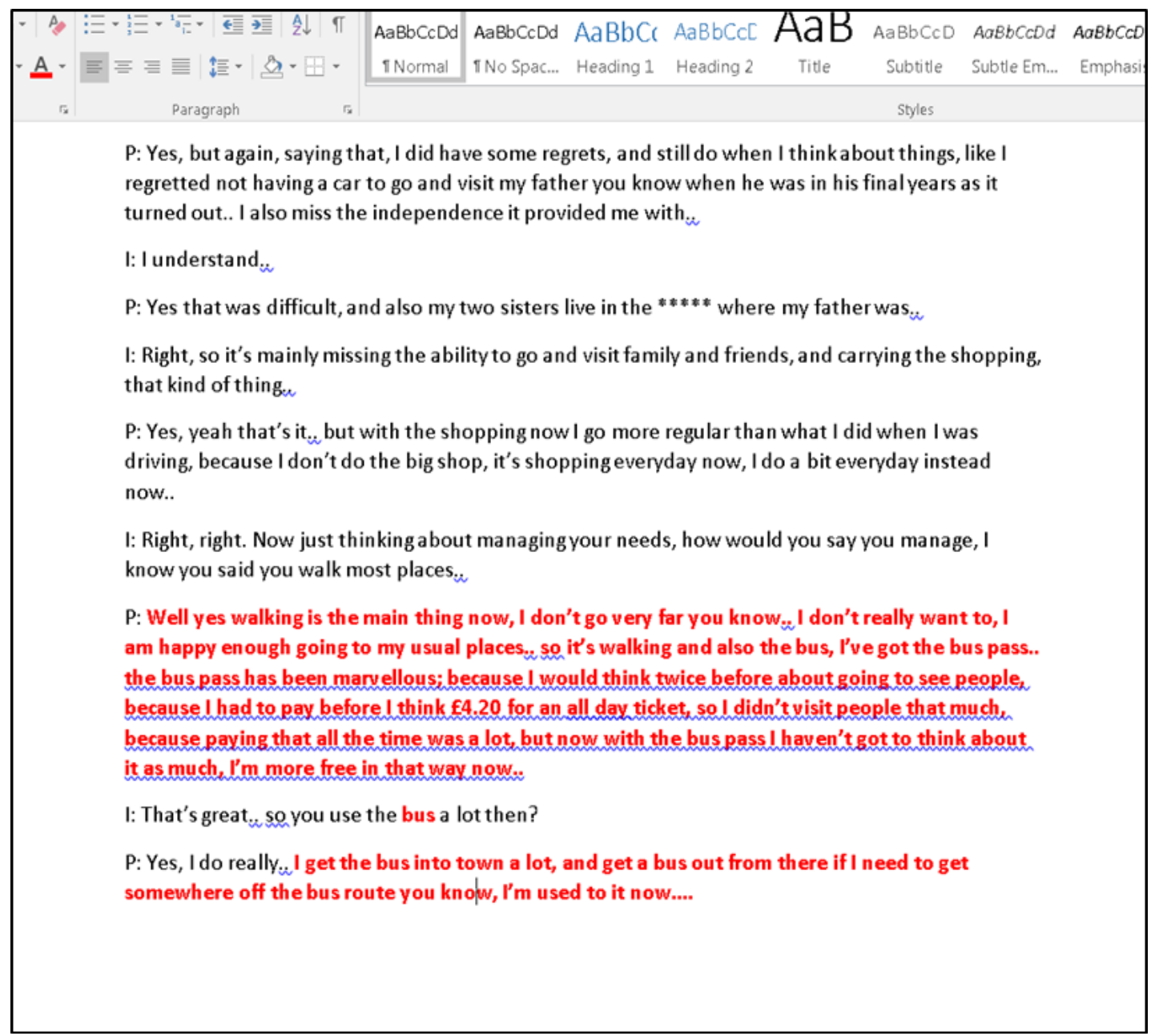




\section{Appendix 14: Collated codes - alternative transport example}

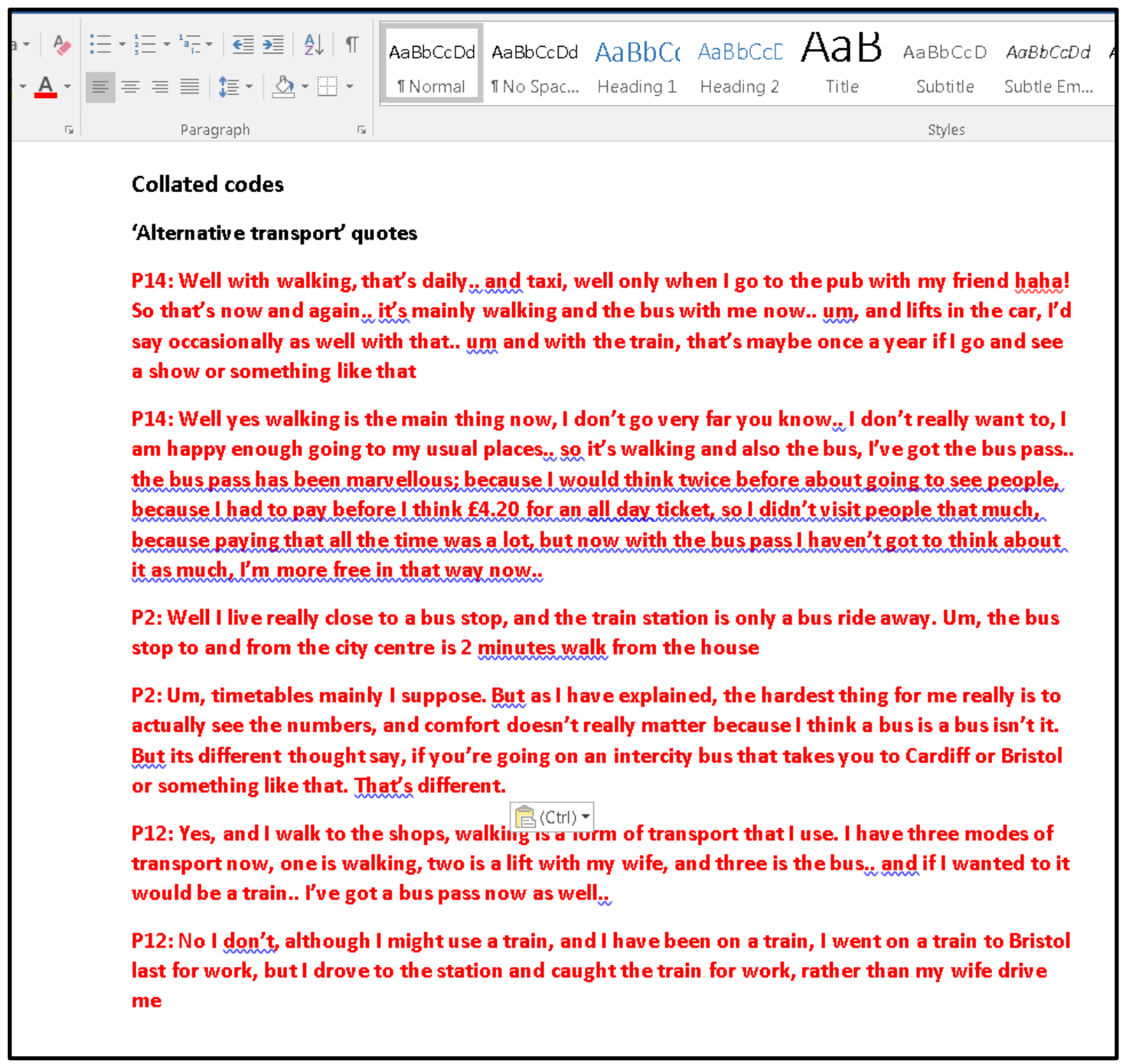


Appendix 15: Coding process undertaken by hand

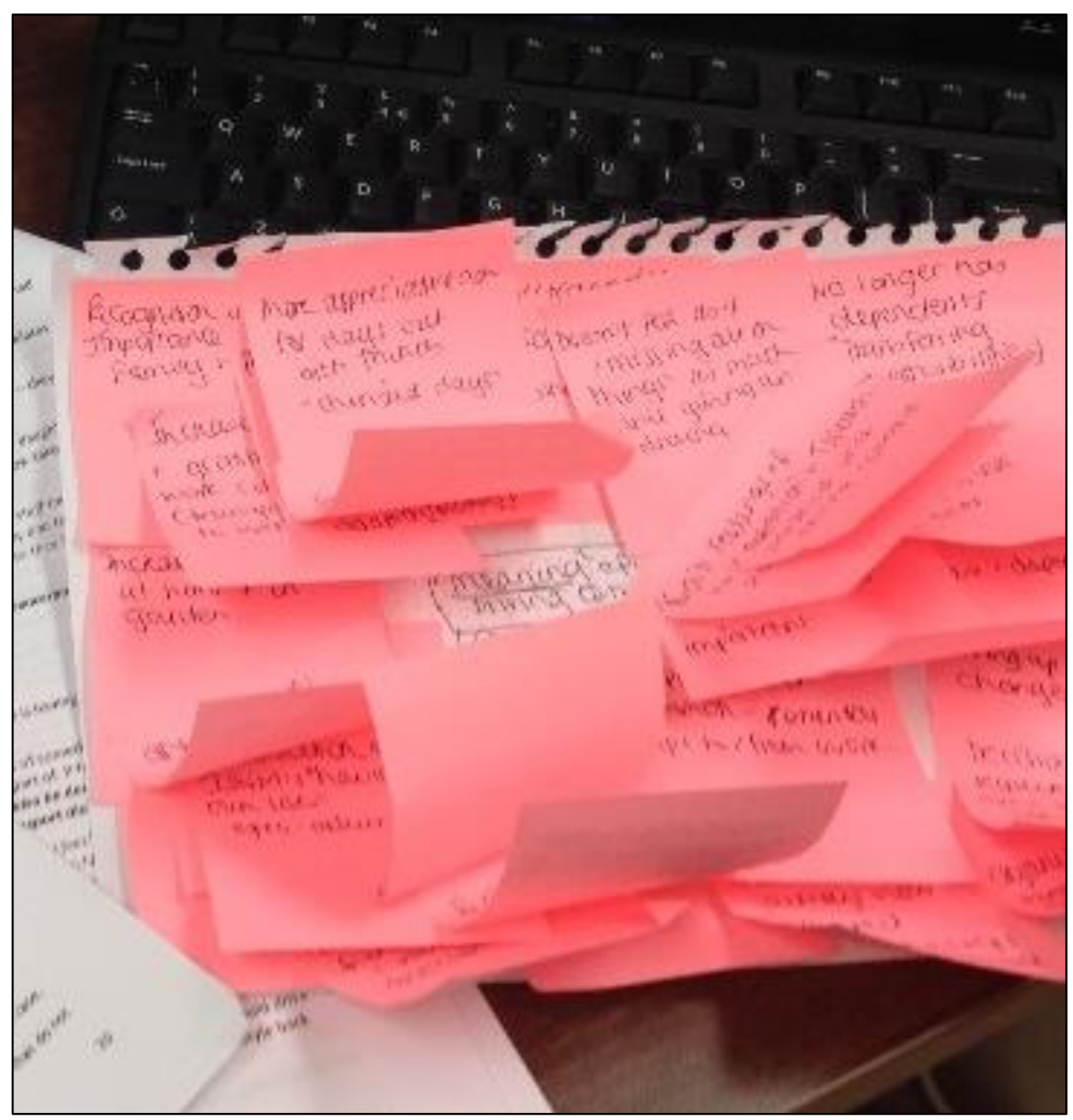

